NIST-SP 1118 Volume I

\title{
Technical Study of the Sofa Super Store Fire - South Carolina, June 18, 2007
}

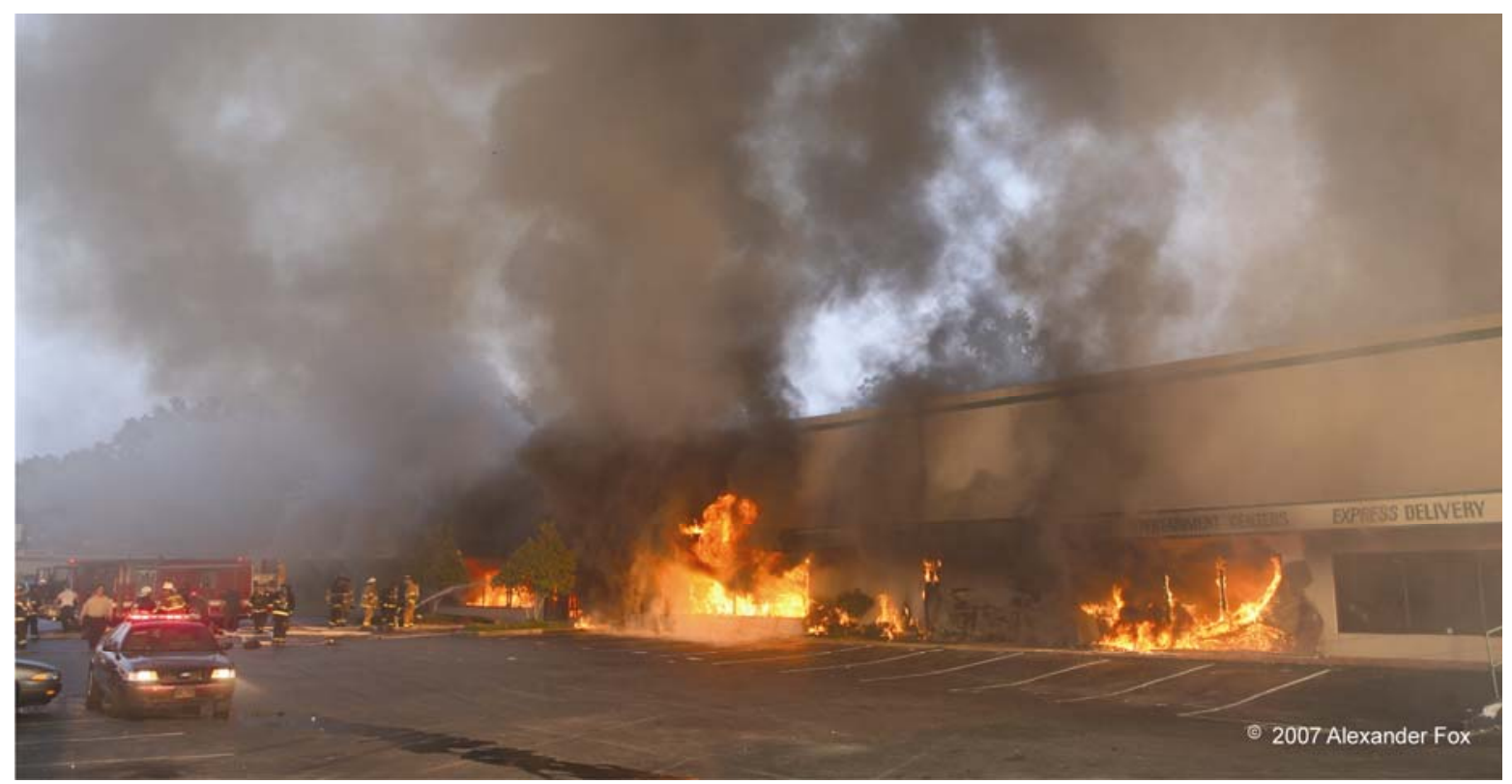

Nelson P. Bryner

Stephen P. Fuss

Bryan W. Klein

Anthony D. Putorti 



\section{Technical Study of the Sofa Super Store Fire - South Carolina, June 18, 2007}

Nelson P. Bryner

Stephen P. Fuss

Bryan W. Klein

Anthony D. Putorti

Fire Research Division

Engineering Laboratory

National Institute of Standards and Technology

March 2011

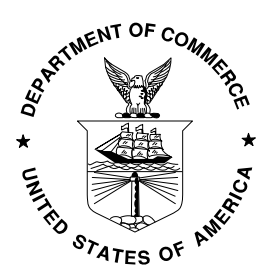

U.S. Department of Commerce Gary Locke, Secretary 


\section{$\underline{\text { Disclaimer }}$}

Certain commercial entities, equipment, products, or materials are identified in this document in order to describe a procedure or concept adequately or to trace the history of the procedures and practices used. Such identification is not intended to imply recommendation, endorsement, or implication that the entities, products, materials, or equipment are necessarily the best available for the purpose.

\section{$\underline{\text { Disclaimer }}$}

The policy of NIST is to use the International System of Units (metric units) in all publications. In this document, however, units are presented in metric units or the inch-pound system, whichever is prevalent to the discipline. Conversion tables are provided in this report.

\section{National Institute of Standards and Technology NIST-SP 1118 Natl. Inst. of Std., 738 pages (March 2011) CODEN: XXXXXX NSPUE2}

U.S. GOVERNMENT PRINTING OFFICE WASHINGTON: 2008

For sale by the Superintendent of Documents, U.S. Government Printing Office Internet: bookstore.gpo.gov — Phone: (202) 512-1800 — Fax: (202) 512-2250 Mail: Stop SSOP, Washington, DC 20402-0001 


\section{ABSTRACT}

A fire occurred on the evening of June 18, 2007, in the Sofa Super Store in Charleston, SC. NIST analyzed the fire ground, consulted with other experts, and performed computer simulations of fire growth alternatives. Based on these analyses, the following sequence of events is likely to have occurred. A fire began in packing material and discarded furniture outside an enclosed loading dock area. The fire spread to the loading dock, then into both the retail showroom and warehouse spaces. During the early stages of the fire in the two latter locations, the fire spread was slowed by the limited supply of fresh air. This under-ventilation led to generation of a large mass of pyrolyzed and only partially oxidized effluent. The smoke and combustible gases flowed into the interstitial space below the roof and above the suspended ceiling of the main retail showroom. As this space filled with unburned fuel, the hot smoke also seeped through the suspended ceiling into the main showroom and formed a hot smoke layer below the suspended ceiling. Up to this time, the extent of fire spread into the interstitial space was not visible to fire fighters in the store. If the fire spread had been visible to the fire fighters in the store, it would have provided a direct indication of a fire hazard in the showroom. Meanwhile, the fire at the back of the main showroom and the gas mixture below the suspended ceiling were both still fuel rich. When the front windows were broken out or vented, the inflow of additional air allowed the heat release rate of the fire to intensify rapidly and added air to the layer of unburned fuel below the suspended ceiling enabling the ignition of the unburned fuel/air mixture. The fire swept from the rear to the front of the main showroom extremely quickly, and then into the west and east showrooms. Nine fire fighters were killed in the Sofa Super Store fire. Based on NIST's simulation of events, this report includes eleven recommendations to help mitigate such future losses.

Keywords: fire investigation, fire modeling, fire spread, fire sprinklers, furniture flammability, retail store fire, sprinklers 


\section{TABLE OF CONTENTS (VOL. I)}

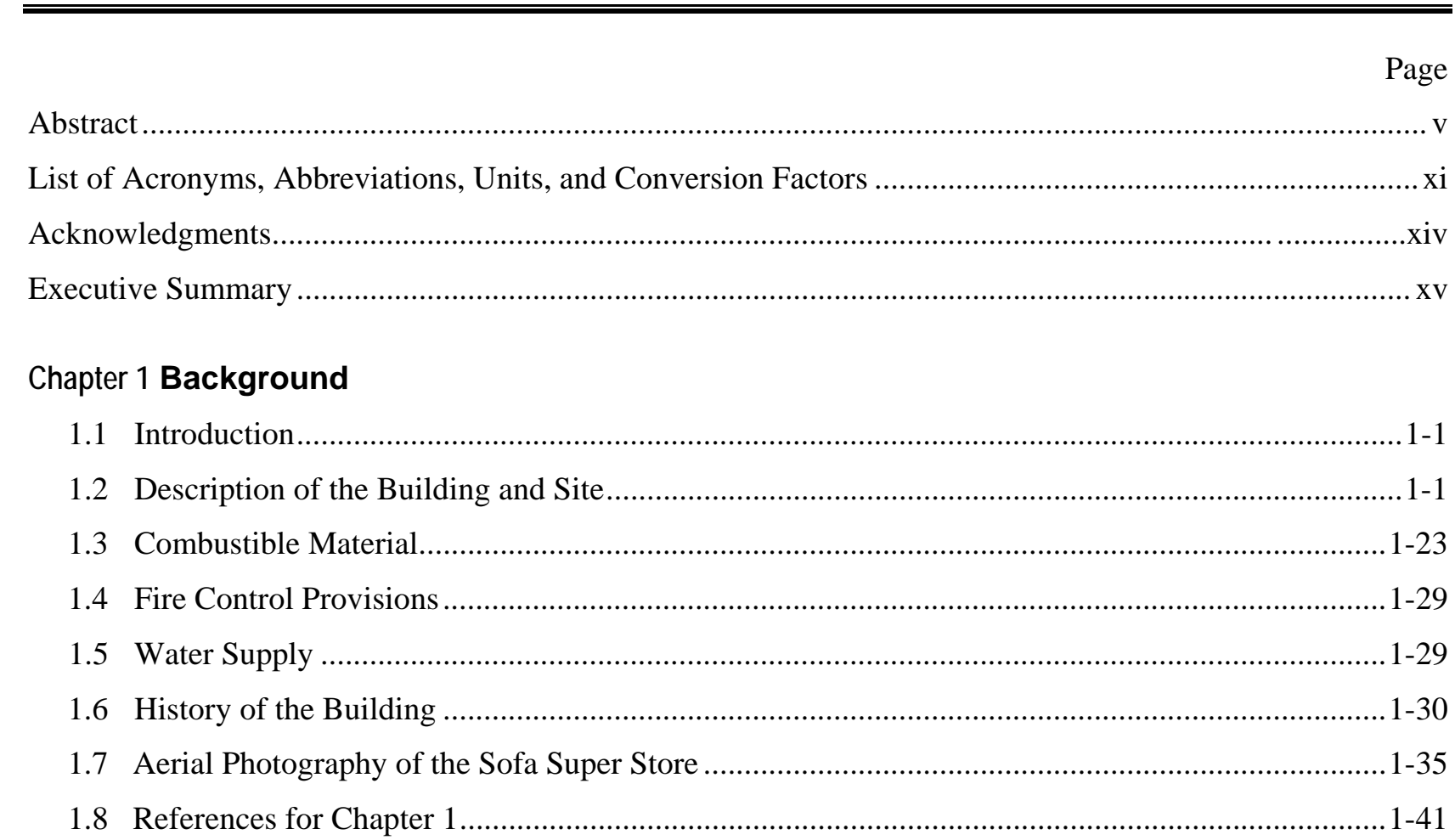

\section{Chapter 2 Description and Time Line of the Incident}

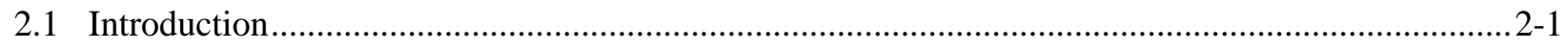

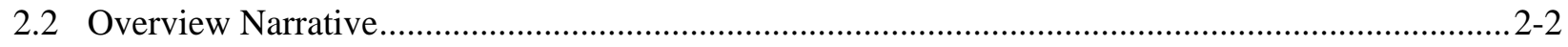

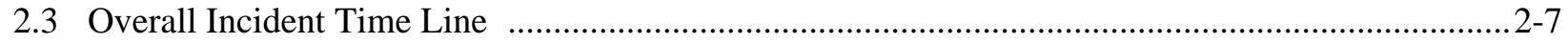

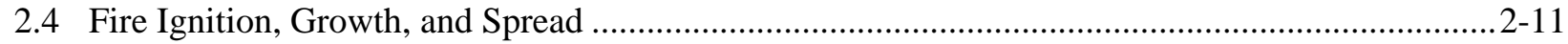

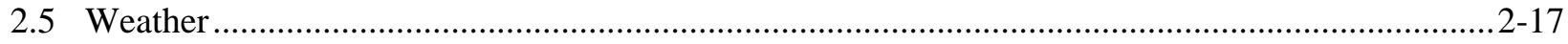

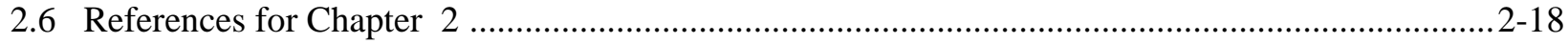

\section{Chapter 3 The Emergency Incident Response}

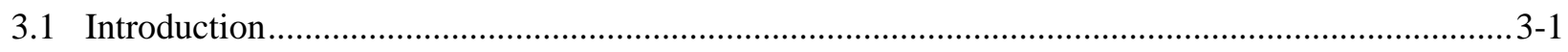

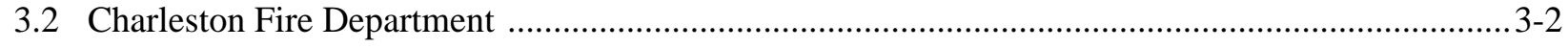

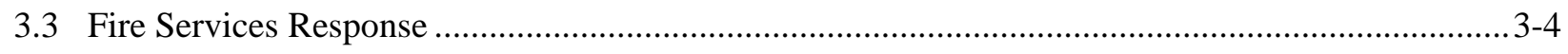

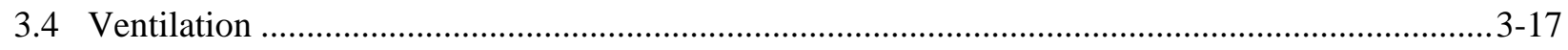

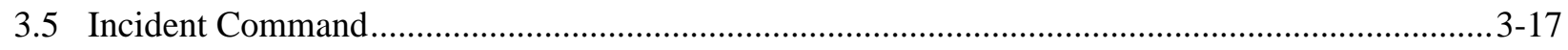

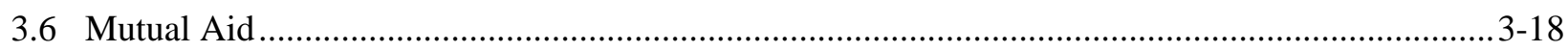




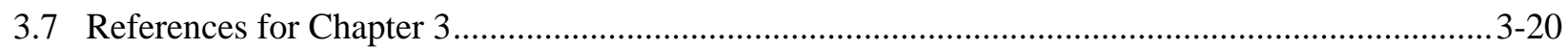

\section{Chapter 4 Computer Simulation Of Fire And Smoke Spread}

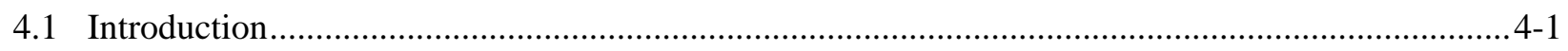

4.2 NIST Fire Dynamics Simulator Overview.............................................................................. 4

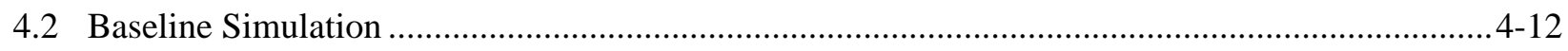

4.4 Baseline Simulation With Sprinklers Added Inside the Loading Dock ....................................... 4-29

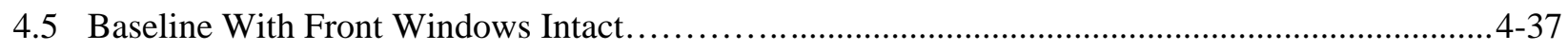

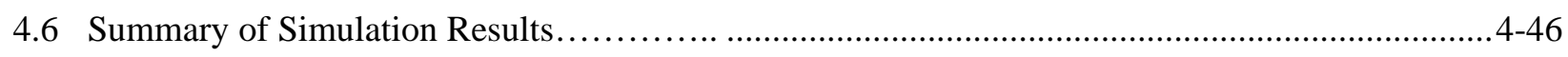

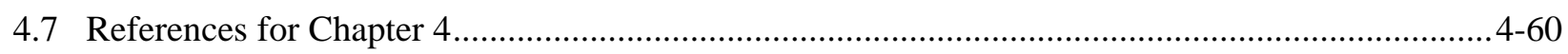

\section{Chapter 5 Model Codes, Standards, And Practices}

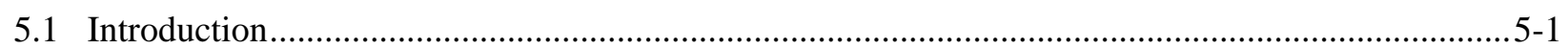

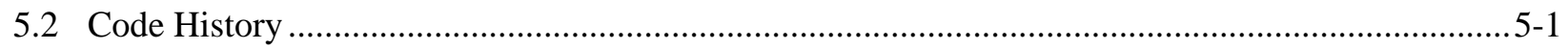

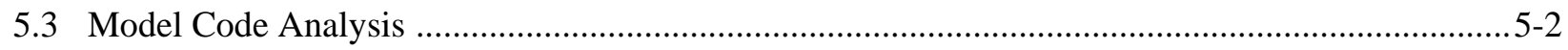

5.4 Limiting Fire Spread in Large Furniture Display Areas .............................................................5-10

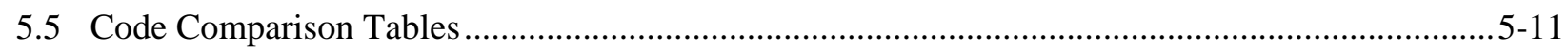

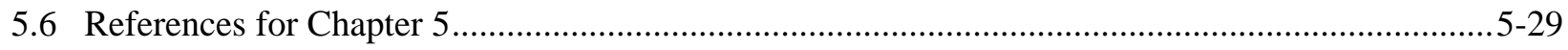

\section{Chapter 6 Summary, Findings and Recommendations}

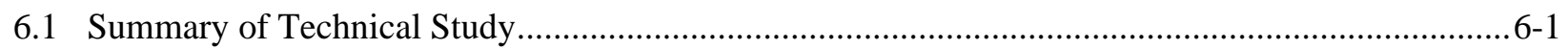

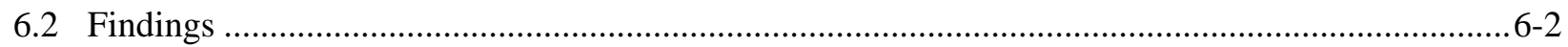

6.3 Recommendations for Improving Model Standards, Codes. and Practices ...................................6-11

6.4 Research Recommendations and Other Appropriate Actions......................................................6-14

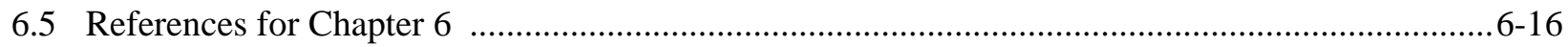




\section{TABLE OF CONTENTS (VoL. II)}

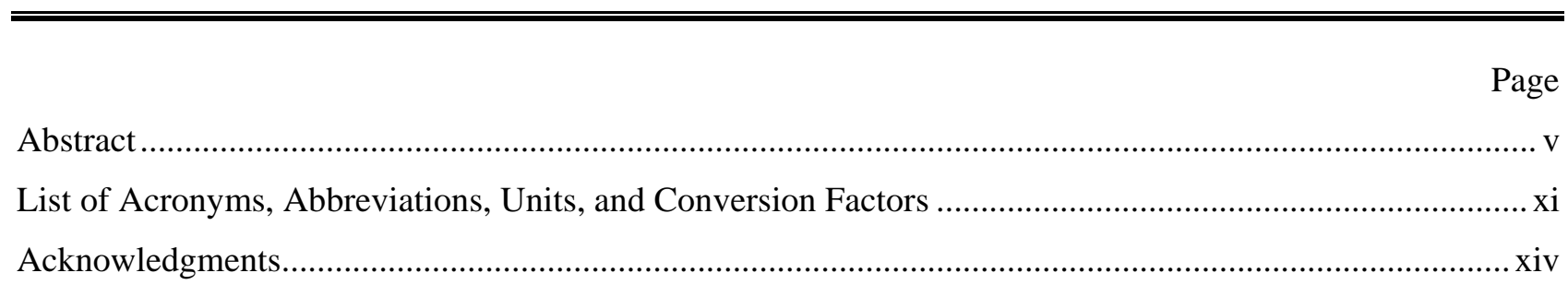

\section{Appendix A Weather Data}

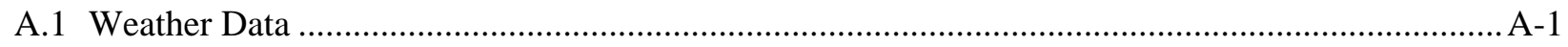

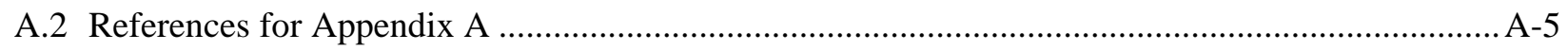

\section{Appendix B Overall Scene Photos}

B.1 Overall Scene Photos

\section{Appendix C Loading Dock Area}

C.1 Loading Dock Area Photos- Before Removal of Roof .................................................................. C-1

C.2 Loading Dock Area Photos- After Removal of Roof ...................................................................... C-6

\section{Appendix D Main Showroom}

D.1 Main Showroom Exterior Photos - Before Removal of Wall and Roof....................................... D-1

D.2 Main Showroom Exterior Photos - After Removal of Wall and Roof .......................................D-11

\section{Appendix E West Showroom}

E.1 West Showroom Exterior Photos .................................................................................................... E-1

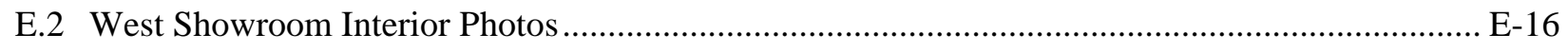

\section{Appendix F East Showroom}

F.1 East Showroom Exterior Photos ……….........................................................................................

F.2 East Showroom Interior Photos ………..........................................................................................

\section{Appendix G Warehouse Photographs}

G.1 Warehouse Exterior Photos..... G-1

G.2 Warehouse Interior Photos. G-15 


\section{Appendix H Repair Shops}

H.1 Repair Shop Photos H-1

\section{Appendix I Rear Wall Of Main Showroom}

I.1 Rear Wall of Main Showroom Photos .......................................................................................... I-1

I.2 Rear of Main Showroom After Removal of Warehouse........................................................... I-12

\section{Appendix J Retail Merchandise Estimates}

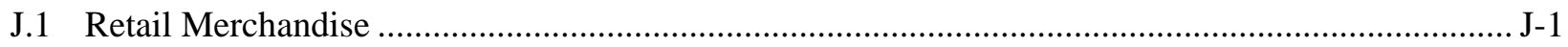

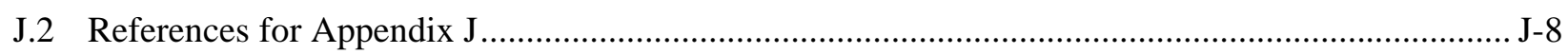

\section{Appendix K Computer Simulation of Fire and Smoke Spread}

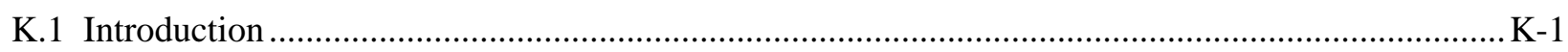

K.2 NIST Fire Dynamics Simulator Overview............................................................................. K-3

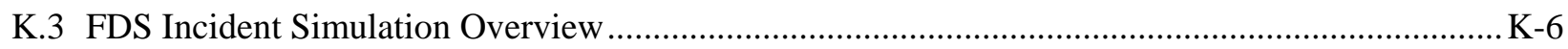

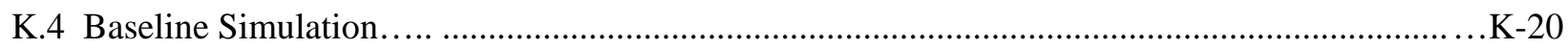

K.5 Baseline with Sprinklers Added on Loading Dock....................................................................42

K.6 Baseline with Front Windows Intact........................................................................................ K-52

K.7 Vertical Ventilation - Small Roof Vent.......................................................................................62

K.8 Vertical Ventilation - Large Roof Vent..............................................................................

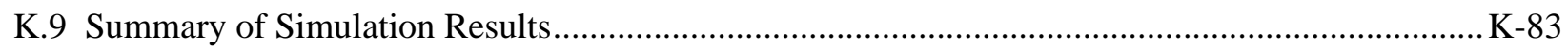

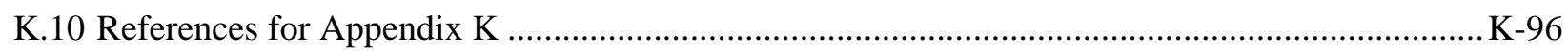

\section{Appendix L Computer Simulation Input Files}

L.1 Fire Dynamic Simulator Version 5.1.0 .................................................................................. L-1

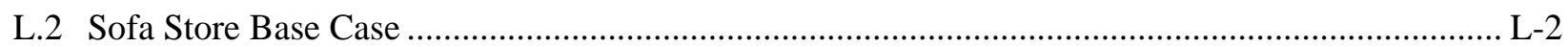

L.3 Base Case with Sprinklers .............................................................................................. L-120

L.4 Base Case with Windows Intact .......................................................................................... L-122

L.5 Base Case with Windows Intact with Small Vent ...................................................................... L-123

L.6 Base Case with Windows Intact with Large Vent ..................................................................... L-124

\section{Appendix M Fire Inspection and Building Pre-Plan}

M.1 City of Charleston Fire Inspection 
M.2 City of Charleston Fire Department Pre-Planning ......................................................................

M.3 City of Charleston Fire Department Pre-Planning Sketch........................................................ M-4

\section{Appendix N Additional Aerial Images}

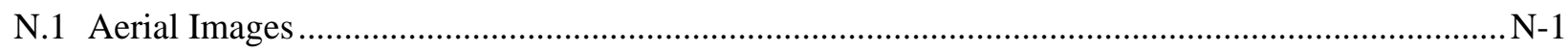

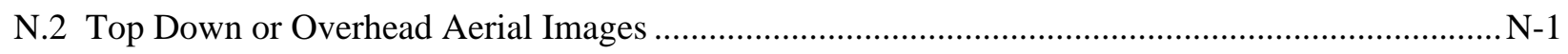

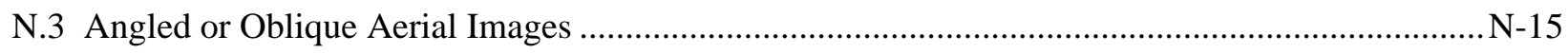

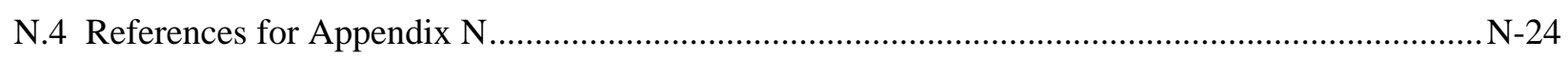

\section{Appendix O Additional Aerial Images}

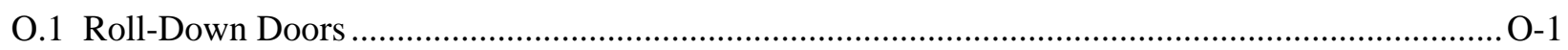

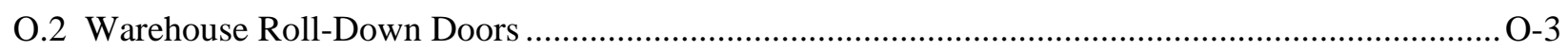

O.3 Holding Area/Breezeway Roll-Down Doors ............................................................................. O-6

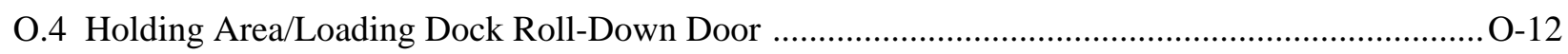

O.5 Main Showroom/West Showroom Roll-Down Door ...................................................................

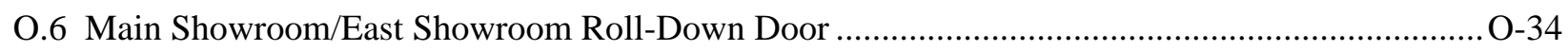

\section{Appendix P Loading Dock Fuels}

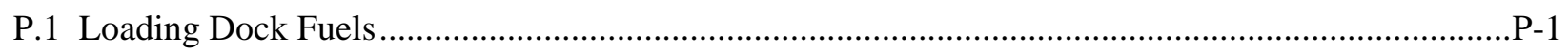

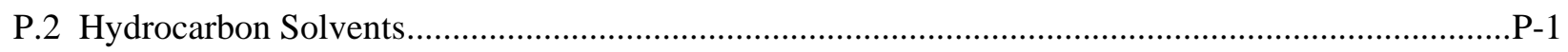

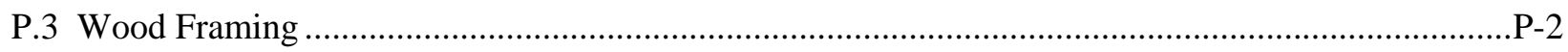

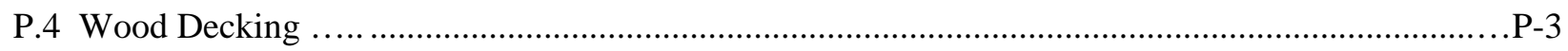

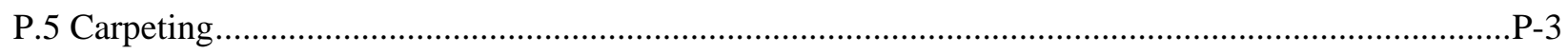

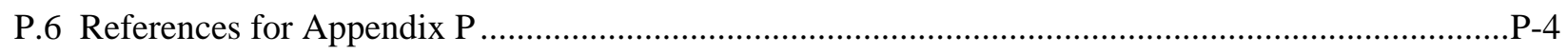

\section{Appendix Q Technical Reports, Media Articles, Web Pages, and Other}

\section{Resources}

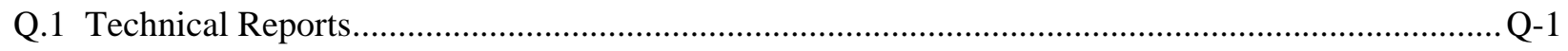

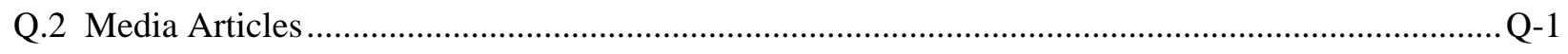

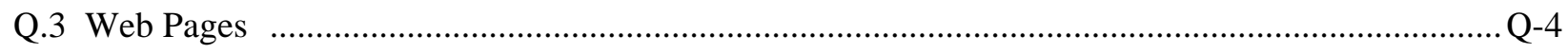

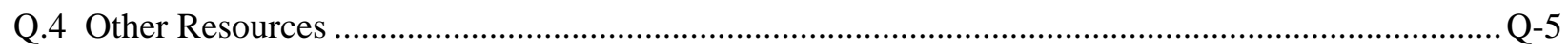




\section{LIST OF ACRONYMS, ABBREVIATIONS, UNITS, AND CONVERSION FACTORS}

\begin{tabular}{ll} 
AHJ & Authority Having Jurisdiction \\
ASTM & American Society for Testing and Materials \\
ATF & Bureau of Alcohol, Tobacco and Firearms \\
BBC & Basic Building Code \\
CCSO & Charleston County Sheriff's Office \\
CSMO & City of Charleston Safety Management Division \\
CFD & Charleston Fire Department \\
CPD & Charleston Police Department \\
DHS & Department of Homeland Security \\
EST & Eastern Standard Time \\
FDS & Fire Dynamics Simulator \\
FEMA & Federal Emergency Management Agency \\
HRR & heat release rate \\
IBC & International Building Code \\
IFC & International Fire Code \\
IC & Incident Command \\
ICC & International Code Council \\
IFSTA & International Fire Service Training Association \\
LLR & South Carolina Department of Labor, Licensing and Regulation \\
NFPA & National Fire Protection Association \\
NIOSH & National Institute for Occupational Safety and Health \\
NIST & National Institute of Standards and Technology \\
RTI & response time index \\
SBC & Standard Building Code \\
SFC & Standard Fire Code \\
T & time \\
\hline
\end{tabular}


UL Underwriters Laboratories

USC United States Code

USFA United States Fire Administration

\section{Units}

$\begin{array}{ll}{ }^{\circ} \mathrm{C} & \text { degrees Centigrade } \\ { }^{\circ} \mathrm{F} & \text { degrees Fahrenheit } \\ \mathrm{ft} & \text { feet } \\ \mathrm{GJ} & \text { Gigajoule } \\ \mathrm{gpm} & \text { gallons/minute } \\ \text { in } & \text { inch } \\ \mathrm{kg} & \text { kilogram } \\ \mathrm{kPa} & \text { kilopascal } \\ \mathrm{kW} & \text { kilowatt } \\ \mathrm{L} & \text { liter } \\ \mathrm{m} & \text { meter } \\ \mathrm{mm} & \text { millimeter } \\ \mathrm{min} & \text { minute } \\ \mathrm{MW} & \text { megawatt } \\ \mathrm{psi} & \text { pounds/in }{ }^{2} \\ \mathrm{~s} & \text { second } \\ \mathrm{W} & \text { Watt } \\ \mu \mathrm{m} & \text { micrometer }\end{array}$




\section{Conversion Factors}

$$
\begin{aligned}
& { }^{\circ} \mathrm{F}=1.8 \mathrm{x}{ }^{\circ} \mathrm{C}+32 \\
& 1 \mathrm{bar}=100 \mathrm{kPa} \\
& 1 \mathrm{foot}=0.3048 \mathrm{~m} \\
& 1 \text { inch }=2.54 \mathrm{~cm} \\
& 1 \mathrm{~m}=3.281 \mathrm{ft} \\
& 1 \mathrm{~mm}=0.03937 \text { in } \\
& 1 \mathrm{~L}=0.2642 \mathrm{gal} \\
& 1 \mathrm{~kg}=2.204 \mathrm{lb} \text { (mass) } \\
& 1 \mathrm{~kg} / \mathrm{m}^{3}=0.06243 \mathrm{lb} / \mathrm{ft}^{3} \\
& 1 \mathrm{kPa}=0.1450 \mathrm{psi} \\
& 1 \mathrm{~kJ}=0.9479 \mathrm{Btu} \\
& 1 \mathrm{~kJ}=1,000 \mathrm{~J} \\
& 1 \mathrm{MJ}=1,000,000 \mathrm{~J} \\
& 1 \mathrm{GJ}=1,000,000,000 \mathrm{~J} \\
& 1 \mathrm{~kJ} / \mathrm{kg}=0.4301 \mathrm{Btu} / \mathrm{lb} \\
& 1 \mathrm{~kJ} / \mathrm{kg}-{ }^{\circ} \mathrm{C}=0.2389 \mathrm{Btu} / \mathrm{lb}-{ }^{\circ} \mathrm{F} \\
& 1 \mathrm{~kW}=3413 \mathrm{Btu} / \mathrm{hr} \\
& 1 \mathrm{~kW} / \mathrm{m}^{2}=317.1 \mathrm{Btu} / \mathrm{hr} / \mathrm{ft}^{2}
\end{aligned}
$$

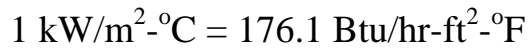

$$
\begin{aligned}
& 1 \mathrm{~W} / \mathrm{m}-{ }^{\circ} \mathrm{C}=0.5778 \mathrm{Btu} / \mathrm{hr}^{-\mathrm{ft}-}{ }^{\circ} \mathrm{F} \\
& 1 \mathrm{~kg}=1000 \mathrm{~g} \\
& 1 \mathrm{~m}=1000 \mathrm{~mm} \\
& 1 \mu \mathrm{m}=0.001 \mathrm{~mm} \\
& 1 \mathrm{~kW}=1,000 \mathrm{~W} \\
& 1 \mathrm{MW}=1,000,000 \mathrm{~W}
\end{aligned}
$$




\section{ACKNOWLEDGMENTS}

The collaboration with the National Institute for Occupational Safety and Health, including Tim Merinar, Matt Bowyer, Jay Tarley, Dawn Castillo, and Robert Koedam, provided on-scene assistance, access to interviews, and support for computer fire model simulations. The cooperation of the Bureau of Alcohol Tobacco and Firearms, including John Golder, Chris Porreca, and David Sheppard provided on-scene assistance and discussions on computer simulations and fire origin and cause. The NIST team also held valuable discussions with Ken Farmer, Robert Neale, and Kenneth Kuntz of the Department of Homeland Security, United States Fire Administration, concerning previous large fire incidents. Lee Baughman of the South Carolina Department of Labor, Licensing, and Regulation provided access to the fire scene. The entire Charleston Fire Department is acknowledged for providing access to staff, fire stations, and fire apparatus to make possible this technical study. The Charleston Police Department provided access to scene photographs and videos. The on-scene assistance and discussion with City of Charleston Safety Management Division, Ted Austin, is also acknowledged. The City of Charleston Zoning Division, Edye Graves, provided background information on building codes for the City of Charleston.

A number of people from NIST assisted the official team members. Of particular note were David Stroup, Glenn Forney, and Anthony Hamins, who devoted considerable time on the fire scene documenting dimensions, materials of construction, and burn patterns. William Grosshandler, Anthony Hamins, and Richard Gann devoted significant time to reviewing and improving the report. The assistance of Adam Barowy and Jonathan Kent in improving the figures, slice files, and digital images was critical and much appreciated. The support that Kelly Opert provided for documenting the reports and media citation significantly improved the readability of the appendices. The energetic assistance of Sue Haga in formatting, assembling, and proofreading these two volumes is also gratefully acknowledged. 


\section{EXECUTIVE SUMMARY}

A fire occurred on the evening of June 18, 2007, in the Sofa Super Store at 1807 Savannah Highway, Charleston, South Carolina. The fire swept from the rear to the front of the main showroom extremely quickly, and then into the west and east showrooms. Nine fire fighters from the Charleston Fire Department were killed in the fire.

Based on the NIST technical study, the following sequence of events are likely to have occurred. From an unknown source, a fire ignited in a pile of packing material and discarded furniture outside an enclosed loading dock area. The fire spread from the exterior to the interior of the loading dock, which was used for staging furniture for delivery and for repair of furniture. The fire spread quickly within the loading dock and moved into both the retail showroom and warehouse spaces. During the early stages, the fire was unable to access enough oxygen (ventilation limited), which slowed its growth. Due to the lack of sufficient air to allow complete combustion, the fire produced large volumes of partially pyrolyzed fuel in the form of smoke and combustible gases. The large volumes of unburned fuel flowed into the interstitial space below the roof and above the suspended ceiling of the main retail showroom. As the interstitial space filled with unburned fuel, the hot smoke also seeped through the suspended ceiling into the main showroom and formed a hot smoke layer below the suspended ceiling. Up to this time, the extent of fire spread into the interstitial space was not visible to fire fighters in the store. If the fire spread had been visible to the fire fighters in the store, it would have provided a direct indication of a fire hazard in the showroom. The fire spread to the rear of the main showroom through the holding area and ignited additional fuel in the rear of the main showroom at which time it became more visible to fire fighters in the main showroom. The fire at the back of the main showroom was still ventilation limited and its growth was slowed by the lack of oxygen. As the fire burned in the rear of the main showroom, the fire pumped more hot unburned fuel into the smoke layer below the suspended ceiling. The lack of oxygen prevented the unburned fuel in the smoke layer from igniting. When the front windows were broken out or vented, additional oxygen flowed in the front windows, along the floor, and to the rear of the showroom and became available to the fire. The additional oxygen allowed the heat release rate of the fire to increase extremely rapidly and ignite the layer of unburned fuel below the suspended ceiling. The fire swept from the rear to the front of the main showroom extremely quickly, then into the west and east showrooms. Both the temperatures and oxygen depletion reached values that were life-threatening to unprotected individuals. Intense heat from sustained burning of furniture in the main showroom weakened the roof joists and supports and resulted in the collapse of a portion of the roof over the main showroom approximately 13 minutes after flames emerged from the front windows (40 minutes after the fire department arrived on scene). Furniture and merchandise in the showrooms and warehouse continued to burn for an additional 140 minutes before the fire was extinguished.

The National Institute of Standards and Technology (NIST) conducted a study to determine the likely technical causes of the rapid fire growth that led to the high number of fire fighter casualties in that fire. NIST is a nonregulatory agency of the U.S. Department of Commerce. The purpose of NIST building and fire safety studies is to use knowledge gained from the studies to help improve safety through recommended changes to codes, standards, and practices. NIST does not have the statutory authority to make findings of fault or negligence by individuals or organizations. 
This technical study included the following tasks:

- Identification of technical issues and major hypotheses requiring examination.

- Data collection, including building design documents, records, and plans from local authorities, video and photographic data, radio transmissions, field data, and interviews with emergency responders, and discussions with store employees.

- Analysis and comparison of building and fire codes and practices, and review and analysis of practices used in operation of the building.

- Simulation and analysis of phenomena, including fire spread, smoke movement, tenability, and operation of active and passive fire protection systems.

The local criminal investigation of the fire took priority over the NIST technical study. NIST access to witnesses and local authorities was limited due to the criminal investigations and civil litigation.

NIST compared the building design and operation to provisions within the model codes in order to assess possible improvements in public safety through revision of model codes, standards and practices. Many of the recommendations are directed toward the current national model codes maintained by the National Fire Protection Association (NFPA) and the International Code Council (ICC), the standards within those codes and elsewhere (e.g., ASTM International, and Underwriters Laboratories (UL)), and the practices associated with their adoption and implementation. Other recommendations are provided for state and local regulatory authorities and first responders.

Since there were no continuous real-time observations or photos in all locations, NIST conducted computer modeling to fill in the gaps and determine the probable sequence of events based on fire physics, coupled to the fire response time line.

\section{Findings}

During the course of this technical study, NIST was able to identify the reasons for the rapid spread of fire and smoke, and the reasons for the difficulties encountered by the fire fighters as they attempted to exit the main showroom. Many of the findings summarized in this section may have had a direct bearing on the tragic outcome of the fire. Those particular findings are highlighted below (boldface). Other findings had a more peripheral role but are important to capture because of the potential to help mitigate the consequences of similar situations in the future.

\section{Fire Growth}

Fire was observed at rear of store at 6:56 p.m. The fire began in trash outside the loading dock and spread into the enclosed loading dock. Fire department arrived at 7:11 p.m., less than four minutes after being dispatched. From the loading dock, the fire spread through the merchandise holding area to the rear of the main showroom, then to the front of the main showroom, and then into the west and east showrooms. At the same time, the fire spread into the holding area and through a metal wall into the warehouse.

The extremely rapid spread of fire through the main and west showrooms trapped six fire fighters in the main showroom and three fire fighters in the west showroom. Although the intense heat from the fire 


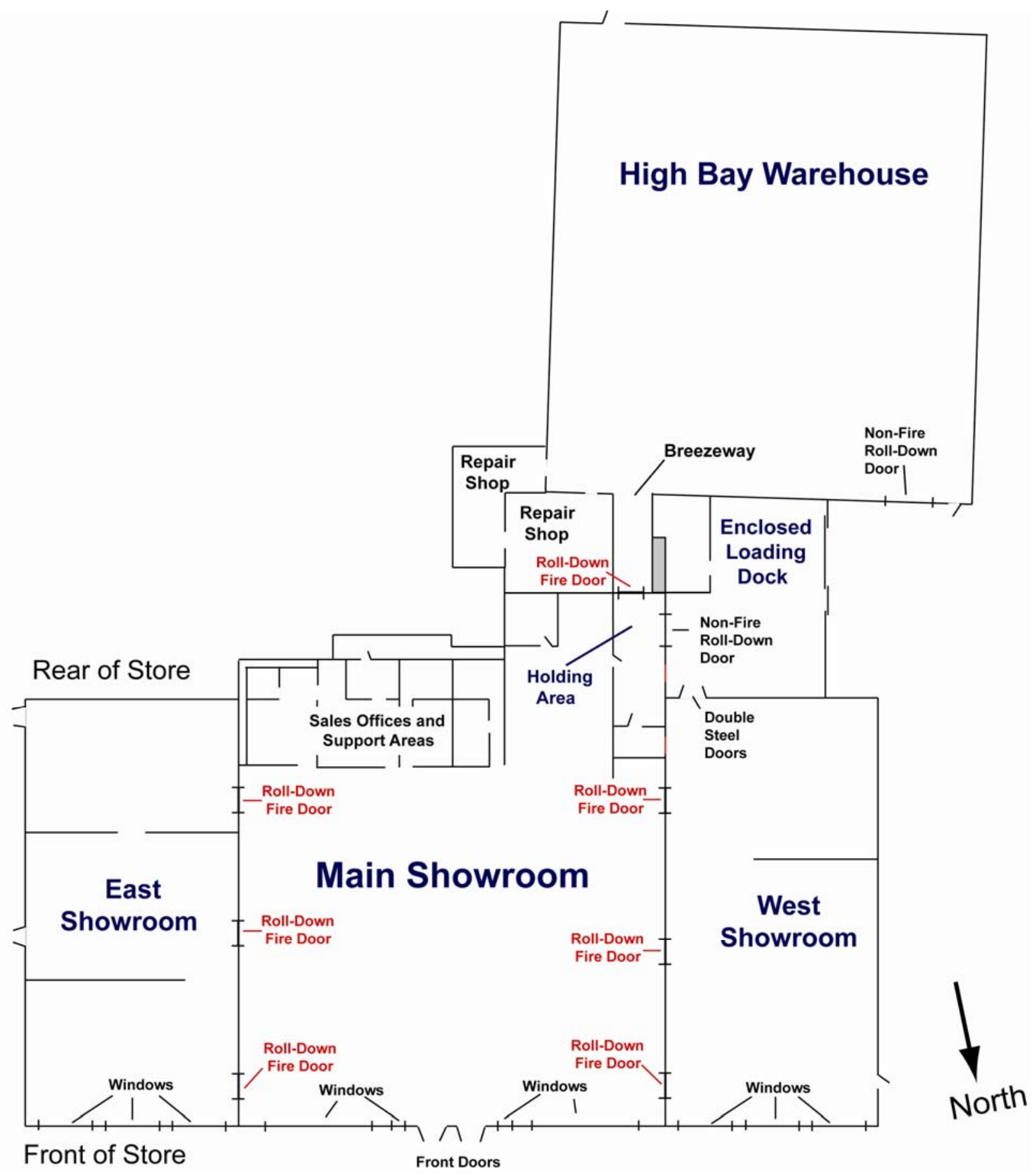

Floor Plan of Sofa Super Store. 
weakened the light weight steel trusses and led to the partial collapse of the roof, the coroner's report indicated that the fire fighters died from thermal burns and/or smoke inhalation, not from compression type injuries that would have been associated with the collapse.

The following sections highlight specific findings that are associated with fire spread.

Loading Dock

- A large amount of fuel (130 GJ) was present, including a) furniture that was staged for delivery, b) wood framing, c) liquid hydrocarbon solvents, and d) flooring.

- An open floor plan and the large amount of fuel allowed rapid fire growth across the loading dock.

- An open non-fire-activated roll-down door allowed smoke and flames to flow into the holding area.

- Metal walls that the loading dock shared with the warehouse and west showroom allowed the fire to spread into those spaces.

- The heat release rate of the fire was slowed by the lack of air; that is, the fire was underventilated.

Holding Area

- Smoke and flames entered the holding area through the open roll-down door (non-fire activated). Furniture and other items within the holding area were ignited by the flames and thermal radiation from the loading dock fire.

- During the early stages of the fire (5 minutes to 10 minutes after fire department arrived), the fire spread into the holding area. The fire in the holding area was not visible from the main or west showrooms.

- Smoke and flames flowed from the holding area into the space above the main showroom suspended ceiling. At a later stage, fire spread either over or through the holding area partition wall and into the rear of the main showroom.

- The heat release rate of the fire was slowed by the lack of air; that is, the fire was underventilated.

Showrooms

- Fire spread through the holding area into the rear of the main showroom, then through the entire main showroom, and then into the west and east showrooms.

- Three fire doors between the main and west showrooms activated, but did not close during the fire. Three fire doors between the main and east showrooms activated; two doors closed completely and the third door partially closed.

- A large amount of fuel was available, including up to 1100 combustible items (480 GJ) displayed in the main, west, and east showrooms. 
- Smoke and flames from the fire on the loading dock and holding area flowed into the space above the main showroom suspended ceiling.

- An open floor plan and the large amount of fuel allowed the fire to grow and spread in the rear of the main showroom.

- During the early stages of the fire (10 minutes to 15 minutes after fire department arrived) the heat release rate of the fire in the rear of the main showroom was slowed by the lack of air; that is, the fire was underventilated.

- Front windows were broken or vented by the fire department to improve visibility.

- Fire spread extremely rapidly from the rear to the front of the showroom as additional air flowed through the broken windows, feeding the fire in the rear of the showroom.

- Within the main and west showrooms, both the temperatures and oxygen depletion reached values that were life-threatening to unprotected individuals.

- The fire resulted in six fire fighter fatalities in the main showroom. Fire spread through three open roll-down fire doors into the west showroom and resulted in three additional fire fighter fatalities.

- Intense heat from sustained burning of furniture weakened the roof supports and resulted in the collapse of the roof over the main showroom and sagging of the roof over the west showroom.

Warehouse

- A large amount of fuel was available, including up to 1900 items (840 GJ) stored on high rack shelves in the warehouse.

- An open floor plan and the large amount of fuel allowed the fire to grow and spread from the front to the rear of the warehouse.

- Intense heat from sustained burning of the furniture weakened roof supports and resulted in collapse of the roof and walls into the warehouse.

- No fire fighter entered the warehouse to attempt to extinguish the flames, and no one was injured in this portion of the structure.

\section{Fire Protection Systems}

The lack of fire sprinklers to control the fire during an early stage of its growth and the lack of effective compartmentation were direct contributors to accelerated fire growth in the retail showrooms and the distribution warehouse. The following was found regarding the installation and operation of fire suppression and other safety systems applicable to the building:

Fire Sprinklers

- Fire sprinklers were not installed in the showrooms or distribution warehouse. 
- Computer model simulations demonstrated that fire sprinklers in the loading dock would have controlled the fire and prevented the fire from extending beyond the loading dock.

- Computer model simulation demonstrated that tenable (survivable) conditions were maintained within the loading dock, showrooms, and warehouse with a sprinkler system installed on the loading dock.

\section{Compartmentation}

- Large open spaces allowed the fire to spread over large areas, including loading dock, showrooms, and warehouse. Interior walls and fire doors did not provide adequate compartmentation.

- The open roll-down door between the loading dock and holding area was not a fireactivated door and allowed the fire to spread to the rear of the main showroom

- Only three of the seven roll-down fire doors activated and closed fully during the fire.

- Uninsulated metal walls (the north wall of the warehouse and the south wall of the west showroom) allowed heat from the fire to ignite fuels that were against the walls in the warehouse and west showroom.

Other Fire Protection Systems

- The store did not have a fire alarm system, smoke detectors, or standpipe.

- There were more than five portable fire extinguishers located in the structure. A store employee discharged two portable extinguishers at the loading dock fire.

\section{Combustible Material}

The large fuel load made up of the retail merchandise staged in the loading dock, displayed in the show rooms, and stored in the warehouse was a key contributor to the spread of the fire and the eventual failure of the building. In addition, the storage of flammable solvents in the loading dock area allowed the fire to spread more quickly to the holding area and to the warehouse.

Fuel Load

- The high total energy content of the structure and contents, estimated at up to $1450 \mathrm{GJ}$, was a contributing factor to the severity of the fire.

- The furniture fuel mass loading was estimated to range up to $16 \mathrm{~kg} / \mathrm{m}^{2}\left(3.4 \mathrm{lbs} / \mathrm{ft}^{2}\right)$ for the showrooms and $52 \mathrm{~kg} / \mathrm{m}^{2}\left(10.6 \mathrm{lbs} / \mathrm{ft}^{2}\right)$ for the warehouse. The high rack storage in the warehouse contributed to the higher fuel mass loading than in the showrooms.

Fuel Package

- The type and configuration of the fuels also contributed to the fire growth in the loading dock, showrooms, and warehouse. 
- A significant fraction of the fuel was upholstered furniture, which has a large surface area, synthetic coverings, and foam padding. The coverings and padding contributed to the rapid spread of the fire.

- Wood was also an important component of the upholstered furniture as well as of the dressers, tables, and nightstands. The wood contributed to the sustained burning that occurred after the initial rapid spread of the fire.

\section{Model Codes and Standards}

Specific findings regarding model codes and standards, both current and in effect at the time of construction:

- Strict adherence to the $\mathbf{2 0 0 6}$ model building and fire codes available at the time of the fire would have required the main showroom and warehouse to be sprinklered.

- The roll-down door between the loading dock and holding area was not a fire door. If the loading dock was considered as a separate occupancy or fire area, current model fire codes require a fire rated door.

- The addition of an enclosed loading dock area between the north wall of the warehouse and the south wall of the west showroom without the upgrading of the fire resistance of these partition walls would have caused the warehouse, loading dock area, and west showroom to be considered a single $2330 \mathrm{~m}^{2}\left(25,040 \mathrm{ft}^{2}\right)$ building lacking the required occupancy separations. This building area exceeds the allowable unsprinklered building areas in the 1991/1994 SBC and 2006 IBC codes for both mercantile and storage occupancies. In addition, the 1991/1994 SBC and 2006 IBC codes would both have required fire sprinklers for a building of this size.

- The 1991 SFPC and 2006 IFC, both require sprinkler protection for the warehouse based on the high-piled storage of upholstered furniture.

- Large amounts of hydrocarbon solvents were stored on the loading dock, but quantities did not appear to exceed the maximum allowable quantities for storage occupancies in the 1991/1994 SBC or 2006 IBC.

- Neither current nor contemporaneous fire codes sufficiently address the uniquely high fire hazard from the type and configuration of the combustibles in a building loaded with upholstered furniture. Furniture is often displayed in large open areas. As demonstrated in the main and west showrooms and warehouse, displaying large amounts of furniture in large open spaces can contribute to extremely rapid fire spread.

\section{Emergency Response}

The NIST study examined emergency response only as needed to reconstruct the behavior and time line of the fire. The NIST study found the following: 
- The fire department arrived on scene in fewer than 4 minutes after the 911 dispatch received the report of an exterior trash fire behind the Sofa Super Store.

- Upon initial survey of the exterior of the structure, the fire department located a fire inside the enclosed loading dock.

- Initial survey of the interior did not find any smoke or fire in the showrooms. Three minutes after arrival, inspection of the rear of the west showroom confirmed the loading area was fully involved in fire.

- Up to 5 minutes after arrival, there were no reports of significant smoke or fire observed inside any of the showrooms.

- Within 5 minutes of arrival the fire department began suppressing the loading dock fire using tank water from the first two arriving engines; it took the fire department about 10 minutes to establish a water supply from a fire hydrant to the exterior loading dock area and about $\mathbf{1 6}$ minutes from a fire hydrant to the front of the store.

- Between 16 minutes and 19 minutes after arrival, radio communications indicated that fire fighters may be disoriented or lost in the structure and a "Mayday" call was transmitted.

- Between 16 minutes and 21 minutes after the first unit arrived, the Assistant Chief led a team to rescue an employee trapped inside the rear of the store.

- The fire department vented the front windows about 24 minutes after arrival.

- Flames emerged from the front windows within 3 minutes of the windows being vented.

- The last fire fighters to exit successfully from the front of the store did so within 4 minutes of windows being vented.The roof collapsed over the west side of the main showroom about 40 minutes after fire department arrived on scene.

- Material in the showrooms and warehouse, including furniture and merchandise, continued to burn for an additional 140 minutes before the fire was extinguished.

\section{Initial Response and Risk Management Plan}

The initial response of the fire department included two engine companies, a ladder truck company, and a battalion chief. With an engineer, a fire fighter, and an officer on each apparatus, the fire department's initial response included 10 people. A comprehensive risk management plan developed according to NFPA 1500 for the Sofa Super Store would likely have identified it as a high hazard occupancy due to the lack of sprinklers and the presence of large open areas and a large fuel load. For high hazard occupancies, NFPA 1710 advocates a minimum crew size of 5 to 6 members for each apparatus, which for this incident would amount to 16 to 19 people for the initial response. 


\section{Water Supply}

The supply of water to the fire fighters was limited to the water on the fire engines for 9 minutes at the loading dock and 15 minutes at the front of the store. When the connection was made to the municipal water supply, the two engines were pumping water to the store through long lines of small diameter 6.4 $\mathrm{cm}$ (2.5 in) hose. The water being supplied was inadequate to suppress the fire in a timely fashion due to the following factors:

- The time required to establish connections to water hydrants.

- The limited number of water supply hose lines established before the structure was evacuated.

- The significant water pressure drop caused by long runs of hose.

\section{Incident Command}

Fire department operations were directed by the Fire Chief on the loading dock and the Assistant Chief at the front of the store. Specific findings regarding incident command include:

- The Assistant Chief led a team of fire fighters around to the rear of the main showroom to rescue the trapped employee.

- During this same time period as the rescue operation, conditions within the showroom deteriorated. Radio communications indicated that fire fighters became disoriented or lost within the store.

- Shortly after the Assistant Chief returned to the front of the store after the rescue effort, fire fighters broke out the front windows and vented the smoke from the main showroom.

- Conditions within the store deteriorated rapidly. At the loading dock, the Fire Chief held back fire teams from re-entering.

- While the trapped employee was being rescued, the Fire Chief radioed “... we need to evacuate the building," but it is not clear what was done at the front of the store to implement this order.

\section{Ventilation}

A burning structure can be ventilated by breaking windows and cutting holes in the roof, which can allow the smoke and hot gases to escape the structure in order to provide better visibility for fire fighters. As the smoke and hot gases exhaust from the structure, fresh air is pulled into the building, which may result in an increased heat release rate.

- The front windows of the main showroom were broken to allow the smoke and hot gases to vent. 
- Venting the front windows of the main showroom did allow the smoke to escape, but it also provided more air to feed the fire and provided a path for the fire to spread.

- The fire trapped six fire fighters in the main showroom and three fire fighters in the west showroom.

\section{Building Record-keeping Practices for Public Safety}

Inspections and record-keeping practices are an integral part of a community fire safety program. Findings relevant to the Sofa Super Store fire include the following:

- Records were not found of the initial building design. Records of modifications -- when located -- lacked sufficient detail to track the changes to the structure.

- Neither the historical nor most current use and occupancy permit for the building was located; however, the use of the Sofa Super Store was consistent with the SBC 1994, IBC 2006, and IFC 2006 occupancy classifications of Group M with Class III commodity.

- Records documenting fire department inspections of the structure noted deficiencies in exit signs and cluttered aisles. The inspection records also documented the lack of fire alarms and sprinklers.

- Fire department inspections did not identify the large fuel load, the non-code compliant wood construction, the solvent storage on the loading dock, or the lack of a fire door between loading dock and holding area as significant fire hazards.

\section{Recommendations}

Based on its study of the Charleston Sofa Super Store fire, NIST makes eleven recommendations, listed in the following Table, that (a) involve modification, adoption, or enforcement of model building and fire codes, (b) involve standard operating procedures for the fire service, and (c) identify research necessary to underpin and provide additional technical justification for these actions.

\section{Table of Recommendations}

1. High Fuel-Load Mercantile Occupancies: NIST recommends that all state and local jurisdictions adopt a building and fire code covering new and existing high fuel-load mercantile occupancies based on one of the model codes (as a minimum requirement), and update local codes as the model codes are revised. 


\section{Table of Recommendations}

2. Model Building and Fire Code Enforcement: NIST recommends that all state and local jurisdictions implement aggressive and effective fire inspection and enforcement programs that address:

a) all aspects of the building and fire codes;

b) adequate documentation of building permits and alterations;

c) means of fire protection systems inspection and detailed record keeping;

d) frequency and rigor of fire inspections, including follow-up and auditing procedures; and

e) guidelines for remedial requirements when inspections identify deviations from code provisions.

3. Qualified Fire Inspectors and Building Plan Examiners: NIST recommends that all state and local jurisdictions ensure that fire inspectors and building plan examiners are professionally qualified to a national standard such as NFPA 1031 Standard for Professional Qualifications for Fire Inspector and Plan Examiner. Professional qualification may be demonstrated through a nationally accepted certification examination, such as the Fire Plan Examiner; Fire Inspector I and II, and Certified Fire Marshal.

4. Sprinklers: NIST recommends that model codes require sprinkler systems, and that state and local authorities adopt and aggressively enforce this provision:

a) for all new commercial retail furniture stores regardless of size; and

b) for all existing retail furniture stores with any single display area of greater than $190 \mathrm{~m}^{2}\left(2000 \mathrm{ft}^{2}\right)$.

5. Comprehensive Fire Risk Management Plans: NIST recommends that state and local jurisdictions develop comprehensive fire risk management plans to:

a) identify low, medium, and high hazard occupancies;

b) allocate resources according to risk identified; and

c) develop operating procedures that respond to specific risks. 


\section{Table of Recommendations}

6. Ventilation of Burning Structures: NIST recommends that state and local authorities:

a) develop guidelines as to how and when ventilation should be implemented during a fire;

b) provide education to fire fighters on the science of fire behavior in vented and non-vented structures and how the addition of air can impact the burning characteristics of the fuel; and

c) provide training to fire fighters on different types of ventilation (vertical, horizontal, or positivepressure) and integrate into daily operations on the fire ground.

7. Research on Upholstered Furniture Flame Spread: NIST recommends that research be conducted to better understand ignition and fire spread on upholstered furniture in order to provide the tools needed by the design profession to improve the fire performance of furniture. The following specific areas require research:

a) prediction of ignition of natural and synthetic coverings for furniture, wall, ceiling and floor lining materials, and room furnishings;

b) prediction of fire spread over actual furniture with and without fire barriers, fire retardants, and fire resistive materials; and

c) quantification of smoke and toxic gas production in realistic room fires.

8. Research on Improving Fire Barriers: NIST recommends that research be conducted to provide the tools needed by the design profession to improve the performance of compartmentation. The following specific areas require research:

a) prediction of fire spread through walls constructed of wood, metal, and gypsum wallboard;

b) prediction of fire spread through doors constructed of glass, wood, and metal; and

c) prediction of performance of roll-down doors and activation devices in actual fires and after extended service.

9. Research on Decision Aids for Allocation of Resources: NIST recommends that research be conducted to:

a) refine computer-aided decision tools for determining the costs and benefits of alternative code changes and fire safety technologies, and

b) develop computer models to assist communities in allocating resources (money and staff) to ensure that their response to an emergency with a large number of casualties is effective. 
10. Research on Ventilation of Burning Structures: NIST recommends that additional research be conducted to :

a) characterize how ventilation can affect the growth and spread of fire within structures; and

b) provide the fire service with guidance on when and how to use ventilation to improve the fire environment during fire service operations.

11. Research on Performance Metrics for Fire Protection: NIST recommends that research be conducted to:

a) develop performance and effectiveness metrics for community fire protection;

b) survey effectiveness of existing fire services; and

c) utilize metrics to optimize development of new fire protection technologies. 
xxviii 


\section{Chapter 1BACKGROUND}

\subsection{INTRODUCTION}

A fire occurred on the evening of June 18, 2007, in the Sofa Super Store at 1807 Savannah Highway, Charleston, South Carolina. Nine fire fighters from the Charleston Fire Department were trapped in the showrooms and lost their lives in the fire.

The National Institute of Standards and Technology (NIST) conducted a study to determine the likely technical causes of the rapid fire growth that led to the high number of fire fighter casualties in that fire. NIST is a nonregulatory agency of the U.S. Department of Commerce. The purpose of NIST building and fire safety studies is to use knowledge gained from the studies to help improve safety through recommended changes to codes, standards, and practices. NIST does not have the statutory authority to make findings of fault nor negligence by individuals or organizations.

This technical study included the following tasks:

- Identification of technical issues and major hypotheses requiring examination.

- Data collection including building design documents, records, and plans from local authorities, video and photographic data, radio transmissions, field data, discussions with store employees, and interviews with emergency responders.

- Analysis and comparison of building and fire codes and practices, and review and analysis of practices used in operation of the building.

- Simulation and analysis of phenomena, including fire spread, smoke movement, tenability, and operation of active and passive fire protection systems.

This report documents the NIST technical study into the Sofa Super Store fire. The following sections of this chapter describe the building and surroundings as they were prior to the fire and review the general history of the building. Chapter 2 provides a time line of the incident, including the ignition and spread of the fire, and fire fighting activities. The fire service and incident response procedures are detailed in Chapter 3. Chapter 4 provides background and results of the computer simulation of the fire and smoke movement. Chapter 5 reviews the model building and fire codes that are relevant to a structure like the Sofa Super Store. The report concludes with a summary of findings and recommendations in Chapter 6 . The appendices provide more detail and information that is peripheral to the main objectives of the study. Animated renderings of NIST fire model simulations are included in the DVD that accompanies this report.

\subsection{DESCRIPTION OF THE BUILDING AND SITE}

\subsubsection{Collection of Building Data}

In the process of developing this description of the Sofa Super Store, the NIST team collected data from a range of sources including: post-fire data, digital photographs [1-4], interviews of fire fighters [5], a discussion with store employees [6], articles from news outlets [8], and investigative reports [8-10]. 
Information from all these sources was incorporated into a series of floor plans and descriptions presented in this chapter.

The NIST team had access to the exterior of the Sofa Super Store the day after the fire. Exterior photographs documented the geometry, construction, and materials of the structure. A week after the fire, the NIST team was allowed access to the entire fire scene and collected additional photographs, both interior and exterior. Dimensional measurements were also collected for the overall structure and specific spaces. The team also documented type, location, and nature of post fire residue. This data allowed the team to estimate what merchandise, equipment, or supplies had occupied the space prior to the fire. For example, the presence of a specific type of hardware such as hinges indicated that recliners had been displayed in the west showroom. Partially burned merchandise, such as sofas, end tables, and chairs demonstrated that living room furniture had been displayed in the east showroom.

Unburned sections of structure including walls, ceilings, and flooring, provided insight into what materials had been incorporated into the structure. For example, surviving sections of an interior wall indicated that $1.3 \mathrm{~cm}(0.5$ in) thick gypsum board had been screwed over $5 \mathrm{~cm}$ x $10 \mathrm{~cm}$ (2 in x 4 in) metal studs. Burn residue of floor tile and unburned portions of carpet allowed the team to estimate the type and location of floor coverings. Examination of steel racks in the warehouse demonstrated the number and spacing of the high rack storage bays. Surviving steel joists, "Z” channels, and siding documented how the roofs and exterior walls had been constructed.

Aerial photography provided information on the history of the structure and how it was constructed. As will be presented in more detail in Section 1.6, aerial images documented that the loading dock was not present in 1994 images, but was present in 1998 images; therefore the loading dock had been added sometime after 1994, but prior to 1998. Aerial photographs provided information on the number, type, and location of skylights, as well as other structural components.

Discussion with store employees and interviews with fire fighters provided information about how the store floor space was configured and what type of merchandise was displayed. Store employees provided insight as to whether a space was used for displaying, repairing, or staging merchandise. For example, employees described how furniture was staged on the loading dock while awaiting delivery. Fire fighters that had visited the store to conduct fire safety inspections or to shop for furniture were able to provide a general description of how the furniture was displayed.

Articles from newspapers, television stations, and the internet [7] were reviewed by the NIST team for potentially new sources of information. The information was examined, and if it could be verified, the new data were included in the description of the store. Investigative reports from Bureau of Alcohol, Tobacco, Firearms, and Explosives (ATF) [8], National Institute for Occupational Safety and Health (NIOSH) [9], and the Post Incident Assessment and Review Team [10] were carefully reviewed and provided additional information into how specific spaces were used and the materials of construction.

\subsubsection{General}

The Sofa Super Store was located at 1807 Savannah Highway, in the West Ashley Subdivision of Charleston, South Carolina. Figures 1-1 and 1-2 are photographs of the building on its lot (additional images in Appendix N). The north-facing front of the store was set back about $30 \mathrm{~m}(100 \mathrm{ft})$ from Savannah Highway, a five-lane, two way street that runs roughly east-to-west. A parking lot for over 50 cars was located in the front and east side of the building. Along Savannah Highway to the east was a 
gasoline station and to the west were a car repair garage, a used car lot, and an open lot. While the rear of the warehouse was along Pebble Road, several residential structures were located between the rear of the main and east showrooms and Pebble Road. There were no residential structures between the rear of the warehouse and Pebble Road. The lot appeared to be at the same elevation as Savannah Highway and Pebble Road. The parking lot in front of the store sloped gradually upward to the store. The east side parking lot was at the same elevation as the poured concrete floor of the east showroom. A driveway along the west side of the showrooms provided access to the warehouse for delivery trucks. The asphalt surface of the driveway was approximately $0.7 \mathrm{~m}(2 \mathrm{ft})$ below the poured concrete floor at the front of the west showroom. The driveway sloped gradually down towards the warehouse, and the asphalt surface

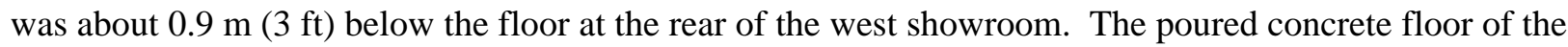
warehouse was approximately $0.8 \mathrm{~m}(2.5 \mathrm{ft})$ below the floor of the showrooms. Wooden fences had been constructed from the northwest corner of the lot at Savannah Highway around the rear of the warehouse and along the rear of the main and east showrooms. Trees lined the fence along the rear of the east and main showrooms with a single large tree located at the corner where the main showroom intersected the repair shops. Various small trees and bushes were outside the fence to the rear of the warehouse, and a shallow drainage ditch was located between the vegetation and Pebble Road.

A distant aerial view of the area, Figure 1-3, shows the store in relation to the local fire stations and community. Note that both Station 11 and Station 10 of the Charleston Fire Department (CFD) were located east on Savannah Highway, about $1.3 \mathrm{~km}$ (0.8 mile) and $2.1 \mathrm{~km}$ (1.3 miles) from the Sofa Super Store, respectively. The nearest station of St. Andrew's Fire Department was approximately $1.6 \mathrm{~km}$ (1 mile) north of the store, on Ashley River Road.

\subsubsection{Collection of Building Data}

The NIST team was on-site the day after the fire and photographed the exterior of the structure. Portions of the structure appeared to represent collapse hazards and had to be removed before the NIST team was allowed access to the interior of the showrooms and warehouse. The NIST team then photographed the interior and exterior of the structure. Selected images of the showroom, warehouse, and loading dock are included in Appendices B, C, D, E, F, G, H, and I. Still photographs and video were also recorded by others including civilians, law enforcement, newspapers, and television stations. The NIST team reviewed these additional photographs and videos as part of this technical study.

Working in cooperation with the National Institute for Occupational Safety and Health (NIOSH) and South Carolina Department of Labor, Licensing, and Regulation, NIST team members recorded the physical dimensions of the structure, the construction materials, and the function of each area within the space. The team was not able to collect every dimension due to the extent of fire damage and the early removal of portions of the structure in order to reduce the collapse hazard. Physical dimensions were collected using tape measures and laser ranging devices. Construction materials were noted as each space was measured. The function of each space, for example, merchandise storage, merchandise display, or wood repair, was noted for each space. If the fire damage was extensive in a particular space, the function was estimated from the fire residue such as steel coil springs indicating mattresses, or steel hinges indicating recliners. As described in the following sections, these dimensions, materials, and estimated space usage were used to develop the floor plans for the structure and were used as input for the computer model. 


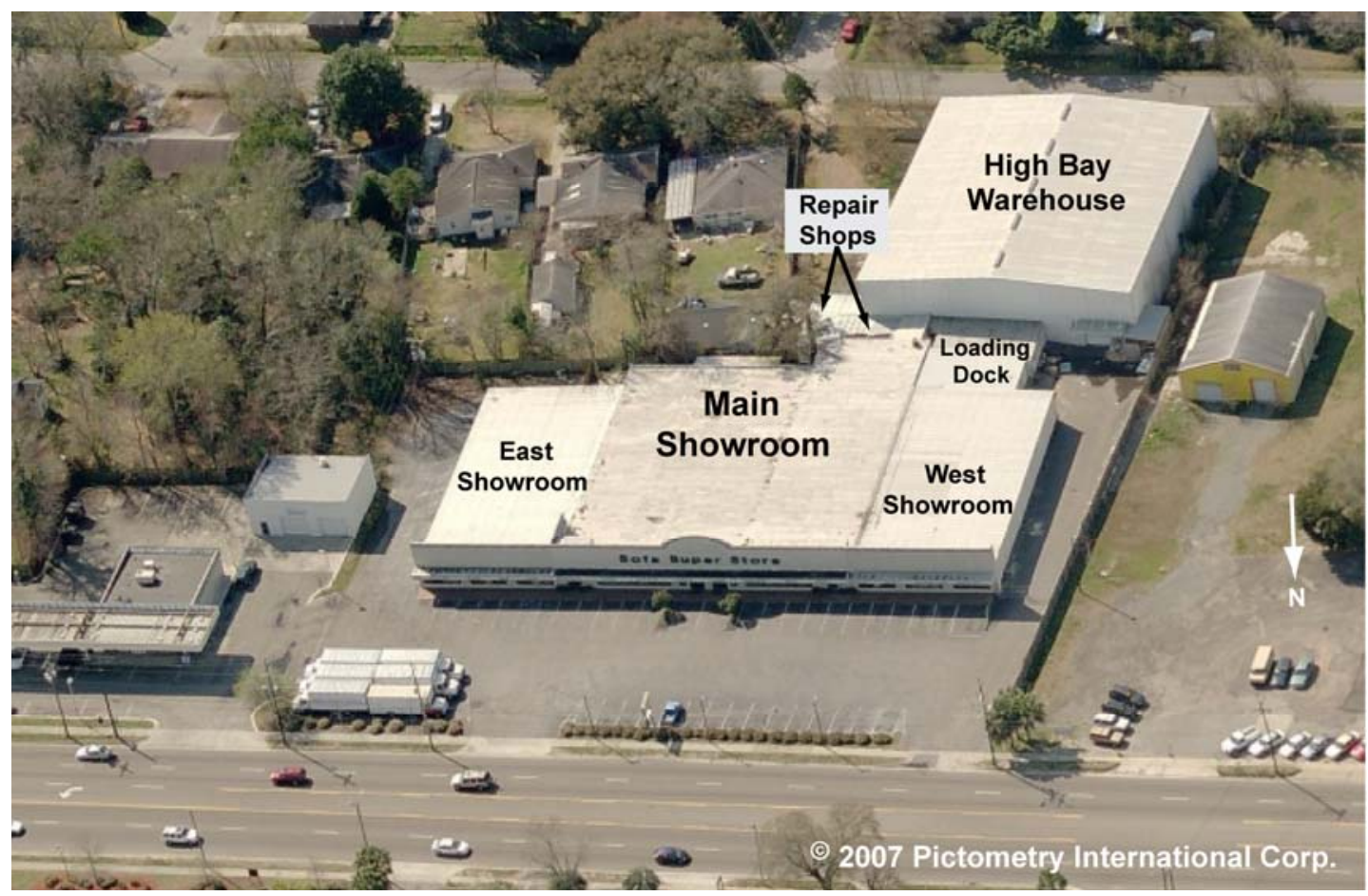

Figure 1-1. Sofa Super Store at 1807 Savannah Highway in Charleston, South Carolina. Background image used with permission of Pictometry. Enhancements by NIST.

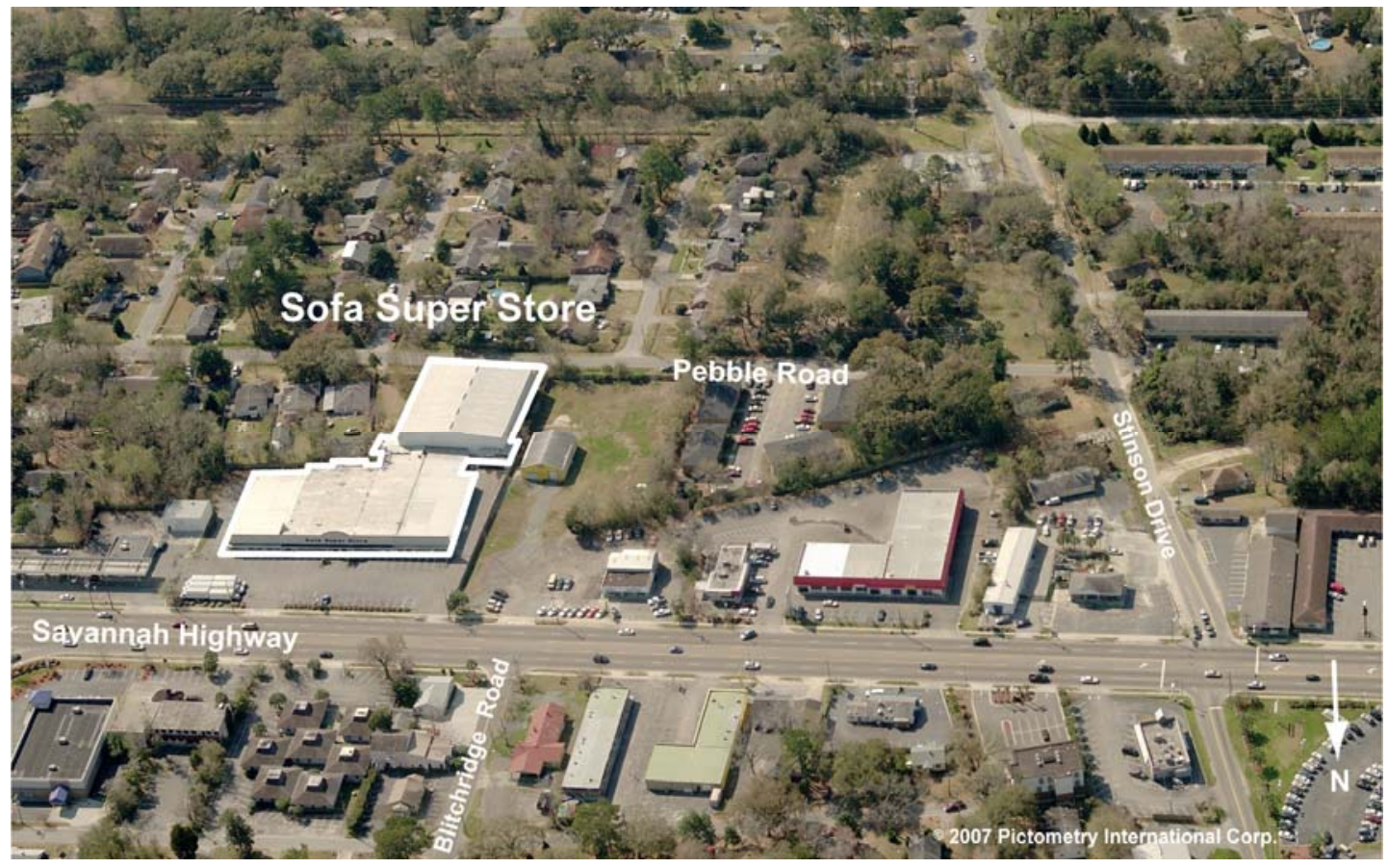

Figure 1-2. Retail Showrooms and Warehouse Distribution Spaces. Background image used with permission of Pictometry. Enhancements by NIST. 


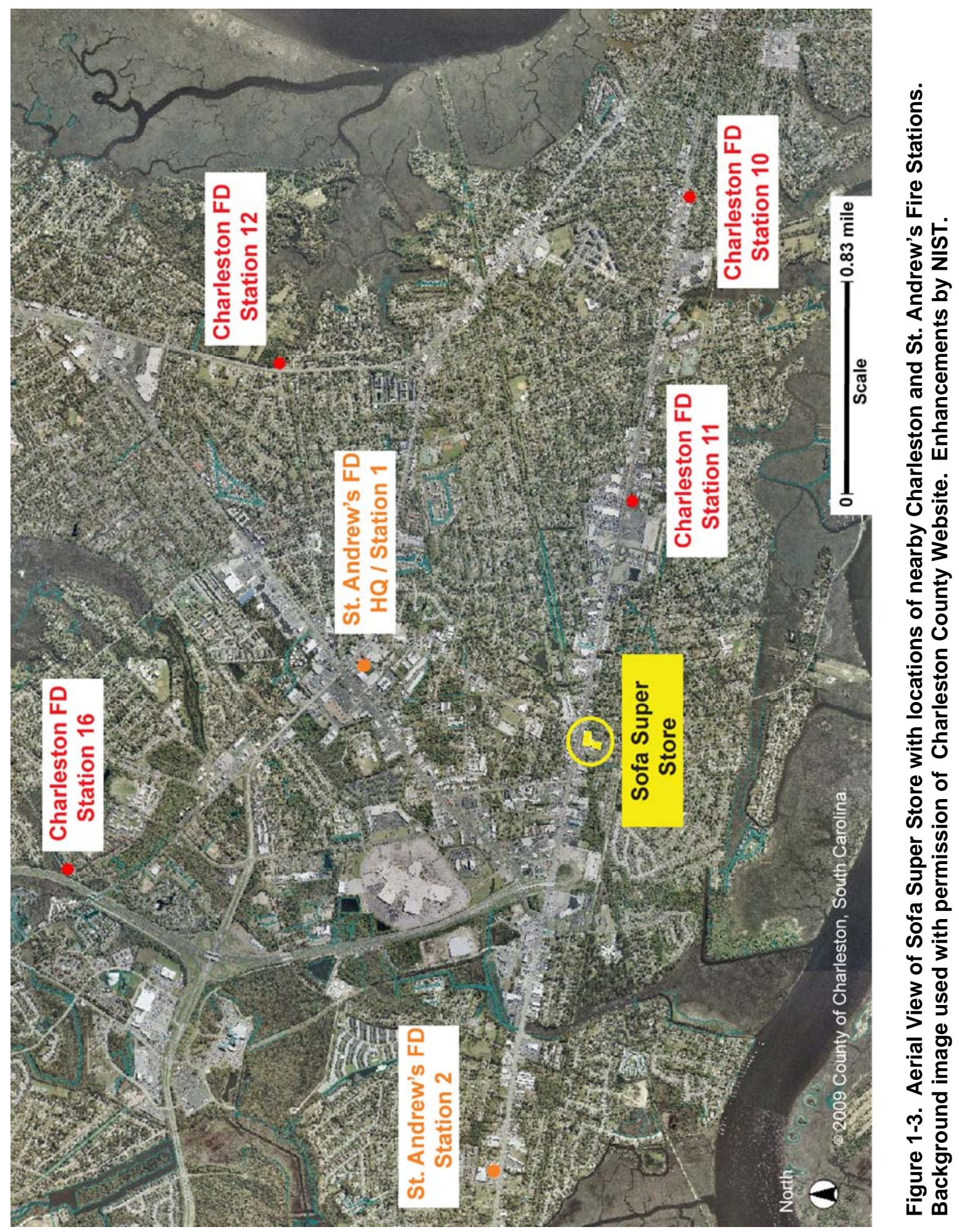


An informal conversation with store employees provided insight into how the furniture was arranged in the showrooms and loading dock area. ${ }^{1}$ The discussion also allowed the team to better understand the configuration of a holding area space located between the loading dock and the main showroom. The team also visited other stores within the Sofa Super Store chain to gain insight into how furniture was typically displayed in the retail space.

Overhead photographs of the Sofa Super Store were collected at regular intervals by remote sensing imaging or aerial photography. Overhead images are often used by commercial companies and municipalities to track land usage or as an aid to land development. DigitalGlobe, a commercial aerial imagery company, recorded aerial images of the store in 1989, 1994, 1998, 2001, 2006, and 2007. Aerial photographs were recorded by a second commercial imagery company, Pictometry, in 2007. The aerial images provided information about the addition of the east and west showrooms, warehouse, loading dock area, and repair shops. The images are discussed in Section 1.7, and all the images are included in Appendix N.

The team was not able to locate a complete set of dimensioned drawings for the entire structure. Each of the floor plans presented in this study was created using the dimensions and photographs collected by the NIST team. Several partial drawings, including a portion of the construction drawings for the warehouse addition, were provided by the City of Charleston.

\subsubsection{Main Retail Showroom}

The interior floor plan of the entire structure is represented in Figures 1-4 and 1-5. The dimensions for each of the spaces were part of the data the NIST team collected while they were on the post-fire scene. The main showroom was $38.4 \mathrm{~m}(126.0 \mathrm{ft})$ wide and $39.1 \mathrm{~m}(128.3 \mathrm{ft})$ deep and with an additional section

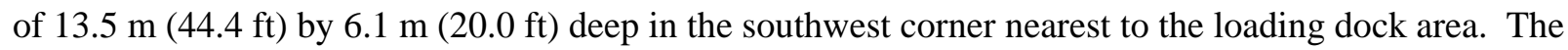
total area of the main showroom was calculated as about $1585 \mathrm{~m}^{2}\left(17,100 \mathrm{ft}^{2}\right)$.

There were two sets of double doors near the center of the front (north) wall, which were the only entrances on the front of the structure (see Figure 1-5 and additional photographs in Appendix D). The two front doors were flanked on either side by small and large glass display windows (see Figures 1-6, 1-7, and Appendix D, Figure D-15). There were no exits or windows on the rear wall of the main showroom. While there may have been exits on the rear wall when the structure was originally built, all the rear exits had been closed or filled using masonry blocks (see Figures I-4 and I-8). The east and west walls of the main showroom each featured three interior fire doors which allowed customers to move to either the east or west showrooms (Figure 1-4). Employees also used these fire doors to re-position furniture between different showrooms and move furniture from the warehouse into the retail showrooms.

\footnotetext{
${ }^{1}$ The informal conversation with store employees was not audio or video recorded by the NIST team nor was a written transcript generated.
} 


\section{High Bay Warehouse}

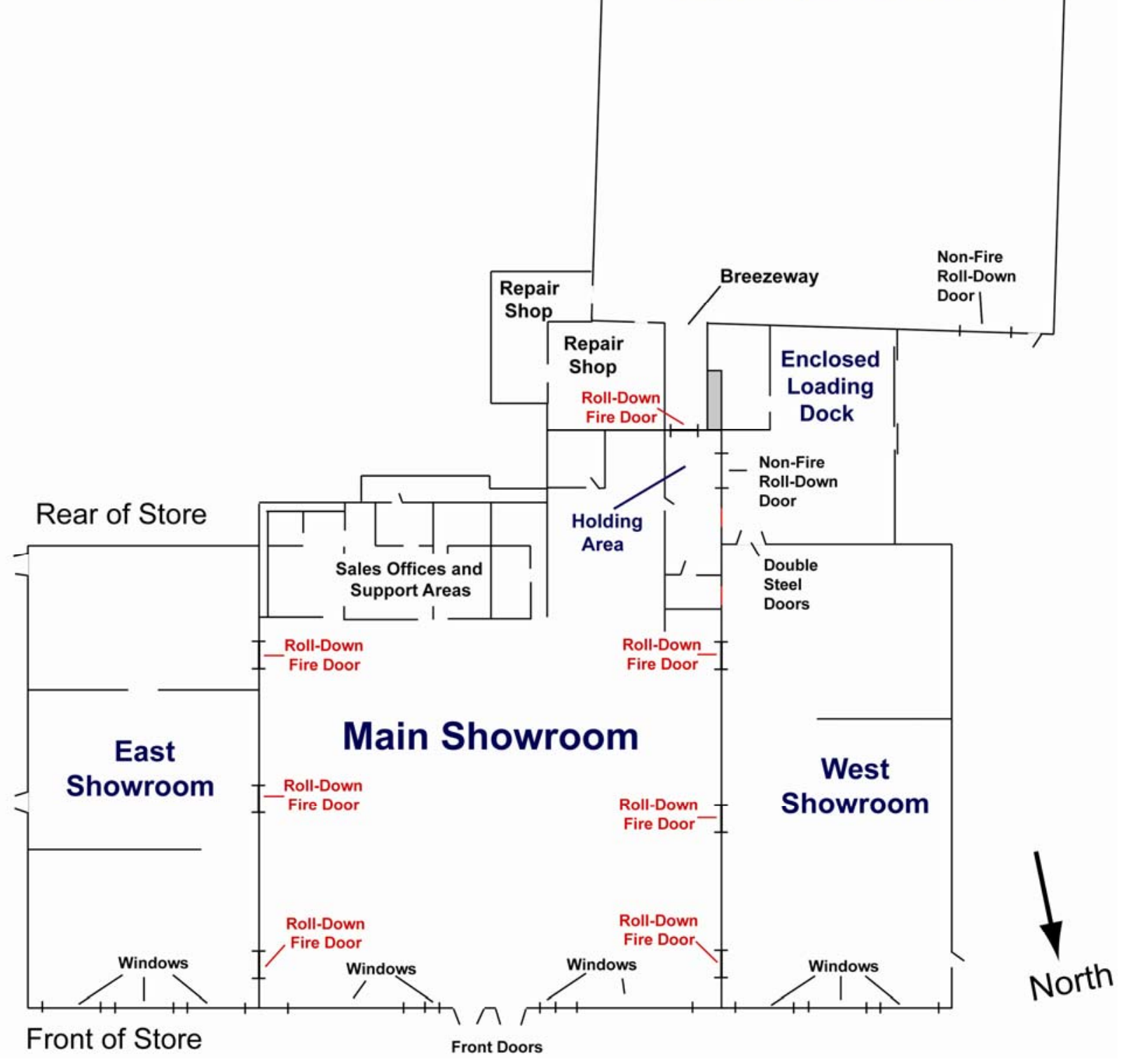

Figure 1-4. Sofa Super Store floor plan. 


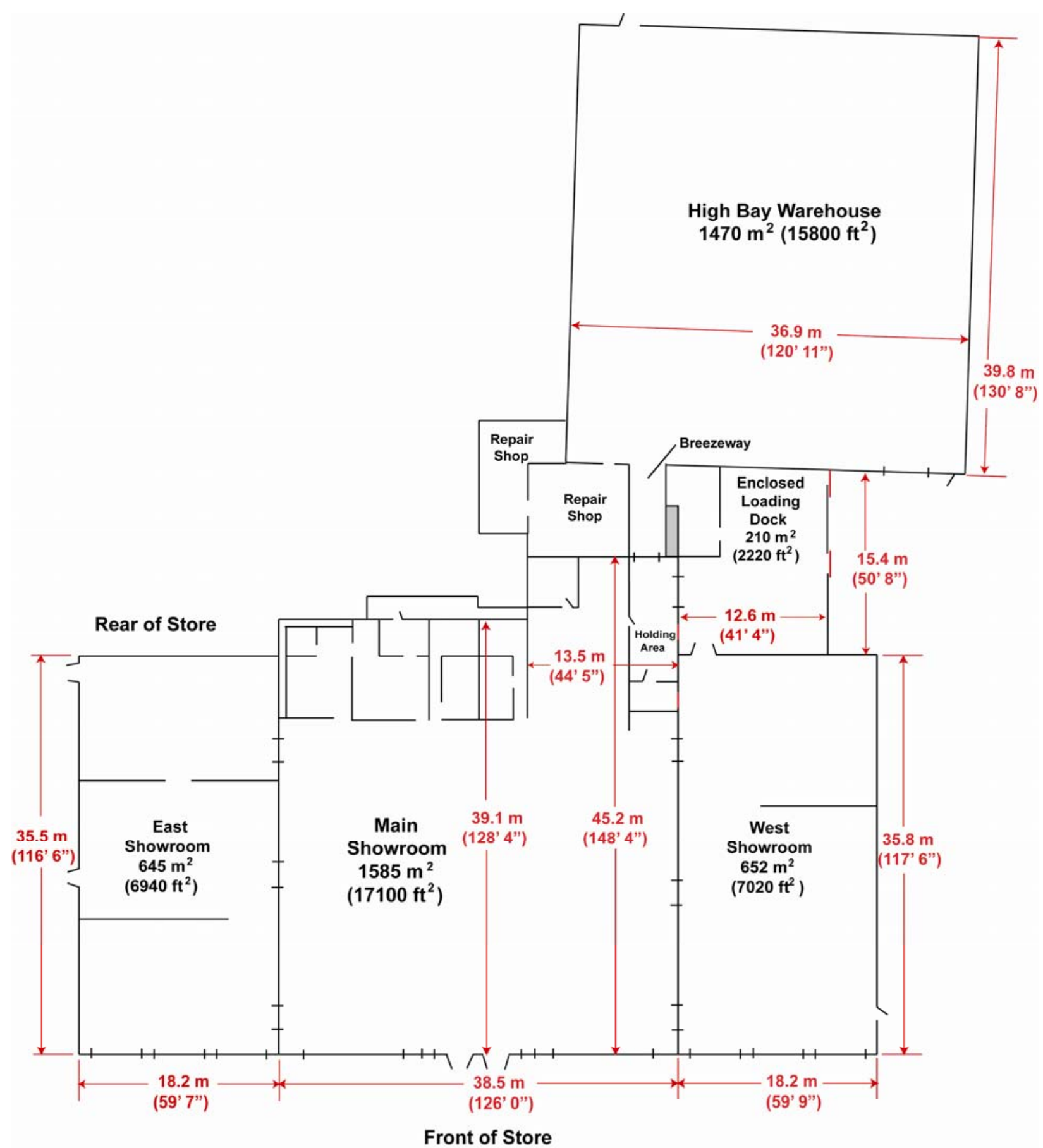

Figure 1-5. Store floor plan with dimensions. 


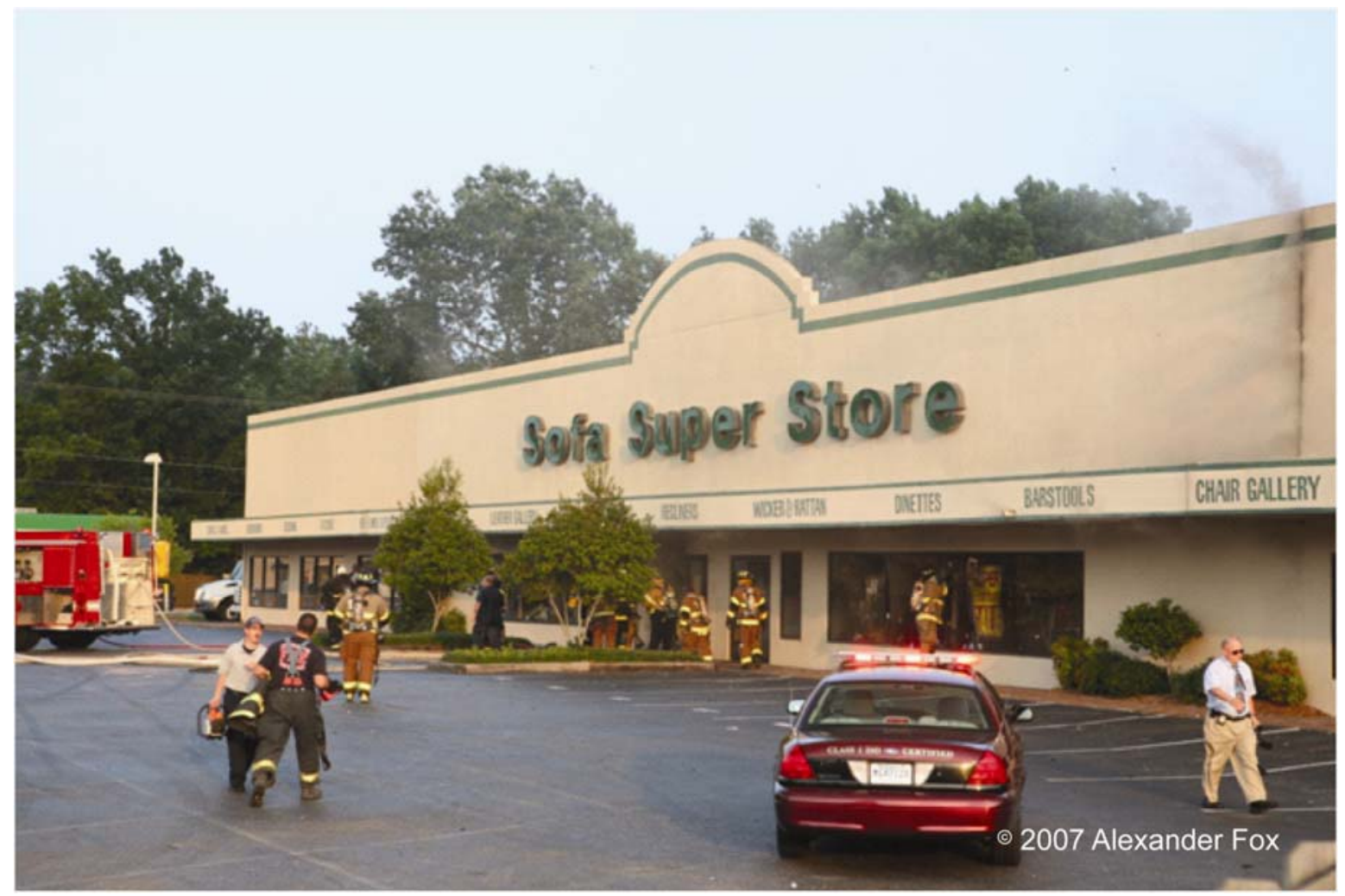

Figure 1-6. Front view of the store showing the large glass display windows flanking the western side of the front doors. Photo used with the permission of Alexander Fox.

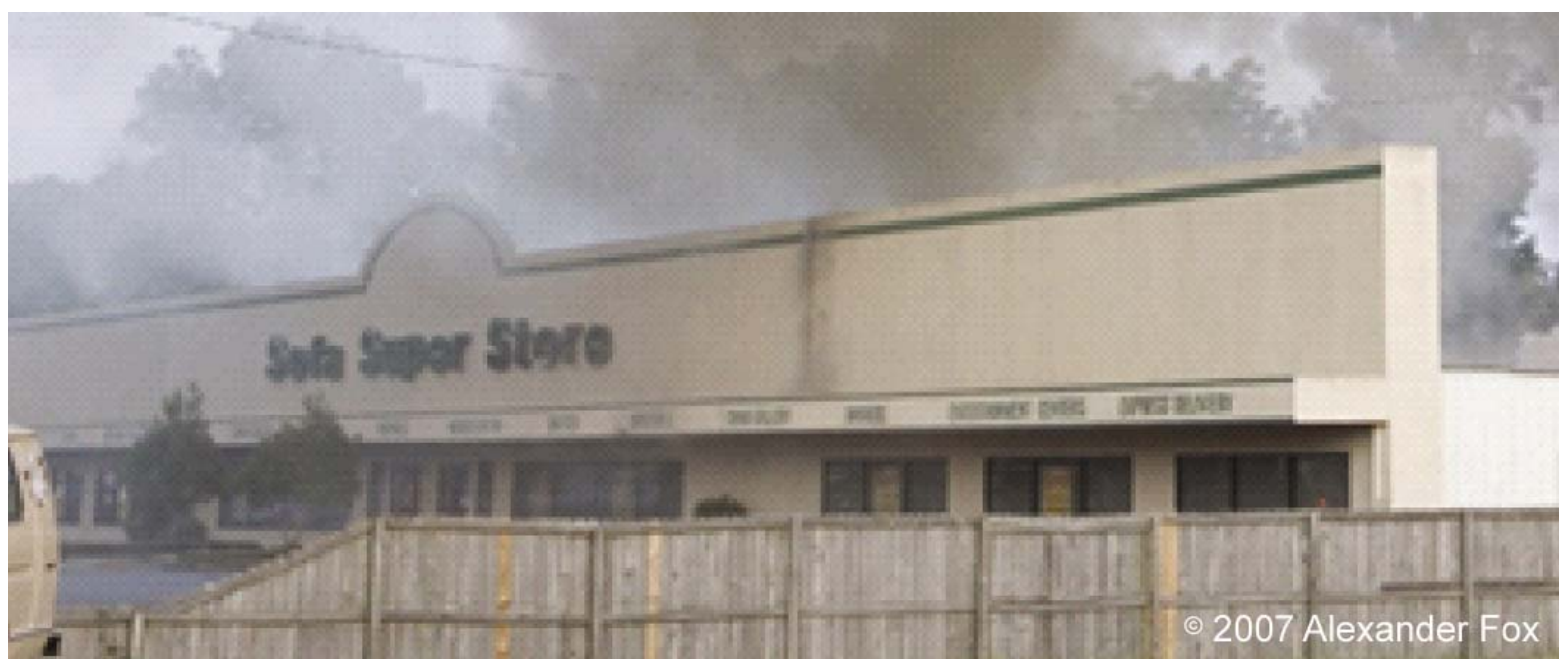

Figure 1-7. Front view of the store showing the large glass display windows on the western side of the store front. Photo used with permission of Alexander Fox. 
In addition to the six roll-down fire doors leading to the other showrooms, there was an additional rolldown fire door which was located in the rear southwest corner of the main showroom that connected to the warehouse. Also, in the rear southwest corner of the main showroom was a non-fire roll-down ${ }^{2}$ door that provided access to the loading dock area.

Roughly three-quarters of the main showroom space was used to display various pieces of furniture (Figure 1-8). This estimate was based on post-fire evidence and observations during visits to other stores that were part of the Sofa Super Store chain. Some of the displays involved a row of similar pieces, such as a number of different recliners, while other displays featured different pieces of furniture, such as chairs, sofas, loveseats, end tables, and coffee tables that were arranged to simulate a living room setting. Behind the furniture display areas, to the rear of the main showroom, were office related spaces including the sales counter, filing rooms, manager's office, employee break room, and restrooms. The floor of the main showroom was formed from poured concrete, and there was no basement. Concrete blocks were used to construct the four exterior walls, and each of the walls extended through and above the composite roof (see Figures C-7, C-8, D-10, D-17, D-18, D-21, D-22, E-24, E-26, F-19, and F-20). Over the main showroom, the composite flat roof was supported by light weight steel trusses which ran roughly east to west or parallel to the front wall (Figures 1-9 and D-27). According to dimensions

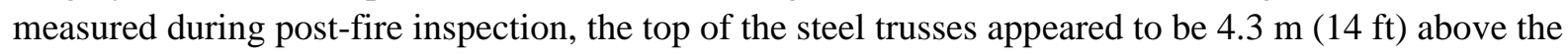
concrete floor at the rear of the main showroom. Using elevations obtained in the showroom at several locations, a suspended ceiling was located about $2.7 \mathrm{~m}(9 \mathrm{ft})$ above the floor. While the heat pump units were located outside and behind the showroom (Figures D-5, D-6, and D-10), the cooling coils, air handling units, and air delivery ducts were suspended below the roof trusses and above the suspended ceiling.

From post-fire examination of the main showroom, the interior walls appeared to have been $12.7 \mathrm{~mm}$ (0.5 in) thick gypsum wallboard. For the portions of the interior wall adjacent to the masonry wall on the west, north, and east sides, wood furring strips, approximately $76 \mathrm{~mm}$ (3 in) wide by $19 \mathrm{~mm}$ (0.75 in) thick had been attached to the masonry walls to allow the subsequent installation of the $12.7 \mathrm{~mm}$ ( $0.5 \mathrm{in})$ gypsum wallboard. For walls in or around the office spaces to the rear of the main showroom, gypsum wallboard was typically mounted to either sheet metal or wood studs. From post-fire inspection of less burned portions of the walls that were located at several locations around the main showroom, the gypsum walls appeared to extend just above the suspended ceiling.

In the rear southwest corner of the main showroom was a small holding area approximately $15 \mathrm{~m}^{2}$ $\left(160 \mathrm{ft}^{2}\right), 2.44 \mathrm{~m}(8 \mathrm{ft})$ wide x $6.1 \mathrm{~m}(20 \mathrm{ft})$ long. This area was the intersection of three doors, a rolldown fire door leading to the warehouse, an electric, but non-fire ${ }^{3}$ roll-down door to the loading dock, and a $0.9 \mathrm{~m}$ (36 in) wide metal door that led into the rear of the main showroom. According to descriptions of the holding area by store employees, at the north end of this space was a storage closet for paper supplies.

\footnotetext{
${ }^{2}$ Roll-down doors refer to door assemblies composed of interlocking steel slots or plates, a frame, and hardware including an overhead mechanism for moving the door up and down. When in the up position, the door is rolled into a cylindrical shape above the wall opening. The door industry refers to these as rolling steel doors, but they may be referred to as roll-up or roll-down doors in common usage. Rated rolling steel fire door assemblies are designed to automatically roll down and cover a wall opening in response to fire conditions. Rolling steel fire doors may also be referred to as roll-down fire doors. This report will use "roll-down door" to describe these doors.

${ }^{3}$ Fire doors are doors that are designed to withstand exposure to fire conditions. Fire doors are "rated" by time (in minutes or hours) that a door can withstand exposure to fire test conditions [12 -19]. Non-fire doors are not required to meet fire exposure standards.
} 
Also according to the employee descriptions, this space did not have a suspended ceiling, but a plywood shelf had been installed at least $2.44 \mathrm{~m}$ (8 ft) above the floor. Furniture or futon cushions were stored on the shelf. The space also contained snack vending machines and lockers for employees as was evidenced by post-fire residue.

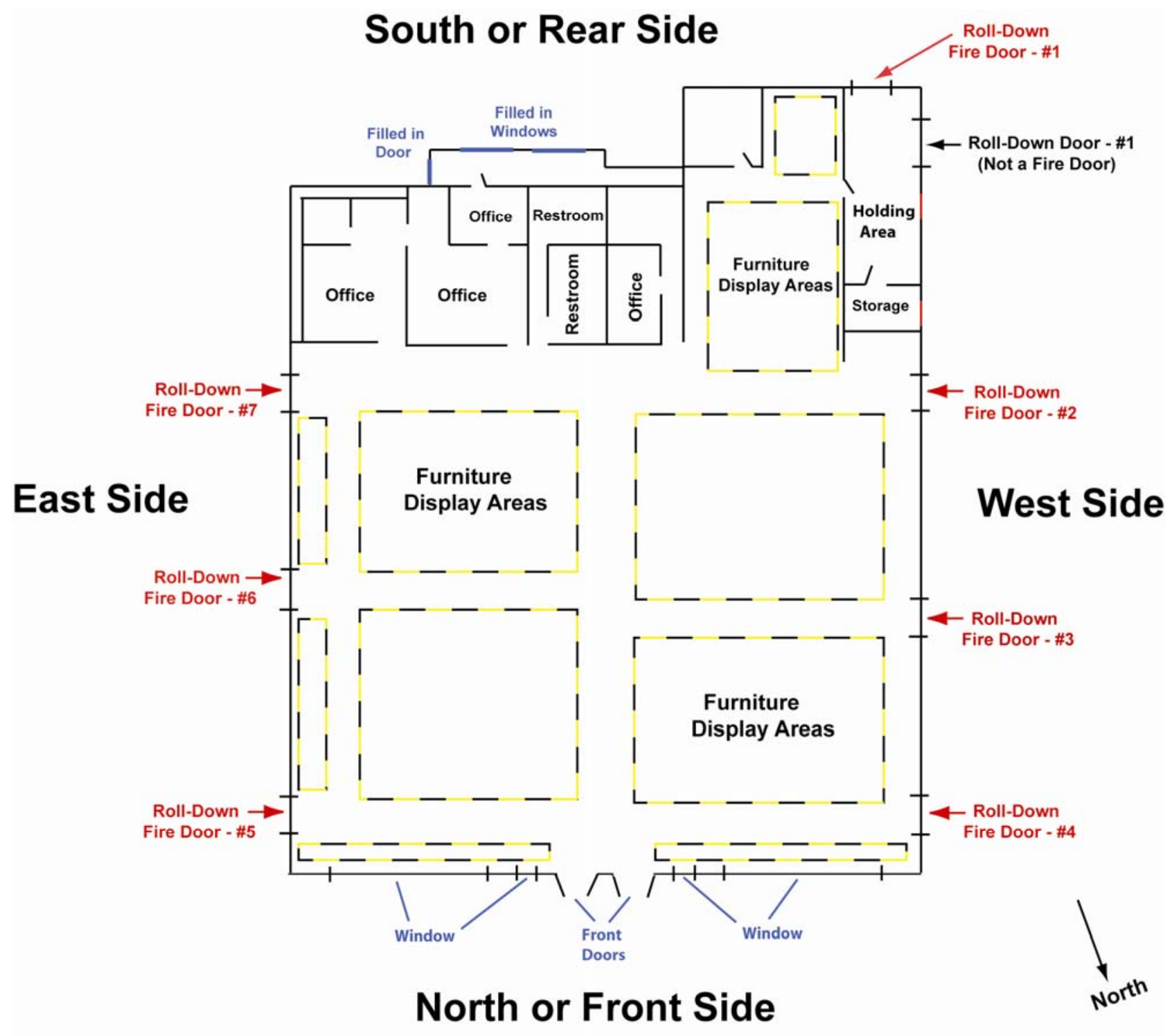

Figure 1-8. Floor space utilization for the main showroom. 


\section{South or Rear Side}

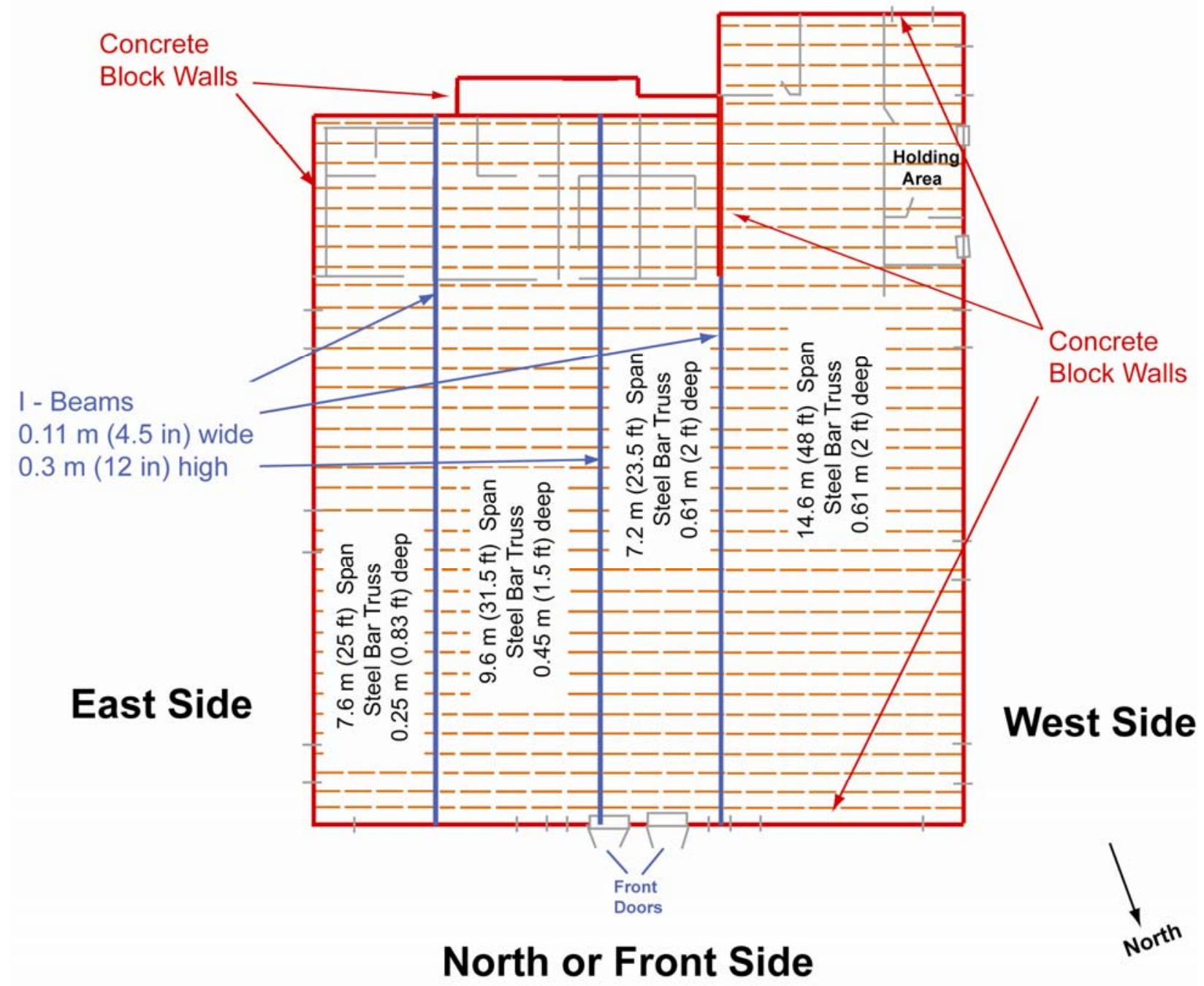

Figure 1-9. Wall and truss construction for the main showroom.

\subsubsection{West Retail Showroom}

From data collected by the NIST team on-site, the interior floor plan of the west showroom has been reconstructed in Figure 1-10. The west showroom was $18.2 \mathrm{~m}(59.8 \mathrm{ft})$ wide and $35.8 \mathrm{~m}$ (117.5 ft) deep for a total calculated area of $652 \mathrm{~m}^{2}\left(7020 \mathrm{ft}^{2}\right)$. The west retail showroom was not part of the original structure. A single exit door was located at the northwest corner of the retail space (see Figure E-8), and a set of double doors at the rear of the showroom led to the loading dock (Figure C-7). The wall shared with the main showroom featured four doors; three roll-down fire doors and a single door (see Figures O-16, O-22, and O-29). Based on post-fire residue, the single door which would have opened into the closet 


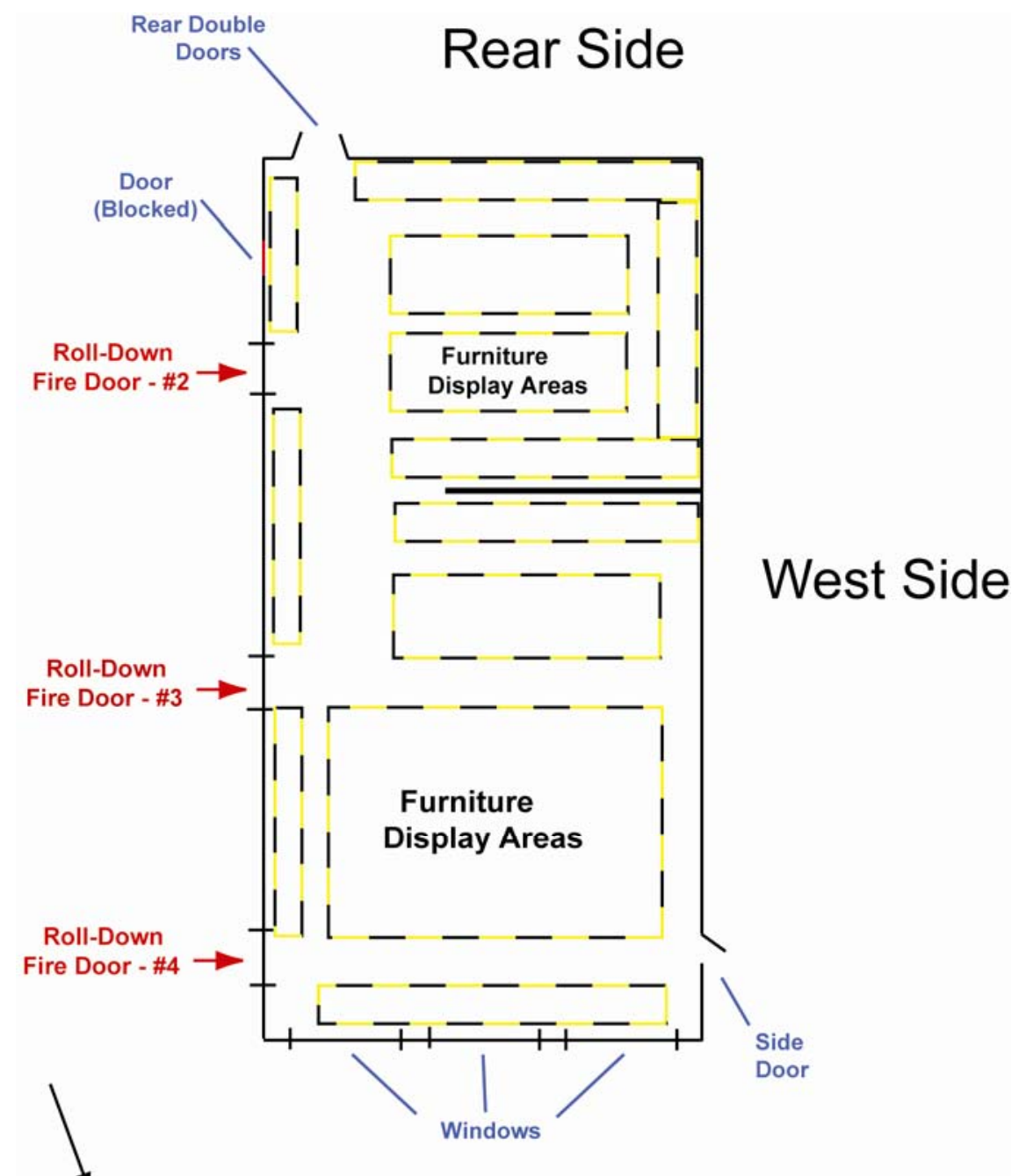

Front Side

Figure 1-10. Floor space utilization plan for the west showroom.

within the holding area appeared to be blocked with supplies in the storage closet. According to employees, these fire doors between the west and main showrooms were used to reposition furniture and to move furniture from the warehouse into the retail areas. The space utilization was based on post-fire evidence and observations during visits to other stores that were part of the Sofa Super Store chain.

Based on post-fire inspection of the showroom, most of the showroom space was used to display various pieces of furniture. As evidenced by unburned material including glass, knobs, hinges, frames, and springs, some of the displays involved a row of similar pieces, such as a number of different recliners, while other displays featured multiple pieces of furniture, such as a chair, loveseat, and coffee table arranged in a living room configuration. Area rugs and carpets were also displayed on the showroom floor as well as in vertical hanging racks (see Figure E-25). The rear portion of the showroom displayed sofas, sleeper sofas, and futons. The rear section included a set of shelves approximately $1.1 \mathrm{~m}$ (42 in) above the floor that allowed a second level of sofas and futons to be displayed above the set located on the floor (see Figures E-20 and E-21). In front of the east to west partition wall, there was another set of 
display shelves that allowed two levels of recliners and a third level of lamps to be displayed (see Figure E-19).

The lower shelf for recliners was approximately $0.6 \mathrm{~m}$ (24 in) above the floor while the second shelf for smaller retail items was about $1.2 \mathrm{~m}$ (48 in) above the floor. The area in the front of the store may have displayed patio or deck furniture. The floor of the west showroom was poured concrete and there was no basement. Wall-to-wall carpeting appeared to have been installed on top of the concrete floor. Area rugs and carpets were also displayed on the floor.

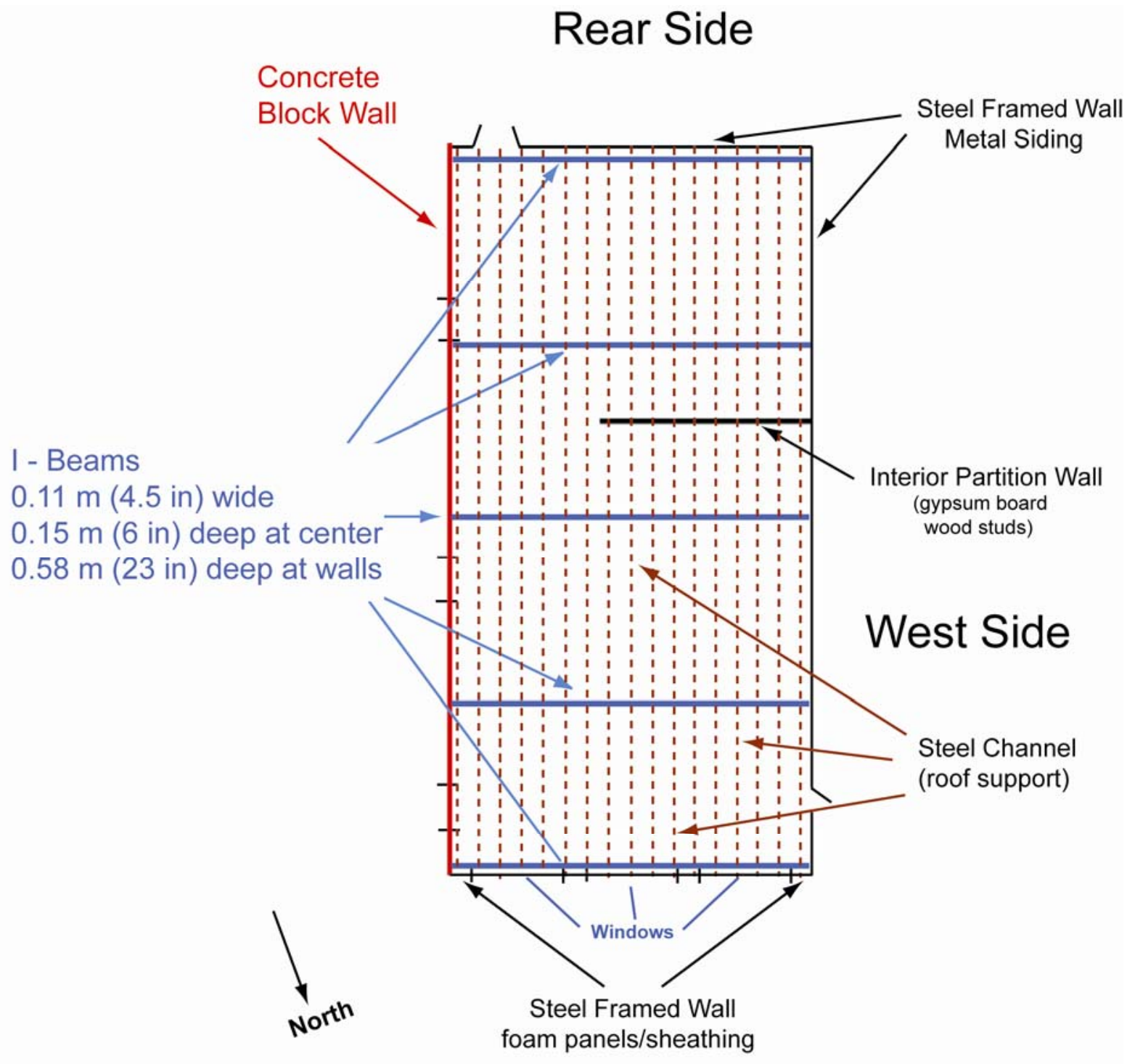

Figure 1-11. Wall and I-beam configuration for the west showroom. 
The lower shelf for recliners was approximately $0.6 \mathrm{~m}$ (24 in) above the floor while the second shelf for smaller retail items was about $1.2 \mathrm{~m}$ (48 in) above the floor. The area in the front of the store may have displayed patio or deck furniture. Based on post-fire inspection of the showroom, the floor of the west showroom was poured concrete and there was no basement. As evidenced by residue examined after the fire, wall-to-wall carpeting appeared to have been installed on top of the concrete floor. Portions of unburned area rugs and carpets were also observed on the floor of the showroom.

Over the west showroom, a sheet metal roof was supported by "Z" shaped steel channel which ran roughly north to south or perpendicular to the front wall (see Figures 1-11, E-16, and E-17). To support the steel channel, the west showroom incorporated steel I-beam columns (see Figure E-18), that supported horizontal beams that were $0.15 \mathrm{~m}$ (6 in) deep at center of span and $0.58 \mathrm{~m}$ (23 in) deep at the east and west walls. Along the east wall adjacent to the main showroom, the top of the horizontal I-beams were $4.32 \mathrm{~m}$ (14.2 ft) above the "Z" shaped steel channel. The roof sloped down toward the west wall where the top of the horizontal beam was $3.56 \mathrm{~m}(11.7 \mathrm{ft})$ above the concrete slab. Sections of " $\mathrm{Z}$ " channel were also installed horizontally between the vertical I-beams (east and west walls) and vertical columns (south and north walls). The exterior south and west walls were corrugated metal siding that was attached to horizontal "Z" channel between the vertical members.

As evidenced by hardware and post-fire residual materials, a suspended ceiling was located about $2.7 \mathrm{~m}$ $(9 \mathrm{ft})$ above the floor. The suspended ceiling consisted of a grid-work of metal channels in the shape of an upside-down " $T$ ", suspended on wires from the " $Z$ " channel roof supports. The grid openings were filled with $0.6 \mathrm{~m}(2 \mathrm{ft}) \times 1.2 \mathrm{~m}(4 \mathrm{ft}) \times 1.6 \mathrm{~cm}(0.63 \mathrm{in})$ panels. While the heat pump units were located outside and behind the showroom (see Figures B-3 and B-6), the cooling coils, air handling units, and air conditioning ducts were suspended below the roof trusses and above the suspended ceiling.

Portions of interior wall that had not been consumed by the fire demonstrated that gypsum wallboard, $12.7 \mathrm{~mm}(0.5 \mathrm{in})$ thick, formed the interior surface and were attached to a combination of sheet metal and wood studs. The gypsum board was attached to sheet metal studs for the south (rear), west, north (front),

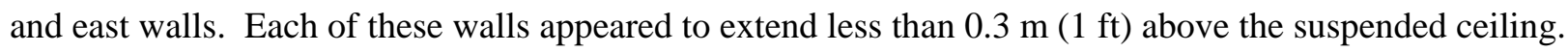
The partition wall which extended from the west wall toward the main showroom was constructed using wood studs and gypsum wallboard. The partition wall did not appear to extend above the suspended ceiling.

\subsubsection{East Retail Showroom}

Using dimensions and data collected on-scene; the interior floor plan of the east showroom has been reconstructed in Figure 1-12. The east showroom was $18.2 \mathrm{~m}$ (59.6 ft) wide and $35.5 \mathrm{~m}$ (116.5 ft) deep for a total calculated area of $645 \mathrm{~m}^{2}\left(6940 \mathrm{ft}^{2}\right)$. The east retail showroom was not part of the original structure. There were two sets of double exit doors located on the east wall of the showroom (Figure F-7). The wall shared with the main showroom featured three roll-down fire doors (Figures O-33, O-39, and O-48). Employees also used these fire doors between the west and main showrooms to reposition furniture and move furniture from the warehouse into the retail areas.

All of the showroom space was used to display various pieces of furniture. The assumptions about space utilization were based on post-fire evidence and observations during visits to other stores that were part of the Sofa Super Store chain. Some of the displays involved a row of similar pieces, such as a number of different beds, while other displays featured different pieces of furniture, such as a bed, end table, chest of 
drawers arranged in a typical bedroom configuration. Unlike the single partition wall in the west showroom, this showroom had two partition walls (see Figures F-13 and F-16). The middle and rear sections included sets of bedroom furniture while the front section displayed living room furniture. The east showroom did not appear to utilize shelving to display two levels of merchandise. Inspection of the showroom demonstrated that the floor of the east showroom was poured concrete, and there was no basement. Post-fire examination suggested that wall-to-wall carpeting had been installed on top of the concrete floor.

Over the east showroom, a sheet metal roof was supported by "Z” shaped steel channel which ran roughly north to south and perpendicular to the front wall (Figure 1-13). To support the steel channel, the east showroom incorporated steel I-beam columns, that supported horizontal beams that were $0.15 \mathrm{~m}$ (6 in) deep at center of span and $0.58 \mathrm{~m}$ (23 in) deep at the east and west walls (Figure F-21). Along the west

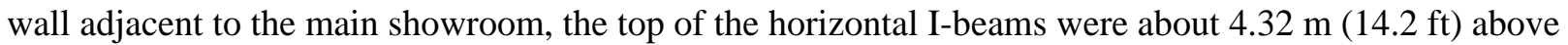
the "Z" shaped steel channel. The roof sloped down toward the east wall where the top of the horizontal beam was $3.6 \mathrm{~m}(11.7 \mathrm{ft})$ above the concrete slab. Sections of "Z" channel were also installed horizontally between the vertical I-beams (east and west walls) and vertical columns (south and north walls). The exterior south and east walls were corrugated metal siding that was attached to horizontal "Z" channel between the vertical members.

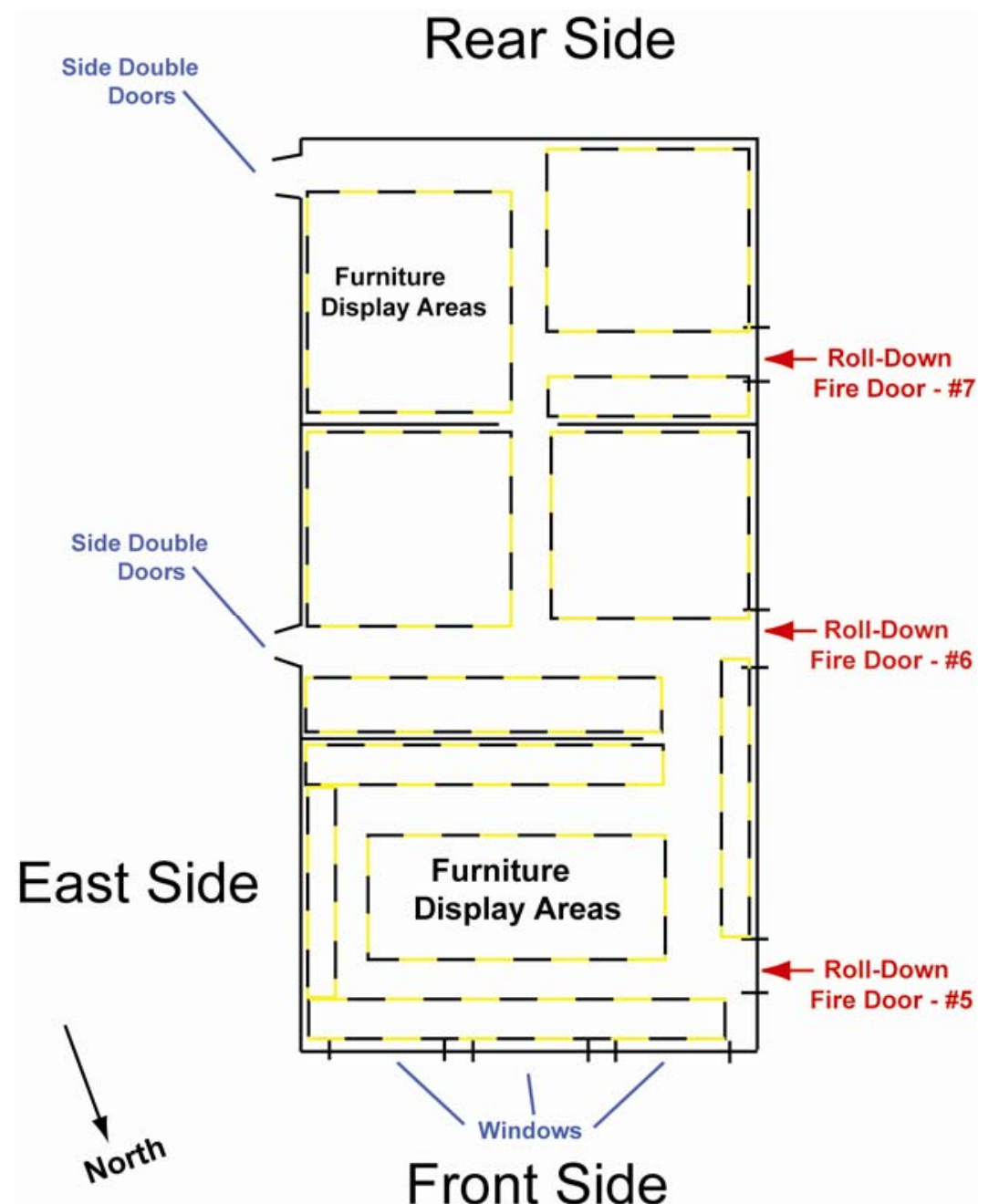

Figure 1-12. Floor space utilization plan for the east showroom. 


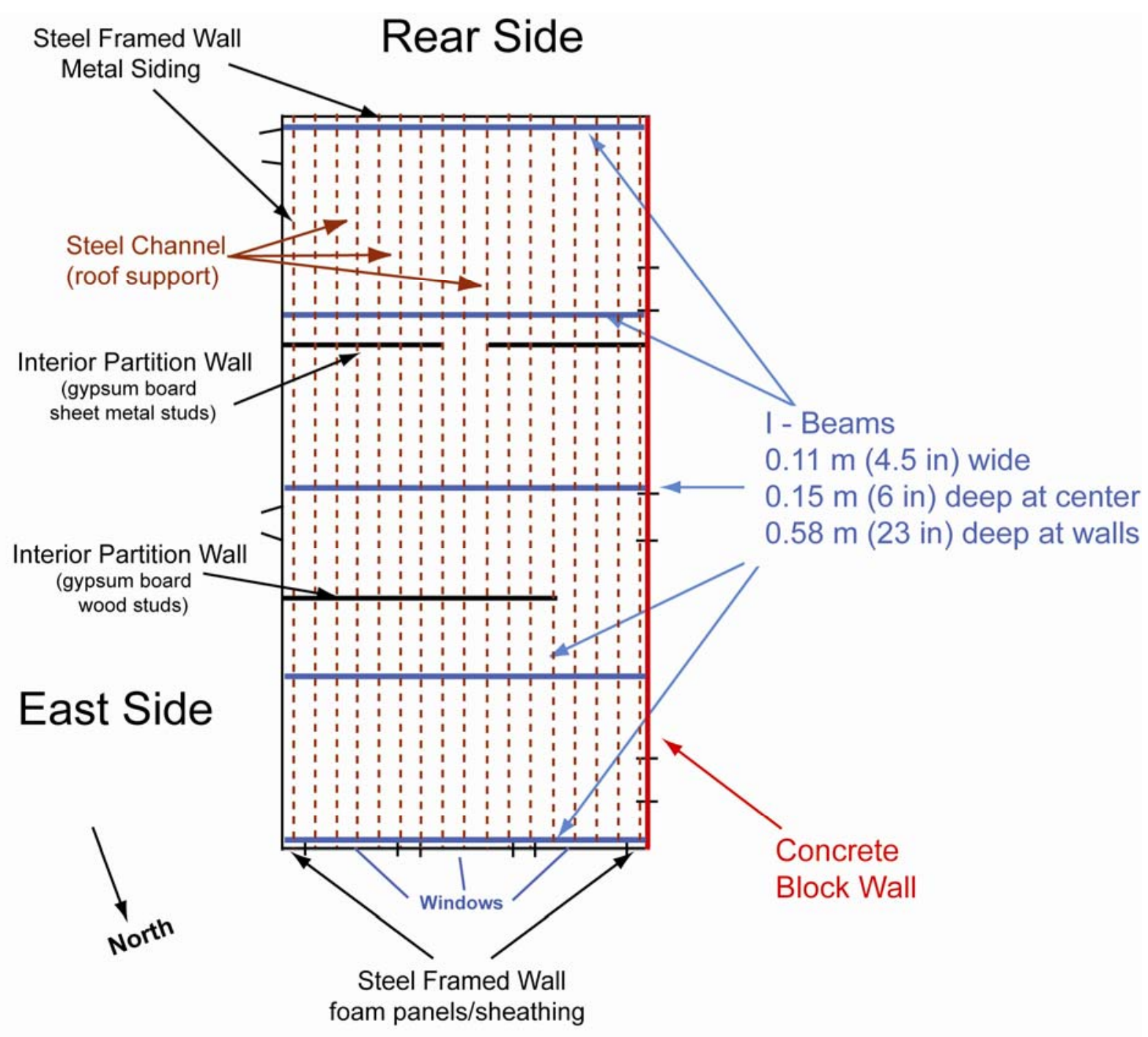

Figure 1-13. Walls and I-beam configuration for the east showroom.

Post-fire examination of remaining intact sections of the ceiling demonstrated that a suspended ceiling was located about $2.7 \mathrm{~m}(9 \mathrm{ft})$ above the floor. The suspended ceiling consisted of a grid-work of metal channels in the shape of an upside-down " $T$ ", suspended on wires from the "Z" channel roof supports

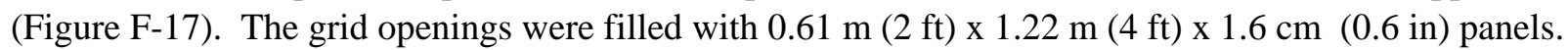
While the heat pump units were located outside and behind the showroom (see Figures F-9 and F-10), the cooling coils, air handling units, and air conditioning ducts were suspended below the roof trusses and above the suspended ceiling.

Surviving sections of showroom walls indicated that painted gypsum wallboard, $12.7 \mathrm{~mm}$ (0.5 in) thick, formed the interior surface and was attached to a combination of sheet metal and wood studs (Appendix F, Figures F-18, F-19, and F-21). The gypsum board was attached to sheet metal studs for the south (rear), west, north (front), and east walls. Each of these walls appeared to extend less than $0.30 \mathrm{~m}$ (1 ft) 
above the suspended ceiling. The front partition wall which extended from the east wall toward the main showroom was constructed using wood studs and gypsum wallboard. The rear partition wall, which had a doorway opening in the center, was constructed using metal studs and gypsum wallboard. Neither of the partition walls appeared to extend above the suspended ceiling.

\subsubsection{Loading Dock, Repair Areas, and Warehouse}

Aerial images (see Section 1.6) demonstrated that the loading dock, repair areas and warehouse were not part of the original structure, but were added in stages after 1989. Using dimensions and data collected on-scene; the interior floor plan of these areas has been reconstructed in Figures 1-14 and 1-15. The enclosed loading dock area was used to stage, load, and repair furniture. The equipment, tools, and supplies that were not consumed by the fire were consistent with materials typically used to repair and refinish damaged furniture. According to descriptions that were provided by employees, the warehouse stored inventory for the multiple locations of the Sofa Super Store retail chain.

The tracking records and files for the store and warehouse inventory were stored inside the structure and were not recovered after the fire. Without specific records, the quantity and type of merchandise in the store, warehouse, and loading dock could not be precisely reconstructed. Since the roof and walls of the loading dock had been removed for safety reasons, the post-fire residue appeared to have been displaced and was not as useful in determining how the furniture had been staged. A discussion with store employees indicated that various pieces of furniture were staged adjacent to the north wall for delivery the next day. Additional items for future delivery ( 1 or 2 days beyond next day) tended to be staged in the area closer to the center of the loading dock. Symbols that represent bedroom sets, dressers, sofas, and chairs were added to the floor plan to illustrate how the furniture might have been arrayed.

Based on dimensions collected at the post-fire scene, the loading dock area was approximately $12.6 \mathrm{~m}$ $(41.3 \mathrm{ft})$ east to west and $15.4 \mathrm{~m}(50.6 \mathrm{ft})$ north to south for an area of $210 \mathrm{~m}^{2}\left(2200 \mathrm{ft}^{2}\right)$. Aerial images indicated that it was built in at least two sections although building permits could not be located for either addition. As evidenced by post-fire residue, both sections were built with wood framing, a wood deck/floor, and sheet metal siding and roof. The section that shared a wall with the warehouse was added first and featured a $2.7 \mathrm{~m}(9 \mathrm{ft})$ ceiling while the portion next to the rear of the west show room had a $3.7 \mathrm{~m}(12 \mathrm{ft})$ ceiling.

As demonstrated by post-fire photographs, gallon cans of organic solvents, including acetone, naphtha, and lacquer thinner, which may have been used to clean or refinish furniture, were stored in the southwest corner of the loading dock area (Figures C-18 and C-19). The loading dock area featured four doors of which two doors on the west side adjacent to the asphalt area were used to load delivery trucks.

The two "loading" doors utilized overhead tracks similar to "barn" doors which allowed staff to slide the doors to the side for better access to the delivery trucks (see Figures C-2 and C-4). The roll-down door that led to the rear of the main showroom allowed access to the warehouse through the breezeway (Figure O-7). This roll-down door used an electric motor with backup manual chain for opening and closing. The double doors on the north wall led to the rear of the west showroom. A large vent/exhaust fan had

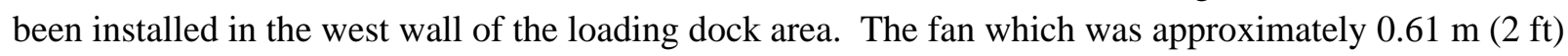
in diameter was positioned in a square opening between the two sliding doors (Figure C-2). 


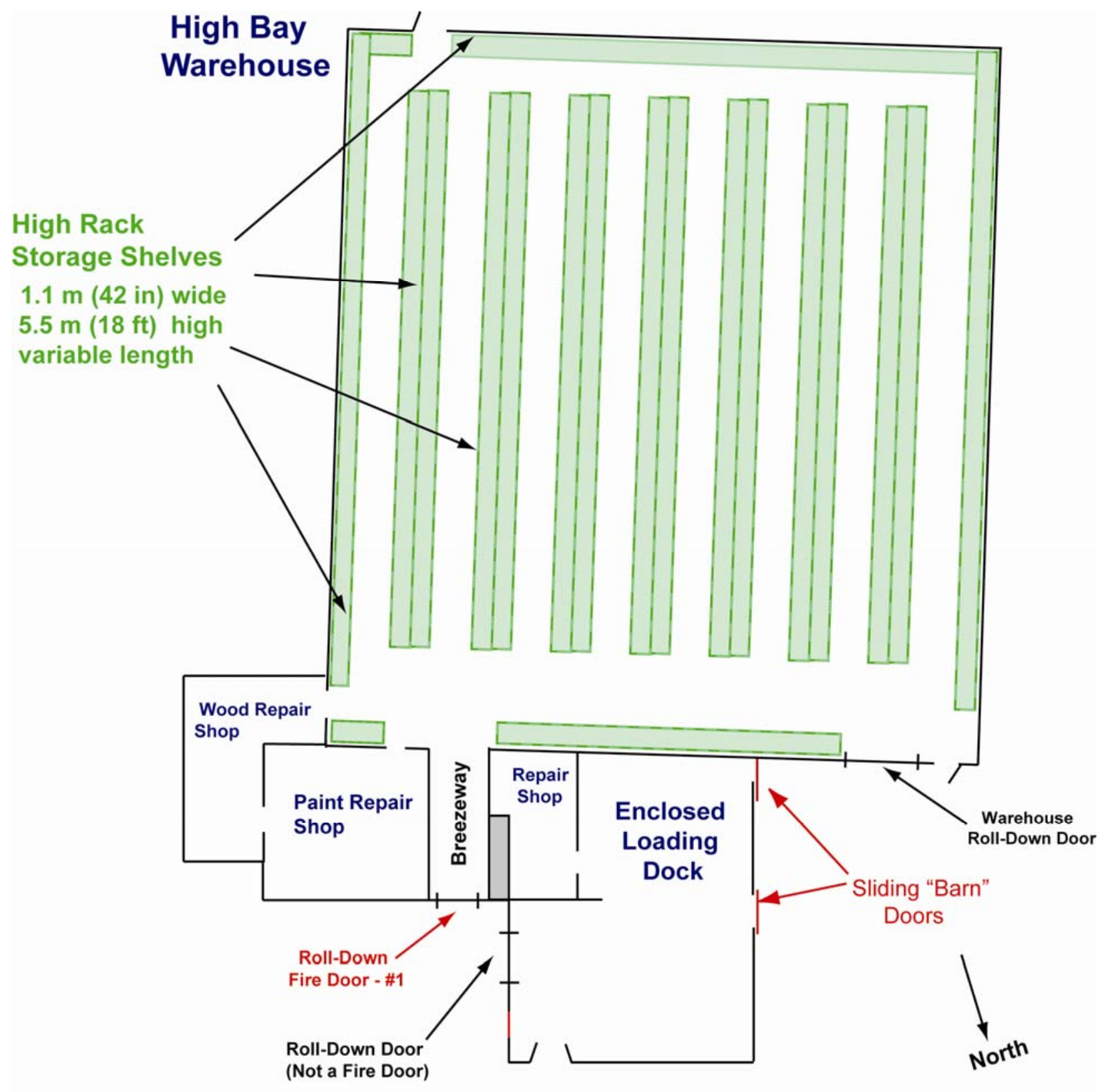

Figure 1-14. Floor space utilization for loading dock area and warehouse.

According to employee descriptions, when the fan was not in operation, a heavy cloth/blanket was apparently draped over the inlet of the fan to reduce drafts. As shown by post-fire residue, the floor or deck of the loading dock had been constructed over the asphalt covered surface between the west showroom and the warehouse. The loading dock floor was $1.1 \mathrm{~m}$ (42 in) above the asphalt surface (see Figures C-3, C-4, and C-23). The floor was constructed using a lower layer of pressure treated lumber that was overlaid with particle board or plywood. As post-fire residue indicated, carpeting was installed 


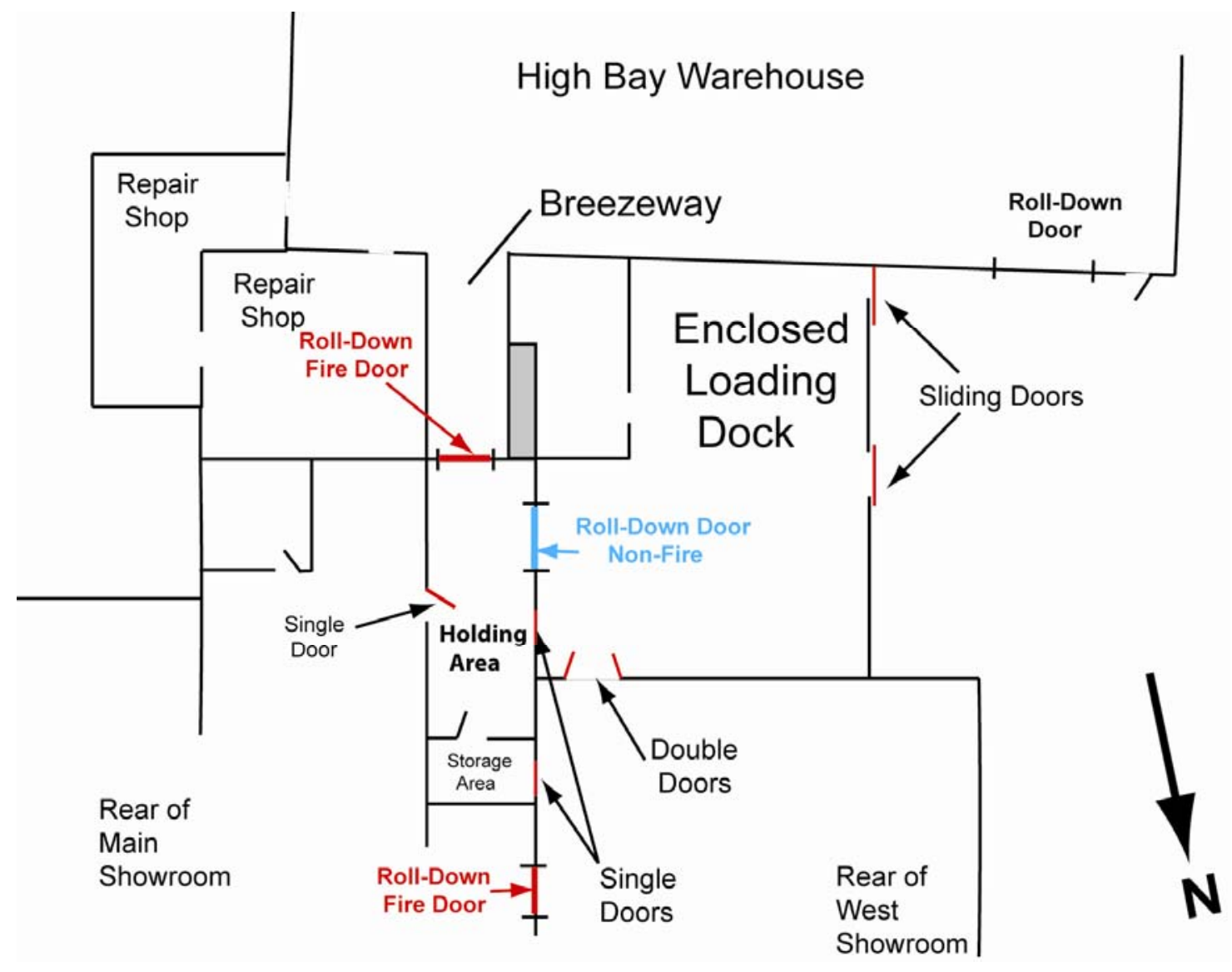

Figure 1-15. Floor plan for the loading dock, the holding area, and the repair shops.

over some portions of the plywood floor. Portions of the loading dock walls included wood studs with an interior surface of gypsum wall board. The roof of the southern section of the loading dock incorporated at least three fiberglass skylights which were visible in aerial images of the store. Each skylight which

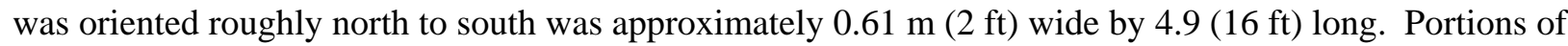
at least one fiberglass skylight were found in roof material removed from the loading dock.

As determined by measurements and data collected on-site, the warehouse was approximately $36.9 \mathrm{~m}$ $(120.9 \mathrm{ft})$ wide and $39.8 \mathrm{~m}(130.7 \mathrm{ft})$ front to rear for an area of $1470 \mathrm{~m}^{2}\left(15800 \mathrm{ft}^{2}\right)$. The warehouse was an open clear span structure with poured concrete floor and sheet metal walls and roof. The roof was

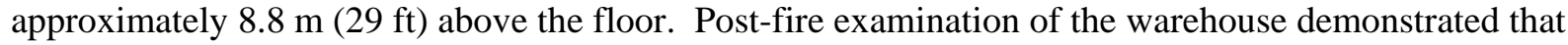
the high rack storage, $1.1 \mathrm{~m}$ (42 in) deep and $6.1 \mathrm{~m}$ (20 ft) tall, was arranged in nine back-to-back rows in the center of the warehouse and single rows around the outside walls (see Figures G-15, G-16, and G-17). If each rack was arranged for six vertical rows, the warehouse would have had the capacity for at least a thousand sofas, chairs, and mattresses. Since the inventory records were not recovered, the specific items stored in the warehouse could not be precisely reconstructed.

The warehouse had two single exit doors, one on the north wall west of the roll-down door, and one on the south or rear wall near the south east corner (see Figures G-5 and G-13). A $4.9 \mathrm{~m}$ (16 ft) x $4.9 \mathrm{~m}$ 
(16 ft) roll-down door in the north wall provided forklift access for unloading furniture that arrived via tractor trailer. Post-fire examination of the warehouse revealed that two doorways had been cut out of the metal siding to provide access to the repair shops located at the north east corner of the structure. A $2.5 \mathrm{~m}$ $(8 \mathrm{ft}) \times 2.5 \mathrm{~m}(8 \mathrm{ft})$ opening in the north wall provided access to the enclosed breezeway which led to the holding area at the rear of the main showroom. According to store employees, when furniture was moved from the warehouse to the retail area, it was moved through the breezeway to the holding area, then through the roll-down door into the loading dock, through the rear of the west showroom, and then into the main or east showroom if necessary. As on-scene inspection of the post-fire indicated, the roof of the warehouse was constructed of sheet metal roof and was supported by "Z" shaped steel channel which was installed roughly perpendicular to the front wall (north to south) (Figure 1-16). The steel channel was supported by I- beam roof joists which were bolted to the steel columns in a design that was similar to the east and west showroom additions.

Between the north wall of the warehouse and the rear of the main showroom were two additional repair areas. Building permits could not be located for either of these two repair rooms. The "wood" repair room appeared to have had power wood working tools such as a lathe and drill press. After the fire, a large number of spray cans of paint/finishes were found in what will be referred to as the "paint" repair room. The paint repair room was adjacent to the breezeway and had wood framing and sheet metal walls and roof. Based on measurements and observations after the fire, the paint repair room was approximately $9.7 \mathrm{~m}(31.7 \mathrm{ft}) \times 7.1 \mathrm{~m}(23 \mathrm{ft})$ with an area of $68 \mathrm{~m}^{2}\left(730 \mathrm{ft}^{2}\right)$. It had a poured concrete floor and

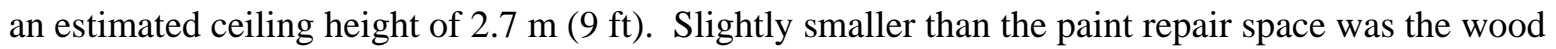
repair area which also had wood framing and sheet metal walls and roof. The wood repair room also

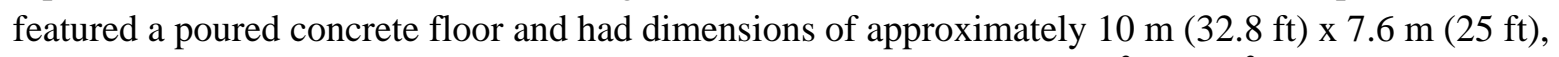
minus some overlap with the paint repair room, to yield an area of $56 \mathrm{~m}^{2}\left(610 \mathrm{ft}^{2}\right)$.

\subsubsection{Holding Area}

In the rear southwest corner of the main showroom was a small holding area approximately $15 \mathrm{~m}^{2}$ $\left(160 \mathrm{ft}^{2}\right), 2.4 \mathrm{~m}(8 \mathrm{ft})$ wide $\times 6.1 \mathrm{~m}(20 \mathrm{ft})$ long. These dimensions were estimated from observations collected on-site after the fire. The fire severely damaged the holding area and materials had been removed from this area in order to allow safe access, so it was difficult to completely characterize the dimensions of this area. Three doors opened into the holding area including a roll-down fire door leading to the warehouse, an electric, but non-fire roll-down door to the loading dock, and a $0.9 \mathrm{~m}$ (36 in) wide metal door that opened into the rear of the main showroom. According to descriptions provided by employees, the north end of this space was a storage closet for paper supplies. As evidenced by post-fire

remnants, a snack vending machine and steel lockers were also located along the west wall of the holding area.

A roll-down fire door was located on the south wall of the area and this door provided access through the breezeway to the warehouse (see Figures O-5, O-6, and O-7). Another roll-down door was situated on the west wall which was shared with the enclosed loading dock. This roll-down door appeared to be the original door to the loading dock from when the structure was in use as a grocery store (Figure O-11). This roll- up door could be operated either manually by pulling on a chain or electrically by energizing the electric motor and allowed access to the loading dock. This door did not have a fusible link for activation during fires and did not appear to be designed as a fire door. Also on the west wall of the

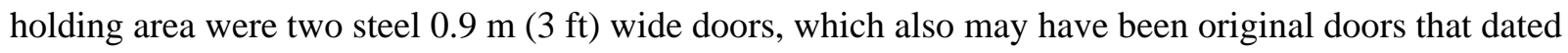




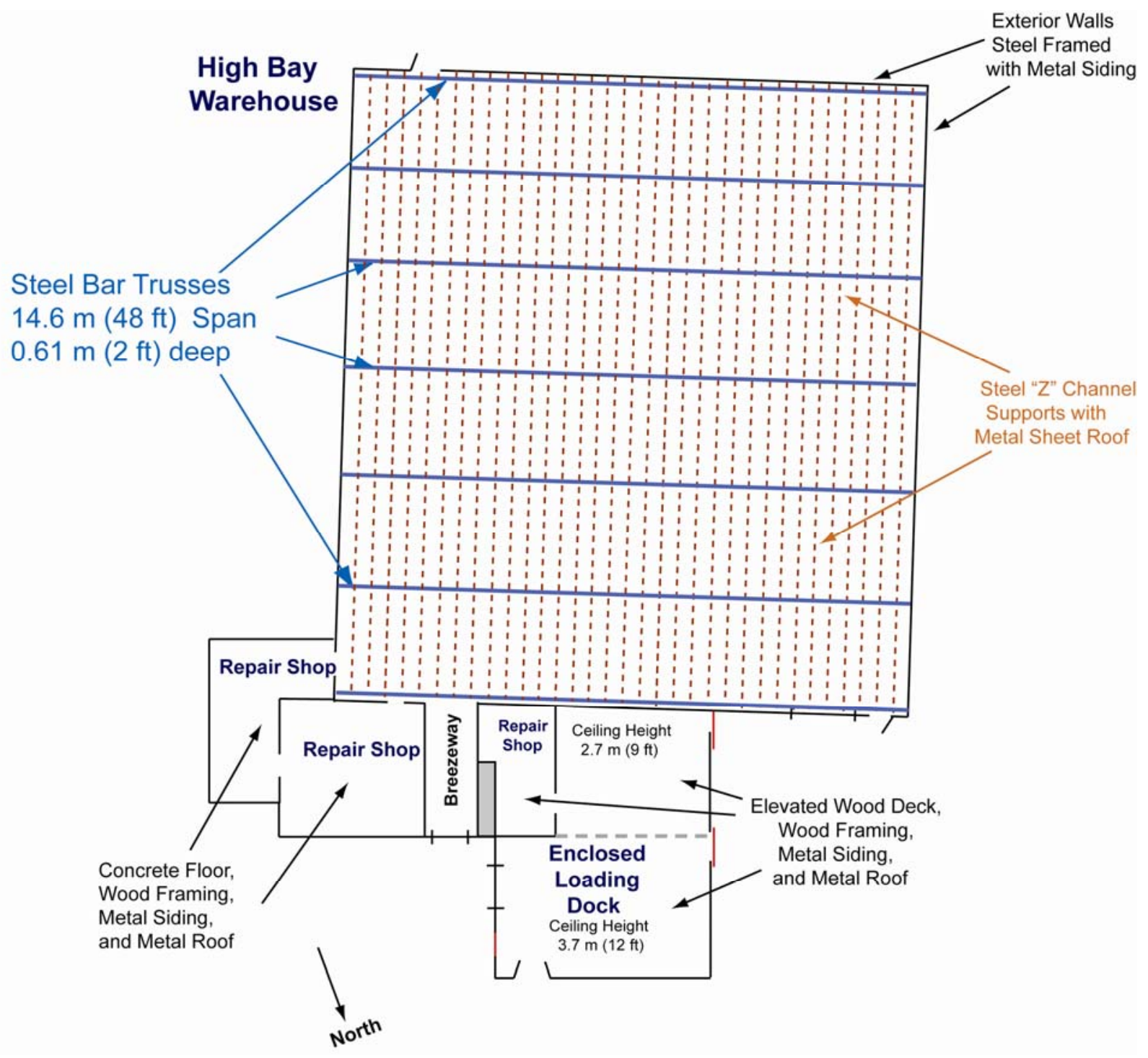

Figure 1-16. Wall and I-beam configuration for the loading dock area and the warehouse.

back to the grocery store ${ }^{4}$. One of these doors, the one nearest to the non-fire roll-down door, would haveopened onto the grocery store loading dock (Figure O-11). The original role of the second door,

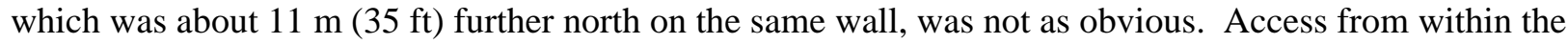
holding area was obstructed for both of these doors. A food vending machine was positioned in front of

\footnotetext{
${ }^{4}$ History of structure discussed in more detail in Section 1.6
} 
the first door (Figure D-19) and a storage closet at the north end of the holding area made access difficult to the second door.

The Charleston Fire Department visited the Sofa Super Store to conduct pre-plan inspections which were typically used to identify fire protection systems and locations of utility shut-offs, as well as sketch the interior floor plan. The pre-plan building inspection sketch (Figure M-4) does identify the location of an external roll-down door, but does not indicate that this door was a fire door. In the same sketch, the other roll-down fire doors on the west and east walls of the main showroom were indicated as fire doors.

Based on observations on-scene after the fire, a fourth door on the east wall of the holding area led to the rear of the main showroom. As revealed during the review of post-fire photographs, this door was a single metal or steel door that appeared to open into the holding area from the main showroom. This door was mounted in a wall that had metal studs with $12.7 \mathrm{~mm}$ (0.5 in) thick gypsum board mounted on both sides. Inspection of metal wall studs after the fire suggested that the wall extended just above the suspended ceiling in the main showroom and the remaining steel studs did not reach the underside of the roof. The south and west walls were concrete block construction and had extended to the underside of the roof. Discussions with store employees indicated that there was no suspended ceiling above the holding area. The underside of the metal roof decking was visible when one looked up towards the roof. At least one large, approximately $1.2 \mathrm{~m}(4 \mathrm{ft})$ by $2.4 \mathrm{~m}(8 \mathrm{ft})$ shelf, which was constructed out of plywood, had been installed at least $2.44 \mathrm{~m}(8 \mathrm{ft})$ above the holding area. Store employees described how furniture or futon cushions were stored on the shelves.

According to store employees, when retail merchandise that was stored in the warehouse was needed for display on the showroom floor, it was pulled through the breezeway into the holding area, then through the non-fire roll-down door into the loading dock area. The merchandise was then pulled through the double steel doors at the rear of the west showroom and maneuvered into one of the retail showrooms.

\subsection{COMBUSTIBLE MATERIAL}

\subsubsection{General}

As expected from a store of this type, the inventory of combustible material within the buildings was the retail merchandise. This included a wide range of furniture including sofas, chairs, tables, beds, dressers, lamps, and rugs. Inventory records were stored within the store, so it is not clear how many of each type of furniture were present in the showrooms or warehouse.

Lacking specific information on the type, number, and location of the merchandise, the amount of merchandise was estimated. The estimates incorporated data that collected on-scene from unburned merchandise, metal hardware such as hinges or handles that were not consumed by the fire, and information provided by store employees and fire fighters. The estimates assumed a range for the fraction of floor space that was used to display merchandise. Different types of merchandise were then assigned dimensions and material properties. This provided estimates for total number of items, mass, and energy content. The estimation process is summarized in this section and described in greater detail in Appendix J.

The number of items that might have been present in the showrooms were created by assuming an area or "foot print" for a sofa, chair, mattress, and dresser (Table 1.1), and how much of the retail floor space might typically be used to display merchandise. From remaining furniture and metal parts that were 
observed on the fire scene, the east showroom appeared to have a higher fraction of mattresses and dressers. The main showroom appeared to display a lower fraction of mattresses, but more sofas and chairs. The west showroom displayed sofas, futons, and recliners, but few mattresses. The estimated fraction of each type of furniture was incorporated in the rough estimates for the main, west, and east showrooms which are tabulated in Appendix J.

The main showroom had about twice the floor space as either west or east showrooms and this is reflected in the number of items estimated to be in each showroom which ranged up to 590, 290, and 240, for the main, west, and east showrooms, respectively (Table 1-2). The total number of items in the combined showrooms ranged from 700 to 1120 items for $50 \%$ and $80 \%$ of floor space, respectively. The estimated mass loadings ranged from $7.6 \mathrm{~kg} / \mathrm{m}^{2}\left(1.6 \mathrm{lb} / \mathrm{ft}^{2}\right)$ to $16.5 \mathrm{~kg} / \mathrm{m}^{2}\left(3.4 \mathrm{lb} / \mathrm{ft}^{2}\right)$ depending on the fraction of floor space and the showroom (Table 1-1). The estimated number of items staged in the loading dock ranged from 40 to 110 items depending on what fraction of the floor space was utilized (Table 1-3). Due to the high rack storage shelves, the warehouse was estimated to have more items stored than in all the showrooms and loading dock combined. Again, depending on the fraction of rack space used to store items in the warehouse at the time of the fire, between 220 and 2000 items for $10 \%$ and $90 \%$ of available rack space were estimated as being stored in the warehouse.

Mattresses, upholstered chairs, sofas, recliners, and futons typically contain significant amounts of polyurethane foam [19, 20]. Dressers, tables, chairs, and end tables are made of wood or wood products [21]. Area rugs and carpeting also contain large amounts of synthetic materials. All of these items contributed to the fuel loading in the store. Average mass and energy content for a range of furniture types are tabulated in Table 1.2. The average mass estimated values ranged from $15 \mathrm{~kg}$ (35 lbs) to $50 \mathrm{~kg}$ (110 lbs) for different types of merchandise. The average energy content estimates ranged from $200 \mathrm{MJ}$ to $620 \mathrm{MJ}$.

Merchandise item totals for a range of fraction of floor space used to display furniture in the showrooms are summarized in Table 1.2. Combining the average mass and number of items provides an estimate for the total mass and total energy content [19-21]. Dividing the total mass values by the available floor space converts these values to mass loading or fuel per area either $\mathrm{kg} / \mathrm{m}^{2}$ or $\mathrm{lbs} / \mathrm{ft}^{2}$ (Table 1-4).

The loading dock and warehouse would likely have contained a different mix of retail merchandise. Retail merchandise which had already been purchased and was awaiting delivery was staged in the loading dock area. Using a similar estimating technique, rough estimates were calculated for the merchandise that might have been staged on the loading dock area (Tables 1-1 and 1-3). Merchandise for the West Ashley store, as well as the other two Sofa Super Store locations were stored in the warehouse.

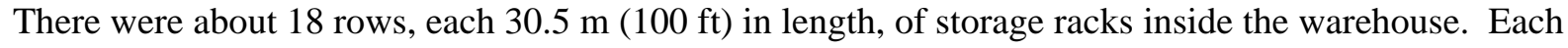
rack featured up to six layers of shelves (Appendix J). Combining the average mass and number of items provides an estimate for the total mass and total energy content. Dividing the total mass values by the available floor space converts these values to mass loading or fuel per area either $\mathrm{kg} / \mathrm{m}^{2}$ or lb/ft ${ }^{2}$ (Table 1-5). The estimated total energy content for the showrooms and warehouse was up to $480 \mathrm{GJ}$ and $840 \mathrm{GJ}$, respectively (Tables 1-4 and 1-5). 
Table 1-1. Dimensions, average mass, and average potential energy content for merchandise items.

\begin{tabular}{|c|c|c|c|c|c|c|c|c|c|}
\hline \multirow[t]{2}{*}{ Item } & \multicolumn{2}{|c|}{ Length } & \multicolumn{2}{|c|}{ Width } & \multicolumn{2}{|c|}{$\begin{array}{l}\text { Height / } \\
\text { Thickness }\end{array}$} & \multicolumn{2}{|c|}{$\begin{array}{c}\text { Average Mass* } \\
\text { [11-13] }\end{array}$} & \multirow{2}{*}{$\begin{array}{c}\text { Average } \\
\text { Energy* } \\
\text { Content } \\
\text { [11-13] } \\
\text { MJ }\end{array}$} \\
\hline & in & $\mathrm{m}$ & in & $\mathrm{m}$ & in & $\mathrm{m}$ & lbs & $\mathrm{kg}$ & \\
\hline Sofa & 84 & 2.1 & 36 & 0.91 & 34 & 0.86 & 120 & 55 & 560 \\
\hline Chair & 42 & 1.1 & 36 & 0.91 & 34 & 0.86 & 70 & 25 & 300 \\
\hline Mattress & 84 & 2.1 & 66 & 1.7 & 16 & 0.41 & 145 & 55 & 600 \\
\hline Dresser & 36 & 0.91 & 18 & 0.46 & 48 & 1.2 & 110 & 50 & 620 \\
\hline Table & 72 & 1.8 & 48 & 1.2 & 6 & 0.15 & 35 & 15 & 200 \\
\hline Rug & 96 & 2.4 & 96 & 2.4 & 0.5 & 0.012 & 35 & 15 & 200 \\
\hline
\end{tabular}

Table 1-2. Estimated number of furniture items for different fractions of floor space used to display merchandise in showrooms.

\begin{tabular}{|c|c|c|c|c|}
\hline \multirow{2}{*}{$\begin{array}{c}\text { Percent of Available } \\
\text { Floor Space Used to } \\
\text { Display Merchandise }\end{array}$} & $\begin{array}{c}\text { Main } \\
\text { Showroom }\end{array}$ & $\begin{array}{c}\text { West } \\
\text { Showroom }\end{array}$ & $\begin{array}{c}\text { East } \\
\text { Showroom }\end{array}$ & $\begin{array}{c}\text { Combined Three } \\
\text { Showrooms }\end{array}$ \\
\cline { 2 - 5 } & 360 & 180 & 160 & 700 \\
\hline $50 \%$ & 440 & 220 & 180 & 850 \\
\hline $60 \%$ & 510 & 250 & 220 & 980 \\
\hline $70 \%$ & 590 & 290 & 240 & 1120 \\
\hline $80 \%$ & \multicolumn{3}{|c|}{} \\
\hline
\end{tabular}


Table 1-3. Estimated number of furniture items for different fractions of floor space used to stage or store merchandise in loading dock and warehouse.

\begin{tabular}{|c|c|c|c|}
\hline \multirow{2}{*}{$\begin{array}{l}\text { Percent of Available } \\
\text { Floor Space Used to } \\
\text { Stage or Store } \\
\text { Merchandise }\end{array}$} & \multicolumn{3}{|c|}{ Total Items* } \\
\hline & Loading Dock & Warehouse & $\begin{array}{c}\text { Combined Loading Dock } \\
\text { and Warehouse }\end{array}$ \\
\hline $10 \%$ & & 220 & \\
\hline $20 \%$ & & 440 & \\
\hline $30 \%$ & 40 & 640 & 690 \\
\hline $40 \%$ & 50 & 860 & 910 \\
\hline $50 \%$ & 70 & 1000 & 1070 \\
\hline $60 \%$ & 80 & 1290 & 1370 \\
\hline $70 \%$ & 90 & 1500 & 1590 \\
\hline $80 \%$ & 110 & 1720 & 1830 \\
\hline $90 \%$ & & 1940 & \\
\hline
\end{tabular}


Table 1-4. Estimated mass loading and total energy content (merchandise) for showrooms.

\begin{tabular}{|c|c|c|c|c|c|c|c|}
\hline \multirow{2}{*}{$\begin{array}{l}\text { Percent of } \\
\text { Available } \\
\text { Floor Space } \\
\text { Used to } \\
\text { Display } \\
\text { Merchandise }\end{array}$} & \multicolumn{2}{|c|}{ Main Showroom } & \multicolumn{2}{|c|}{ West Showroom } & \multicolumn{2}{|c|}{ East Showroom } & \multirow{2}{*}{$\begin{array}{l}\text { Combined Three* } \\
\text { Showrooms } \\
\begin{array}{c}\text { Estimated Total Energy } \\
\text { Content } \\
\text { GJ }\end{array}\end{array}$} \\
\hline & $\begin{array}{c}\text { Estimated } \\
\text { Mass } \\
\text { Loading } \\
\mathrm{kg} / \mathrm{m}^{2} \\
\\
\left(\mathrm{lbs} / \mathrm{ft}^{2}\right)\end{array}$ & $\begin{array}{c}\text { Estimated } \\
\text { Total } \\
\text { Energy } \\
\text { Content } \\
\\
\text { GJ }\end{array}$ & $\begin{array}{c}\text { Estimated } \\
\text { Mass } \\
\text { Loading } \\
\mathrm{kg} / \mathrm{m}^{2} \\
\\
\left(\mathrm{lbs} / \mathrm{ft}^{2}\right)\end{array}$ & $\begin{array}{c}\text { Estimated } \\
\text { Total } \\
\text { Energy } \\
\text { Content } \\
\\
\text { GJ }\end{array}$ & $\begin{array}{c}\text { Estimated } \\
\text { Mass } \\
\text { Loading } \\
\mathrm{kg} / \mathrm{m}^{2} \\
\left(\mathrm{lbs} / \mathrm{ft}^{2}\right)\end{array}$ & $\begin{array}{c}\text { Estimated } \\
\text { Total } \\
\text { Energy } \\
\text { Content } \\
\\
\text { GJ }\end{array}$ & \\
\hline $50 \%$ & $\begin{array}{c}7.7 \\
(1.6)\end{array}$ & 150 & $\begin{array}{l}10.2 \\
(2.1)\end{array}$ & 80 & $\begin{array}{l}11.3 \\
(2.1)\end{array}$ & 80 & 270 \\
\hline $60 \%$ & $\begin{array}{c}9.5 \\
(1.9)\end{array}$ & 180 & $\begin{array}{l}11.7 \\
(2.5)\end{array}$ & 90 & $\begin{array}{l}12.0 \\
(2.4)\end{array}$ & 90 & 360 \\
\hline $70 \%$ & $\begin{array}{l}10.9 \\
(2.2)\end{array}$ & 210 & $\begin{array}{l}13.3 \\
(2.9)\end{array}$ & 110 & $\begin{array}{l}14.2 \\
(2.9)\end{array}$ & 110 & 420 \\
\hline $80 \%$ & $\begin{array}{l}12.6 \\
(2.6)\end{array}$ & 250 & $\begin{array}{l}15.9 \\
(3.3)\end{array}$ & 120 & $\begin{array}{l}15.9 \\
(3.3)\end{array}$ & 120 & 480 \\
\hline
\end{tabular}


Table 1-5. Estimated mass loading and total energy content (merchandise) for the loading dock and the warehouse.

\begin{tabular}{|c|c|c|c|c|c|}
\hline \multirow{2}{*}{$\begin{array}{c}\text { Percent of } \\
\text { Available } \\
\text { Floor Space } \\
\text { Used to Stage } \\
\text { or Store } \\
\text { Merchandise }\end{array}$} & \multicolumn{2}{|c|}{ Loading Dock } & \multicolumn{2}{|c|}{ Warehouse } & \multirow{2}{*}{$\begin{array}{c}\text { Combined Loading } \\
\text { Dock and Warehouse* } \\
\begin{array}{c}\text { Estimated Total Energy } \\
\text { Content } \\
\text { GJ }\end{array}\end{array}$} \\
\hline & $\begin{array}{c}\text { Estimated } \\
\text { Mass } \\
\text { Loading } \\
\mathrm{kg} / \mathrm{m}^{2} \\
\\
\left(\mathrm{lbs} / \mathrm{ft}^{2}\right)\end{array}$ & $\begin{array}{c}\text { Estimated } \\
\text { Total } \\
\text { Energy } \\
\text { Content } \\
\text { GJ }\end{array}$ & $\begin{array}{l}\text { Estimated } \\
\text { Mass } \\
\text { Loading } \\
\mathrm{kg} / \mathrm{m}^{2} \\
\left(\mathrm{lbs} / \mathrm{ft}^{2}\right)\end{array}$ & $\begin{array}{c}\text { Estimated } \\
\text { Total } \\
\text { Energy } \\
\text { Content } \\
\text { GJ }\end{array}$ & \\
\hline $10 \%$ & & & $\begin{array}{c}5 \\
(1.0)\end{array}$ & 65 & \\
\hline $20 \%$ & & & $\begin{array}{c}12 \\
(2.4)\end{array}$ & 190 & \\
\hline $30 \%$ & $\begin{array}{c}8.4 \\
(1.7)\end{array}$ & 20 & $\begin{array}{c}17 \\
(3.5)\end{array}$ & 280 & 300 \\
\hline $40 \%$ & $\begin{array}{c}10.2 \\
(2.1)\end{array}$ & 25 & $\begin{array}{c}23 \\
(4.7)\end{array}$ & 375 & 400 \\
\hline $50 \%$ & $\begin{array}{l}13.9 \\
(2.8)\end{array}$ & 30 & $\begin{array}{c}29 \\
(5.9)\end{array}$ & 460 & 490 \\
\hline $60 \%$ & $\begin{array}{l}15.8 \\
(3.2)\end{array}$ & 40 & $\begin{array}{c}35 \\
(7.0)\end{array}$ & 560 & 600 \\
\hline $70 \%$ & $\begin{array}{l}18.6 \\
(3.8)\end{array}$ & 40 & $\begin{array}{c}40 \\
(8.2)\end{array}$ & 650 & 690 \\
\hline $80 \%$ & $\begin{array}{l}21.4 \\
(4.4)\end{array}$ & 50 & $\begin{array}{c}46 \\
(9.4)\end{array}$ & 750 & 800 \\
\hline $90 \%$ & & & $\begin{array}{c}52 \\
(10.6)\end{array}$ & 840 & \\
\hline
\end{tabular}




\subsection{FIRE CONTROL PROVISIONS}

\subsubsection{Fire Alarms}

There were no records or reports of fire alarms or smoke detectors installed in the showrooms or warehouse. During a routine fire inspection (Appendix M, Figure M-1 and M-2), no fire alarms or smoke detectors were noted. During separate pre-planning building inspections by the individual response units, fire alarm indicators were marked as “not applicable” (Figure M-3).

\subsubsection{Fire Suppression}

There were no records or reports of any fire sprinklers ${ }^{5}$ or manual hose line capability within the building. During a routine fire inspection (Figure $\mathrm{M}-1$ and $\mathrm{M}-2$ ), no sprinkler system or standpipe systems were noted. The presence of at least five portable fire extinguishers was indicated. During separate preplanning building inspections by units of the fire department, fire sprinklers and standpipe were each marked as "not applicable" (Figure M-3).

\subsubsection{Fire Doors}

The pre-plan building inspection sketch (Figure M-4) identified the location of six roll-down fire doors, three on the east wall of the west showroom and three on the west wall of the east showroom. In the sketch, each of these six doors was indicated as a fire door. The inspection also listed the external rolldown door between the loading dock and holding area, but does not indicate that this door was a fire door.

\subsection{WATER SUPPLY}

The area in which the Sofa Super Store was located had immediate access to a municipal hydrant system to support fire ground operations. Water hydrants were located along Savannah Highway to the west and east of the store, on Pebble Road behind the store, and at Blitchridge and Wappoo Roads to the north of the store. The location of the six hydrants is shown in Figure 1-17. Each hydrant typically had a pair of $6.4 \mathrm{~cm}$ (2.5 in) outlets and a single $10.2 \mathrm{~cm}$ (4 in) outlet.

The pre-plan inspection report that was dated April 26, 2006 (Appendix M) listed the pre-plan hydrant ${ }^{6}$ as the hydrant on Pebble Road behind the store (intersection of Pebble Road and Sarah Street). The hydrant that had been located at the corner of Wappoo Road and Savannah Highway had been removed and not replaced.

\footnotetext{
${ }^{5}$ The terms "fire sprinkler," "automatic sprinkler system," “automatic fire sprinklers,” and "sprinklered” refer to water based fire protection systems designed, installed, and maintained in accordance with fire protection engineering standards such as NFPA 13 Standard for the Installation of Sprinkler Systems,[22] and NFPA 25 Standard for the Inspection, Testing, and Maintenance of Water-Based Fire Protection Systems [23]. This report will use "fire sprinklers" to refer to these systems.

${ }^{6}$ Pre-plans or pre-planning response documents are often generated by a fire department to identify the location of water and utility shut-offs for specific structures. This allows the fire department to plan how it will position its units if a fire occurs.
} 
Water supply lines, 20.3 cm (8 in) diameter, were located along Savannah Highway, Stinson Drive, Dupont Road, First Drive, and Blitchridge Road (Figure 1-18). A smaller supply line, 15.2 cm (6 in) diameter, ran south of the warehouse along Pebble Road. On Wappoo Road, the water line was $20.3 \mathrm{~cm}$ (8 in) south of Savannah Highway and 25.4 cm (10 in) north of Savannah Highway.

\subsection{HISTORY OF THE BUILDING}

NIST found no building records that identified the original owner, architect, design engineer, or builder of the Sofa Super Store building at 1807 Savannah Highway, Charleston, SC. Anecdotes indicated that the building originally was a Piggly Wiggly Supermarket that was erected in the late 1950s or early 1960s. The roll-down door between the loading dock area and the holding area was consistent with what would have been a loading dock door for the original grocery store. As an exterior door, the roll-down delivery door was not designed as a fire door and did not have a fusible link. The grocery store refrigerator/freezer compressor equipment was located in the enclosed area behind the store (Figure 1-19). The incinerator was also located at the rear of the store and was still visible although no longer operational.

Existing records indicate that the property was annexed into the City of Charleston from Charleston County in 1990, and also provide building permits for the addition of the west showroom in 1994, the east showroom in 1995, and the warehouse in 1996. Building permits were not located for the loading dock area or the repair areas which were added subsequent to the completion of the warehouse. The time line of construction and additions is summarized in Table 1-6. 


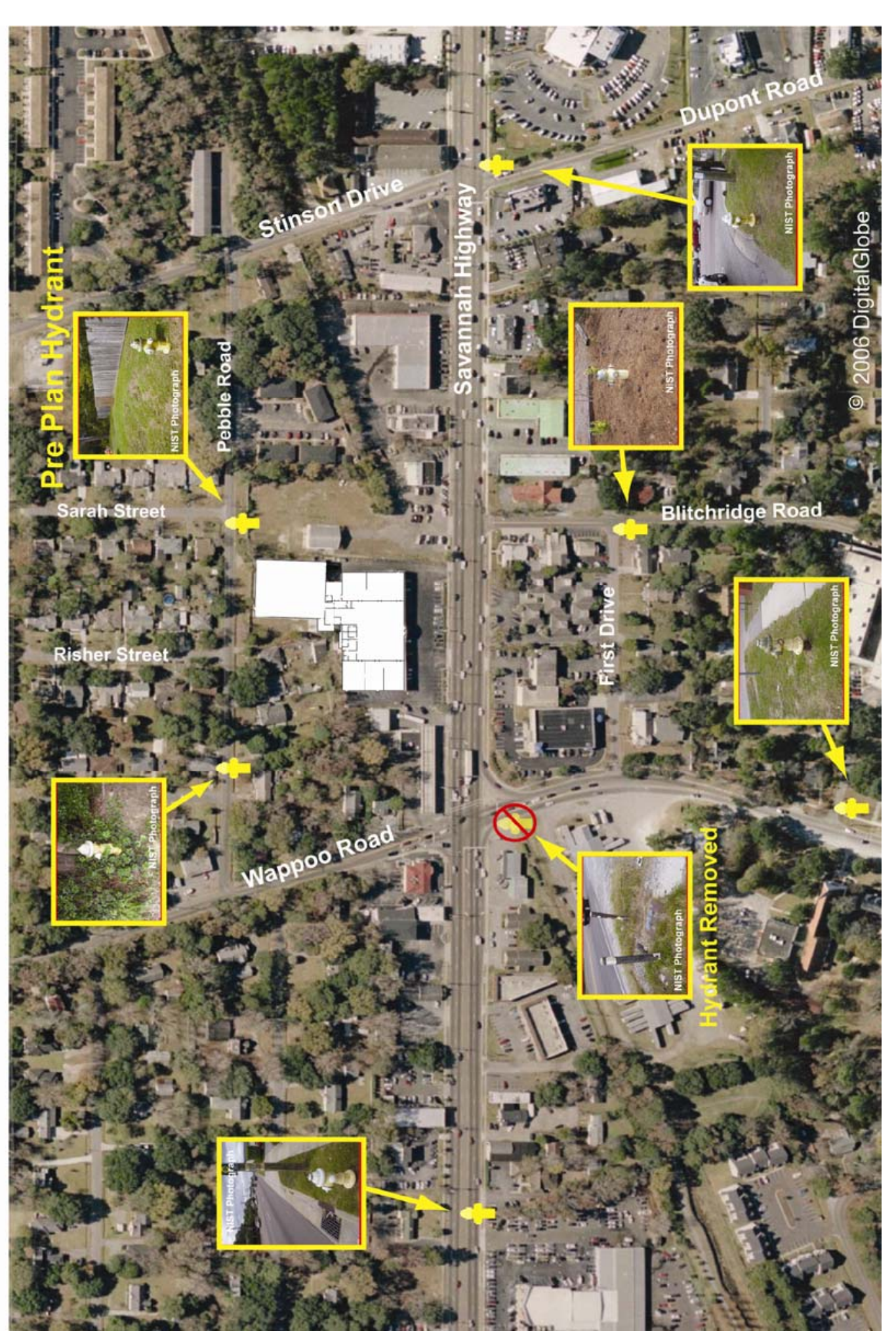

응

ธ

오.

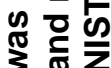

둥

윰

政

잉

高

워

흥 흐

웡 శ్ ฮี

흔다

잉ำ

올웅으

긍 응

한 응흔

要员

흥 훙

ส

产 要

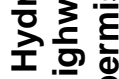

근

응

फ

むั

ตั す

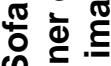

け흥

ฮั 웡

๘

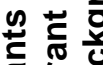

๘

휙조

도

ఏ宁产

능 흥은

눈

을 능 흔

ठ응

4.

กั

구응ㅇ

글웡 엉

능 워

는 윤 


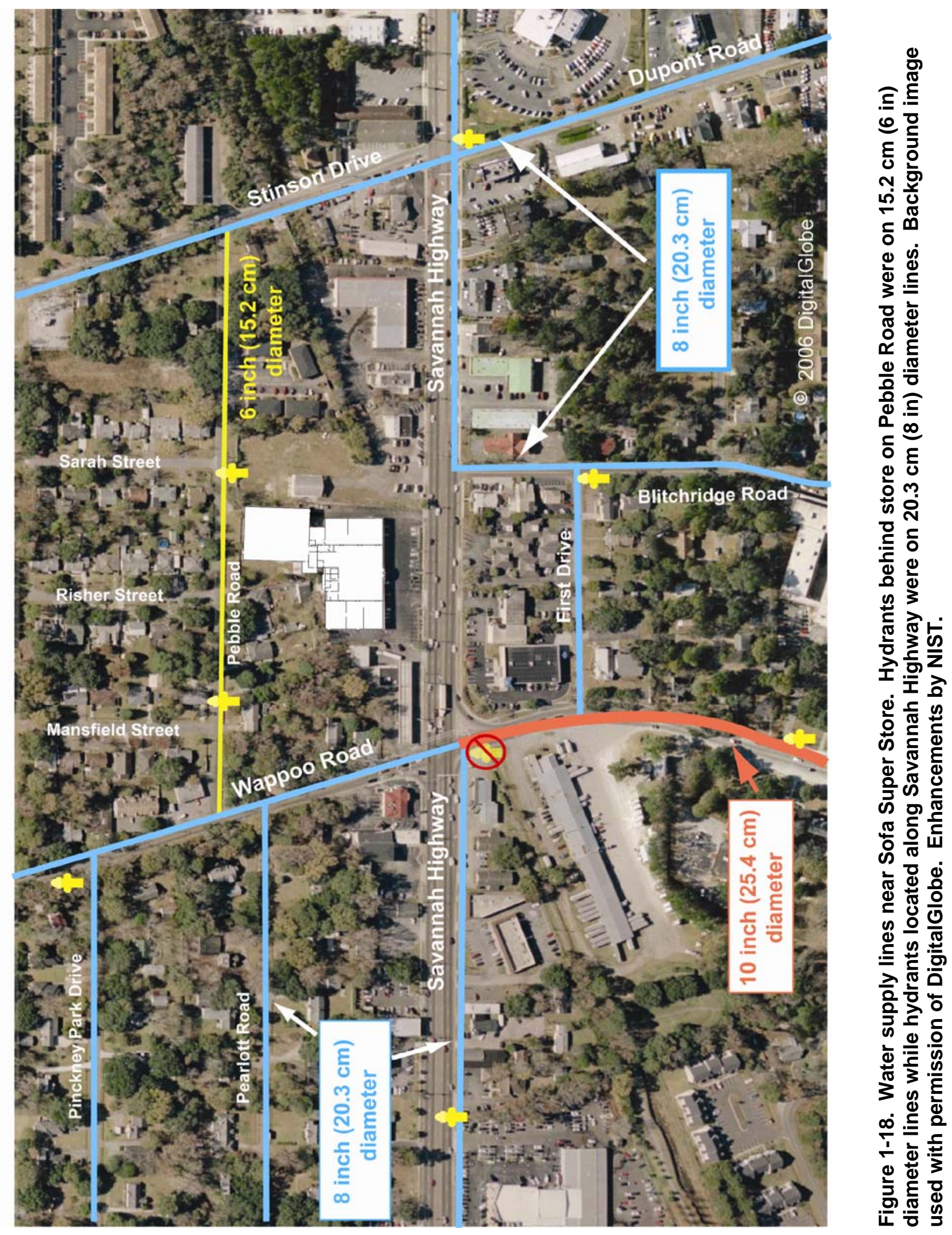




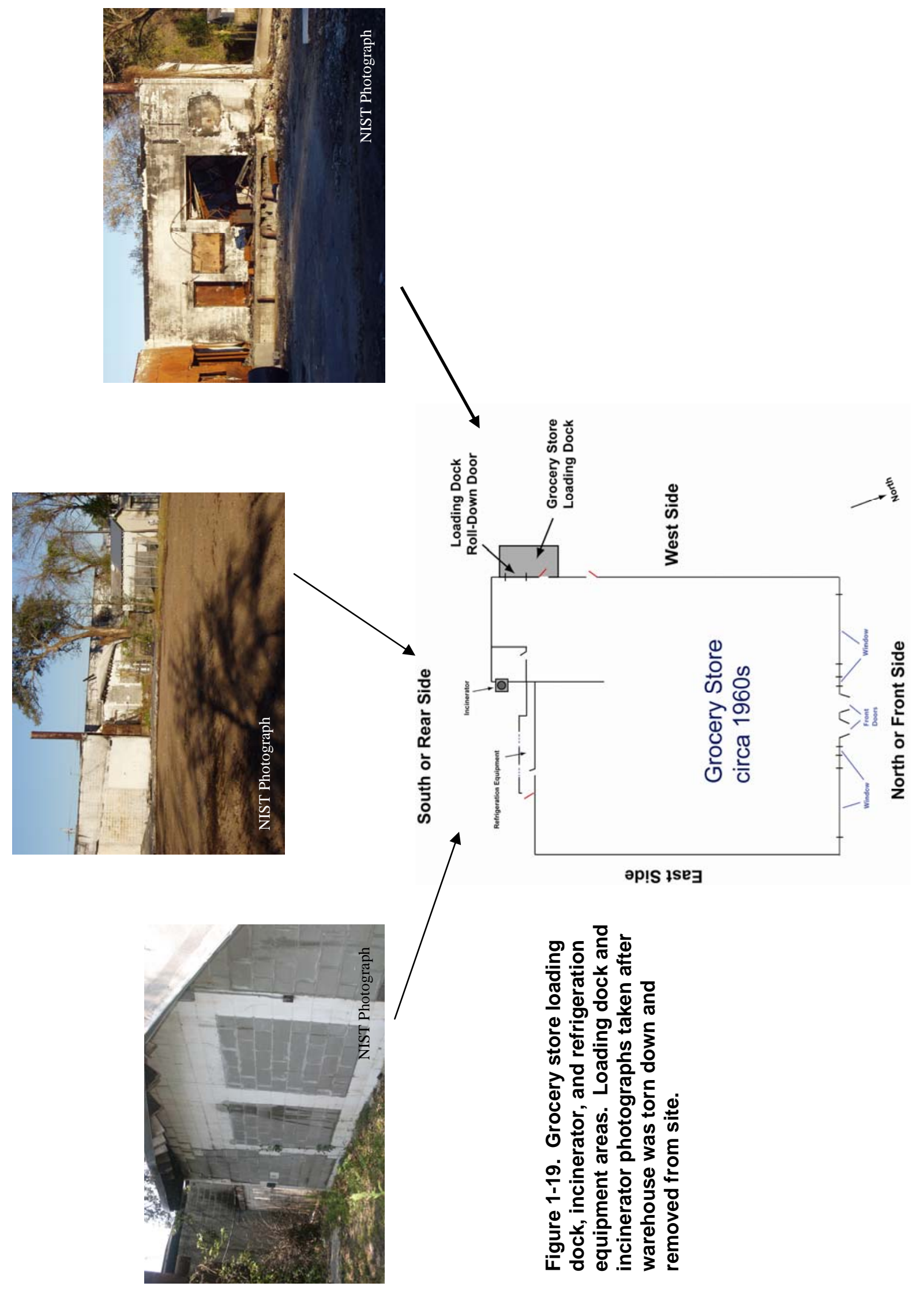


Table 1-6. Time Line of Construction and Changes of Use

\begin{tabular}{|c|c|c|}
\hline Year & Modification & Extent of Construction \\
\hline circa 1960 & $\begin{array}{l}\text { Original construction as a grocery } \\
\text { store }\end{array}$ & $\begin{array}{l}\text { New construction } \\
1630 \mathrm{~m}^{2}\left(17,500 \mathrm{ft}^{2}\right) \\
\text { Concrete block walls } \\
\text { Lightweight steel bar joists } \\
\text { Composite roof - sheet metal decking, foam } \\
\text { insulation, and polymer membrane }\end{array}$ \\
\hline 1990 & Annexed into Charleston City & \\
\hline 1994 & Addition of west showroom & $\begin{array}{l}\text { Commercial alteration } \\
650 \mathrm{~m}^{2}\left(6,970 \mathrm{ft}^{2}\right) \\
\text { Sheet metal walls } \\
\text { Steel I-beam roof joists } \\
\text { Sheet metal roof } \\
\text { Three roll-down fire doors in common wall } \\
\text { with main showroom }\end{array}$ \\
\hline 1995 & Addition of east showroom & $\begin{array}{l}\text { Commercial alteration } \\
650 \mathrm{~m}^{2}\left(7,020 \mathrm{ft}^{2}\right) \\
\text { Sheet metal walls } \\
\text { Steel I-beam roof joists } \\
\text { Sheet metal roof } \\
\text { Three metal roll-down fire doors in common } \\
\text { wall with main showroom }\end{array}$ \\
\hline 1996 & $\begin{array}{l}\text { Addition of high rack storage } \\
\text { warehouse }\end{array}$ & $\begin{array}{l}\text { Commercial alteration } \\
1450 \mathrm{~m}^{2}\left(15,600 \mathrm{ft}^{2}\right) \\
\text { Sheet metal walls } \\
\text { Steel I-beam roof joists } \\
\text { Sheet metal roof }\end{array}$ \\
\hline $\begin{array}{l}1996-1998 \\
\text { (no building permit } \\
\text { located) } \\
\text { Visible in } 1998 \text { aerial } \\
\text { photograph }\end{array}$ & $\begin{array}{l}\text { Addition of loading dock - south } \\
\text { section }\end{array}$ & $\begin{array}{l}\text { Commercial alteration } \\
95 \mathrm{~m}^{2}\left(1000 \mathrm{ft}^{2}\right) \\
\text { Elevated wood deck } \\
\text { Wood framing - studs and joists } \\
\text { Metal walls } \\
\text { Metal roof }\end{array}$ \\
\hline $\begin{array}{l}1996-1998 \\
\text { (no building permit } \\
\text { located) } \\
\text { Visible in } 1998 \text { aerial } \\
\text { photograph }\end{array}$ & Addition of paint repair shop & $\begin{array}{l}\text { Commercial alteration } \\
70 \mathrm{~m}^{2}\left(730 \mathrm{ft}^{2}\right) \\
\text { Wood framing - studs and joists } \\
\text { Sheet metal walls } \\
\text { Sheet metal roof }\end{array}$ \\
\hline $\begin{array}{l}1998-2006 \\
\text { (no building permit } \\
\text { located) } \\
\text { Visible in } 2006 \text { aerial } \\
\text { photograph }\end{array}$ & $\begin{array}{l}\text { Addition of loading dock - north } \\
\text { section }\end{array}$ & $\begin{array}{l}\text { Commercial alteration } \\
110 \mathrm{~m}^{2}\left(1200 \mathrm{ft}^{2}\right) \\
\text { Elevated wood deck } \\
\text { Wood framing - studs and joists } \\
\text { Sheet metal walls } \\
\text { Sheet metal roof }\end{array}$ \\
\hline $\begin{array}{c}2001-2006 \\
\text { (no building permit } \\
\text { located) } \\
\text { Visible in } 2006 \text { aerial } \\
\text { photograph }\end{array}$ & Addition of wood repair shop & $\begin{array}{l}\text { Commercial alteration } \\
60 \mathrm{~m}^{2}\left(610 \mathrm{ft}^{2}\right) \\
\text { Wood framing - studs and joists } \\
\text { Sheet metal walls } \\
\text { Sheet metal roof }\end{array}$ \\
\hline
\end{tabular}




\subsection{AERIAL PHOTOGRAPHY OF THE SOFA SUPER STORE}

Remote sensing images or aerial photographs have been routinely recorded by commercial imaging companies and have been used for monitoring land use or in planning new residential areas or commercial facilities. The early remote sensing images were usually black and white and of lower resolution. Aerial photographs taken more recently are typically in color and with better resolution.

NIST obtained aerial images from DigitalGlobe of the West Ashley area of the city of Charleston from 1989, 1994, 1998, 2001, and 2006. These images were taken directly overhead the store at $110 \mathrm{~m}$ (370 ft), $230 \mathrm{~m}$ (740 ft), $340 \mathrm{~m}$ (1100 ft), $450 \mathrm{~m}$ (1480 ft), and $1120 \mathrm{~m}$ (3700 ft) resolutions. ${ }^{7}$ NIST also obtained aerial photographs from Pictometry at narrow and wide fields of view. Angle or oblique views were obtained from north, south, east, and west views at 40 degree angles. Figures 1-20 through 1-24 were taken at $366 \mathrm{~m}(1200 \mathrm{ft})$ resolution. Other images at different resolutions as well as the angle or oblique images are in Appendix N.

These images provide some insight into the chronological order in which the Sofa Super Store was expanded, but since photographs were not available for each year, NIST could not identify the specific years when the loading dock and repair areas were constructed.

An aerial photograph from 1989 (Figure 1-20) demonstrates that only the main showroom was present on the site. The residential structures behind the main showroom had already been constructed. The car repair shop to the west of the store was also built. The gas station to the east of the store does not appear in this photograph in its current configuration. The low resolution of the image makes it more difficult to analyze, but the structure to the east appears perpendicular to the current gas station configuration.

An image from 1994 (Figure 1-21) verifies that the west showroom was added first and was constructed before February, 1994. The east showroom, warehouse, loading dock, and repair areas do not appear in the image. The gas station to the east of the store does appear in its current configuration.

Figure 1-22 is an aerial photograph taken in March 1998 which shows that the west and east showrooms as well as the warehouse had been added to the structure. Examination of the area between the rear of the west showroom and the warehouse reveals that the southern portion of the loading dock area had been constructed, but not the northern section. Neither the paint repair shop nor the wood repair shops had been constructed at this time.

An aerial image from 2001 (Figure 1-23) demonstrates that the paint repair shop had been added. It appears that the wood repair shop was not yet constructed. Some portion of the north section of the loading dock appears to have been added, possibly just the deck or floor. The north portion of the loading dock was not enclosed when this photograph was taken.

Figure 1-24,which is an aerial photograph from December 2006, reveals that the north section of the loading dock was enclosed and the wood repair shop was added to the east side of the paint repair shop.

\footnotetext{
${ }^{7}$ Image resolution refers to meters or feet per pixel in an image. A $110 \mathrm{~m}$ resolution image had 2500 pixels with each pixel representing $0.045 \mathrm{~m}$. This translated into an image displaying an area approximately $110 \mathrm{~m}$ x $110 \mathrm{~m}$. Similarly, a $1120 \mathrm{~m}$ resolution displayed an area $1120 \mathrm{~m}$ x $1120 \mathrm{~m}$.
} 


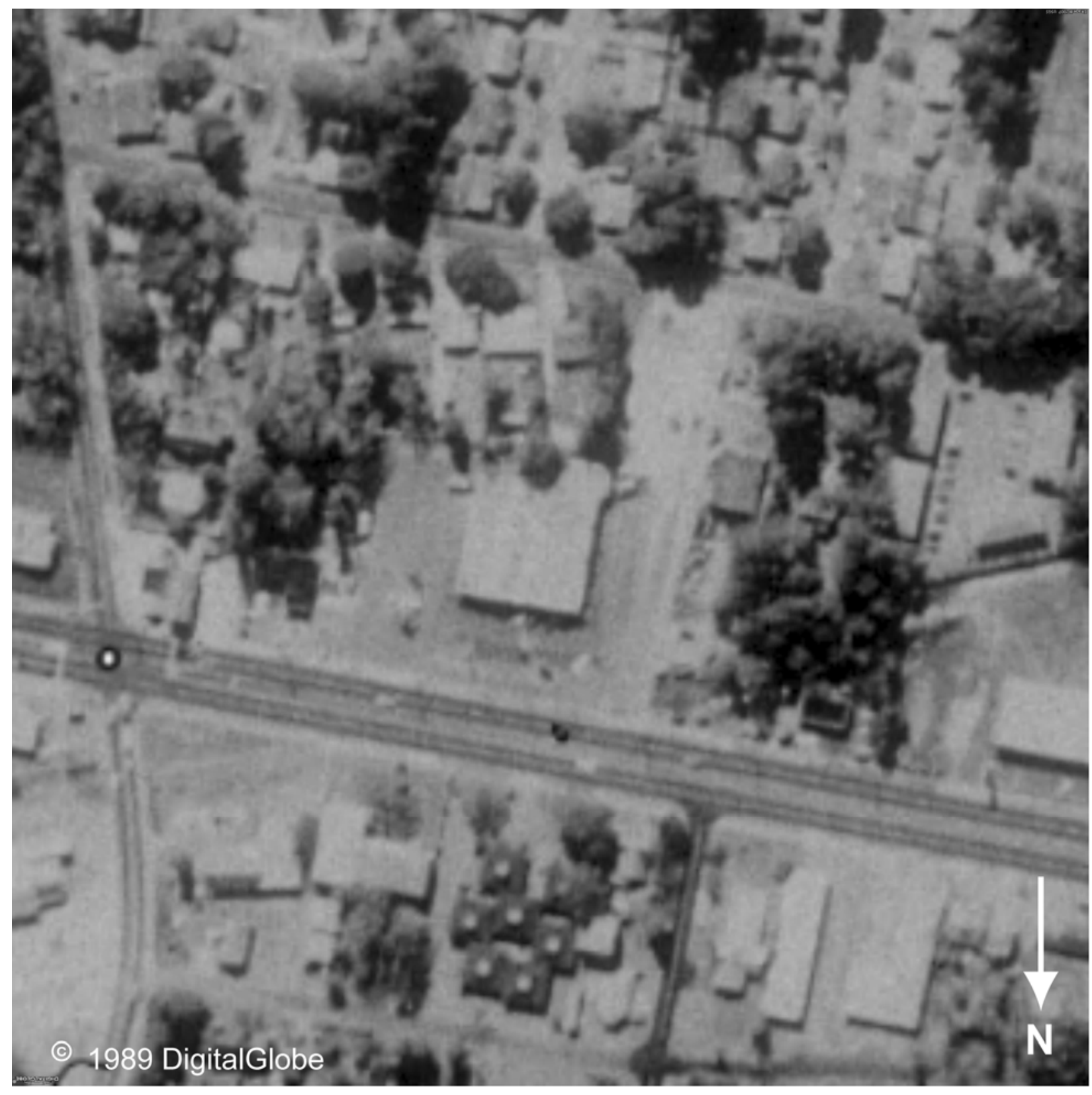

Figure 1-20. Aerial photograph of Sofa Super Store on February 12, 1989. 


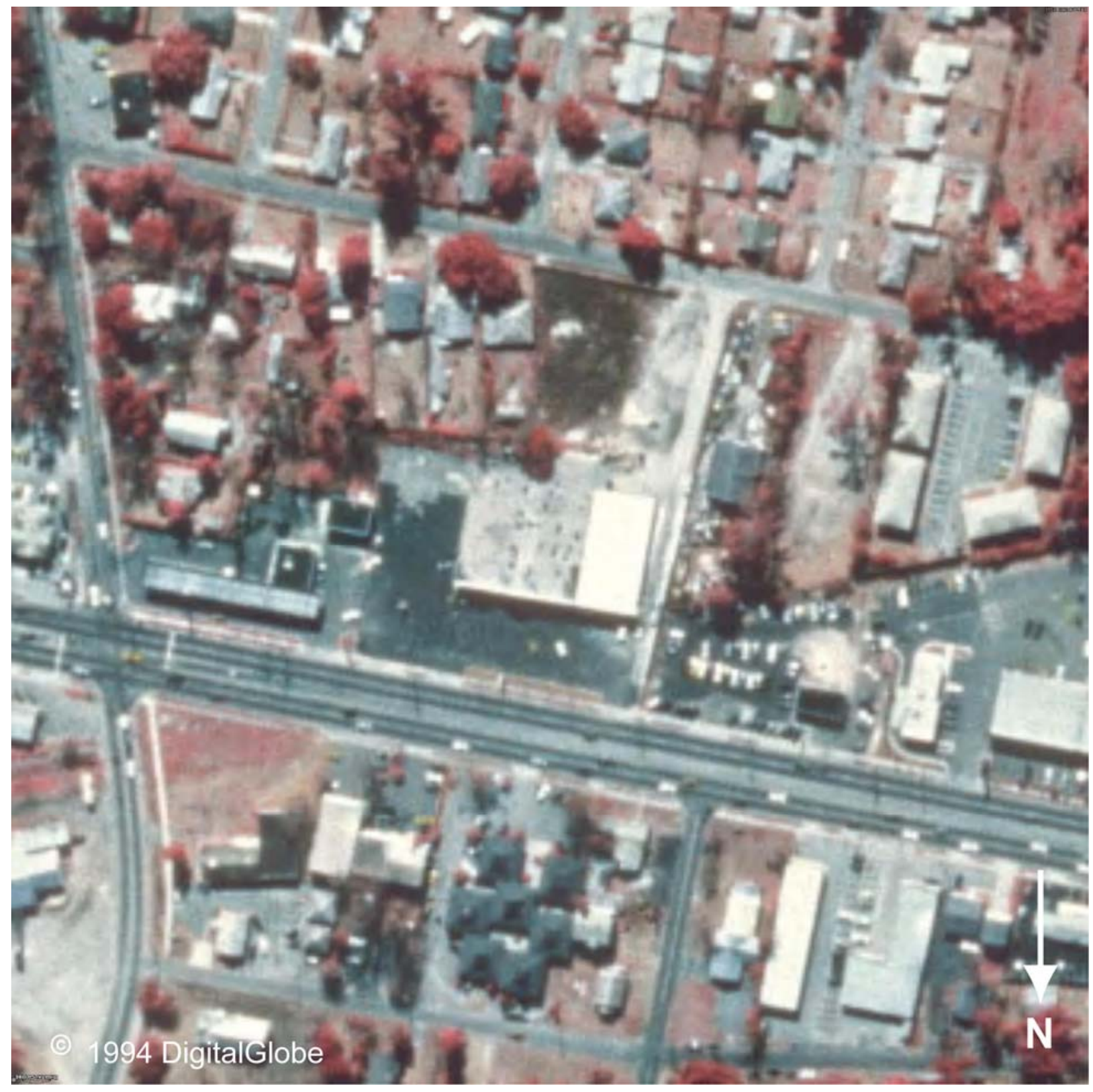

Figure 1-21. Aerial photograph of Sofa Super Store on February 14, 1994. 


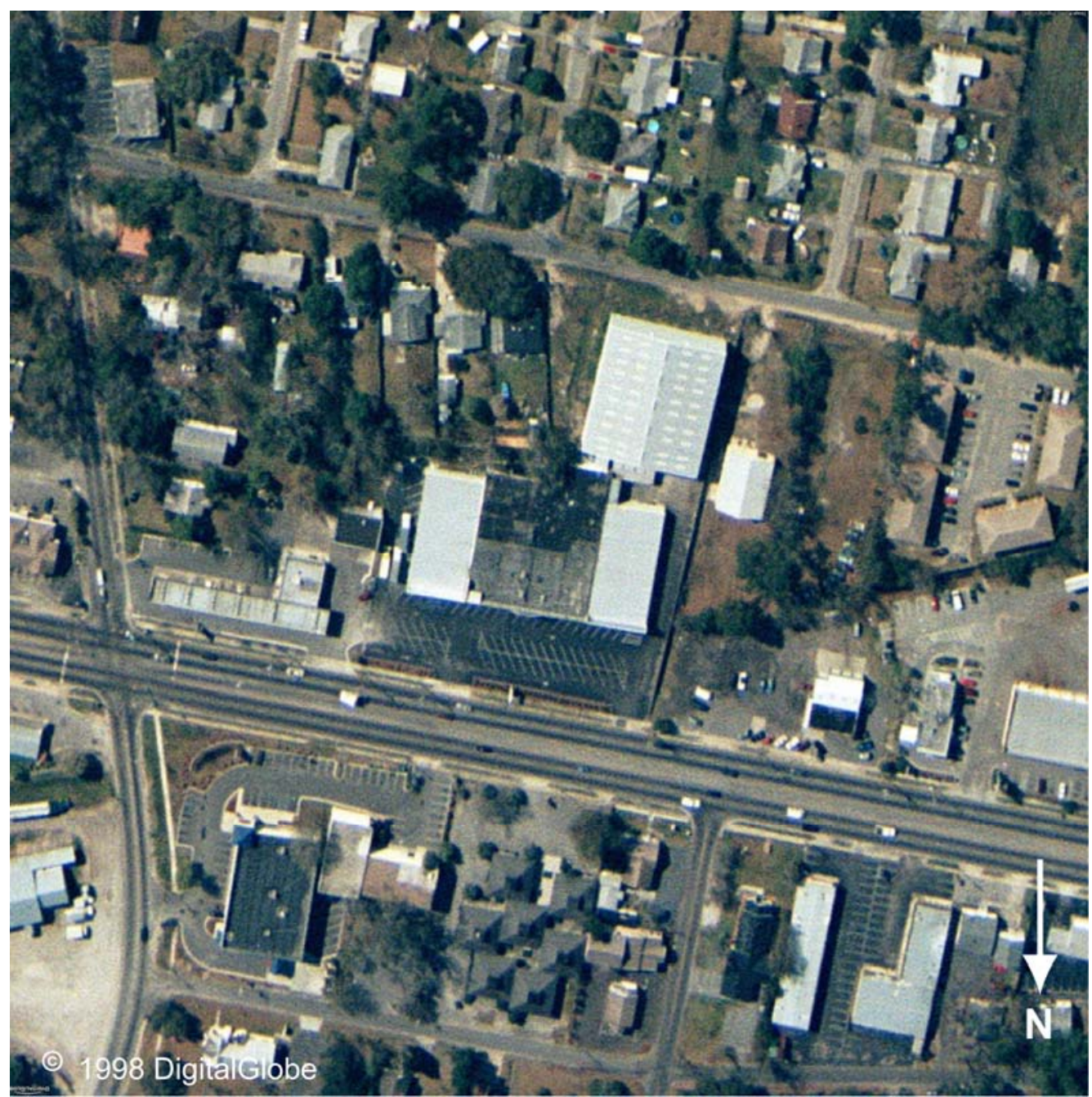

Figure 1-22. Aerial photograph of Sofa Super Store on March 1, 1998. 


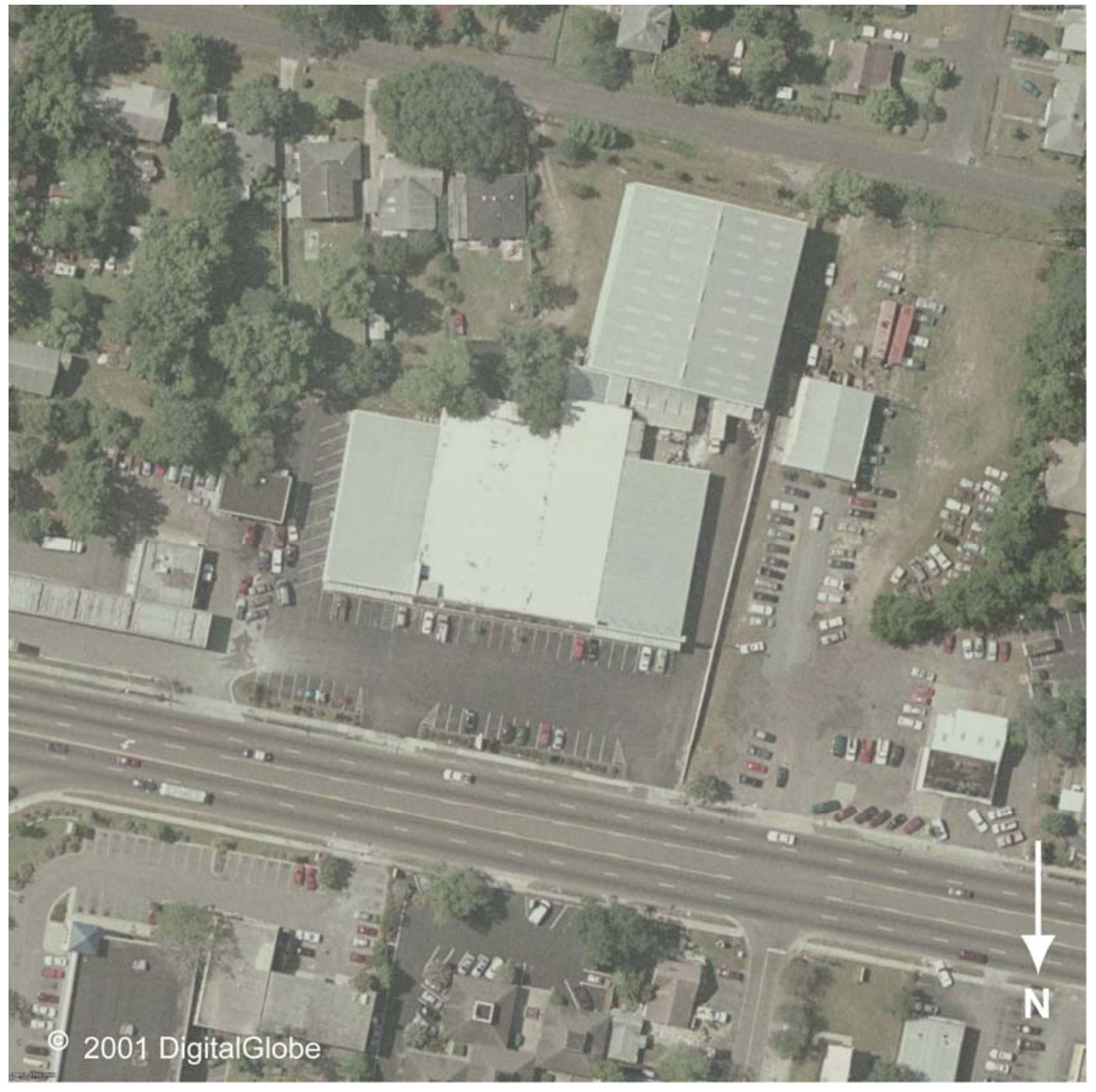

Figure 1-23. Aerial photograph of Sofa Super Store on April 1, 2001. 


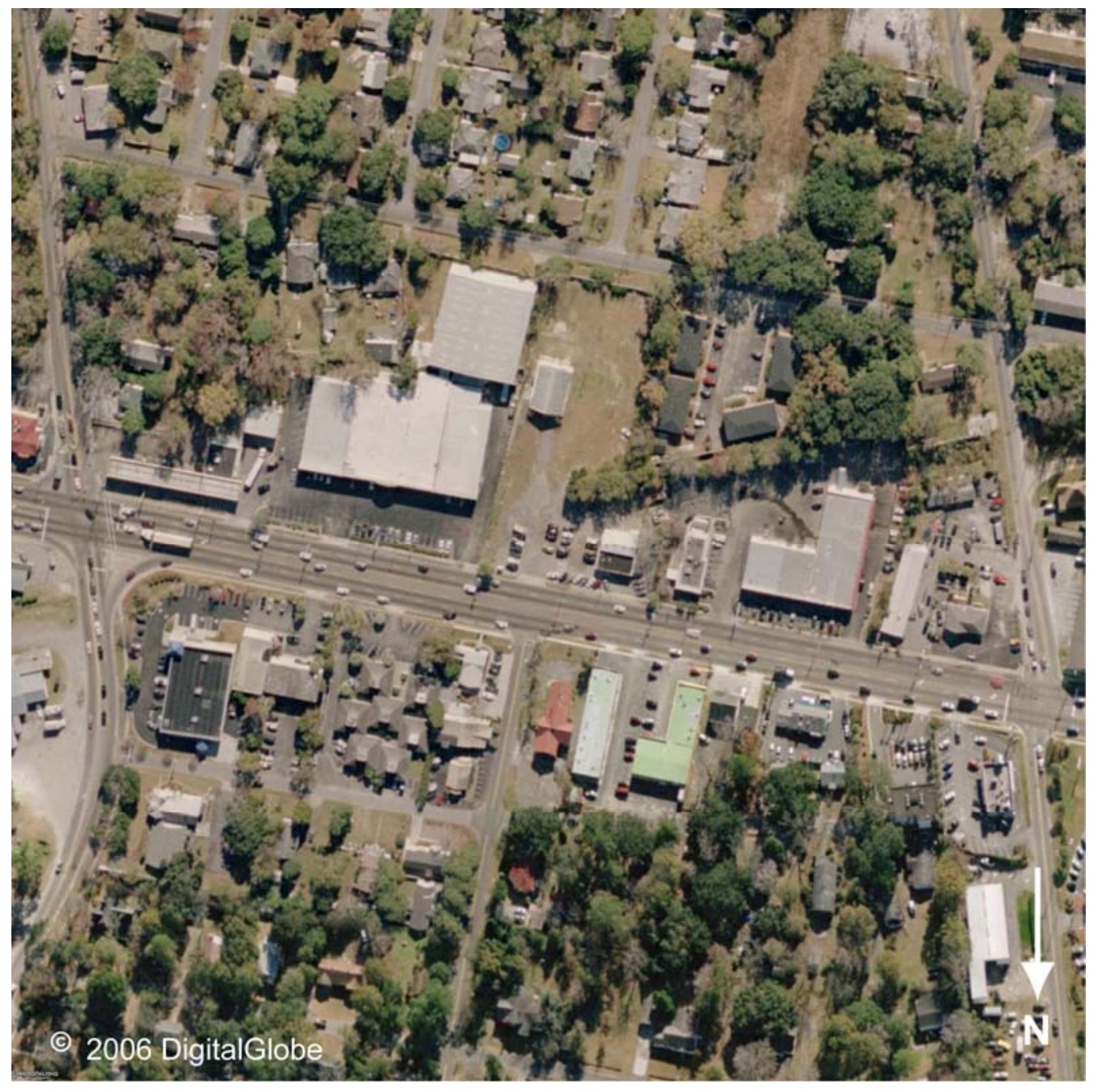

Figure 1-24. Aerial photograph of Sofa Super Store on December 1, 2006. 


\subsection{REFERENCES FOR CHAPTER 1}

[1] Digital photographs taken during fire by public individuals including Stewart English and Alexander Fox.

[2] Digital photographs taken during and after the fire by law enforcement organizations including the Charleston Police Department and Charleston County Sheriff's Office.

[3] Digital photographs taken during and after the fire by news outlets including The Post and Courier and Associated Press.

[4] Digital photographs taken after the fire by NIST Team.

[5] Interviews of fire fighters conducted by National Institute for Occupational Safety and Health (NISOH). Interviews organized by the NIOSH investigation team and NIST team allowed to participate. Interviews included fire fighters from Charleston, St. Andrew's, and St. James Island Fire Departments.

[6] Informal discussion between store employees and the NIST team.

[7] Articles from a number of news outlets including The Post and Courier, Associated Press, Fire Engineering, washingtonpost.com, MSNBC.com, charlston.net, and ENR_com News. A listing of articles that were reviewed was placed in Appendix Q.

[8] Sofa Super Store Fire - Report of Investigation, ATF National Response Team Origin and Cause Report, Investigation 763010-07-0172, Report 32, June 22, 2007.

[9] Fatality Assessment and Control Evaluation Investigation Report \#F2007-18, National Institute for Occupational Safety and Health, Fire Fighter Fatality Investigation and Prevention Program, Morgantown, WV, February 2009. http://www.cdc.gov/niosh/fire/pdfs/face200718.pdf.

[10] "Fire Fighter Fatality Investigative Report, Sofa Super Store, 1807 Savannah Highway, Charleston, South Carolina, June 18, 2007,” City of Charleston Post Incident Assessment and Review Team, Phase II Report, June 2008.

[11] NFPA 80, Standard for Fire Doors and Other Opening Protectives, National Fire Protection Association, Quincy, MA, 2010.

[12] UL 10B, Fire Tests of Door Assemblies, Underwriters Laboratories Standard for Safety.

[13] 1991 Standard Building Code, Southern Building Code Congress International, Inc., Birmingham, AL.

[14] 1991 Standard Fire Code, Southern Building Code Congress International, Inc., Birmingham, AL.

[15] 1994 Standard Building Code, Southern Building Code Congress International, Inc., Birmingham, AL.

[16] 1994 Standard Fire Code, Southern Building Code Congress International, Inc., Birmingham, AL.

[17] 2006 International Building Code, International Code Council, Inc., Falls Church, VA. 
[18] 2006 International Fire Code, International Code Council, Inc., Falls Church, VA.

[19] Denize, Hamish, “The Combustion Behavior of Upholstered Furniture Materials in New Zealand,” Fire Engineering Research Report 00/04, University of Canterbury, Christchurch, New Zealand, March 2000.

[20] Firestone, James, “An Analysis of Furniture Heat Release Rates by Nordtest,” Fire Engineering Research Report 99/07, University of Canterbury, Christchurch, New Zealand, March 1999.

[21] Stroup, D.W., Bryner, N., Lee, J.L., McElroy, J., Roadarmel, G., Twilley, W. H., "Structural Collapse Fire Tests: Single Story, Wood Frame Structures,” NISTIR 7094, National Institute of Standards and Technology, Gaithersburg, MD, March 2004.

[22] NFPA 13 Standard for the Installation of Sprinkler Systems, National Fire Protection Association, Quincy, MA, 2010.

[23] NFPA 25 Standard for the Inspection, Testing, and Maintenance of Water-Based Fire Protection Systems, National Fire Protection Association, Quincy, MA, 2011.. 


\section{Chapter 2 DESCRIPTION AND TIME LINE OF THE INCIDENT}

\section{$2.1 \quad$ INTRODUCTION}

\subsubsection{Background}

The deaths of nine fire fighters on June 18, 2007, in the Charleston Sofa Super Store fire was the single greatest loss of life for the fire service in the United States since 343 fire fighters died in the collapse of the World Trade Center on Sept. 11, 2001. For South Carolina, this fire was the deadliest fire since 11 people died in the Lancaster County Jail fire on Dec. 27, 1979 [1-2].

The fire and resulting structure loss at the Sofa Super Store involved the main and west showrooms, repair areas, and warehouse. The only section of the store that did not collapse was the east showroom where the fire spread was limited to the rear portion of that space. No part of the structure was sprinklered.

The time lines presented in this chapter identify the specific events that occurred during the Sofa Super Store fire that started just after 6:56 p.m., Daylight Savings Time (DST), June 18, 2007, as well as the order in which they transpired. The time line focuses on the growth and spread of the fire as it moved through the Sofa Super Store, but it also incorporates the response of the fire service in order to provide a broader perspective. The response of the fire service is presented in greater detail in Chapter 3 of this study.

\subsubsection{Collection of Time Line Data}

In the process of developing this time line, the NIST team collected data from a range of sources including: video recordings [3-4], digital photographs [5-8], interviews of fire fighters [9], a discussion with store employees [10], radio and cell phone recordings and transcripts [11], articles from news outlets [12], and investigative reports [13-15].

Video recordings and digital photographs provided information about fire growth during the incident. If these images were time stamped or linked to specific events where the time was known then the information was incorporated into the time line. Since none of the photographers or videographers was present before the fire began, neither the video nor digital photographs captured the initial stages of the incident. All digital photographs and video were recorded outside the structure and did not provide images of fire growth inside the store.

Interviews with fire fighters provided information about the conditions inside and outside the structure. In combination with the fire department radio transmissions, it was possible to link the conditions to the time line. The arrival time of the fire department units was documented via the radio transmissions from arriving fire units to central dispatch. The City of Charleston released audio recordings of the radio communications [11] and the Post Incident Assessment and Review Team tabulated the radio and phone transmissions into a single time-linked table [15].

Articles from newspapers, television stations, and the internet [12] were reviewed by the team for potentially new sources of information. The information was examined, and if it could be verified, the 
new data were included in the time line. Investigative reports from Bureau of Alcohol, Tobacco, Firearms, and Explosives (ATF) [13], National Institute for Occupational Safety and Health (NIOSH) [14], and the Post Incident Assessment and Review Team [15] were carefully reviewed and provided critical insight into how the fire spread. Specifically, the time-linked reports by the fire fighters of smoke and fire conditions within the showrooms were invaluable in developing the time line.

\subsection{OVERVIEW NARRATIVE}

On June 18, 2007, at 6:56 p.m., the time of the first sighting of the fire, the Sofa Super Store was open and employees were inside the showroom and warehouse areas within the structure. The fire was first observed by a passerby driving along Savannah Highway in front of the store and was reported to store employees. After being notified by the passerby of a fire on the outside of the loading dock, the store manager located the fire inside the loading dock around a door frame. According to the investigation by the ATF [13], a fire was discovered in a pile of trash/debris outside the structure between the rear of the showroom area and the warehouse. Upon initial verification of the fire, the store manager discharged a portable dry chemical fire extinguisher, but was unable to extinguish the fire. Upon returning to the showroom area, the store manager asked other employees to call 911. The manager subsequently returned with a second extinguisher, found the loading dock more fully involved in fire, and discharged the extinguisher into the loading dock area from outside the loading dock. At 7:08 p.m., a report of a fire at the Sofa Super Store was received by the Charleston County 911 Emergency Center and the Charleston Fire Department was dispatched. All of the employees in the showroom area were able to exit the store through the front doors of the showroom.

At approximately 7:10 p.m., one minute after being notified, Engine 11 (E-11), Engine 10 (E-10), Ladder 5 (L-5), Battalion Chief 4 (BC-4), and an Assistant Chief (AC) from the Charleston Fire Department (CFD) were en route to the scene of the reported fire. While en route to the scene, the BC observed a smoke plume at the rear of the store and reported to dispatch. This confirmation initiated an additional unit, Engine 16, being dispatched to the fire scene. Upon arriving on the scene at 7:11 p.m., BC 4 reported a trash/debris fire at the rear of the showroom. Engine 10 was directed by the BC to position the apparatus near the loading dock and begin suppressing the trash fire (Figure 2-1).

By 7:12 p.m., additional units, including an AC and Engine 11, had arrived on scene, and an initial search of the main showroom did not reveal either fire or smoke in the main showroom. When the AC asked the store employees if there was anyone left in the store, the response was that everybody was out [9]. A second search to the rear of the west showroom was conducted by the AC and fire fighters and after opening doors at the rear of the west showroom, fire was discovered in the loading dock area. By 7:16 p.m., fire crews were applying water using a $3.8 \mathrm{~cm}$ (1.5 in) diameter hose line on the fire in the loading dock. At the same time, at the front of the store, crews were pulling a $3.8 \mathrm{~cm}$ (1.5 in) diameter hose line in the front door, through the main showroom, and into the west showroom. At the time, neither E-10 at the loading dock nor E-11 at the front of the store had been connected to water hydrants, so any water being used for suppression would have been drawn from the onboard tanks of E-10 or E-11. Additional units, including Engine 12 (E-12), Engine 16 (E-16), Engine 15 (E-15), Engine 19 (E-19), and the Fire Chief were on scene or en route. 


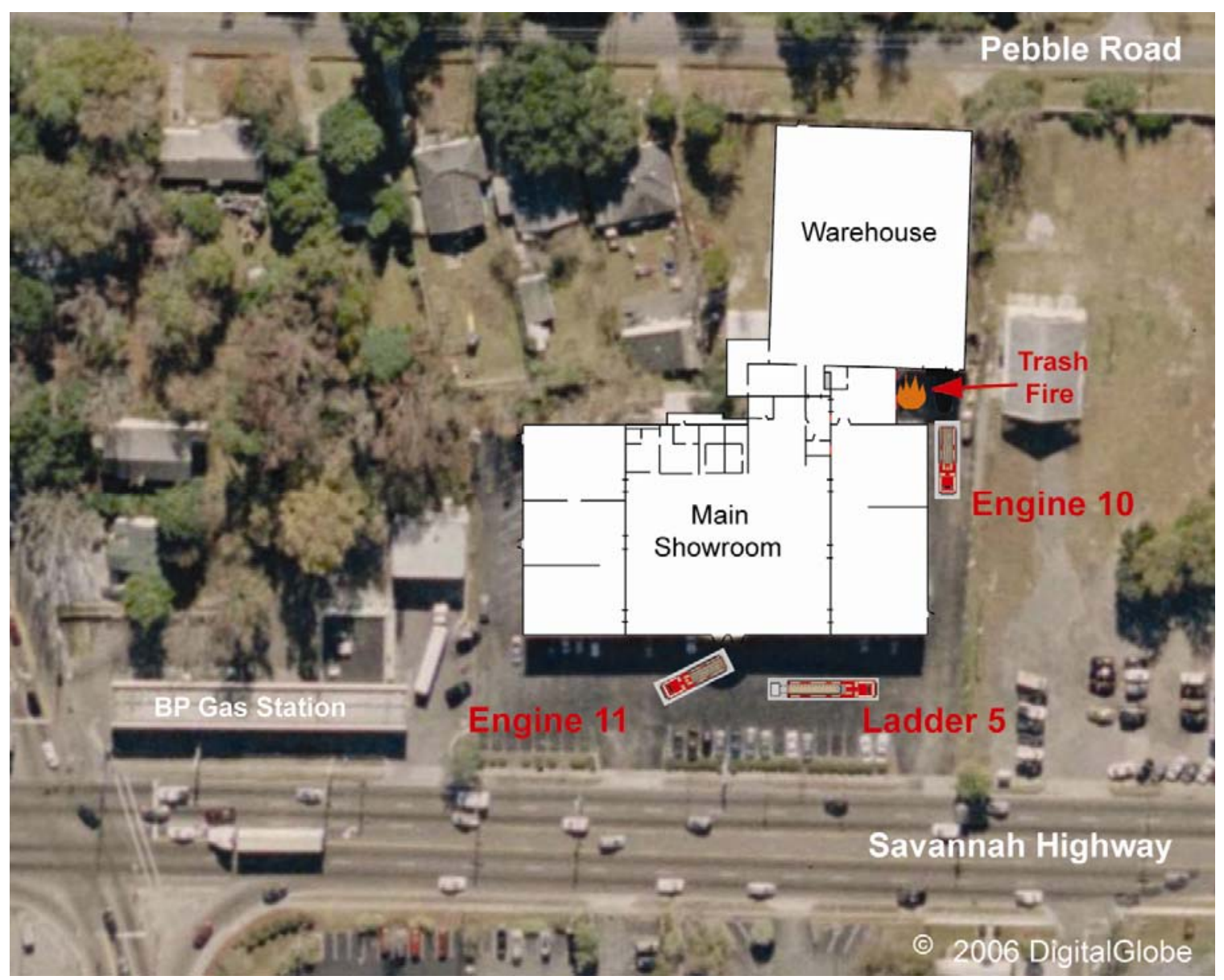

Figure 2-1. Location of Engines 10 and 11, and Ladder 5 at approximately 7:12 p.m. Background image used with permission of DigitalGlobe. Enhancements by NIST.

In the next 10 minutes, two engines were connected to water hydrants (Figure 2-2). E-10 was connected through E-12 to a hydrant at the corner of Blitchridge Road and First Drive. By 7:21 p.m. a water supply line was connected to the engine pumping water to the loading dock fire teams. E-12 was pumping water through approximately $230 \mathrm{~m}$ (750 ft) of $6.4 \mathrm{~cm}$ (2.5 in) diameter supply line. Requests to increase the water pressure were radioed to E-12 at 7:25 p.m. By 7:27 p.m. the engine positioned at the front of the store (Figure 2-3) was also connected to a fire hydrant. E-11 was being supplied by E-16 which had located a water hydrant at 1714 Savannah Highway in front of Morris Nissan automobile dealership. E-16 was pumping water to E-11 through about $560 \mathrm{~m}$ (1850 ft) of $6.4 \mathrm{~cm}$ (2.5 in) diameter supply line.

Although the roll-down fire door in the breezeway between the holding area and warehouse had activated and closed direct access to the warehouse, the fire inside the enclosed loading dock spread to the front of the warehouse through a shared corrugated metal wall. The fire heated the metal wall sufficiently to cause items inside the warehouse to ignite. 


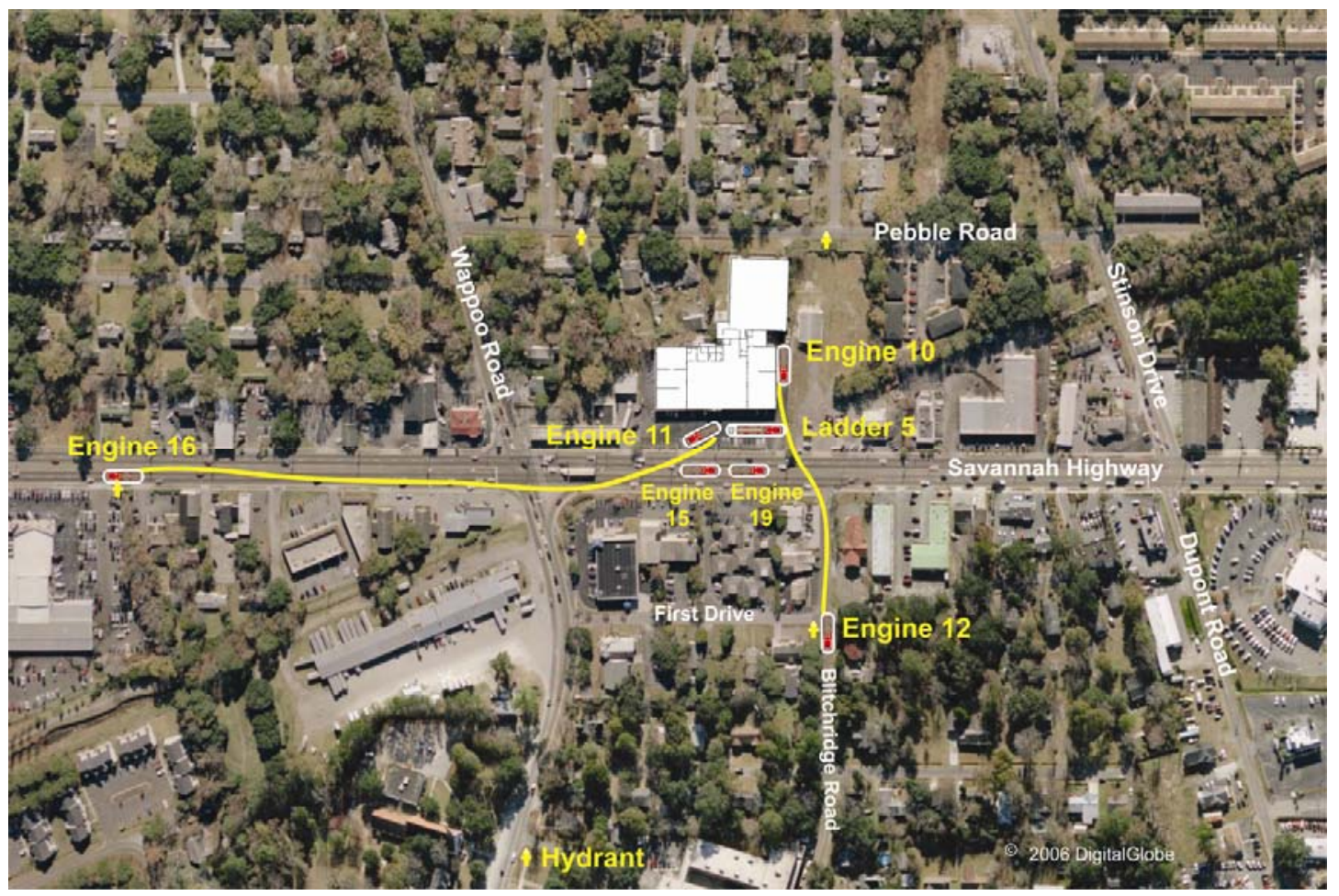

Figure 2-2. Positioned at fire hydrants on Savannah Highway and Blitchridge Road, Engines 16 and 12 were pumping water to Engines 10 and 11 at about 7:27 p.m.

Background image used with permission of DigitalGlobe. Enhancements by NIST.

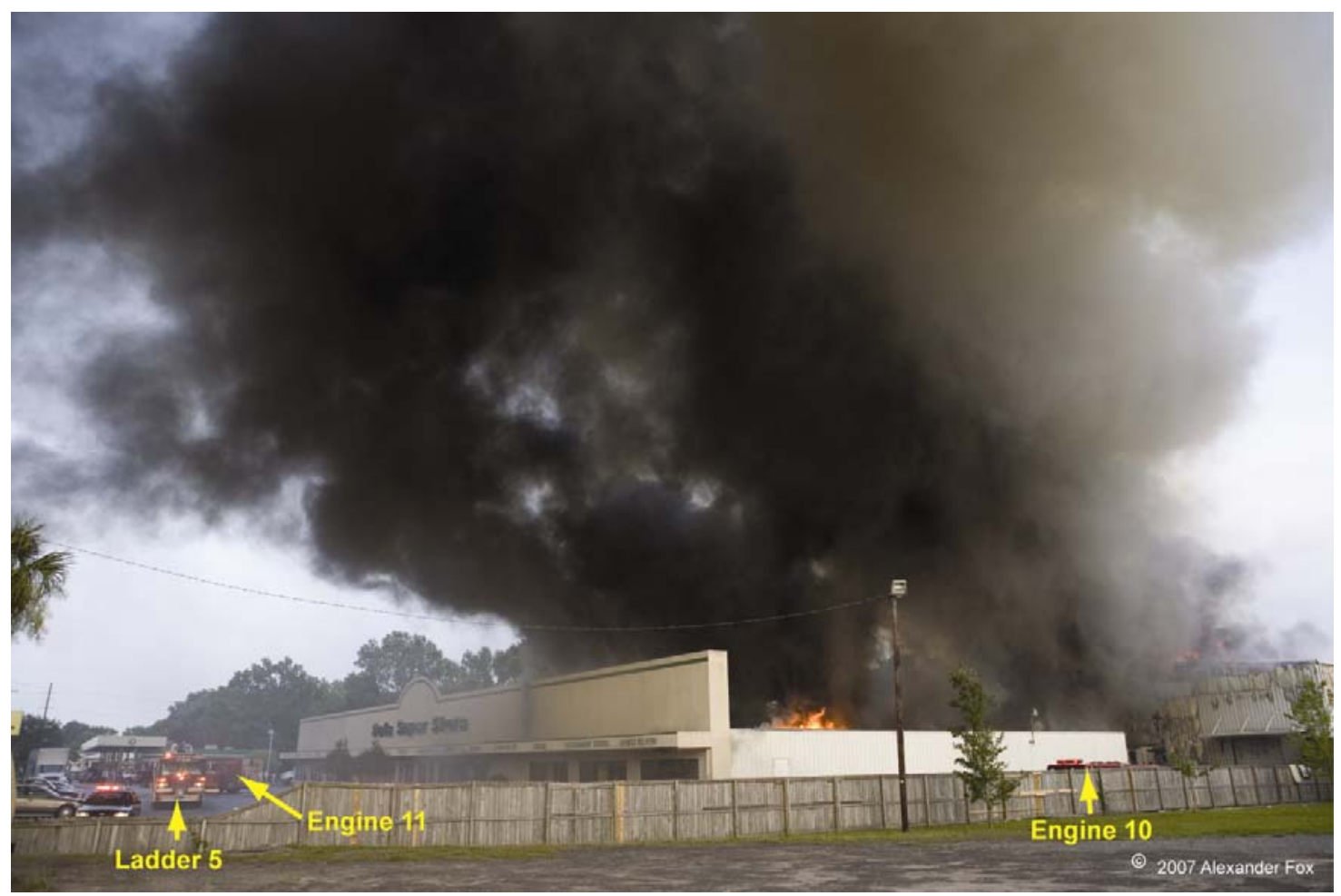

Figure 2-3. Engine 11 and Ladder 5 at front of Sofa Super Store. Engine 10 next to loading dock. Both engines connected to water supply. Photo taken at approximately 7:30 p.m. Background image used with permission of Alexander Fox. Enhancements by NIST. 
At approximately the same time, 7:27 p.m., dispatch notified the Fire Chief of a cell phone call from a man claiming to be trapped inside the store. The caller indicated to the fire department that he was an employee who worked in the repair shop. The roll-down fire door in the breezeway had closed and prevented the employee from escaping the warehouse/repair shop areas. The employee was banging on the wall with a hammer. The Fire Chief radioed the AC and directed him to respond to the trapped employee. Since at this stage in the fire, all the fire fighters and chiefs were using the same radio channel, any fire fighter with a radio also would have heard the report of a trapped employee in the rear of the store. The AC asked the store manager if the trapped person was an employee of the store, and the store staff verified that the man was someone who repaired furniture for the store. The AC took a team of fire fighters and went around the east end of the store, chopped through a locked wooden gate, and located the employee banging on the metal wall (Figure 2-4). Using pry bars, the fire fighters were able to create an opening in the metal wall and extract the trapped employee. After 7:31 p.m., the AC, rescue team, and rescued employee returned to the front of the store.

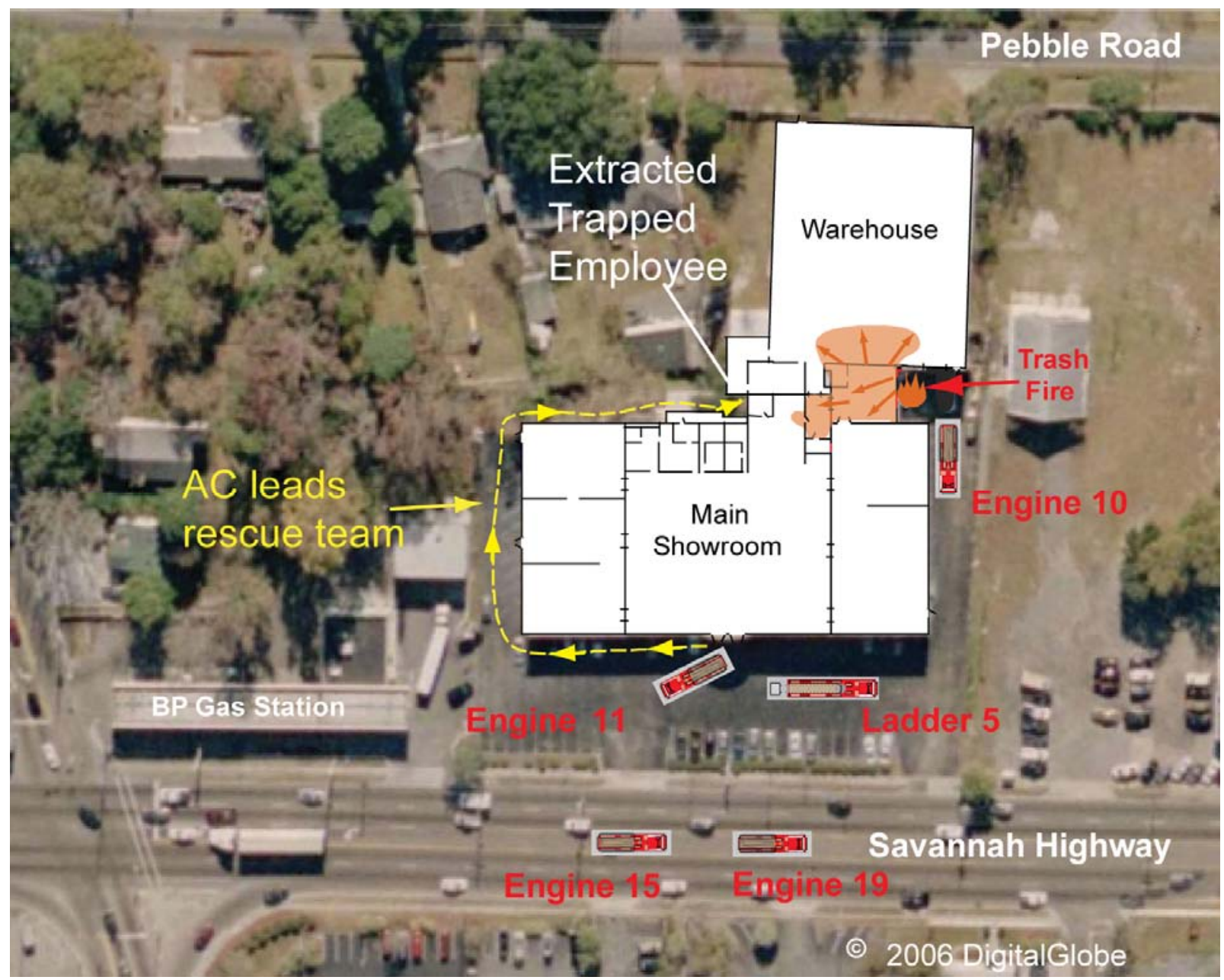

Figure 2-4. An Assistant Chief directed rescue of the trapped employee. The team moved around the east side of the store and located the trapped employee at the rear of the store. This occurred between approximately 7:27 p.m. and 7:31 p.m. Background image used with permission of DigitalGlobe. Enhancements by NIST. 
During the rescue effort at about 7:27 p.m., several inaudible radio communications suggested that fire fighters were lost or disoriented. Several minutes later, between 7:29 p.m. and 7:30 p.m., there were additional radio communications that were still difficult to understand, but seem to be one or more fire fighters asking for directions to exit or requesting assistance to escape. Other radio calls were interspersed with calls for help related to getting the trapped employee out. Beginning around 7:31 p.m., additional broken radio traffic more clearly indicated that several fire fighters were in distress. An unknown fire fighter called "Mayday," and dispatch advised the Fire Chief that the L-5 engineer had activated the emergency button on his radio. At 7:35 p.m., the Fire Chief radioed, “....we need to vacate the building."

By the time the AC returned to the front of the store from rescuing the trapped employee the fire conditions at the front of the store had changed dramatically. Brown smoke was flowing out of the front doors. At about 7:35 p.m., the front windows of the main showroom were vented and broken out. As clean air was drawn into the main showroom through the lower part of the broken windows, heavy brown smoke poured from the upper sections of the broken windows. Less than a minute later, the brown smoke changed to thick black smoke. The fire then spread rapidly from the southwest rear of the main showroom to the northwest front of the main showroom and out the front windows and to the east side of the main showroom and out through the front windows on the east side of the main showroom. The fire also spread rapidly into the west showroom through three roll-down fire doors that did not close. Nine fire fighters were trapped in the fire, resulting in their deaths.

The metal roof over the enclosed loading dock area partially collapsed and was supported by several remaining vertical wood columns. At approximately 7:51 p.m., the roof over the west side of the main showroom collapsed into the main showroom. Portions of the parapet wall and front façade collapsed onto the front parking lot. The fire continued to burn vigorously in the main showroom and eventually almost the entire roof over the main showroom collapsed onto the showroom floor. Post-fire photographs demonstrate that the fire consumed almost all the available fuel in the main showroom (Appendix D).

The fire had also spread into the west showroom and consumed most of the furniture in the front twothirds of the retail space. By approximately 7:50 p.m., the intense heat had caused the roof to sag to within $1.2 \mathrm{~m}(4 \mathrm{ft})$ of the floor in the front portion of the space (Appendix E, Figure E-11). Significant amounts of unburned furniture remained in the rear of the west showroom (Appendix E, Figure E-21).

The fire had also spread into the rear of the east showroom through the partially closed roll-down fire door (Figure 1-8, door \#7) at near the rear of the east showroom. Although significant amounts of merchandise were burned, the damage to the roof supports was limited and structural collapse did not occur in the east showroom.

The fire was brought under control after 10 p.m. Recovery operations continued until after 4:00 a.m. the next morning, June 19, 2007. 


\section{3}

\section{OVERALL INCIDENT TIME LINE}

The overall incident time line was assembled from the photographs, radio transmissions, interviews and other sources (Section 2.1.1).

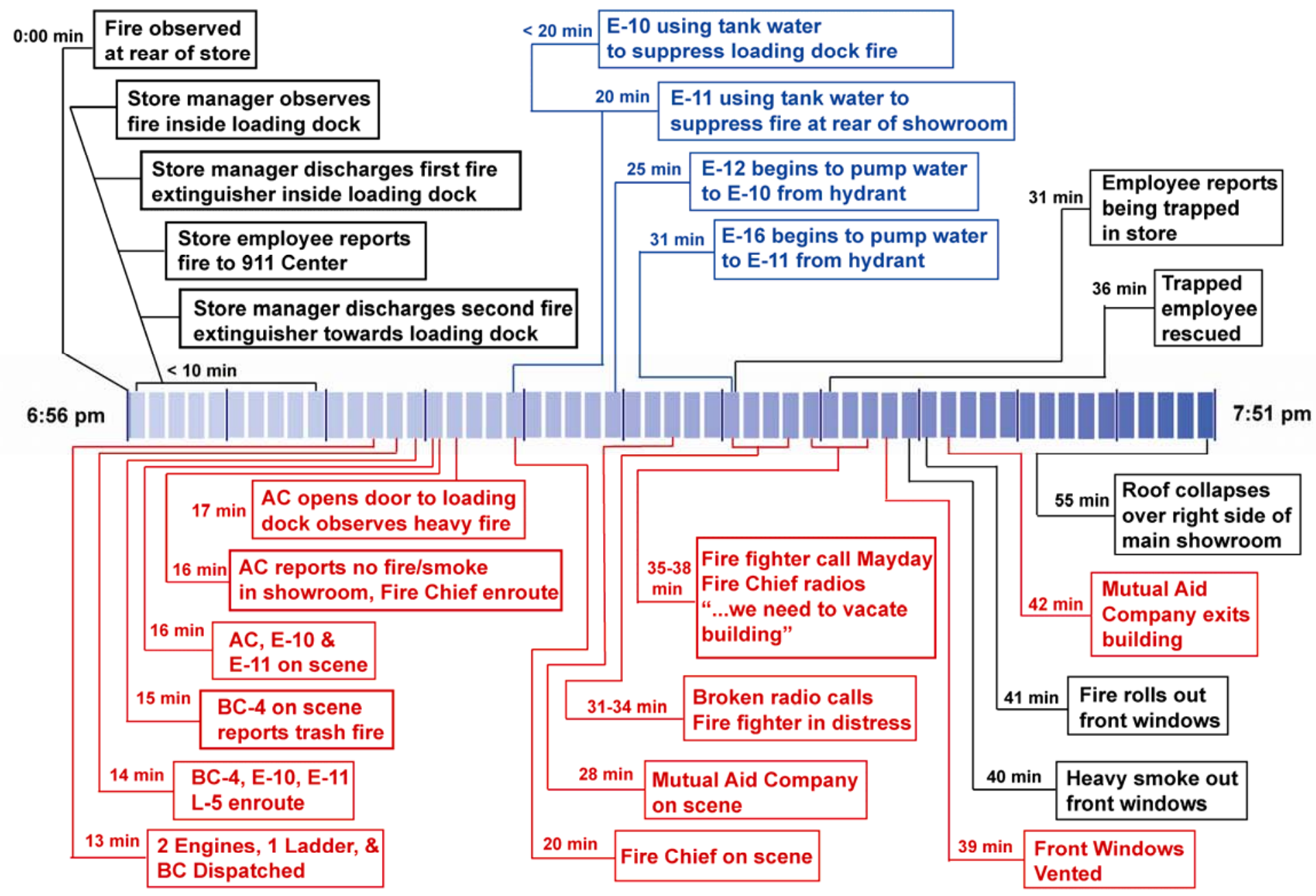

Figure 2-5. Overview time line of the Sofa Super Store Fire. Engine and ladder companies are designated by letter "E" and "L," respectively. For example, E-10 is Engine 10 and L-5 is Ladder 5. Assistant and Battalion Chiefs are designated "AC" and "BC". 


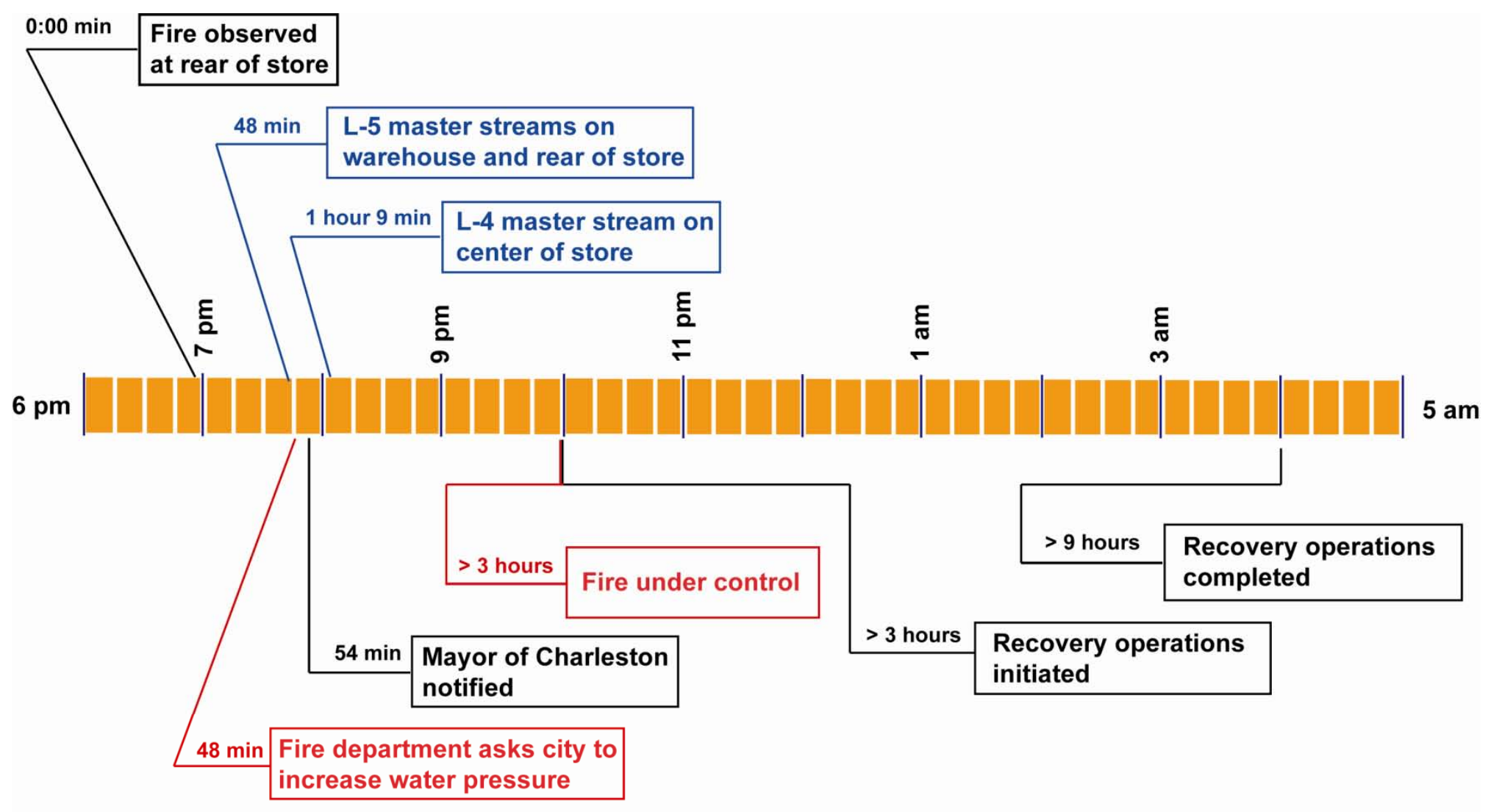

Figure 2-6. Overview time line of the Sofa Super Store Fire. Ladder companies are designated by letter "L," respectively. For example, L-5 is Ladder 5 . Items in red involved actions by fire department. Items in blue involved water suppression activities. 
Table 2-1. Incident Time Line. (Uncertainty is +l- 2 min)

\begin{tabular}{|c|c|c|}
\hline DST $^{*}$ & Fire Time & Description \\
\hline \multirow[t]{4}{*}{ 6:56 p.m. } & -15 & Fire observed at rear of store \\
\hline & & $\begin{array}{l}\text { Store manager discharges first extinguisher at fire on loading } \\
\text { dock }\end{array}$ \\
\hline & & Fire reported to 911 Center \\
\hline & & $\begin{array}{l}\text { Store manager discharges second fire extinguisher through } \\
\text { holding area door towards fire on loading dock }\end{array}$ \\
\hline 7:08 p.m. & -3 & Dispatch receives report of fire behind store \\
\hline 7:09 p.m. & -2 & $\begin{array}{l}\text { E-11, E-10, L-5, and BC-4 dispatched } \\
\text { E-10, E-11, L-5, and BC-4 en route } \\
\text { BC-4 confirms smoke plume } \\
\text { E-16 dispatched }\end{array}$ \\
\hline 7:11 p.m. & 0 & BC-4 on scene and reports trash fire outside store loading dock \\
\hline 7:12 p.m. & 1 & $\begin{array}{l}\text { AC, E-10, E-11 on scene } \\
\text { AC reports no fire/smoke in showroom } \\
\text { Fire Chief en route }\end{array}$ \\
\hline \multirow[t]{3}{*}{ 7:13 p.m. } & 2 & $\begin{array}{l}\text { E-12 dispatched } \\
\text { AC and E-11 crew at rear of west showroom } \\
\text { AC opens door and observes fire in loading dock } \\
\text { AC radios E-15 to come to scene }\end{array}$ \\
\hline & 3 & E-6 dispatched \\
\hline & 4 & $\begin{array}{l}\text { Fire Chief radios dispatch to send E-19 } \\
\text { E-10 using on board water to suppress fire on loading dock. } \\
\text { E-16 on scene }\end{array}$ \\
\hline \multirow[t]{2}{*}{ 7:16 p.m. } & 5 & $\begin{array}{l}\text { Fire Chief on scene } \\
\text { E-11 using on board water to suppress fire at rear of west } \\
\text { showroom }\end{array}$ \\
\hline & 6 & E-12 on scene, lay hose line to supply water to E-10 \\
\hline 7:20 p.m. & 9 & E-19 on scene \\
\hline
\end{tabular}

* Times are approximate and are rounded to the nearest minute. For comparison, NIOSH [14]truncated times to the minute.

† Engine and ladder companies are designated by letter "E" and "L", respectively. For example, E-10 is Engine 10 and L-5 is Ladder 5. Assistant and Battalion Chiefs are designated "AC” and "BC”. The Fire Chief is designated "Fire Chief”. 


\begin{tabular}{|c|c|c|}
\hline DST $^{*}$ & Fire Time & Description \\
\hline & 10 & $\begin{array}{l}\text { E-12 begins pumping water to E-10 at loading dock } \\
\text { E-16 looking for water hydrant on Savannah Highway }\end{array}$ \\
\hline & 11 & $\begin{array}{l}\text { E-6 on scene } \\
\text { E-11 radios that onboard tank is half empty }\end{array}$ \\
\hline \multirow[t]{2}{*}{ 7:24 p.m. } & 13 & $\begin{array}{l}\text { Fire Chief requests E-12 boost water pressure } \\
\text { BC-5 on scene } \\
\text { St. Andrew's Fire (Mutual Aid) Department on scene }\end{array}$ \\
\hline & 14 & $\begin{array}{l}\text { E-10 radios that onboard water tank is one quarter full } \\
\text { Fire Chief requests E-12 to boost water pressure }\end{array}$ \\
\hline \multirow[t]{2}{*}{ 7:27 p.m. } & 16 & $\begin{array}{l}\text { E-16 begins pumping water to E-11 at front of store } \\
\text { Dispatch notifies Fire Chief of cell phone call from trapped } \\
\text { employee } \\
\text { Fire Chief directs AC to respond to trapped employee } \\
\text { 2.5” hose line in operation at warehouse } \\
\text { Inaudible radio transmissions - "lost or trapped inside” }\end{array}$ \\
\hline & $18-19$ & $\begin{array}{l}\text { Inaudible radio transmissions- "which way out or everyone out" } \\
\text { E-11 radios 2.5” hose line is charged } \\
\text { Distress radio calls, "need help out" and "need help getting out" }\end{array}$ \\
\hline $\begin{array}{l}\text { 7:31 p.m. } \\
\text { to } \\
\text { 7:34 p.m. }\end{array}$ & $20-23$ & $\begin{array}{l}\text { Fire Chief requests dispatch of E-3 } \\
\text { L-5 repositioned to west side of store } \\
\text { BC-5 reports trapped employee rescued } \\
\text { Fire fighter calls “Mayday” } \\
\text { Fire Chief radios, “....we need to vacate the building” } \\
\text { Dispatch notifies Fire Chief that L-5 engineer activated } \\
\text { emergency button }\end{array}$ \\
\hline 7:35 p.m. & 24 & Front windows vented, brown smoke pours out broken windows \\
\hline 7:36 p.m. & 25 & Thick black smoke rolls out front windows \\
\hline 7:37 p.m. & 26 & $\begin{array}{l}\text { Fire rolls out front windows } \\
\text { E-13 dispatched }\end{array}$ \\
\hline \multirow[t]{2}{*}{ 7:38 p.m. } & 27 & $\begin{array}{l}\text { Fire Chief radios "Everybody abandon the building” } \\
\text { E-11 air horns sounded to signal evacuation }\end{array}$ \\
\hline & & $\mathrm{BC}-\mathrm{T}^{*}$ radios $\mathrm{E}-16$ to boost water pressure \\
\hline
\end{tabular}

${ }^{*} \mathrm{BC}-\mathrm{T}$ is the Battalion Chief in charge of Training Section. 


\begin{tabular}{|c|c|l|}
\hline DST $^{*}$ & Fire Time & \multicolumn{1}{|c|}{ Description } \\
\hline & 29 & St. Paul's Fire Company laying hose to L-5 \\
\hline $7: 44$ p.m. & 33 & E-13 on scene \\
\hline $7: 48$ p.m. & 37 & AC requests dispatch to call water department to boost pressure \\
\hline $7: 50$ p.m. & 39 & Ladder 4 dispatched \\
\hline 7:51 p.m. & 40 & Fire Chief requests dispatch to notify Charleston Mayor \\
\hline 8:05 p.m. & $\begin{array}{c}54 \\
(1 \text { hour \& } 9 \\
\text { minutes })\end{array}$ & Master stream off ladder platform still operating \\
\hline $10: 00$ p.m. & $\begin{array}{c}176 \\
(3 \text { hours \& } \\
11 \text { minutes })\end{array}$ & Fecovery operations begin \\
\hline 04:00 a.m. & $\begin{array}{c}536 \\
(9 \text { hours \& } \\
11 \text { minutes })\end{array}$ & Recovery operations continue \\
\hline
\end{tabular}

\subsection{FIRE IGNITION, GROWTH, AND SPREAD}

The fire began in a pile of trash and discarded furniture, which had accumulated on the asphalt outside the loading dock area. The fire spread into or through a wall that had an exterior surface of metal siding, wood studs and framing, and an interior surface of plywood and/or gypsum board. Store merchandise was staged on the enclosed loading dock for delivery over the next several days. Since there were six trucks utilized to deliver merchandise to customers, there could have been multiple sofas, futons, loveseats, chairs, tables, rugs, dressers, and mattresses inside the loading dock for delivery (Figure 1-14). As the fire spread into the enclosed dock, these furniture items provided additional fuel in addition to the wood framing, synthetic carpeting, and wooden deck of the dock itself.

The fire spread from the loading dock through the open loading dock door into the holding area. The fire spread more quickly to the interior of the warehouse than to the rear of the west showroom because of differences in wall construction. As the fire grew inside the loading dock, the energy from the fire heated up the metal siding of the warehouse and rear of the west showroom. At the rear of the west showroom, the interior surface was gypsum board mounted on metal studs (Appendix E, Figures E-23 and E-24). Due to the structural steel in the rear wall of the west showroom and the metal studs, there was a concealed space of at least $15 \mathrm{~cm}$ (6 in) between the metal siding on the outside loading dock side and the interior gypsum wall. This concealed space helped provide an insulating volume that slowed the transfer of energy from the hot metal siding into the rear of the west showroom. On the other hand, the warehouse wall did not appear to have an interior surface of gypsum board (Appendix G, Figures G-15 and G-18), so the energy from the hot metal siding of the warehouse was transferred more quickly to combustibles inside the warehouse. The fire spread through the loading dock and into the 
holding area and warehouse is shown qualitatively in Figure 2-4. Additional animated images of the fire spread are presented in Chapter 4 and Appendix K of this report.

From the holding area, the fire spread into the rear or southwest corner of the main showroom. The rolldown fire door between the holding area and the warehouse closed and prevented the fire from spreading from the holding area to the warehouse. The fire growth is shown qualitatively in Figure 2-7 and estimated to have occurred around 7:31 p.m. It is not clear how the fire spread or moved into the rear of the main showroom. Smoke and flames were flowing from the loading dock into the holding area and into the interstitial space above the suspended ceiling above the main showroom. There did not appear to be significant fuel in this interstitial space, below the metal decking of the roof and above the suspended ceiling. The hot gases could have ignited items and these items could have dropped through the ceiling into the main showroom and ignited furniture. The fire could also have penetrated the partition wall between the holding area and the rear of the main showroom. The wall was constructed of gypsum board mounted on both sides of metal studs. Or, it is possible that the fire moved through a metal door into the rear of the main showroom. While the exact path is not understood, the fire did spread into the rear of the main showroom, which resulted in additional furniture being ignited.

Partially burned fuel in the form of smoke and combustible gases from the fire on the loading dock filled the interstitial space above the ceiling in the main showroom, and the smoke began to flow through ventilation openings down into the main showroom. At about the same time, the fire spread from the holding area into the rear of the main showroom. The smoke being generated by the fire in the rear of main showroom and the smoke flowing down through the ceiling was forming a layer of unburned fuel below the ceiling of the main showroom. At this stage, the fire did not have access to sufficient oxygen to burn completely.

The smoke layer in the main showroom continued to thicken and as the layer dropped further down, the visibility in the showroom decreased dramatically. In order to improve visibility, the fire fighters broke the front windows and allowed smoke to flow out of the showroom. However, breaking the windows also allowed additional air to flow into the main showroom. As this air flowed to the rear of the main showroom, the fire had additional oxygen and began to burn more intensely. The increased burning rate of the fire released additional energy, increased the temperature of the smoke layer, and ignited the layer of smoke and partially burned fuel below the ceiling in the main showroom.

The fire spread extremely rapidly from the rear of the main showroom toward the front of the west side of the main showroom. The fire first appeared at the front windows of the main showroom at approximately 7:36 p.m. and is qualitatively shown in Figure 2-8. Moments later the fire moved toward the east side of the main showroom as shown in Figure 2-9. The three roll-down fire doors between the main showroom and west showroom (doors \#2, \#3, \#4 in Figure 1-8) did not close, and this allowed the fire to move from the main showroom into the west showroom (Figure 2-10). On the east side of the main showroom, two roll-down fire doors near the front of the store (doors \#5 and \#6 in Figure 1-8) did close, and the third fire door near the rear of the showroom (door \#7 in Figure 1-8) closed only about one-third of the way down. The fire did not spread through the closed fire doors, but did spread through the partially closed fire door into the rear of the east showroom. 


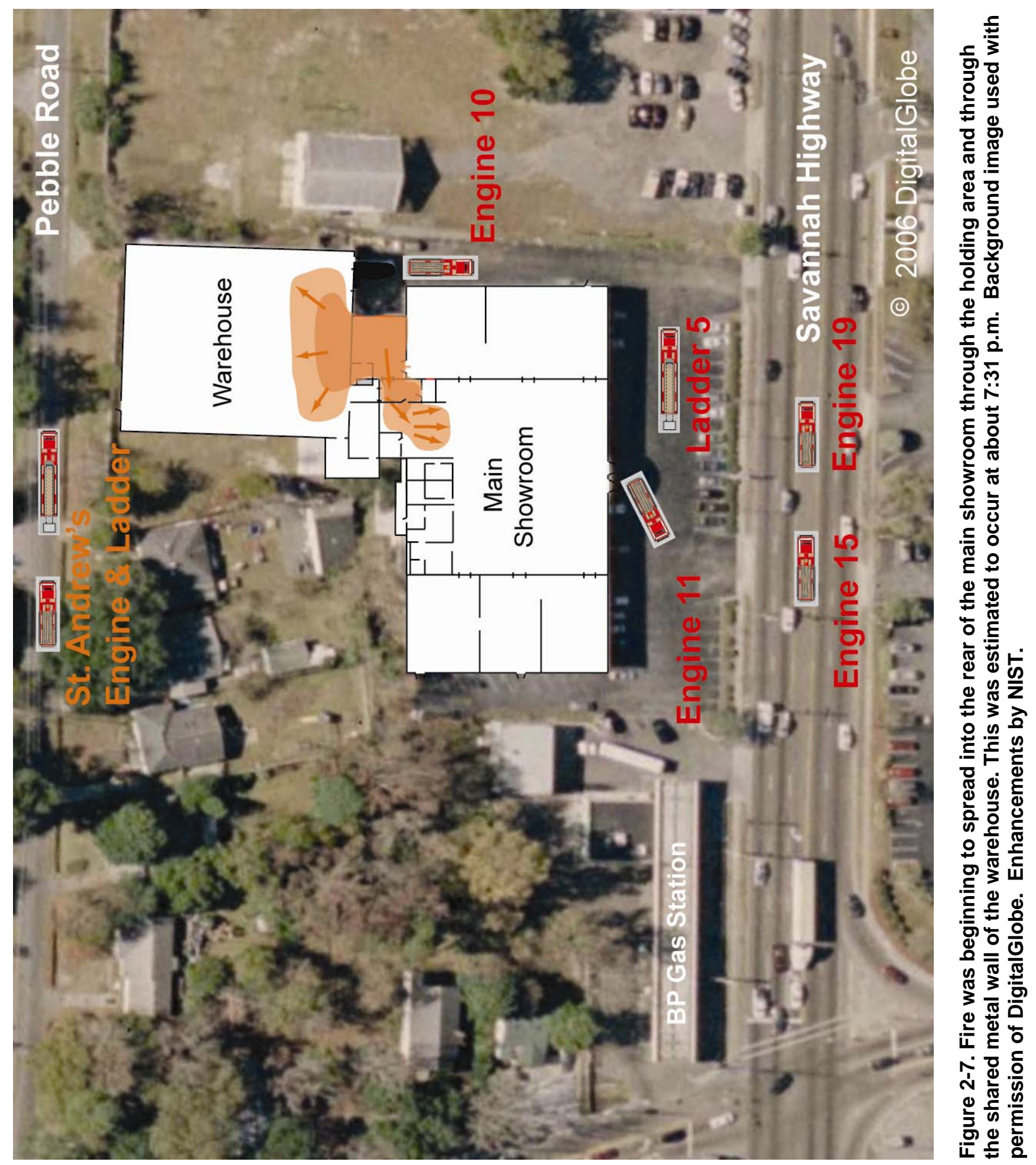




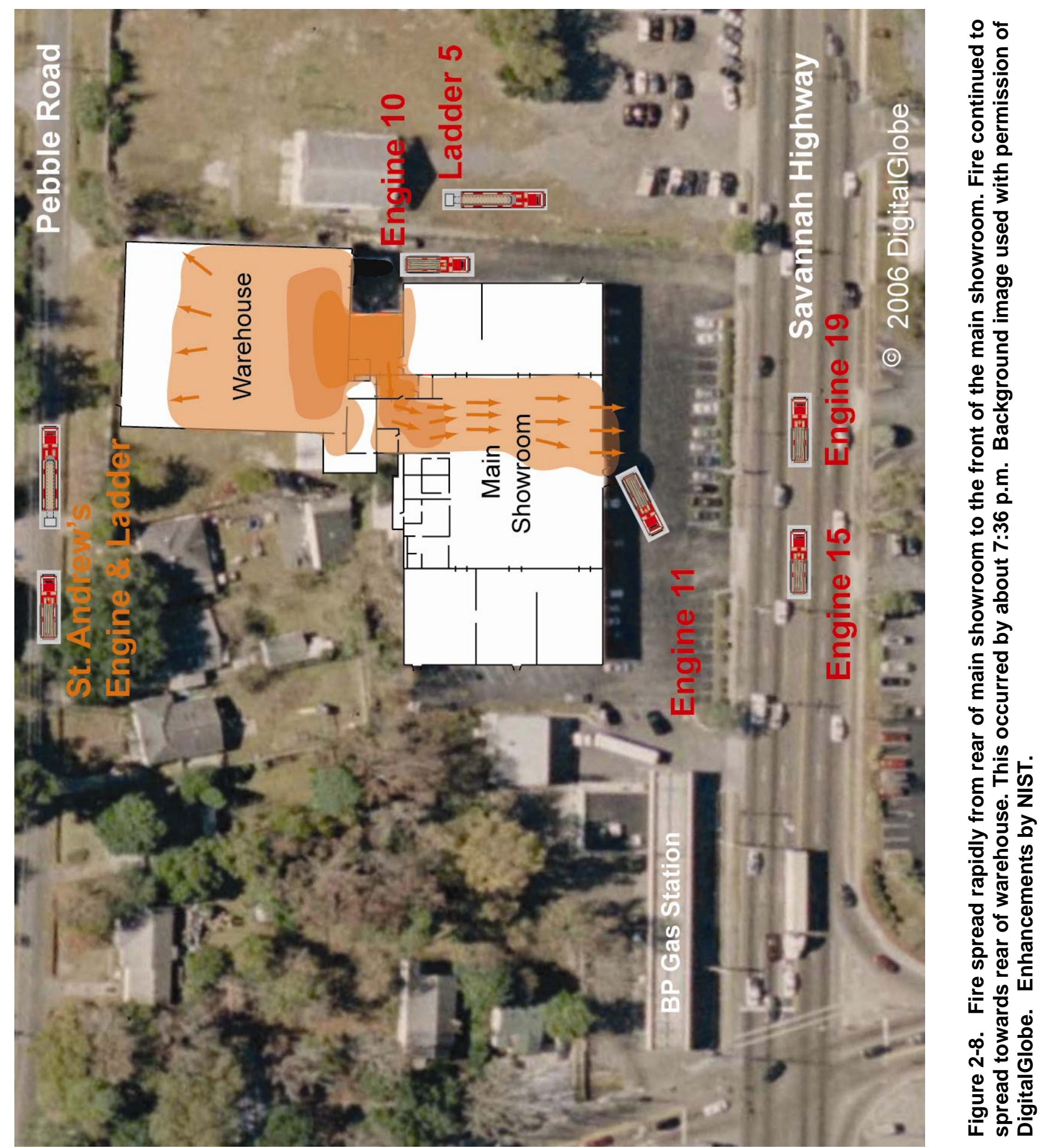




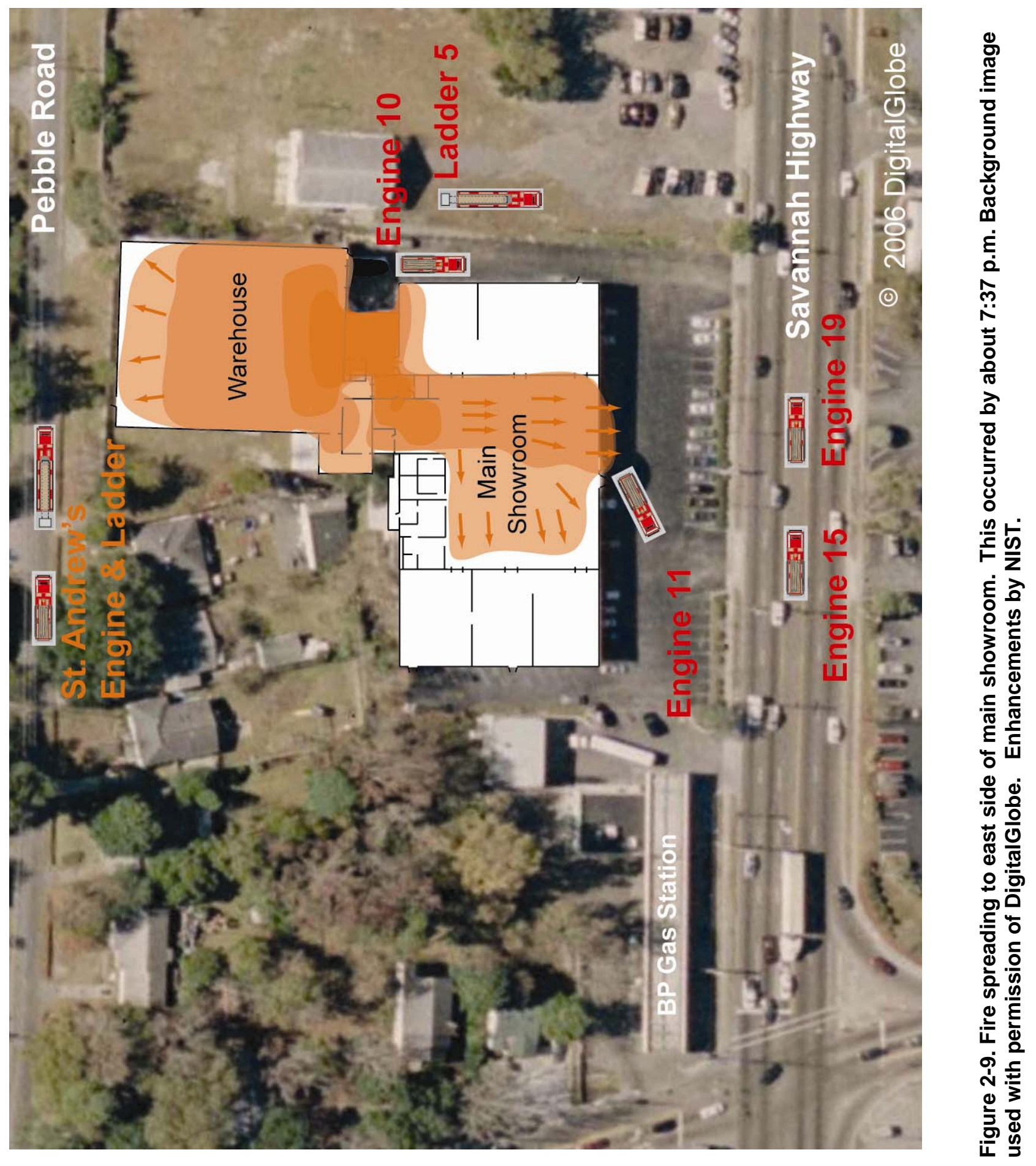




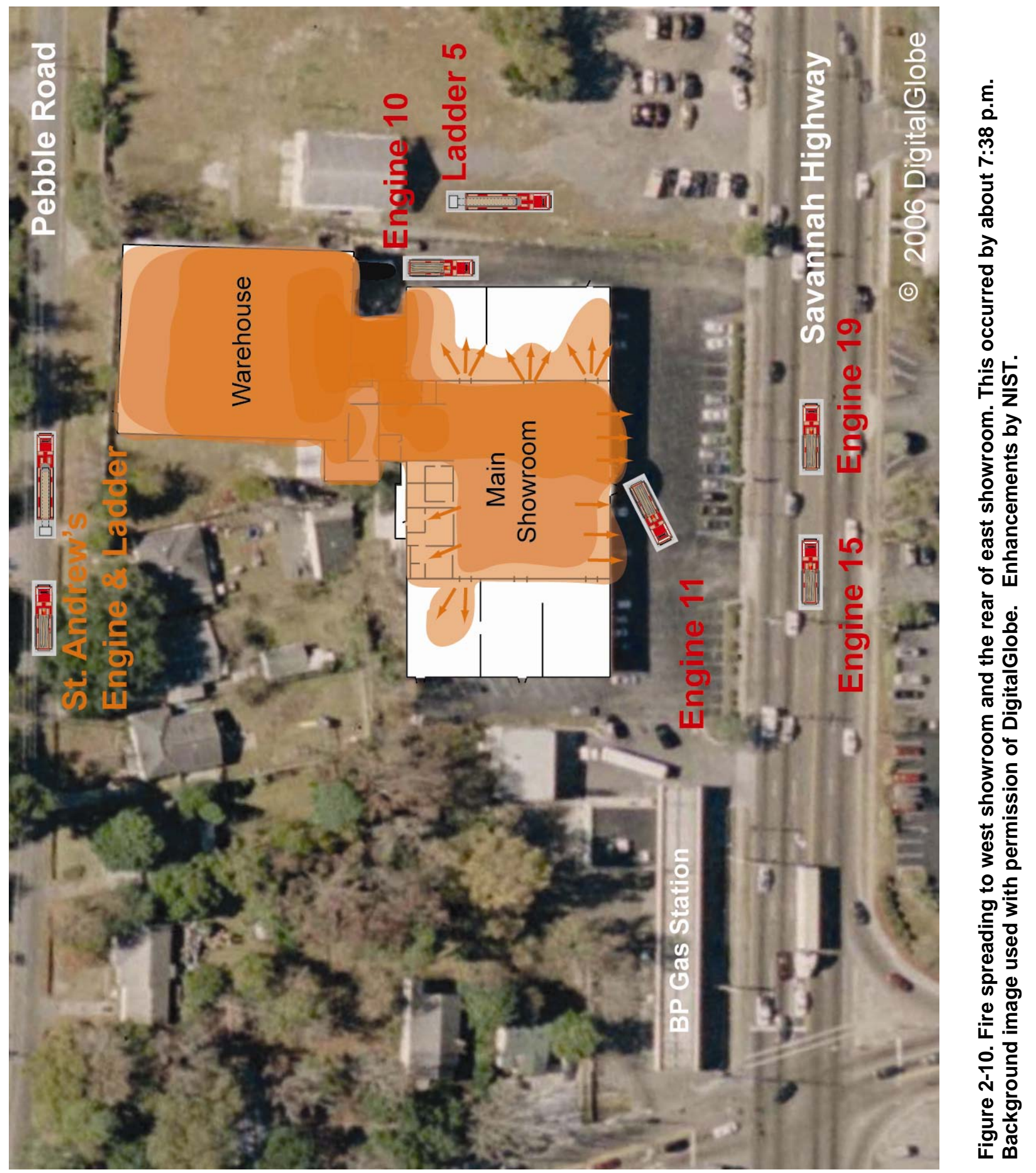




\section{$2.5 \quad$ WEATHER}

Weather data were recorded about $13.6 \mathrm{~km}$ (8.5 miles) north of the store at the Charleston International Airport. The conditions from approximately the beginning of the fire to the end of suppression activities are tabulated in Table 2-2. Additional weather data for June 18, 2007 are tabulated in Appendix A [16].

From photographs that were taken during the fire, such as Figures 1-7 and 2-3, the smoke plume appeared to move from the rear of the warehouse toward the front of the showrooms, which is consistent with a wind blowing from the south (warehouse) toward the north (front of store).

Table 2-2. Weather Data for Sofa Super Store Fire.

\begin{tabular}{|l|c|c|c|c|}
\hline Weather Data & $\begin{array}{c}\text { June 18, } 2007 \\
6: 56 \mathrm{p} . \mathrm{m} .\end{array}$ & $\begin{array}{c}\text { June 18, 2007 } \\
7: 56 \mathrm{p} . \mathrm{m} .\end{array}$ & $\begin{array}{c}\text { June 18, 2007 } \\
8: 56 \mathrm{p} . \mathrm{m} .\end{array}$ & $\begin{array}{c}\text { June 18, } 2007 \\
9: 56 \mathrm{p} . \mathrm{m} .\end{array}$ \\
\hline Sky Conditions & Few clouds & Clear & Clear & Few clouds \\
\hline Temperature & $27.8^{\circ} \mathrm{C}\left(82^{\circ} \mathrm{F}\right)$ & $26.1^{\circ} \mathrm{C}\left(79^{\circ} \mathrm{F}\right)$ & $25.6^{\circ} \mathrm{C}\left(78^{\circ} \mathrm{F}\right)$ & $25.6^{\circ} \mathrm{C}\left(78^{\circ} \mathrm{F}\right)$ \\
\hline Relative Humidity & $69 \%$ & $82 \%$ & $85 \%$ & $79 \%$ \\
\hline Wind Speed & $4.0 \mathrm{~m} / \mathrm{s}(9 \mathrm{mph})$ & $4.5 \mathrm{~m} / \mathrm{s}(10 \mathrm{mph})$ & $4.5 \mathrm{~m} / \mathrm{s}(10 \mathrm{mph})$ & $3.6 \mathrm{~m} / \mathrm{s}(8 \mathrm{mph})$ \\
\hline Wind Direction & $190^{\circ}$ & $190^{\circ}$ & $200^{\circ}$ & $190^{\circ}$ \\
(from near south) & (from near south) & $\begin{array}{c}\text { southwest) } \\
\text { (from near south) }\end{array}$ \\
\hline
\end{tabular}

\footnotetext{
* Weather data definitions and descriptors are provided on the National Climatic Data Center website, http://cdo.ncdc.noaa.gov/gcldc/QCLCD [16].
} 


\section{$2.6 \quad$ REFERENCES FOR CHAPTER 2}

[1] “Smoky Death,” The Evening Independent Newspaper, St. Petersburg, FL, Dec. 28, 1979.

[2] “Ten Inmates killed in fire at historic jail,” The Ledger Newspaper, Lakeland, FL, Dec. 28, 1979.

[3] Video images recorded during the fire by Howard Armstrong and John Pundt.

[4] Video images recorded after the fire by the NIST Team.

[5] Digital photographs taken during fire by private individuals including Stewart English and Alexander Fox.

[6] Digital photographs taken during and after the fire by law enforcement organizations including the Charleston Police Department and Charleston County Sheriff's Office.

[7] Digital photographs taken during and after the fire by news outlets including The Post and Courier and Associated Press.

[8] Digital photographs taken after the fire by the NIST Team.

[9] Interviews of fire fighters conducted by National Institute for Occupational Safety and Health (NISOH). Interviews organized by the NIOSH investigation team and the NIST team allowed to participate. Interviews included fire fighters from Charleston, St. Andrews, and St. James Island Fire Departments.

[10] Informal discussion between store employees and the NIST team.

[11] Radio Transmissions and Phone Call Transcript Sofa Super Store - Charleston, SC, June 18, 2007. Released by City of Charleston on Aug. 10, 2007. Audio recordings available at http://www.postandcourier.com/news/2007/aug/10/911_tapes_sofa_store_fire_be_released _afternoon/ .

[12] Articles from a number of news outlets including The Post and Courier, Associated Press, Fire Engineering, washingtonpost.com, MSNBC.com, charlston.net, and ENR_com News. A listing of articles that were reviewed was placed in Appendix Q.

[13] Sofa Super Store Fire - Report of Investigation, ATF National Response Team Origin and Cause Report, Investigation 763010-07-0172, Report 32, June 22, 2007.

[14] Fatality Assessment and Control Evaluation Investigation Report \#F2007-18, National Institute for Occupational Safety and Health, Fire Fighter Fatality Investigation and Prevention Program, Morgantown, WV, February 2009. http://www.cdc.gov/niosh/fire/pdfs/face200718.pdf.

[15] “Fire Fighter Fatality Investigative Report, Sofa Super Store, 1807 Savannah Highway, Charleston, South Carolina, June 18, 2007,” City of Charleston Post Incident Assessment and Review Team, Phase II Report, June 2008.

[16] National Climatic Data Center - http://cdo.ncdc.noaa.gov/gcldc/QCLCD. 


\section{Chapter 3 EMERGENCY INCIDENT RESPONSE}

\subsection{INTRODUCTION}

\subsubsection{General}

The overall incident time line presented in Chapter 2 summarized the fire events from a broad perspective. The following overview of the emergency incident response focuses on the sequence of events from the first responders' perspective. By identifying the observations and actions of the fire fighters, insight can be gained about how the fire spread through the Sofa Super Store. With the additional insight, this overview builds and extends upon the time line in Chapter 2.

While this overview notes key tactical challenges facing the fire department and how they responded, the NIST study addressed the emergency response only as needed to reconstruct the behavior and time line of the fire. Additional analysis of the fire department response and recommendations were reported in the National Institute for Occupational Safety and Health Line of Duty Death Report 2007-18 [1], the City of Charleston Post Incident Assessment and Review Team, Phase II Report [2], and South Carolina Office of Occupational Safety and Health (SC-OSHA) Report of S.C. OSHA Findings in June 18, 2007 Charleston Sofa Super Store Fire [3].

\subsubsection{Collection of Incident Response Data}

In the process of developing this overview of incident response, the NIST team collected data from a range of sources including: video recordings [4], digital photographs [5-7], interviews of fire fighters [8], radio and cell phone recordings and transcripts [9], and investigative reports [1-3, 10].

Video recordings and digital photographs provided information about fire fighter actions during the incident. If these images were time stamped or linked to specific events where the time was known then the information was incorporated into this overview of incident response. Since none of the photographers or videographers was present before the fire, neither the video nor the digital photographs captured the initial actions of the Charleston Fire Department (CFD). All of the digital photographs and video were recorded outside the structure and did not provide images of fire fighter activities inside the store.

Interviews with fire fighters provided information about their activities inside and outside the structure. For inside the structure, the information included: where the fire was located, how they entered the showroom, what the interior conditions were, how they pulled hose lines, when they ran out of air, and how they exited the structure. Exterior operational information included: where the fire equipment (engines and ladder trucks) was positioned, where water lines were connected to hydrants, how the fire was or was not spreading, and how rescue attempts were conducted. The information provided by the fire fighters was critical to developing this overview of the fire service response.

In combination with the interview information, the CFD radio transmissions allowed the response of CFD to be confirmed and linked to the time line. For the CFD, the arrival time of the fire companies, the Fire Chief, and additional support was documented via the radio transmissions with central dispatch. The CFD used a different radio system than the surrounding mutual aid fire departments and CFD radio recordings did not include any transmissions from mutual aid departments. 
Investigative reports from National Institute for Occupational Safety and Health (NIOSH) [1], the Post Incident Assessment and Review Team [2], South Carolina Occupational Safety and Health Administration (SC-OSHA), and Bureau of Alcohol, Tobacco, Firearms and Explosives (ATF) [10] were carefully reviewed and provided critical insight into fire service response. Specifically, the reports identified specific actions of the fire service at specific times both inside and outside the structure and those time-linked actions were invaluable in developing the overall incident response.

\subsection{CHARLESTON FIRE DEPARTMENT}

The Charleston Fire Department (CFD) provides fire suppression services to a community of approximately 108,000 people [11]. Emergency medical services are provided for the City of Charleston by two surrounding counties, Charleston and Berkeley. Charleston is situated geographically in the south east portion of the state where the Cooper and Ashley rivers intersect and flow into the Atlantic Ocean. The city of North Charleston is to the north of Charleston, and Mount Pleasant is to the east (Figure 3-1). Covering an area of $236 \mathrm{~km}^{2}$ (91 square miles), Charleston is divided into six distinct areas or subdivisions, the Peninsula/Downtown, West Ashley, Johns Island, James Island, Daniel Island, and Cainhoy Peninsula. The Sofa Super Store was located in the West Ashley subdivision as shown in Figure 3-1. The location of a number of fire stations, some of which are CFD stations and others that are mutual aid departments, North Charleston, Mt. Pleasant, St. Andrew's, and James Island are also shown in Figure 3-1. The fire stations that were located nearest to the Super Sofa Store are shown in Figure 3-2 (street map) and Figure 3-3 (aerial view). As shown in Figure 3-4, the jurisdictional boundaries between the municipal and unincorporated areas were intermingled. Adjoining properties in the same block could be in different jurisdictions. In the past, this led to situations where the first units to arrive at an incident were from outside their jurisdiction.

The department's approximately 237 uniformed personnel operated from 14 stations with a combined response capability of 16 engine companies and three ladder companies [12]. The Fire Chief supervises three Assistant Chiefs (AC) and twelve Battalion Chiefs (BC), who command three shifts and work 24 hours on and 48 hours off. When fully staffed, each apparatus was assigned four fire fighters; a captain, an engineer/driver and two fire fighters [12]. Depending on staffing availability for each shift, stations were routinely operated with three fire fighters (captain, engineer/driver, and a fire fighter). On June 18, 2007, the department had 61 fire fighters, four BC, and an AC on-duty.

A fire department or municipality can develop the minimum recommended complement of engine and truck company personnel by using the National Fire Protection Association (NFPA) Standards 1500 [13] and 1710 [14]. Compliance with NFPA 1500 requires that a fire department develop and adopt a comprehensive risk management plan to identify and evaluate potential hazards. The risk management plan would have identified the Sofa Super Store as a low-, medium-, or high-hazard occupancy. For low hazard occupancies, compliance with NFPA 1710 advocates a minimum crew of four members operating from each type of apparatus. With the total floor space of $4700 \mathrm{~m}^{2}\left(50,400 \mathrm{ft}^{2}\right)$ and combustible merchandise, the Sofa Super Store probably would have been identified as a medium- to high-hazard occupancy. For high hazard occupancies, the standard advocates a minimum crew of five or six members operating from each type of apparatus. Unit staffing levels directly affect the fire fighting crew's tactical performance capabilities, the speed at and duration of which they can be relied upon to accomplish 


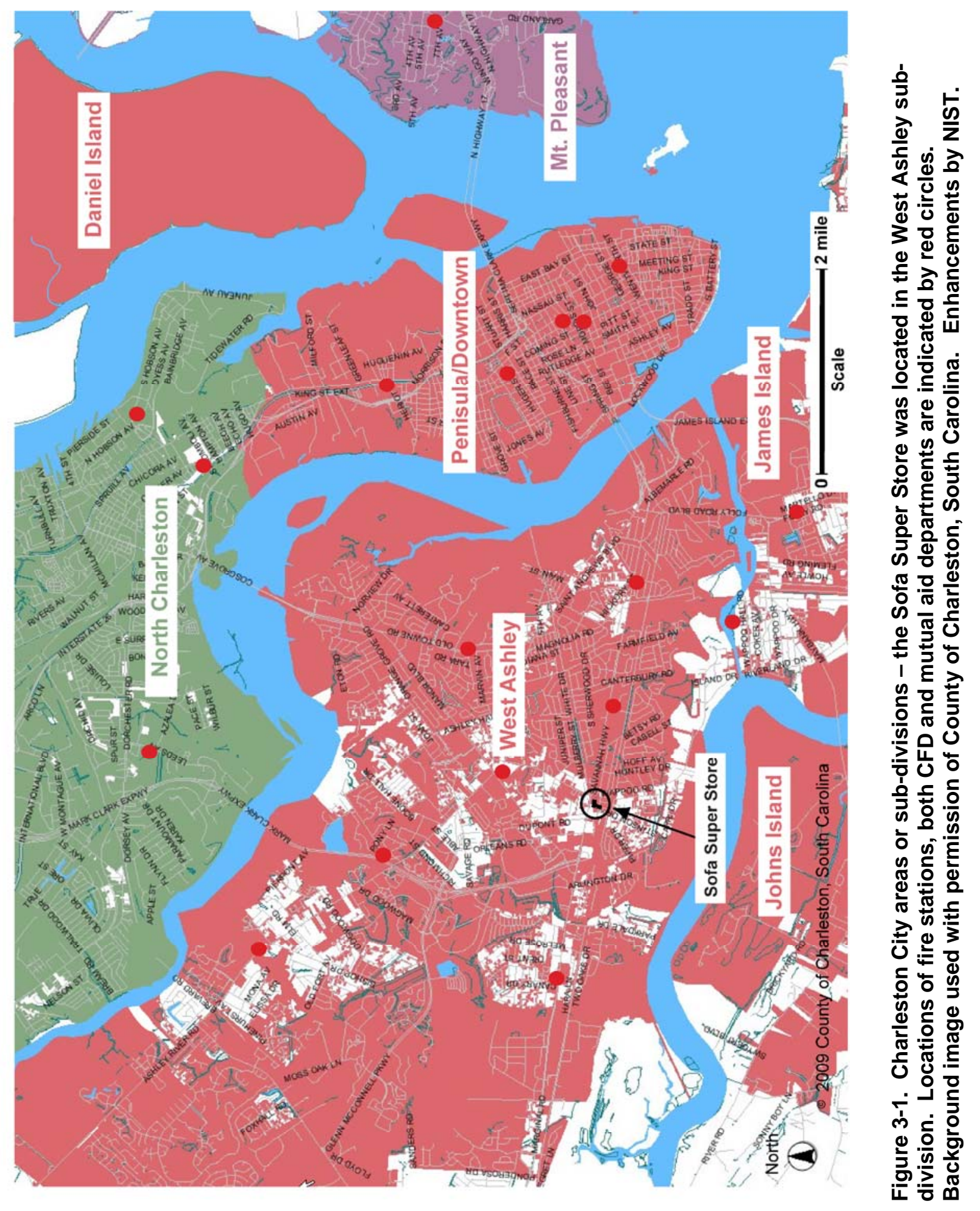


various tasks, such as establishing water supply, advancing hose lines, or effecting rescues, as well as the overall scope and effectiveness of the tactical intervention strategy being applied in a given situation.

In the past, the CFD inspected the Sofa Super Store, assessed fire hazards associated with store, and noted locations of electrical and gas supply (Appendix M). In addition, as part of pre-planning for buildings within their response area, the first due companies, Engines 11 and 10 and Ladder 5 inspected Sofa Super Store. Their inspection noted a hydrant location to the rear of the warehouse on Pebble Road at the intersection with Sarah Road (Appendix M). The inspection did not identify new additions to the structure, the lack of a fire door between the holding area and loading dock, the lack of a suspended ceiling above the holding area, the wood construction of the loading dock, or the solvents stored on the loading dock. The frequency of the inspections could not be documented. The training and qualification of inspection team members to a national standard, such as NFPA 1031, Professional Qualifications for Fire Inspector and Plan Examiner [15], could not be documented. Professional qualification may be demonstrated through a nationally accepted certification examination, such as the Fire Plan Examiner [16]; Fire Inspector I and II [17,18], and Certified Fire Marshal [19].

CFD procedures indicated that for fires involving structures less than five stories in height, the first alarm assignment was two engine companies, a ladder truck company, and a BC [1, 8]. For structures over five stories, the first alarm assignment was three engines, a ladder truck, a BC, and an AC. Procedures also stated that a confirmed report of smoke would trigger the assignment of an additional engine company. When a ranking officer arrived on the fire ground, that officer automatically became the incident commander. A captain arriving with an engine or truck company would be incident commander until a $\mathrm{BC}$, AC, or Fire Chief arrived in which case the ranking officer would automatically become the incident commander. Once on the scene, an incident commander could request additional fire companies as incident conditions warranted.

\subsection{FIRE SERVICE RESPONSE}

\subsubsection{Initial Alarm}

A driver on the Savannah Highway observed a smoke plume/fire at the rear of the west showroom of the Sofa Super Store at approximately 6:56 p.m. The driver notified the store manager who walked back to the loading dock area and observed a fire near the ceiling in the loading dock area. The manager discharged a portable fire extinguisher but was not able to extinguish the fire. The manager returned to the main showroom and instructed an employee to call 911. The manager located a second portable fire extinguisher and returned to the holding area. Because of the heat and smoke from the fire on the loading dock, he was unable to enter the loading dock through the open roll-down door between the holding area and the loading dock, but discharged the extinguisher towards the fire through the open door. The manager heard the roll-down fire door (Figures O-5, O-6, and O7) to the warehouse close before he returned to the showroom. 


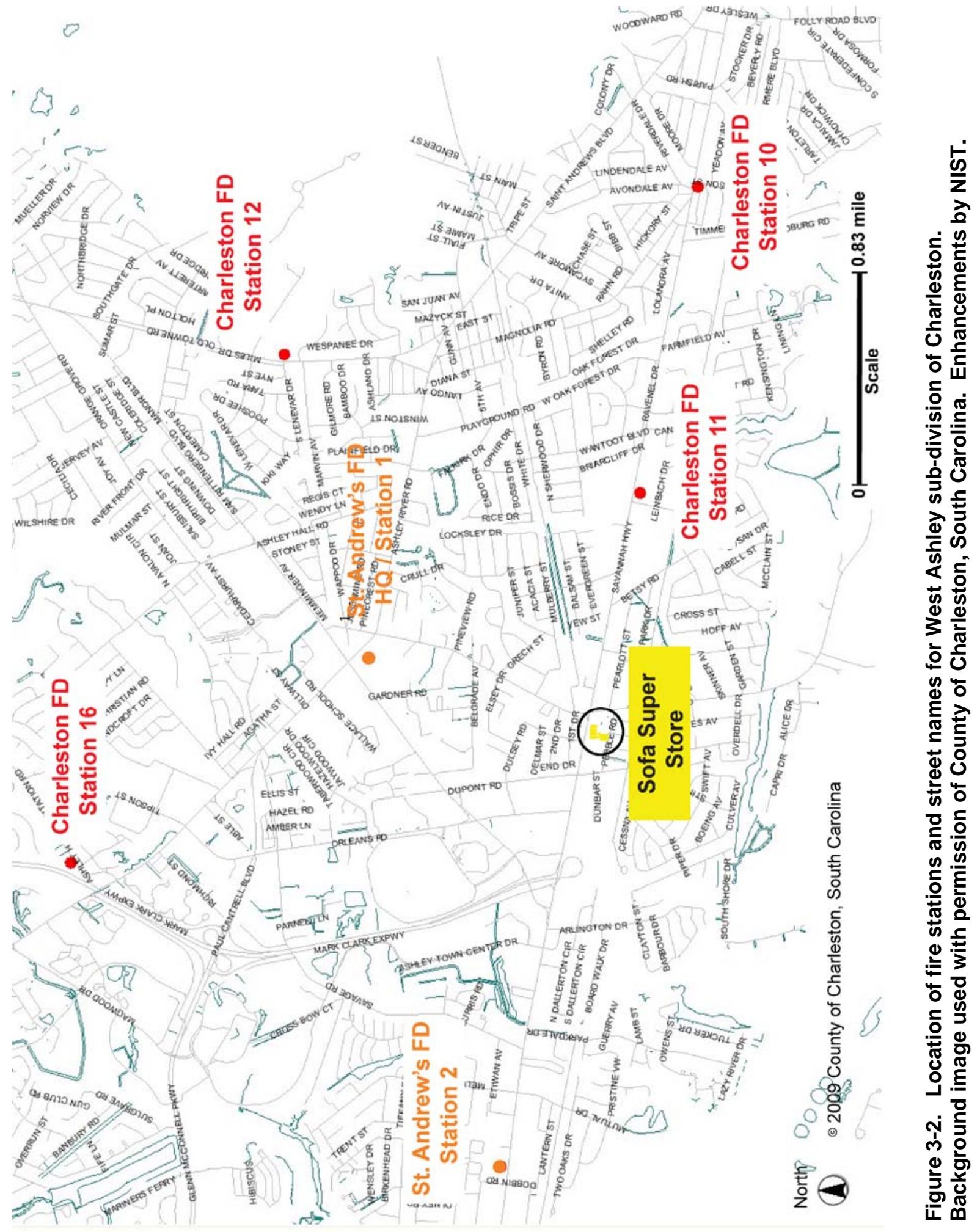




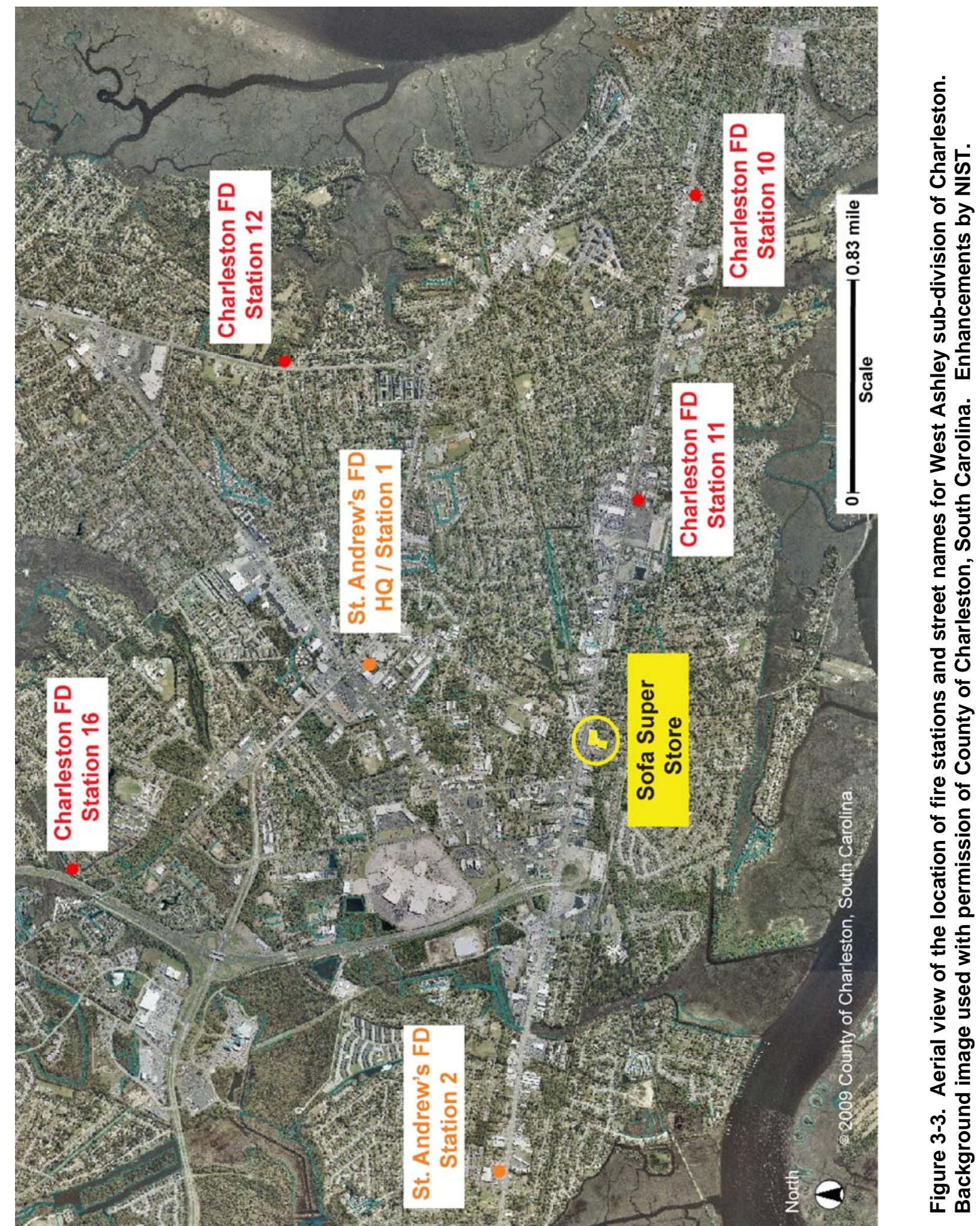




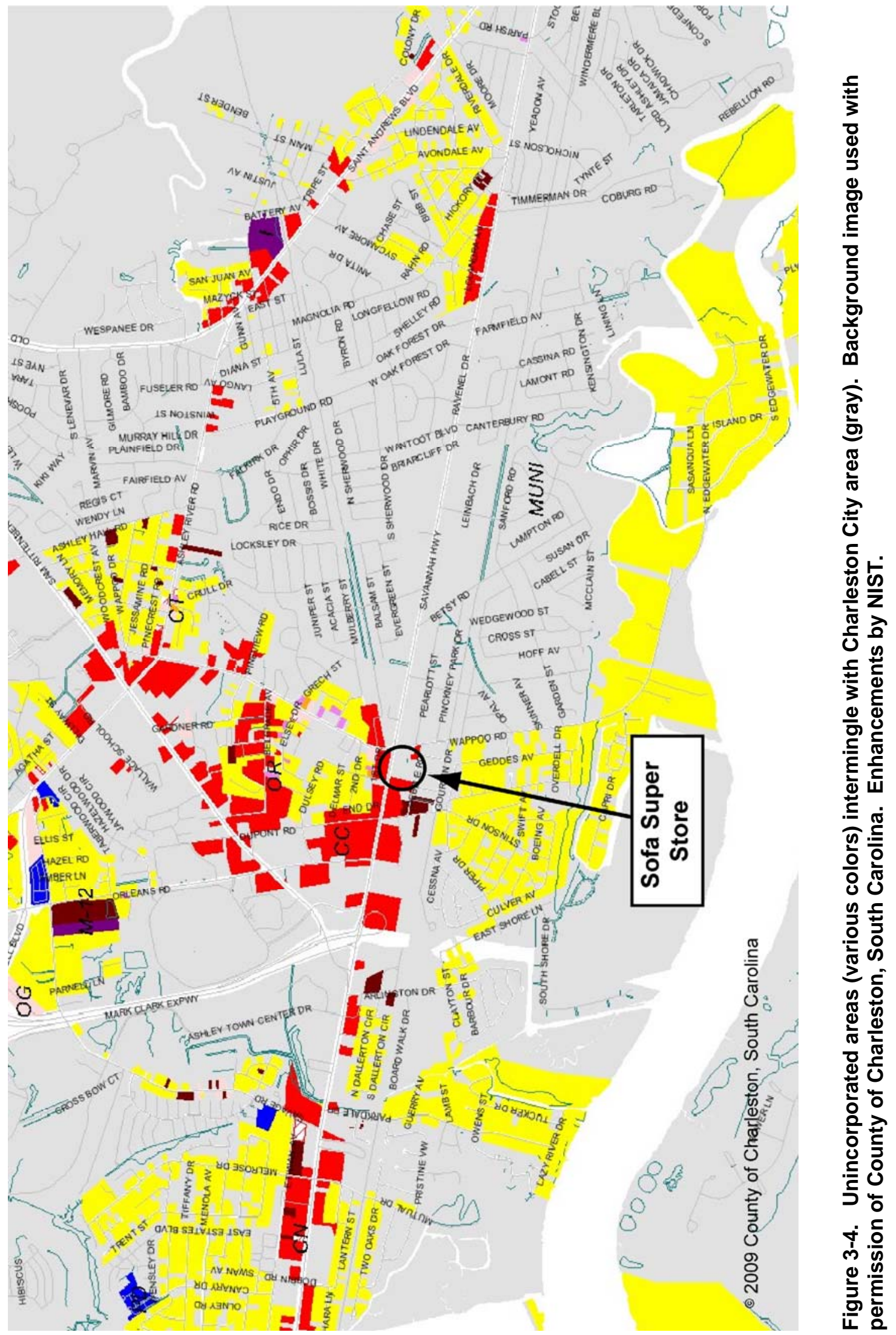




\subsubsection{Dispatch and Arrival of Initial Companies}

At 7:09 p.m., the CFD was dispatched for a possible fire behind the furniture store at 1807 Savannah Highway in the West Ashley area. Engine 11 (E-11) and an AC were en route from Station 11 at 1517 Savannah Highway, approximately $1.3 \mathrm{~km}$ (0.8 miles) east of the Sofa Super Store. BC-4 was also dispatched and responded. The second due engine, Engine 10 (E-10) was out of its station, but responded and was en route at 7:09 p.m. Responding from Station 10 which it shared with E-10, Ladder 5 (L-5) was also en route from their station at 805 Savannah Highway, approximately $3.4 \mathrm{~km}$ (2.1 miles) east of the furniture store. While en route to the store, BC-4 observed smoke and confirmed the fire and initiated the dispatch of the third engine assignment.

At 7:11 p.m. BC-4 arrived on the scene and reported a trash fire at the side of the store. The AC arrived next by 7:12 p.m., entered the front of the store, and walked down the center aisle to the rear of the main showroom. As BC-4 returned to the front of the store from the loading dock area, he conferred with the AC who indicated that he did not find any fire or smoke in the main showroom. As E-10 arrived at the store, it was directed to back down the driveway to the west of the store to set-up to attack a trash fire. After relocating his car, BC-4 joined E-10 near the loading dock. As E-11 arrived, it was positioned in front of the store to support operations through the front doors of the main showroom (Figure 3-5).

At this time, the first two arriving companies, E-10 and E-11, were positioned to attack the fire, E-10 at the loading dock, and E-11 at the front of the store. Each engine was equipped with a $2900 \mathrm{~L}$ (750 gal) water tank, which provided water until a connection to a hydrant was established. The third company on the initial dispatch, Ladder 5, was equipped with an aerial ladder, but with neither a water tank nor a water pump.

\subsubsection{Loading Dock Fire}

The captain from E-10 used a $2.5 \mathrm{~cm}$ (1 in) diameter hose to extinguish the trash and debris burning outside the loading dock (Figures C-1 and C-4). The E-10 crew observed fire inside the loading dock and used a $3.8 \mathrm{~cm}$ (1.5 in) diameter pre-connected hose line to initiate an interior attack on the fire inside the loading dock.

As BC-4 directed the suppression operations at the loading dock, he radioed the AC and informed him that the fire had spread to the interior of the loading dock.

At this early stage in the response, only five minutes after dispatch, the fire department had located the trash fire on the asphalt paved area and had discovered that the fire had spread to the interior of the loading dock. The AC surveyed the interior of the showrooms and did not observe any fire or smoke. Based on observations of the fire fighters in the showroom, the fire did not appear to have spread into the showrooms.

After reporting that the fire had spread to the interior of the loading dock, BC-4 instructed E-12 to lay a supply hose to E-10 at the loading dock to provide water for the suppression operations. At the time at which E-12 received the command to lay hose, E-12 had been dispatched, but was notyet enroute. Until E-12 connected E-10 to a hydrant, the water available for suppression was limited to E-10's onboard water tank. 


\subsubsection{Discovery of Fire at Rear of West Showroom}

While the fire fighter and engineer of Engine 11 worked to locate a hydrant, the AC and the E-11 captain re-entered the showroom to search for extension of the fire into the retail space. Accompanied by a store employee, the E-11 captain and AC went to the rear of the west showroom. The AC opened a door that connected to the loading dock and observed that the fire had spread into the loading dock. Using a glove protected hand, the E-11captain was able to close the door . The E-11 captain immediately requested a $3.8 \mathrm{~cm}$ (1.5 in) hose line be pulled to the rear of the west showroom. The AC radioed that the fire had spread to inside the rear of the building and instructed E-15 to pull a $3.8 \mathrm{~cm}$ (1.5 in) hose line to the rightrear of the building.

At this point (7:14 p.m.), the fire department was aware that the fire had spread into the showroomas demonstrated by the radio communication "I've got fire inside the rear of the building and it's walking it's way right on into the, into the showroom." But, it is not clear if "showroom" referred to the rear of the west showroom, the rear of the main showroom, or both. While the fire had been detected through the double doors at the rear of the west showroom, it is not clear whether fire fighters had discovered any fire spread above the suspended ceiling or into the holding area.

\subsubsection{Suppression Activities at Loading Dock Fire}

The captain of E-10 selected a $3.8 \mathrm{~cm}$ (1.5 in) diameter hose line for an interior attack into the enclosed loading dock area. Wearing full protective gear and self-contained breathing apparatus, the captain and a fire fighter from E-10 advanced the charged $3.8 \mathrm{~cm}$ (1.5 in) hose into the loading dock area approximately

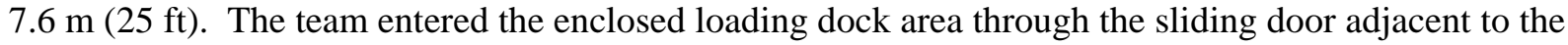
warehouse (Appendix C, Figure C-4). The loading area appeared to be fully involved in fire from floor to ceiling. The interior team directed water at about $230 \mathrm{~L} / \mathrm{min}(60 \mathrm{gal} / \mathrm{min})$ on the fire, but were not able to control the fire. The team indicated that the flow from their fog nozzle appeared to push the fire around the room. As the team retreated from the loading dock area, the hose line burst or was burned through by the fire near the doorway. The fire fighting team moved through the water spray from the burst hose line and exited the structure through the door adjacent to the warehouse.

By 7:17 p.m., E-12 had arrived on the scene and began to lay a $6.4 \mathrm{~cm}$ (2.5 in) supply line to E- 10 . Fire fighters from E-12 repaired the burst $3.8 \mathrm{~cm}$ (1.5 in) hose line while the captain and fire fighter from E-10 attempted another interior attack using the $2.5 \mathrm{~cm}(1 \mathrm{in})$ hose line. The smaller diameter hose line was not effective in controlling the fire inside the loading dock, so the E-10 team backed out. The $3.8 \mathrm{~cm}$ (1.5 in) hose line had been returned to service, so the E-10 team attempted a third interior attack.

By 7:16 p.m., the Fire Chief arrived on the fire scene and met with the AC and BC 4. After surveying the fire in the loading dock area, the Fire Chief halted the interior attack and ordered the interior team to back out of the enclosed loading dock. At 7:20 p.m. E-12 radioed E-10, indicating that the supply line to E-10 was being charged from the hydrant at the corner of Blitchridge Road and First Drive.

\subsubsection{Extension of Fire into the Warehouse}

As the interior of the enclosed loading dock area was fully involved in fire and the crew of E-10 exited the loading dock, BC-4 identified the spread of the fire into the warehouse. The only opening from the showrooms or loading dock area was a roll-down fire door from the holding area through the breezeway 
and into the warehouse (roll-down fire door \# 1 in Figure 1-8). The store manager reported hearing this fire door close before he exited the main showroom.

After observing the black smoke plume, units from St. Andrew's Fire Department, a mutual aid department, self dispatched to the fire scene. At 7:24 p.m., the mutual aid department arrived and after discussion with the Fire Chief, at least two engine companies and a ladder company from St. Andrew's Fire Department were assigned to the rear of the warehouse. Once the mutual aid units connected to a hydrant on Pebble Road, they deployed their ladder and directed an aerial water stream onto the rear of the warehouse.

E-10 was receiving water through a supply line from E-12 which had located a hydrant at the intersection of Blitchridge Road and First Drive (see Figures 1-17 and 2-4). It is not clear how much or how steady the water supply was to E-10. The supply lines were laid across Savannah Highway and radio calls requested the Charleston Police to stop automobile traffic from driving across the hose lines. E-12 was pumping water to E-10 at the loading dock through about $230 \mathrm{~m}(750 \mathrm{ft})$ of $6.4 \mathrm{~cm}$ (2.5 in) hose, but received requests to increase the pressure. Crews from E-10 were applying water through at least one $6.4 \mathrm{~cm}$ (2.5 in) line and one $3.8 \mathrm{~cm}$ (1.5 in) line.

BC-4 directed the E-12 crew and other off-duty fire fighters to cut a hole through the external roll-down door on the north side of the warehouse. E-10 radioed that the tank water was down to one-quarter full, and the Fire Chief instructed E-12 to increase water supply pressure by "50 more pounds." ${ }^{1}$ Two $6.4 \mathrm{~cm}$ (2.5 in) hose lines were pulled from E-10 in an attempt to suppress the fire from outside the warehouse. However, the fire was spreading rapidly across the furniture items, and crews did not enter the warehouse or attempt to conduct an interior attack. BC-4 directed an off-duty captain and additional off-duty fire fighters to move L-5 from the front (north side) of the store to the adjacent grass lot (west side). Once a water supply was established to L-5, the aerial ladder/platform was used to initiate an aerial stream to suppress the fire in the warehouse and loading dock as well as protect an adjacent auto repair garage to the west of the store.

\subsubsection{Suppression of West Showroom Fire}

As the E-11 captain left the rear of the west showroom and returned to the front of the store, the captain found L-5 fire fighters pulling a $3.8 \mathrm{~cm}$ (1.5 in) hose in the front door. The AC directed E-16, which was en route to the front of the store with instructions to pull a $6.4 \mathrm{~cm}$ (2.5 in) hose in the front door. Both hose lines deployed through the front doors were pulled to the rear of the west showroom. Since fire crews were pulling the hoses to the rear of the west showroom, the fire department appeared to be focused on suppressing the fire on the loading dock. They did not appear to have evidence that the fire had spread through the open roll-down door into the holding area, into the void space above the suspended ceiling, and eventually into the rear of the main showroom.

After the E-16 engineer dropped off his captain and fire fighter near the front of the store, the engineer began to deploy a $6.4 \mathrm{~cm}$ (2.5 in) supply line to E-11. In this case, E-16 deployed the end of a hose near E-11 at the front of the store and then drove east on Savannah Highway to locate a hydrant. The hydrant that had been installed near the intersection of Wappoo Road and Savannah Highway had been removed

\footnotetext{
${ }^{1}$ Pounds was used as shorthand for pounds per square inch (psi), a measure of water pressure. Double jacketed fire hose lines typically have working pressures of $300 \mathrm{psi}(2070 \mathrm{kPa})$ and fire engine water pumps can produce in excess of $500 \mathrm{psi}(3450 \mathrm{kPa})$ of water pressure at the pump outlet.
} 
(Figures 1-16 and 1-17), so E-16 continued east on Savannah Highway until the engineer located a hydrant in front of Morris Nissan automobile dealership at 1650 Savannah Highway (Figures 1-16, 1-17, and 2-4).

At 7:16 p.m., the L-5 engineer requested that E- 11 charge with water or pressurize the $3.8 \mathrm{~cm}$ (1.5 in) hose line. Until a supply line was connected to E-11, the water available to the fire fighters working through the front door was limited to the on-board tank of E-11. By 7:16 p.m., the Fire Chief had arrived on the scene and discussed the fire situation with the AC and BC-4. While the AC directed operations at the front of the store, the Fire Chief directed operations in the loading dock area.

The E-16 engineer notified E-11 that the supply line to E-11 was being charged with water. As water began to move through the supply hose from E-16 to E-11 at 7:26 p.m., the E-16 engineer radioed that water was coming. By 7:27 p.m., E-11 was receiving water through a single supply line. It is not clear how much or how steady the water supply was to E-11. The supply line was laid across Savannah Highway and radio calls were still requesting the Charleston Police to stop automobile traffic from driving across the hose lines. E-16 was supplying water to E-11 at the front of the store through approximately $560 \mathrm{~m}(1850 \mathrm{ft})$ of $6.4 \mathrm{~cm}$ (2.5 in) hose. Interior crews had pulled at least three lines, a $2.5 \mathrm{~cm}(1 \mathrm{in})$, a $3.8 \mathrm{~cm}(1.5 \mathrm{in})$ and a $6.4 \mathrm{~cm}$ (2.5 in), through the front door of the store. It is not clear that E-11 was receiving sufficient water for simultaneous operation of all of these hose lines.

\subsubsection{Rescue of Trapped Employee}

At about 7:27 p.m., when both engines were initially connected to hydrants, a Charleston Fire Department dispatcher notified the Fire Chief that it had received a cell phone call from an employee trapped inside the rear of the building. After the Fire Chief spoke over the radio with the AC, the AC and BC-5 led a team of four fire fighters from St. Andrew's Fire Department around to the rear of the main showroom to rescue the trapped employee. The team had to break through a locked wooden gate at the rear of the east showroom (Appendix F, Figure F-9) in order to gain access to the rear of the main showroom and then to the exterior wall of the repair shop. The trapped employee was using a hammer to bang on a metal exterior wall. Guided by the sound of his banging, fire fighters located the trapped employee and used a fire ax and forcible entry tool to open a hole in an exterior wall of the repair shop. The team rescued the employee through a hole in the wall in the workshop that was connected to the warehouse (not from the showroom) (Appendix H, Figure H-3). After rescuing the trapped employee, the team returned to the front of the store.

\subsubsection{Fire in the Rear of the Main Showroom}

While the fire department attempted to suppress the fire on the loading dock and at the rear of the west showroom, the fire had also spread to the holding area (Figure 2-5). The store manager reported that the roll-down fire door to the warehouse closed before he had exited the store. The employee who was rescued from the repair shop also indicated that he was trapped because the roll-down fire door to the warehouse was closed. The fire did not spread from the warehouse to the rear of the main showroom through the closed roll-down fire door.

Post-fire inspection of the holding room documented that the roll-down door from the loading dock to the holding area did not close during the fire. Examination of the operating mechanism after the fire 
demonstrated that this roll-down door did not have fusible links or other components that would have automatically closed the door in case of a fire. The smoke and flames from the loading dock flowed through this open door and into the holding area.

Thermal radiation from smoke and flames ignited furniture items that were staged inside the holding area. The metal frames that were visible in the post fire photographs (see Figures D-28, D-29, and D-30) demonstrate that multiple items including sofas and futons were in the holding area the time of the fire. Store employees reported that the holding area lacked a suspended ceiling and that one could see the underside of the roof if one looked up while in the holding area.

\section{(i) Smoke Fills the Void Space}

The lack of a suspended ceiling above the holding area allowed the hot smoke to flow into the void space above the suspended ceiling but below the roof of the main showroom. The volume above the suspended ceiling of the main showroom was significant, representing about one-third the volume of the main showroom structure and would have required significant time to fill. The wisps of smoke emerging from the vertical seam between the main and west showrooms (Figure 1-6) at about 7:34 p.m. were consistent with the smoke filling a significant portion of the interstitial volume.

\section{(ii) Fire Spreads from Holding Area to Rear of Main Showroom}

It is not clear how the fire moved from the holding room to the rear of the main showroom. There were at least three possible paths that would have allowed the fire to spread into the main showroom:

- First, the hot smoke moving into the interstitial space might have ignited items above the suspended ceiling. From post-fire photographs of the east showroom interstitial space which was the only interstitial space not completely consumed by the fire, the combustible fuels above the suspended ceiling may have been limited to flexible wire-reinforced plastic air ducts, electrical wiring, and $0.1 \mathrm{~m}$ (4 in) x $0.1 \mathrm{~m}$ (4 in) x $1.8 \mathrm{~m}(6 \mathrm{ft})$ wood supports for the air handling units. The hot fire gases could have ignited some of these items above the suspended ceiling and the burning items/material might have dropped down into the main showroom. If the hot gases/flames had ignited combustible items above the suspended ceiling, the fire would likely have spread very quickly into the rear of the main showroom.

- A second potential path for the fire might have been through the partition wall. However since the wall was constructed out of $12.7 \mathrm{~mm}$ ( 0.5 in) thick gypsum board on both sides, it would have taken the fire some time to penetrate both sides of the partition wall. If the wall was constructed using two layers of fire resistant Type X, $15.6 \mathrm{~mm}$ (0.625 in) thick gypsum board on both sides of a metal studs, the wall would have been rated as a two-hour fire wall [20]. If the fire team on the loading dock had directed a solid stream of water onto the partition wall then the impingement of the water stream on the gypsum wall would have likely shortened the time to failure of the wall. For the second path, significant time would have been required for the fire to penetrate both sides of the gypsum lined partition wall. Video of the fire shows fire penetration into the main showroom approximately 40 minutes into the fire.

- The third potential path that might have allowed the fire to spread was through the metal door between the holding area and the main showroom. It is unlikely that this metal door was open during the early part of the fire because smoke would have flowed through an open door into the rear of the main showroom and the fire spread would have been visible to fire fighters in the showroom. After the early part of the fire, it appears that the door may have opened or 
been partially opened sometime during the fire. Hot gases or flames from the loading dock would have ignited the items within the holding area, which included futons and a sofa. The heat from the burning items in the holding area and the loading dock might have heated the door frame sufficiently to warp the frame. The fire would then have moved through the cracks, or possibly the partially opened door into the main showroom. It is also possible that a fire fighter might have opened the door to check for fire and was unable to close the door. Once the door was unlatched, if it was unlatched, the fire induced air flow may have pulled the door open. The hot smoke and burning items in the holding area may have also prevented a fire fighter from closing the door.

Of the three potential paths identified above, the third path, fire spreading through the door appears most consistent with the fire development.

\section{(iii) Fire Growth in Rear of Main Showroom}

Once the fire spread from the holding area into the rear of the main showroom, there was more fuel available to the fire. The fire in the rear of the main showroom did not have ready access to air and was under-ventilated. Post-fire review of photographs and videos, as well as fire fighter interviews, demonstrated that the only ventilation paths to the rear of the showroom were the open front doors, the roll-down door to the loading dock, and the double doors at the rear of the west showroom. Fire fighters described a "cone" of clear air at the front doors of the main showroom. This would have been consistent with fresh air being drawn into the front of the structure. The fire on the loading dock was welldeveloped and consuming large amounts of air. It is unlikely that the fire at the rear of the main showroom had access to air from the loading dock or through the double doors at the rear of the west showroom. The CFD did not ventilate the roof, so no vertical pathway existed in the rear of the main showroom. There were no doors or windows on the rear (south) side of the main showroom. Although there were open fire doors between the main showroom and the east and west showrooms, the exterior doors on the west and east showrooms were closed. The fire growth in the rear of the main showroom was slow due to the lack of air.

With only limited access to air, the fire would have initially ignited the outer layers of fabric and foam on the furniture. The fabric and foam would likely have supported an intense, but relatively short, release of heat that might not have been sufficient to spread the fire due to the limited amount of oxygen. The slower burning wood components of the furniture might have allowed the fire to continue to burn, albeit at much lower heat release rate, for a longer period of time.

\subsubsection{Fire in the Front of the Main Showroom}

As the AC returned to the front of the store, the fire was spreading into the main showroom. Inside the showroom were crew members of Engines 6, 11, 15, 16, and 19 and L-5. At this stage in the response, the crews had already pulled a $3.8 \mathrm{~cm}$ (1.5 in) hose and a $6.4 \mathrm{~cm}$ (2.5 in) hose through the front doors, through the main showroom, and to the rear of the west showroom. An additional $6.4 \mathrm{~cm}$ (2.5 in) hose

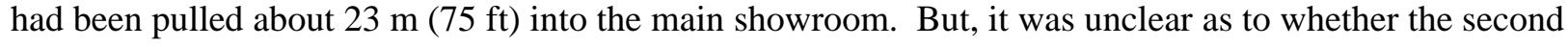
$6.4 \mathrm{~cm}$ (2.5 in) hose line was intended for the rear of the main showroom or the rear of the west showroom. Even with the hose lines in place, E-11 did not appear to be providing sufficient water to charge or pressurize all three hose lines simultaneously. The amount of water was not sufficient to control the fire at the rear of the main showroom. 
As the fire continued to grow in the rear of the main showroom and the smoke filled the volume above the ceiling, smoke continued to accumulate in the main showroom. As the smoke layer above the heads of the fire fighters continued to thicken and eventually dropped closer to the floor the visibility decreased. The fire fighters within the smoke filled main showroom became disoriented as evidenced by radio transmissions, and at approximately 7: 27 p.m., fire fighters began to request help [8, 9].

As observed in photographs and videos, the smoke that initially appeared at the front of the store was light brown in color and did not flow upward quickly. This lack of upward flow or buoyancy resulted in the smoke moving across the store front rather than flowing up past the façade (Figure 3-7). The brown color was consistent with partially burned combustion products from an under-ventilated fire, a fire that did not have sufficient air for complete combustion. The lack of buoyancy was likely the result of the smoke being diluted with cooler air as the smoke moved towards the front of the showroom. As the fire continued to grow and spread in the rear of the main showroom, the brown smoke emerged from the front doors in increasing quantities (Figure 3-8). The smoke exhibited more buoyancy, either because of less mixing or higher temperature, and flowed in a more vertical plume up the building façade. At about 7:35 p.m. the fire fighters broke the front windows to allow more of the smoke to vent and improve the visibility in the main showroom. After the windows were vented, air was drawn into the front of the main showroom through the lower portion of thebroken windows in addition to the doors. Photographs demonstrate that furniture just inside the front windows which smoke had obscured, became visible after the windows were broken. The amount of smoke at the front of the main showroom increased and changed from a brownish to a blacker color. The change in smoke color was still consistent with partially oxidized combustion products from a fire that was ventilation-limited.

The smoke continued to mix with air from either the loading dock through the holding area or from the vented windows at the store front. The air provided additional oxygen to the fire, which increased and released more energy. The additional energy increased the temperature of the smoke below the suspended ceiling in the main showroom. Eventually, the hot smoke mixed with sufficient air to create a layer below the suspended ceiling. As the fire at the rear of the main showroom ignited this layer of unburned combustion products, the fire rapidly moved from the rear of the showroom (southwest corner) to the front of the store (Figure 3-9). The fire then spread into the east side of the main showroom before emerging from the front of the store (northeast corner). After spreading to the entire main showroom, video recorded during the fire [4] demonstrated that the fire spread through the open fire doors into the west showroom and eventually to the front windows of the west showroom. 


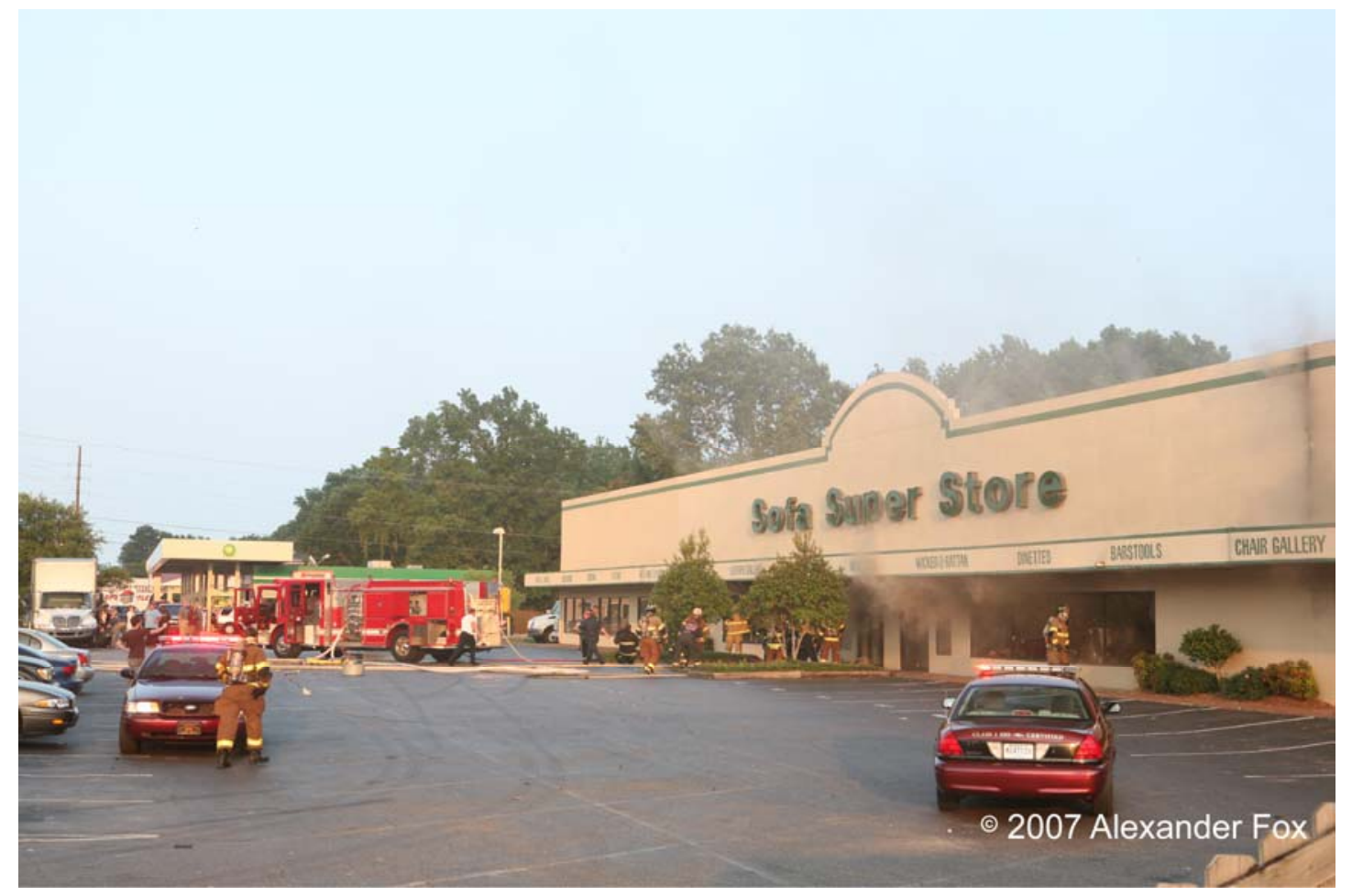

Figure 3-7. Light brown smoke began to flow out of broken front windows. Photo taken at approximately 7:36 p.m. Photo used with permission of Alexander Fox.

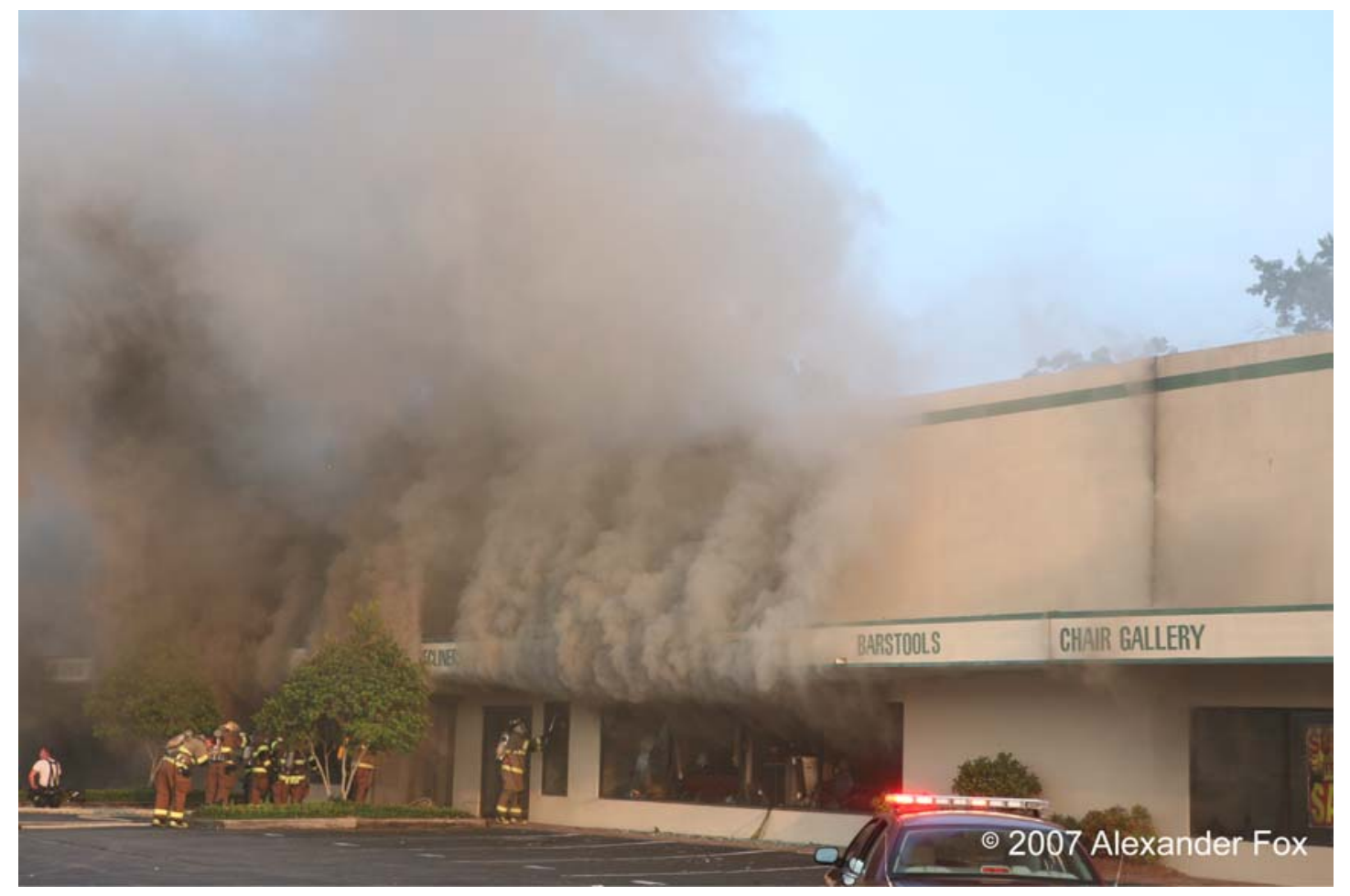

Figure 3-8. Additional smoke moved out of broken windows. Photo taken at approximately 7:36 p.m. Photo used with permission of Alexander Fox. 


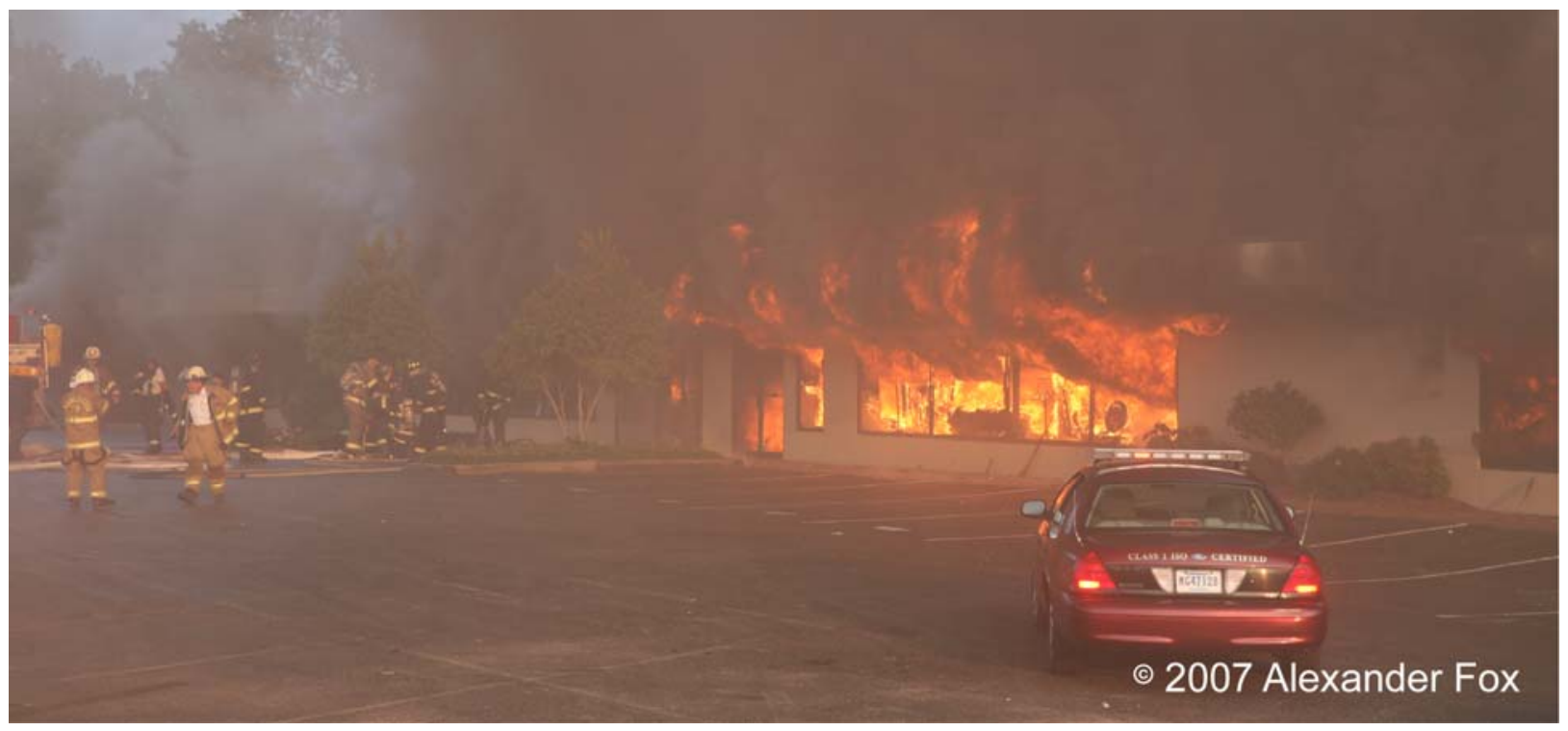

Figure 3-9. Black smoke and flames flowed out of front windows as fire spread to the main showroom. Photo taken at approximately 7:38 p.m. Photo used with permission of Alexander Fox.

\subsubsection{Evacuation}

According to post-fire interviews of fire fighters, at approximately 7:27 p.m., the smoke layer continued to collect below the ceiling and began to increase in temperature. During post-fire interviews, fire fighters who were inside the main showroom described how they move toward the front of the store in response to the increased temperature and low visibility conditions. Some fire fighters were able to follow hose lines to the front door, while others moved toward the noise of E-11, which was located at the front of the store. As fire had spread to the rear of the main showroom and conditions inside the main showroom continued to deteriorate, at approximately, 7:35 p.m., the Fire Chief radioed that “...we need to vacate the building." Once the smoke layer ignited, the fire spread extremely quickly. At about 19:38 p.m., the Fire Chief ordered "Everybody abandon the building." Multiple blasts of a fire engine air horn signaled for all fire fighters to exit the structure. Nine fire fighters were trapped within the showrooms, three within the west showroom and six within the main showroom.

\subsubsection{Search for Trapped Fire Fighters}

As the smoke layer dropped in the main showroom and visibility deteriorated, fire fighters began to call for assistance over their radios. Beginning around 7:27 p.m., broken radio calls indicated fire fighters in distress and "Mayday." Due to the number of radio calls, it was not initially clear how many fire fighters needed assistance, who the trapped fire fighters were, or where they were located. It was not immediately clear which fire fighters had been on the teams inside the showrooms. The Fire Chief directed two twoman teams to attempt to enter and search for the trapped fire fighters. Both teams entered the main 
showroom, but were forced to retreat by the intense heat. At approximately 7:38 p.m., the last of the search teams exited the front of the structure.

\subsubsection{Post-Evacuation}

After the main and west showrooms were fully involved in fire, the fire department used multiple $6.4 \mathrm{~cm}$ (2.5 in) hose lines to direct water on the fire from the front of the store. An engine from a mutual aid company laid supply lines to L-5, which had been relocated to the grassy lot to the west of the store. L-5 initiated two streams of water from its elevated platform and directed water toward the showrooms, loading dock, and warehouse. At around 7:44 p.m. the fire department requested that the city water department increase the water pressure in the supply lines in West Ashley. L-4 arrived and set up in the parking lot in front of the store and directed additional water streams down onto the showrooms from its elevated ladder. At about 10:00 p.m. the fire was declared under control and recovery operations were initiated. At approximately 4:00 am the next morning, recovery operations were completed.

\subsection{VENTILATION}

The CFD did not routinely cut vents or holes in roofs to exhaust hot gases. Fire fighters were not directed to ventilate any portion of the roof on the Sofa Super Store.

During the early stages of the fire, the fire on the loading dock was under-ventilated. It appears that the skylights above the $2.7 \mathrm{~m}(9 \mathrm{ft})$ high section of the enclosed loading dock allowed the fire to vent through the roof early in the fire evolution.

As the fire spread from the loading dock area to the holding area, flames extended from the loading dock and holding areas and impinged on the underside of the roof above the holding area. The intense heat ignited roofing material above the metal decking. After sustained flame impingement from underneath the metal decking and the burning roofing materials, the intense heat caused the metal decking to warp and this created cracks that allowed combustion products to vent through the roof.

As the fire spread to the rear of the main showroom, the fire still behaved as though it was under ventilated. At approximately, 7:35 p.m., the front windows of the store were broken by fire fighters. Shortly after the windows were broken, the fire was provided with additional air either from the vent front windows or through the loading door roll-down door. The additional oxygen allowed the fire to spread rapidly from the rear to the front of the main showroom.

\subsection{INCIDENT COMMAND}

The initial Incident Command (IC) was established with the arrival of BC 4 at approximately 7:11 p.m. BC-4 directed E-10 to back down the driveway to the loading dock area and begin suppressing the trash fire.

At about 7:12 p.m. the AC arrived on scene and became Incident Commander. The AC met with BC-4 and decided that BC-4 would direct operations at the loading dock while the AC would check for extension of fire into the retail showrooms. The AC did locate the fire in the loading dock when the door at the rear of the west showroom was opened. Initially, the AC performed incident command functions by directing E-12 to supply water to E-10 at the loading dock and E-16 to supply water to E-11 at the 
front of the store. The AC also directed responding companies to perform specific tasks such as E-15 pulling hose lines into the front of the store.

By 7:16 p.m., the Fire Chief had arrived on scene and became the IC. The Fire Chief met with the AC and BC-4 and instructed the AC to direct operations at the front of the store while the Fire Chief would direct loading dock operations. The Fire Chief subsequently directed operations at the loading dock, but also functioned as an incident commander by requesting additional resources, coordinating coverage of the city when units responded to the fire, and requesting the water company to increase water pressure.

The transition of incident command from BC-4, to AC, to Fire Chief was accomplished as each higher ranking chief arrived on the scene. The fire department did not appear to set up or designate a specific location as a command post. The Fire Chief moved between the loading dock area and the front of the store to continually assess the fire ground operations on the west and north sides of the structure. It is not clear how the conditions on the east and south sides of the structure were monitored during the fire.

There was not a single location for incoming fire fighters to check in or receive coordinated assignments. CFD procedures allow off-duty fire fighters to respond to and participate in fire ground activities. Department procedures required each fire fighter to provide a chief officer with an identification card before participating in fire ground activities. Department procedures did not require that the off-duty fire fighter check in with the incident commander, just a chief officer.

The lack of a single command post and the ability of off-duty fire fighters to check in with different chief officers did not allow easy or coordinated tracking of personnel on the fire ground. For example, when the Fire Chief received the call from a trapped employee, the chief directed the AC to rescue the employee. However, it is not clear who was directing operations at the front of the store or inside the showrooms while the AC was leading the successful rescue effort.

\subsection{MUTUAL AID}

Most emergency services providers, and fire departments in particular, develop and operate with the assistance of mutual aid agreements with neighboring departments to augment their capability to respond to incidents when their assets are committed or otherwise unable to satisfy the community's emergency response requirements. Such agreements are typically intended to facilitate rapid augmentation the requesting department's staffing or equipment during an emergency, when needs exceed their capabilities.

Mutual aid agreements vary widely in scope and content. Some agreements are designed to provide assets as specifically requested while others provide for the routine deployment of another department's specialized assets such as hazardous materials units, advanced life support (ALS), bomb disposal units, water supply, aerial apparatus, or other specialty units when an alarm is initially transmitted. In the latter situation, the mutual aid assets are in effect shared by signatories to the agreements, and are used independent of actual jurisdictional or organizational ownership. All agreements benefit the member agencies by providing emergency surge capabilities (staffing, equipment, etc.) from other agencies that would be prohibitively expensive to operate and maintain in each jurisdiction.

While mutual aid arrangements have an obvious practical value, they also have limiting characteristics. Assets which are infrequently used by a department requesting the mutual aid from another may be in use by the department possessing the asset on a regular basis, and therefore unavailable when needed by others. In a wide scope event, there may be more departments in need of specific assets than are available 
within the member compact. Jurisdictional differences in equipment, tactics, and communications systems may also present interoperability challenges to the effective use of mutual aid assets, as was the situation at this incident. Some agreements are relatively small in scope, limited for example, to nearby departments. Others may apply to all the departments in a county or cover a multi-county or even a multi-state region.

Most agreements center on strategic principles that assure that the specific mutual aid requested will normally come from the nearest jurisdiction with the assets available. Depending on the amount of aid needed (the number, magnitude, and/or the diversity of the assets required), the aid is typically moved toward the incident in a fashion that first thins the assets of the area departments nearest the incident and then progressively back-fills or covers those departments providing the initial aid with units from departments further away, providing for successive concentric waves of resource augmentation.

On-scene mutual aid was provided to the CFD by the St. Andrew's Fire Department and St. James Island Fire Department. Each of the mutual aid departments responded on their own, not at the request of CFD. Interviews with fire fighters indicated that St. Andrew's responded because the smoke plume was visible from two of their stations (HQ and Station 2). Fire fighters reported that St. Paul's responded because several volunteer members of St. Paul's Department were also full-time fire fighters with CFD. Radio communication over the CFD's radios alerted many off-duty fire fighters. Units from Mt. Pleasant, North Charleston, St. James Island, and Summerville departments back-filled CFD stations and covered CFD response areas while CFD units were at the fire scene.

Engine and truck companies from St. Andrew's positioned themselves on Pebble Road and conducted suppression on the warehouse. A crew from St. Andrew's also assisted the AC in extracting the trapped employee. Later in the fire, St. Paul's Fire Department laid a water supply line to L-5 which was positioned to the north of the repair garage which was west of the store. St. James Island Department responded with an engine and a water tanker which were also positioned in support of L-5. This enabled L-5 to initiate a master stream on the loading dock and warehouse. L-4 responded and was positioned in the parking lot in front of the store. Fire fighters from St. Andrew's Fire Department assisted in laying a water supply line to L-4 along Savannah Highway which enabled Ladder 4 to initiate a master stream on all three of the showrooms. 


\subsection{REFERENCES FOR CHAPTER 3}

[1] Fatality Assessment and Control Evaluation Investigation Report \#F2007-18, National Institute for Occupational Safety and Health, Fire Fighter Fatality Investigation and Prevention Program, Morgantown, WV, February 2009. http://www.cdc.gov/niosh/fire/pdfs/face200718.pdf.

[2] "Fire Fighter Fatality Investigative Report, Sofa Super Store, 1807 Savannah Highway, Charleston, South Carolina, June 18, 2007 .” City of Charleston Post Incident Assessment and Review Team, Phase II Report, June 2008.

[3] "Report of S.C. OSHA Findings in June 18, 2007 Charleston Sofa Super Store Fire,” South Carolina Department of Labor, Licensing and Regulation, Office of Occupational Safety and Health; undated report, file recorded 9/21/2007.

[4] Video images recorded during the fire by Howard Armstrong and John Pundt.

[5] Digital photographs taken during the fire by the private individuals including Stewart English and Alexander Fox.

[6] Digital photographs taken during the fire by law enforcement organizations including the Charleston Police Department.

[7] Digital photographs taken during the fire by news outlets including The Post and Courier and Associated Press.

[8] Interviews of fire fighters conducted by National Institute for Occupational Safety and Health (NISOH). Interviews organized by the NIOSH investigation team and NIST team allowed to participate. Interviews included fire fighters from Charleston, St. Andrew's, and St. James Island Fire Departments.

[9] Radio Transmissions and Phone Call Transcript Sofa Super Store - Charleston, SC, June 18, 2007. Released by City of Charleston on Aug. 10, 2007. Audio recordings available at http://www.postandcourier.com/news/2007/aug/10/911_tapes_sofa_store_ fire_be_released_afternoon/.

[10] Sofa Super Store Fire - Report of Investigation, ATF National Response Team Origin and Cause Report, Investigation 763010-07-0172, Report 32, June 22, 2007.

[11] U.S. Census 2005, http://www.census.gov/popest/cities/SUB-EST2008.html.

[12] City of Charleston website, http://www.charlestoncity.info/dept/content.aspx?nid=114.

[13 NFPA 1500, Standard on Fire Department Occupational Safety and Health Program, 2010 National Fire Codes, National Fire Protection Association, Quincy, MA, pp. 1500-11, 2007.

[14] NFPA 1710, Standard for the Organization and Deployment of Fire Suppression Operations, Emergency Medical Operations, and Special Operations to the Public by Career Fire Departments, 2010 National Fire Codes, National Fire Protection Association, Quincy, MA, pp. 1710-9, 2010.

[15] NFPA 1031, Professional Qualifications for Fire Inspector and Plan Examiner, National Fire Protection Association, Quincy, MA, 2003. 
[16] Fire Plan Examiner (CFE) Program - NFPA 1, Fire Code, NFPA 13, Installation of Sprinkler Systems, NFPA 72, National Fire Alarm Code, and NFPA 101, Life Safety Code.

http://www.nfpa.org/certifications

[17] Certified Fire Inspector I (CFI/I) Program- NFPA 1, Fire Code, NFPA 13 Installation of Sprinkler Systems, NFPA 25, Inspection, Testing, and Maintenance of Water-Based Fire Protection Systems, NFPA 72, National Fire Alarm Code, and NFPA 101, Life Safety Code. http://www.nfpa.org/certifications

[18] Certified Fire Inspector II (CFI/II) Program- CFI/I codes listed above and NFPA 24, Installation of Private Fire Service Mains and Their Appurtenances, and NFPA 220, Types of Building Construction. http://www.nfpa.org/certifications

[19] Certified Fire Marshal - International Building Code, International Fire Code, NFPA 921 Guide for Fire and Explosion Investigations, International Fire Service Training Association (IFSTA) Introduction to Fire Origin and Cause, and IFSTA Fire and Life Safety Educator. http://www.iccsafe.org/accreditation

[20] Fire Resistance Design Manual - Gypsum Systems, GA-600-2009 Fire Resistance Design Manual, $19^{\text {th }}$ Edition, Gypsum Association, Hyattsville, MD, 2009, www.gypsum.org. 


\section{Chapter 4 \\ COMPUTER SIMULATION OF FIRE AND SMOKE SPREAD}

\subsection{INTRODUCTION}

\subsubsection{General}

Computer simulations, also known as numerical modeling, have been demonstrated to be useful, when properly applied, as a tool to help fill in details of the fire dynamics and to demonstrate the value of alternative building designs and fire safety measures [1]. When properly verified and validated, models can be used to obtain quantitative results. The Sofa Super Store simulation results are an approximation of the actual event, and should be considered considered as qualitative rather than quantitative. In other words, it is likely that the simulations do not return exactly the same results as might have been present in the real world situation, but can provide a reasonable approximation of conditions. These simulated scenarios can then be used to further examine relative differences when simulations that include changes to the modeled environment are compared with each other.

This chapter provides a brief description of the models and the inputs that were used to simulate the fire and smoke spread during the Sofa Super Store fire for five different scenarios. The computations included simulated fire and smoke spread, potential temperatures, and oxygen concentrations that may have existed in the actual incident. Each of the simulation results was analyzed and compared to published tenability criteria [2], excluding any protective clothing or use of self-contained breathing apparatus (SCBA). Additional details and data on how the inputs were selected, assumptions about ventilation events, geometry, material properties and simulation results are detailed in Appendix K. The input files for each of the simulation runs are included in Appendix L.

\subsubsection{Simulation of the Fire and Smoke Spread}

The value of the computer simulation of the Sofa Super Store fire is its ability to generate a clearer picture of the conditions that existed within the Sofa Super Store as the fire progressed. The simulation can be used to examine the change in the initial conditions and analyze possible interventions on the dynamics of the fire and the environment within the store. The store environment and fire dynamics are characterized in this study by the following dependent variables:

- heat release rate of the fire as a function of time;

- visibility as a function of location and time;

- temperature as a function of location and time;

- oxygen volume fraction as a function of location and time; and

- velocity of the air and fire plume as a function of location and time. 


\section{(i) Fire Growth and Spread Inside the Store}

The focus of this simulation was the examination of conditions that may have been present in the Sofa Super Store during the first 40 minutes (2400 s) after the fire department discovered the fire in the loading dock area. For these model simulations, the fire department was on scene at time $=0$, the fire was discovered at the rear of the west showroom at 2 minutes, E-12 began pumping water to E-10 (loading dock) at 10 minutes, broken radio calls began to indicate fire fighters in trouble at 16 minutes, front windows were vented at 24 minutes, fire was emerging from front windows at 26 minutes, last fire fighter successfully exited structure at 27 minutes, and the roof over the main showroom partially collapsed at 40 minutes. Each 40 minute simulation covered the time period from fire department's arrival at 7:11 p.m., to just after the partial collapse of the main showroom roof at 7:51 p.m.

\section{(ii) Fire-Spread into Showrooms versus Warehouse}

The fire spread from the loading dock into both the warehouse and showrooms. The manner in which the fire spread to these two areas was significantly different. The spread of the fire into the showrooms was not reported by the fire fighters for at least 10 minutes after they entered the showrooms. The simulation was designed to provide insight into how the fire might have spread into the showrooms in a concealed or less visible manner. This simulation considered different scenarios for fire-spread into the showrooms, including 1) through the double doors at the rear of the west showroom, and 2) through the holding area.

The movement of the fire into the warehouse was observed and reported by the fire fighters (Section 3.3.6). The energy (heat) from the fire apparently moved through a metal wall and into the warehouse, igniting the fuel load stored in the warehouse. Because the movement of fire into the warehouse was straightforward, it was not the focus of this simulation.

\section{(iii) Impact of Sprinklers on the Loading Dock Fire}

Fire sprinklers are very effective in controlling the growth and spread of fires. Fire sprinklers were not installed in the showrooms, loading dock, or warehouse of the Sofa Super Store. The simulation considered the effect of sprinklers by including a scenario in which fire sprinklers were installed in the enclosed loading dock.

\section{(iv) Impact of Ventilation}

Ventilation can significantly impact how a fire grows and develops. The fire service often ventilates a structure by breaking windows or cutting holes in roofs in order to allow the smoke and hot gases to be exhausted from the structure. Less smoke and hot gases can improve visibility and make working conditions more tenable. Ventilation can also provide additional air to the fire and can result in a greater release of heat or energy.

The fire at the rear of the main showroom moved quickly toward the front of the store after the front windows were broken by the fire service. This simulation considered how different ventilation scenarios might have affected the fire-spread, including 1) breaking the front windows, and 2) leaving the front windows intact.

In addition to ventilating structures by breaking windows, the fire service might also cut holes in the roof. The simulation considered different scenarios involving holes in the roof, including: 1) a small opening above the holding area; and 2) a large opening above the rear of the main showroom. 


\subsubsection{Computer Model Simulations of the Fire Dynamics}

The simulation of the Sofa Super Store fire included the following five scenarios or cases:

1) Baseline Scenario - an approximation of what actually occurred in Sofa Super Store.

2) Sprinklered Scenario - fire sprinklers added to the loading dock.

3) Front Windows Intact Scenario - baseline case except front windows remained intact.

4) Small Vent Scenario - roof vented with a small hole, $1.7 \mathrm{~m}^{2}\left(18 \mathrm{ft}^{2}\right)$, above holding area front windows intact.

5) Large Vent Scenario - roof vented with a large hole, $5.9 \mathrm{~m}^{2}\left(64 \mathrm{ft}^{2}\right)$, above rear of main showroom, front windows intact.

The baseline scenario represents an approximation of what actually occurred in the store on June 18, 2007, based upon the evidence and time line described in the previous chapters. The baseline, sprinklered, and intact front windows cases will be described briefly in this chapter. Each of the scenarios is described in more detail in Appendix $\mathrm{K}$.

\subsection{NIST FIRE DYNAMICS SIMULATOR OVERVIEW}

\subsubsection{General}

The NIST Fire Dynamics Simulator (FDS) is a computational fluid dynamics model of fire-driven fluid flow. It solves a form of the Navier-Stokes equations appropriate for low-speed, thermally driven flow with an emphasis on smoke and heat transport from fires [3]. A companion software program, Smokeview, allows for the simulation results to be easily displayed. Smokeview allows the viewing of FDS results in three-dimensional images. Smokeview can display contours of temperature, velocity, and gas concentration in planar slices. It can also display properties with iso-surfaces that are threedimensional versions of a constant value of a property of interest. Iso-surfaces are most commonly used to provide a three-dimensional approximation of the flame surface where fuel and oxygen mix in a stoichiometric ratio, yielding a reaction and a flame surface. Complete descriptions of the FDS model and Smokeview, as well as the technical references which support the model, are given in references [3-5].

Inputs required by FDS include the geometry of the structure, the computational cell size, the location of the fire source, the energy release rate of the fire source, the mass, geometry and thermal properties of walls, ceilings, floors, and furnishings, and the size, location, and timing of door and window openings to the outside of the structure. The selection of thermophysical properties and dimensions for the input parameters can have a significant impact on the outcome of the simulation, and because considerable uncertainty exists in the values of these parameters, a range of values is used.

For a specific set of inputs, FDS calculates the fire-spread and smoke movement within the Sofa Super Store. The results of the simulation including the spread of fire and smoke within the loading dock, holding area, and showrooms, are compared to the photographic and video record and the statements of witnesses to assess the agreement between the simulation and the actual fire. The input parameters are systematically adjusted and the simulation re-run. This process of refining the input parameters continues until the best possible agreement has been achieved. 


\subsubsection{Computational Domain and Cell Size}

A computational fluid dynamics model requires that a room or building be divided into a series of small boxes or cells. The model computes the density, velocity, temperature, pressure and species concentration of the gases in each cell as it steps through time. Based on the laws of conservation of mass, momentum, species, and energy, the model tracks the generation and movement of fire gases.

Collected on scene by the NIST team, data describing the geometry, materials of construction, and estimated number and type of retail merchandise were incorporated as input parameters for the FDS simulations. Figure 4-1 shows a Smokeview rendering of the computational domain of the Sofa Super Store.

The computational domain for the incident simulation consisted of a total of 1,102,382 cells that encompassed a total volume of approximately $140,000 \mathrm{~m}^{3}\left(5\right.$ million $\left.\mathrm{ft}^{3}\right)$. Figure $4-1$ shows an isometric view of the structure with cells to show relative scale. The black lines surrounding the structure indicate bounds of the volume within the computational domain. This outer perimeter reflects the computation of the fire and smoke within the building. It also includes the outdoor conditions that might have affected the flow of air to the fire and the flow of smoke from the fire. Figure 4-2 and Figure 4-3 show front and side views of the Sofa Super Store, respectively, as rendered by Smokeview. Two different cell sizes were used in the simulation. For volumes that contained parts of the structure, cells were $37.5 \mathrm{~cm}$ (14.8 in) on each side. Cells that were outside of the structure were used to track smoke movement, and were $75 \mathrm{~cm}$ (29.5 in) on each side.

Selecting the appropriate cell size required balancing the need to resolve critical dimensions and physical phenomena against the need to budget enough time to perform the hundreds of computer runs necessary to assess the importance of different variables on the outcome. The FDS input parameters were adjusted by comparing the simulation results with the available photos, videos, witness statements and other documentation of the fire. This methodology has been used previously by NIST researchers in post-fire studies [6-13]. Over 250 computer simulations were required to match the observed phenomena and time line. The simulation that best matched with observations and time lines is presented as the baseline case. Each of the other cases presented in this report used the baseline case as the starting point and was subsequently modified to incorporate fire sprinklers, maintain the front windows intact, or create openings in the roof. Approximately four days were required to generate each 2400 second simulation.

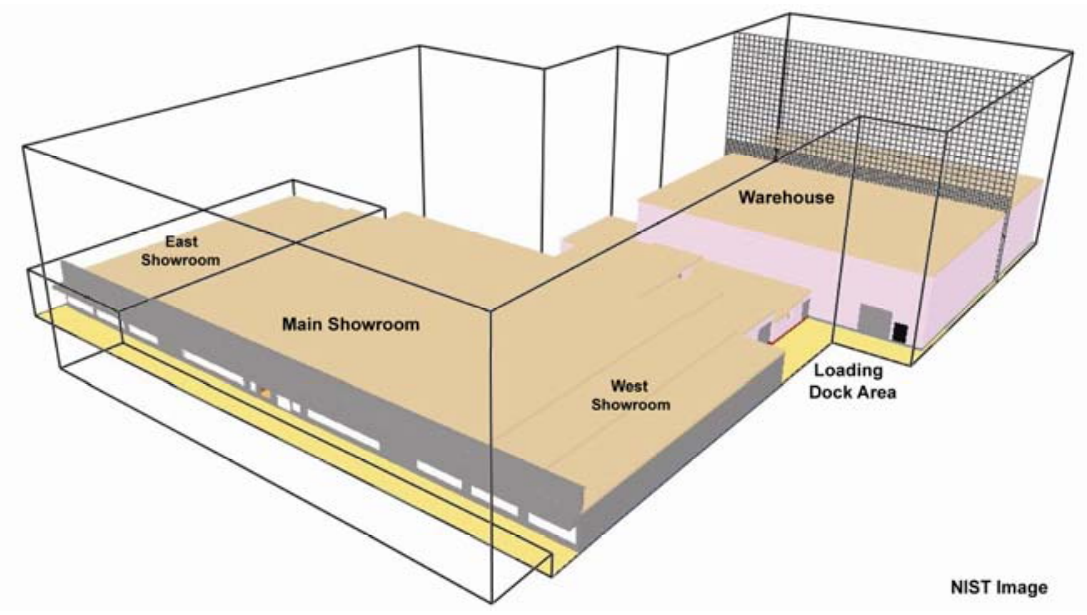

Figure 4-1. Computational domain of the Sofa Super Store. Image rendered by Smokeview. 


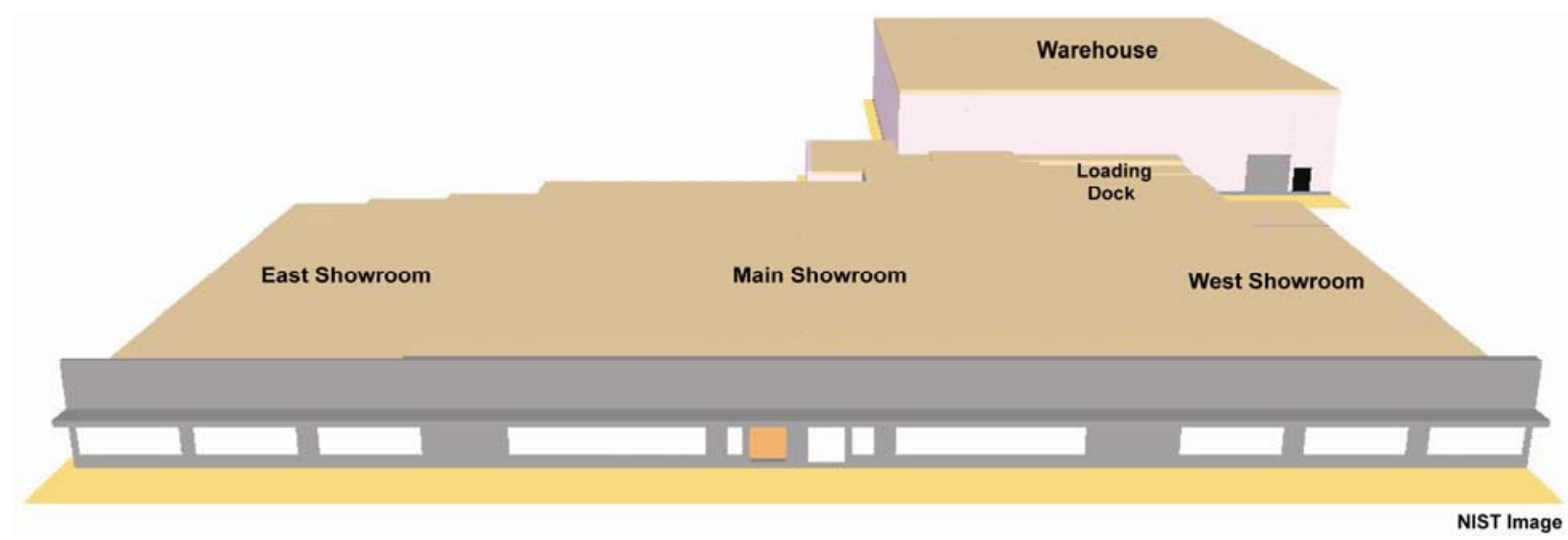

Figure 4-2. Front view of the Sofa Super Store as rendered by Smokeview.

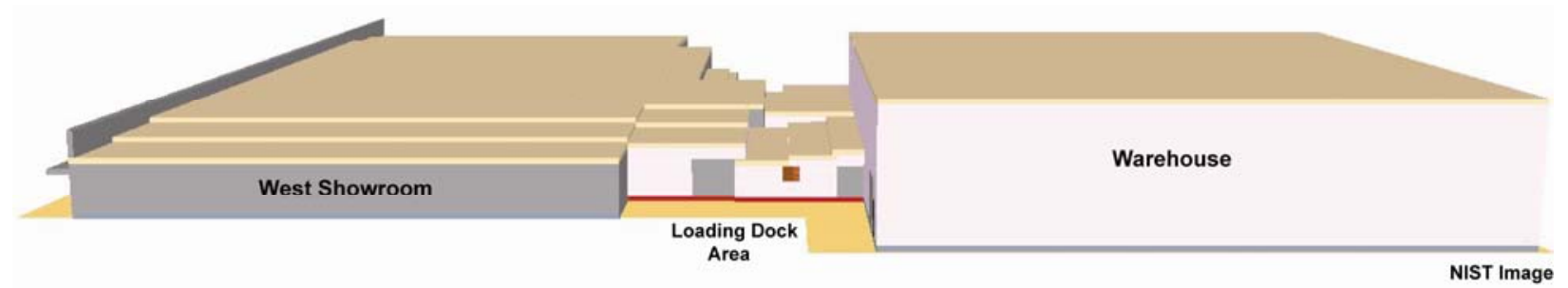

Figure 4-3. Side view of the Sofa Super Store as rendered by Smokeview.

\subsubsection{Geometry}

Building features such as walls, floors, windows, doors and furniture are described in FDS as "obstructions" (OBST in the input file, Appendix L). The obstructions may be colored for identification and may be assigned material properties. The obstructions may be entered into the simulation with exact measurements from the building. However, FDS can only work with items that fall exactly on cell boundaries. FDS takes the obstructions as they are defined in the input file and adjusts them to match the cell boundaries. As a result, items may either grow or shrink to match the cells. Given the cell dimensions, these size adjustments were of only secondary importance.

Figure 4-4 is a plan view of the Sofa Super Store, as rendered by Smokeview, showing a layout of the furniture and walls. Furniture in the main showroom was consumed almost completely by the fire (see Figures B-15 to B-17, and D-20 to D-25). There was some remaining furniture in the west showroom, primarily in the rear (south) end of the building (see Figures E-17 to E-25). This area of the showroom stored sleep sofas in displays that were stacked two high on wood-framed racks. The damage in the east addition was much less severe because the roll-down doors closed when their fusible links released (see Figures F-11 to F-16). The rear roll-down fire door between the main and east showrooms was partially blocked by a coat rack and did not close completely. The warehouse contained multiple rows of highrack storage. The fire consumed nearly all of the furniture in the warehouse (see Figures G-15 to G-17) and loading dock (see Figures B-4 to B-6). The consumption of fuel in the main and west showrooms 
was so extensive that the furniture layout used in the model was based largely on post-fire residue and witness accounts. Post-fire residue included metal hardware, steel frames, hinges, and springs. Witnesses described the showrooms as being "crowded" with furniture. The general description of the main showroom placed aisles down the center of the room, from the front door to the rear office area. Further, three aisles stretched across the showroom, east to west, aligned approximately with the roll-down doors. The remaining floor space was filled with upholstered furniture laid out tightly in typical rectilinear configurations. Because the exact layout was not known, furniture in the simulation was arranged in rows. Some of the rows were created by arranging furniture in "U" shaped configurations with a sofa and two chairs. In other places, rows consisted of single furniture items. The rear of the west addition was arranged in a manner that was similar to what could be discerned from the furniture that was in place during the post-fire scene examination.

Figure 4-5 shows a rendered view from the interior of the main showroom. The light colored area in the lower center of this image is the rear roll-down door (roll-down fire door 2 in Figure 1-8) on the wall separating the main showroom from the west showroom. This figure also shows the open non-fire rolldown door in the wall that separated the loading dock from the holding area. At the south end of the holding area, the light-colored area represents the location of the roll-down door (fire door 1 in Figure 1-8) in the wall that separated the original structure from the breezeway that provided access to the warehouse. According to witness accounts this door closed early in the event and this would be consistent with the fusible links activating.

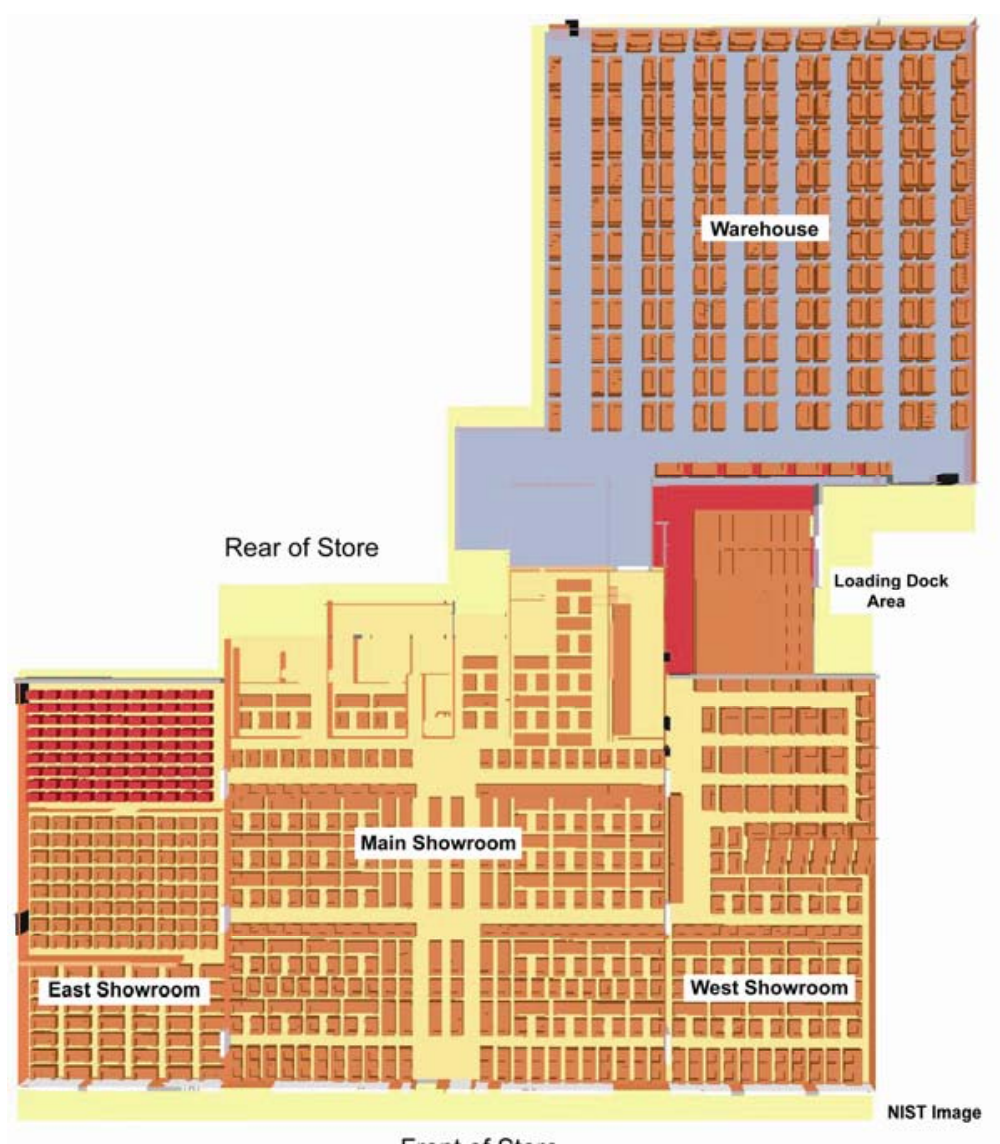

Figure 4-4. Overhead view showing furniture layout used in the FDS simulations. 


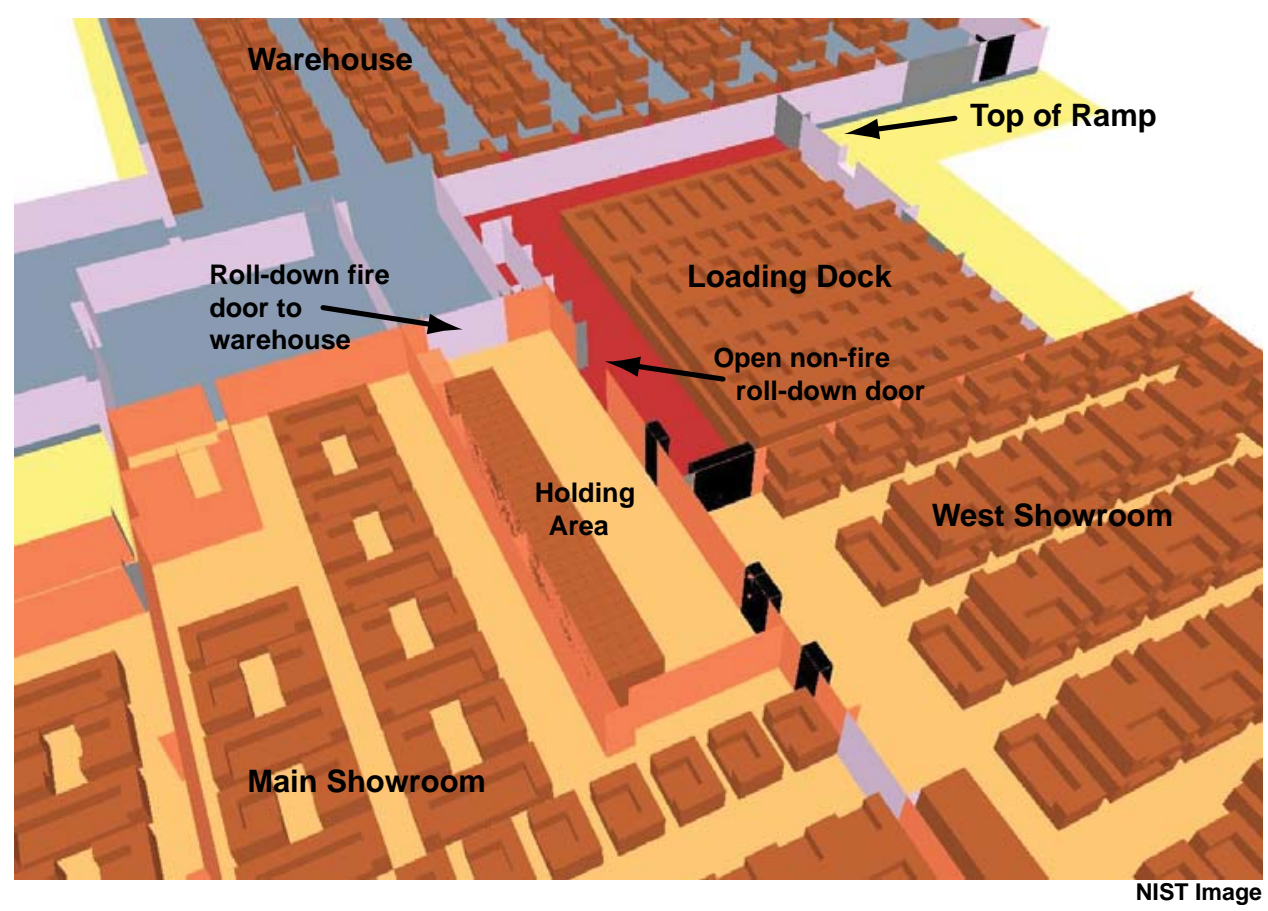

Figure 4-5. Overhead view including sections of the main and west showrooms, the holding area, loading dock, breezeway, warehouse and work areas in the simulation.

\subsubsection{Synchronizing the Model}

In order to develop an understanding of the fire progression and the conditions inside the structure, it was necessary to synchronize the simulated time line with the physical time line. The development of the incident time line was presented in Chapter 2. Since the earliest available photos and video were captured well into the event (approximately 13 minutes after the first dispatch), it was determined that the most appropriate way to synchronize the simulated time line with the physical time line was through a combination of radio transmission transcripts and witness statements.

At 7:07 p.m., a report of a fire at the Sofa Super Store was received by the Charleston County 911 Emergency Center. A store manager attempted to put out the fire with a portable dry chemical fire extinguisher, but he was unsuccessful. After locating a second portable extinguisher, and heading back toward the loading dock, the store manager was unable to enter the loading dock because of the intense heat and smoke. From a position within the holding area, he discharged the second extinguisher into the loading dock. As he discharged the extinguisher, he heard one of the roll-down doors closing. The sound was presumably from the door (fire roll-down 1 in Figure 4-5) at the end of the holding area.

Battalion Chief 4 was the first city fire department unit to arrive on scene. At 7:10:46 p.m. ${ }^{1}$, BC-4 made a radio transmission to dispatch stating, "Bunch of trash and debris burning along side the building." That was followed 10 seconds later by, “...it may have got in the building. It’s right up against the wall.” Following these transmissions, BC-4 relocated to the front of the building to direct Engine 10 to back down the driveway to the loading dock area. Engine 10 arrived on scene at 7:11:40 p.m. When BC-4 and

\footnotetext{
${ }^{1}$ Times in Table 2-1 rounded to nearest minute, so 7:10:46 p.m. rounded to 7:11 p.m.
} 
E-10 captain returned to the loading dock area, flames were visible inside the loading dock through the opening in the wall that housed the exhaust fan. This sequence of events was used to synchronize the model time line to the physical time line, where time 0 in the simulation is equal to 7:10:53 p.m.

\subsubsection{Heat Transfer and Materials}

Radiative heat transfer is included in the model and is shown as the solution of the radiation transport equation for a non-scattering gray gas. All solid surfaces are assigned thermal boundary conditions, plus information about their burning behavior. Heat and mass transfer to and from solid surfaces are based on empirical correlations. FDS utilizes material properties of the furnishings, walls, floors, and ceilings to compute fire growth and spread. For materials that burn, additional parameters such as reference temperature, heat of combustion, heat of reaction and maximum burning rate are specified. The properties for the materials, to the extent they were available, were taken from published fire data and references.

The assumption was made that all furnishings in the building were composites of foam and fabric, and that this material or composite constituted the entire fuel load. Table K-2 (Appendix K) details the properties for each of these layers. It was assumed that a single step reaction occurred for each material, and that all of the material was converted into gaseous fuel. The reaction was based on polyurethane foam, represented as $\mathrm{C}_{6.3} \mathrm{H}_{7.1} \mathrm{O}_{2.1} \mathrm{~N}$ [5, Appendix C, Table C.3]. Other fuels such as flooring, wood display shelves, ceiling tile, paper documents, or wood framing, were not included as fuel for these simulations.

Interior finishes were categorized into the following list of materials: gypsum board, concrete block, concrete slab, sheet metal, steel, glass, carpet, ceiling tile, and wood. Table K-3 summarizes the properties assigned to materials in the simulation. Sheet metal and steel were assigned the same properties but were distinguished by thickness.

The simulations did not include specific items as components of the fuel package because these items were considered to have negligible impact on the rapid fire spread through the showrooms during the early stages of the fire. These items included spray cans of solvents and paint at the rear of the main showroom and the foam insulation and membrane in the roof. Post-fire examination of an enclosed storage area outside the rear wall of the main showroom revealed dozens of spray cans that appeared to have contained paint or solvents. It was assumed that the fire spread across the main showroom to reach this storage area. Therefore, it was unlikely that the fuels in this storage area contributed significantly to the fire spread in the main showroom during the first 40 minutes of the fire.

The foam insulation and roof membrane were located above the metal roof decking. If flames from the fire had impinged on the underside of the metal decking and increased the temperature of the decking, the foam insulation could have softened, melted, and eventually pyrolyzed. The pyrolysis products would then have leaked into interstitial void space below the decking and above the suspended ceiling through cracks or holes in the metal decking. If the unburned fuel/pyrolysis products had combined with sufficient air, then it would have resulted in increased heat release rate.

The flames from the loading dock had direct access to the underside of the metal decking above the holding area because it lacked a suspended ceiling. However, a suspended ceiling had been installed above the rest of the main showroom. If the suspended ceiling tiles had remained intact, flames from fire on the showroom floor would not have been able to impinge on the underside of the metal decking and it would have been difficult for additional air to flow into the interstitial space. 
Photographs taken during the fire demonstrate flames above the roof, but the flames appeared to be present only in close proximity to the holding area. During post-fire interviews, fire fighters did not report significant numbers of dislodged ceiling tiles or describe any flames above the ceiling except for around the holding area. This is consistent with the lack of flames on the roof, with the exception of the roof above the holding area. Since the direct impingement of flames appeared to be limited to the metal decking above the holding area, the energy content of the foam above the holding area was estimated to be less than $0.5 \%$ of the energy content of the fuels in the the enclosed loading dock. During the first 40 minutes of the fire, the quantity of smoke and unburned fuel from the loading dock that was channeled through the holding area into the void space was assumed to be much greater than the leakage of foam pyrolysis through the metal decking above the holding area.

\subsubsection{Combustion}

The combustion process is handled by tracking where fuel and air mix at certain concentrations and react to produce heat. This is known as a mixture fraction combustion model [3], in which burning occurs in regions where the fuel and air are in specified stoichiometric proportion. This reaction processes generates heat along with products of combustion such as carbon monoxide (CO), carbon dioxide $\left(\mathrm{CO}_{2}\right)$ and water $\left(\mathrm{H}_{2} \mathrm{O}\right)$, that are tracked as they move throughout the cells.

\subsubsection{Boundary Conditions and Vent Openings}

The placement of obstructions within the simulation forms the structure of the building and its contents. The flow calculations performed by FDS allow air, hot gases, smoke and flames to flow through the simulated building. Thermal radiation travels by line-of-sight and may be intercepted by obstacles within the cells.

During the course of a fire, some items within the building may be consumed by the fire or otherwise change position. FDS does not have the capability to calculate burn-through or collapse but the user can remove items during the course of the calculations. Items that are removed can represent objects that fall or are destroyed by fire, or objects that are changed by people such as doors or windows that are opened.

An opening or vent at the boundary of the simulation domain is defined in the simulation as a 'VENT' in the FDS input file (see Appendix L). All sides of the computational domain were modeled as being open to the environment. In these simulations, vents were used to allow fresh air to enter the simulation domain and to allow smoke and heat to exit the domain. Vents may be either simple openings that allow natural flow to occur based on the buoyancy of the hot gases, or vents may use a specified or forced flow rate such as the flow from a fan.

A vent can also be used to introduce heat into the simulation and thus create the effect of a fire source in the model, by ejecting fuel according to a prescribed heat release rate (HRR) ${ }^{2}$. Simulating the movement of the fire from the trash pile, through the wall, and into the loading dock, vents were used to initiate the fire on the loading dock. Later in the fire evolution, additional vents were used to simulate the spread of the fire from the holding area into the rear of the main showroom.

\footnotetext{
${ }^{2}$ Heat Release Rate (HRR) is the rate at which a fire generates or releases energy or heat.
} 
Doors and windows were opened during the simulation based on time estimates obtained from photos, video, radio transmissions and interview statements. Additionally, some venting was triggered by temperature events. Roofs on the loading dock and warehouse were equipped with skylights that failed at various points during the fire. Likewise, the roll-down fire doors on the warehouse breezeway and the east showroom were closed in the simulation when temperatures nearby reached the activation temperature of the fusible links, $73.9^{\circ} \mathrm{C}\left(165^{\circ} \mathrm{F}\right)$. Fusible links that were stamped with " $165^{\text {” " were }}$ observed by the NIST team in post-fire inspections. The performance or melting of the link at $73.9^{\circ} \mathrm{C}$ $\left(165^{\circ} \mathrm{F}\right)$ was not tested by NIST.

The CFD used the front doors to the main showroom access the showroom to survey fire-spread, to pull hoses, and to conduct suppression. Throughout each simulation, the front doors were open. Time stamped photographs were used to determine the times at which the windows of the main showroom were vented by fire fighters at the scene. A series of photographs documented the removal of the front windows on the main showroom between 7:35:05 p.m. and 7:35:57 p.m. Photos were also used to estimate the times at which the windows on the west showroom failed. These windows failed between approximately 7:38 p.m. and 7:44 p.m. In the simulation, windows were removed at times corresponding to estimates based on photographs and not based on the interior conditions or material properties of the windows.

Radio transmission logs were used in conjunction with interview statements to estimate the time at which the door connecting the west showroom to the loading dock was opened by CFD. The timing events associated with venting the loading dock roof, main showroom ceiling and roof and west showroom interstitial space were all based on the conditions simulated by the model. NIST did not conduct fullscale tests to quantify the performance of roof, ceiling, or skylight assemblies.

Photographs taken during the early stages of the fire show heavy smoke and flames exiting at the roof level. Figure 4-6 shows a photograph taken at 7:28:15 p.m. This photo shows heavy smoke venting from the loading dock and rear of the main showroom. Flames are also visible and appear to be coming from the roof of the main showroom. Because it was not possible to determine the exact location or size of the holes in the ceiling and roof, several holes were used in the simulations to represent the ventilation that took place. Table K-4 summarizes the ventilation conditions used in the simulations.

\subsubsection{Fire Sources Used in the Simulation}

Although the cause of the fire was undetermined, the area of origin was identified [14]. The fire initiated on a pile of discarded furniture outside the loading dock. The discarded furniture was generally located in the corner formed by the loading dock exterior (west) wall and the ramp that was used to access the loading dock door. Figure 4-7 shows a photograph of this area.

In the simulation, the fire was initiated ${ }^{3}$ in the loading dock at floor level, between the door and the ventilation fan access hole. This is identified as "Loading Dock Source” in Figure 4-8 and produced a

\footnotetext{
${ }^{3}$ In FDS, the initiating fire is treated as an inflow of heat and combustion products through a vent. A vent was used within the simulation to introduce heat into the modeling domain and create the effect of a fire source in the model, by injecting fuel according to a prescribed HRR.
} 


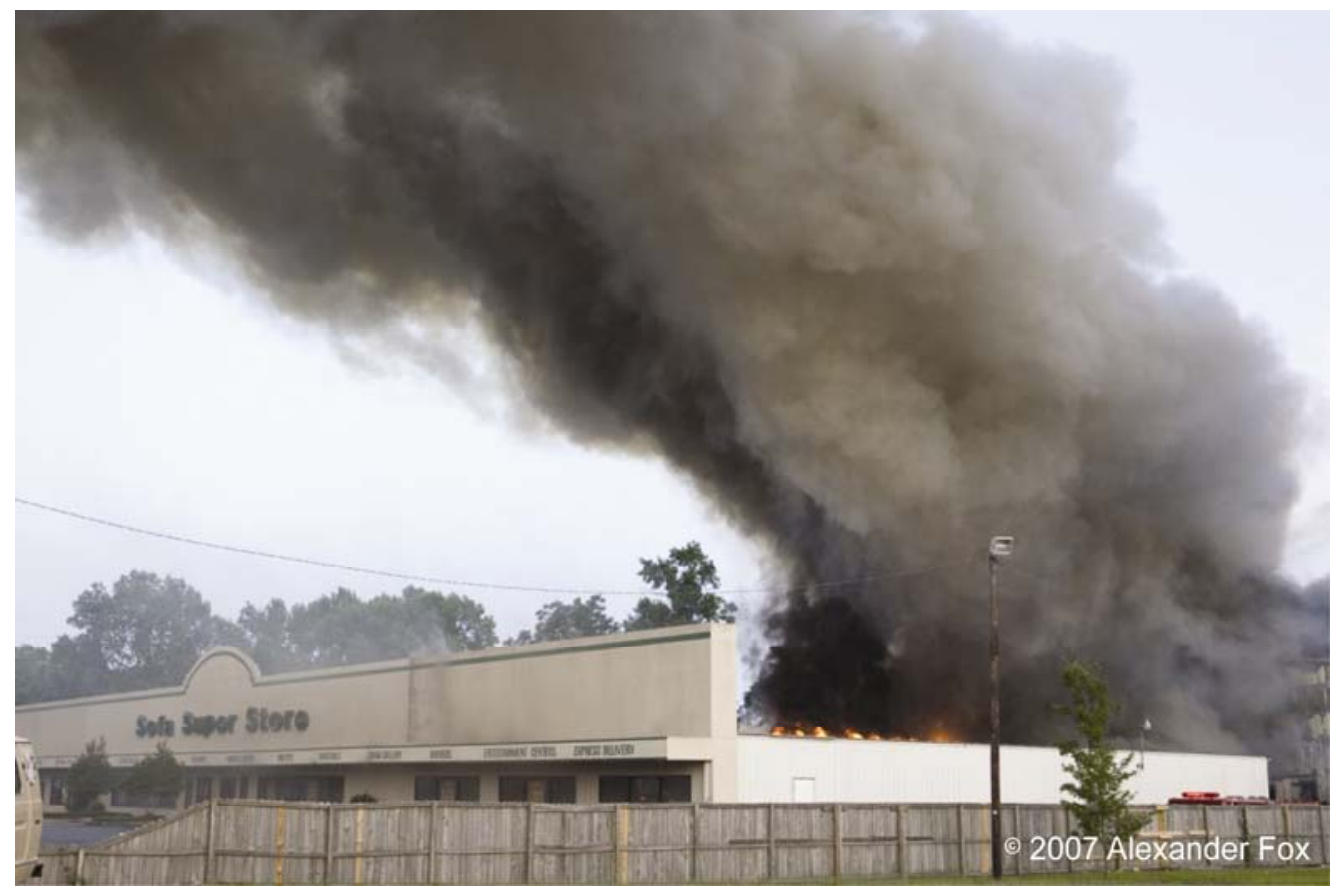

Figure 4-6. Photograph showing the north and west sides of the showroom. Photo was taken at 7:28:15 p.m.

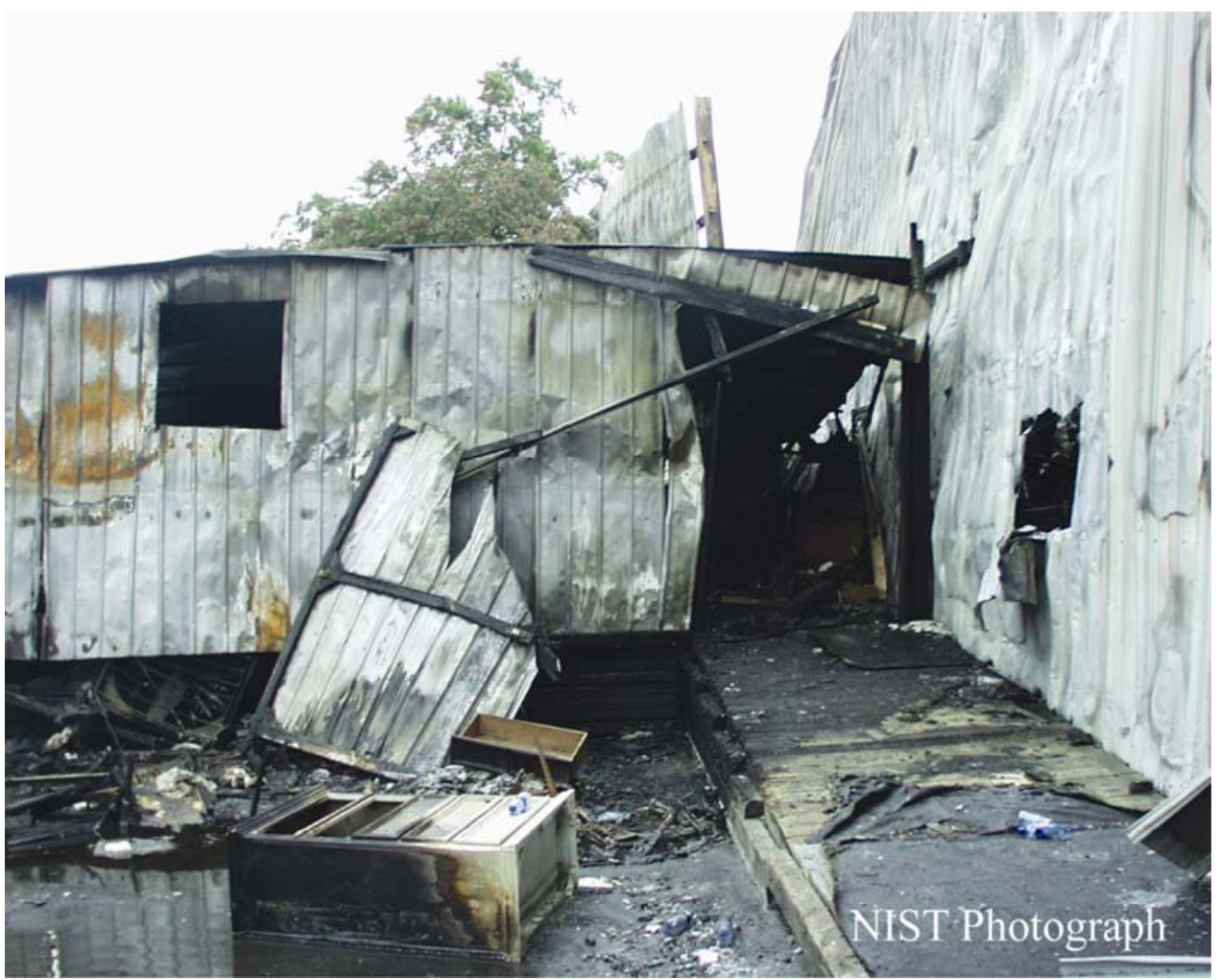

Figure 4-7. Photograph showing the outside of the loading dock. This was identified as the area of fire origin. 
peak HRR of $700 \mathrm{~kW}$. The fire source was activated at the start of the simulation, operated for $600 \mathrm{~s}$, and then shut off. No attempt was made to simulate the fire on the exterior side of the wall.

The route by which fire made its way through the holding area and into the main showroom is not precisely known. The most likely means would have been for fire to breach the wall or door of the holding area into the rear of the main showroom, or for ignition to occur as a result of burning material dropping from above the ceiling. Because the route of spread was not known, fire-spread into the main showroom was assumed to be initiated in the area near the holding area wall. This area is identified in Figure 4-8 as "Main Showroom Source 1" and "Main Showroom Source 2." These initiating fires were ramped separately using parameters for ultrafast $\mathrm{t}^{2}$ fire curves [15]. Source 1 was initiated at $525 \mathrm{~s}$ (7:19:38 p.m.) and peaked at 4 MW. Source 2 was initiated at 660 s (7:21:53 p.m.) and peaked at 6 MW. A range of fire development parameters and conditions was input into different model runs and the simulation results were compared to observations. The parameters and conditions described above provided simulation outputs that were most consistent with the observations.

\subsection{BASELINE SIMULATION}

\subsubsection{Overall Accuracy}

The baseline simulation represents an estimate of what actually occurred in the Sofa Super Store based upon the evidence and time line described in the previous chapters. The resulting HRRs in the different portions of the store, visibility as estimated from the predicted smoke flows, and the temperatures and oxygen volume fractions at different elevations are presented in the following sections.

The following sections describe the simulation of properties that were not measured or observed on site. These simulated properties characterize the fire development (HRR, fire-spread rate, smoke movement, and temperature field) and are presented in the context of loss of tenability within the building due to lack of oxygen and heat.

\subsubsection{Heat Release Rate}

The total HRR for the fire, excluding the warehouse, is plotted as a function of time in Figure 4-9. The HRR produced by the warehouse contents dominated the total HRR in the mid and late stages of the simulation, but since the breezeway door closed early in the fire time line, there was no flow or transfer of material between these areas of the structure. In addition, the fire department did not enter the warehouse to suppress the fire there. This analysis will focus on conditions in the loading dock and showrooms.

The HRR grew quickly from the initiating $700 \mathrm{~kW}$ fire, reaching $90 \mathrm{MW}$ in $280 \mathrm{~s}$ as fire spread through the loading dock and into the holding area. Figure 4-10 separates the HRR events in the loading dock, holding area and rear showroom, main showroom, and west showroom. During the first $500 \mathrm{~s}$, the loading dock fire dominated the HRR at about $85 \mathrm{MW}$. As the fire spread into the holding area and rear of the main showroom the HRR for the holding area and the rear of the main showroom began to increase to about $100 \mathrm{MW}$ at around $1200 \mathrm{~s}$. This increase in fire-spread to the holding area and main showroom was simulated by turning on Source 1 and 2 (Figure 4-8) in the computer model. As the fire spread into the rear of the main showroom, the fire became underventilated and began to decrease in HRR. The total HRR continued to decrease until about $1450 \mathrm{~s}$ when the removal of the windows in the main showroom, beginning at $1457 \mathrm{~s} \mathrm{(7:35:10} \mathrm{p.m.),} \mathrm{provided} \mathrm{a} \mathrm{fresh} \mathrm{influx} \mathrm{of} \mathrm{oxygen} \mathrm{leading} \mathrm{to} \mathrm{the} \mathrm{subsequent} \mathrm{rapid} \mathrm{fire}$ 


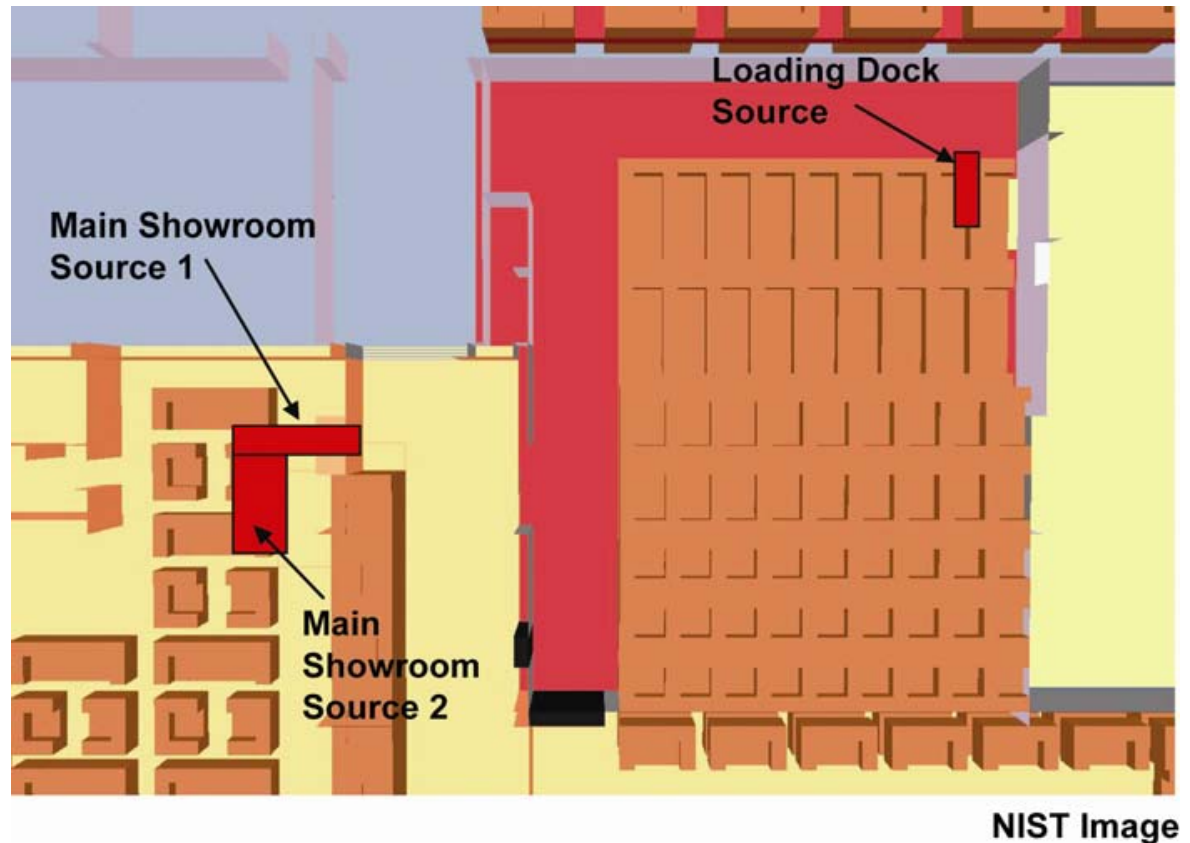

Figure 4-8. Diagram showing locations of initiating fire sources in the loading dock and rear of main showroom.

growth. The HRR of the fire grew to over $100 \mathrm{MW}$ in the main showroom and $50 \mathrm{MW}$ in the west showroom. The energy release rate of the holding area/rear main showroom increased slightly and then leveled out at about $40 \mathrm{MW}$. The loading dock HRR exhibited a transient peak at about $50 \mathrm{MW}$ and then decreased to about $15 \mathrm{MW}$.

\subsubsection{Fire Growth and Smoke Spread}

The earliest available photos of the fire were taken at 7:22 p.m., approximately 13 minutes after the first dispatch. Therefore, knowledge of the early fire development is based on eyewitness accounts obtained during interviews of fire fighters. Some information was also gleaned from transcripts of the CFD radio transmissions. The fire initiated outside the enclosed loading dock in a pile of discarded furniture. This fire developed for an unknown period of time, and eventually spread into the enclosed loading dock through the floor and gaps in the construction. For each simulation, the model fire was initiated inside the loading dock. The model time line was synchronized to the physical time line at 7:12:43 p.m., the time BC-4 made the statement to the Assistant Chief, "Chief, I know it's inside that part of the building right there." This transmission was made after BC-4 had guided Engine 10 down the driveway to the loading dock area. The model time corresponding to this event was $110 \mathrm{~s}$. By this time, fire inside the loading dock had progressed to the point that flames were venting from the exhaust fan in the west wall as well as through a gap between the roof sections of the loading dock. Figure 4-11 is an image rendered $110 \mathrm{~s}$ into the simulation viewing the west side of the structure that shows fire and smoke venting from the loading dock wall and roof. It should be noted that the orange color in Smokeview tracked the location of stoichiometric fuel and air mixture. If the temperature were high, then the orange surface could be thought of as a flame; if the temperature were below a threshold value, then no flame was actually present, just a non-burning mixture of fuel and air. 


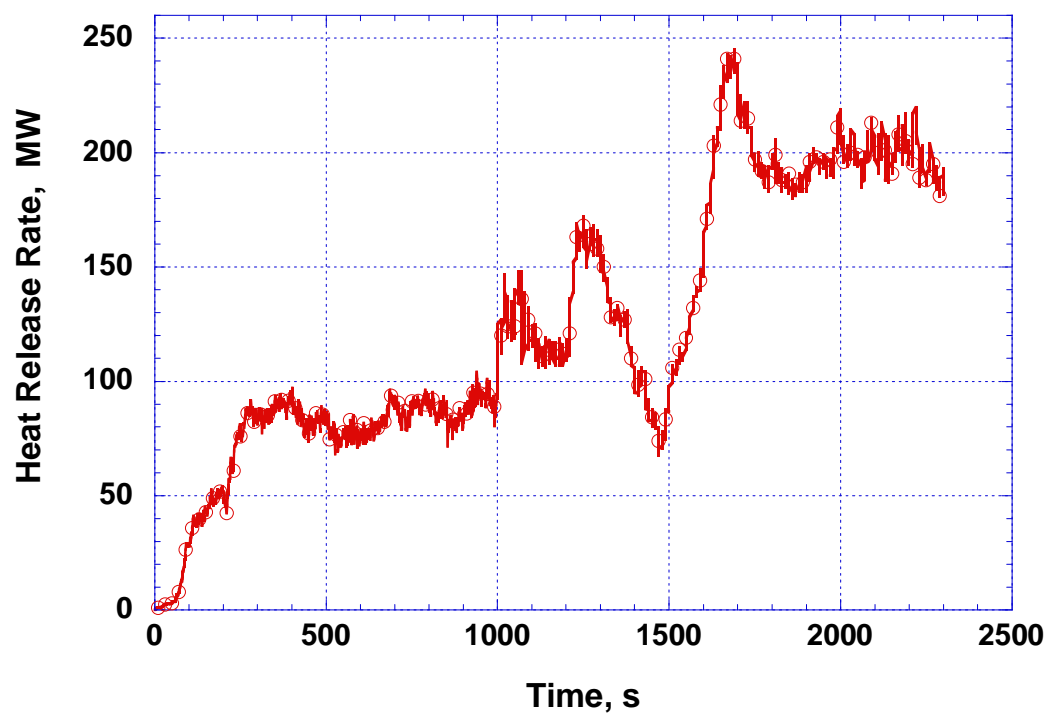

Figure 4-9. Total heat release rate, excluding the warehouse.

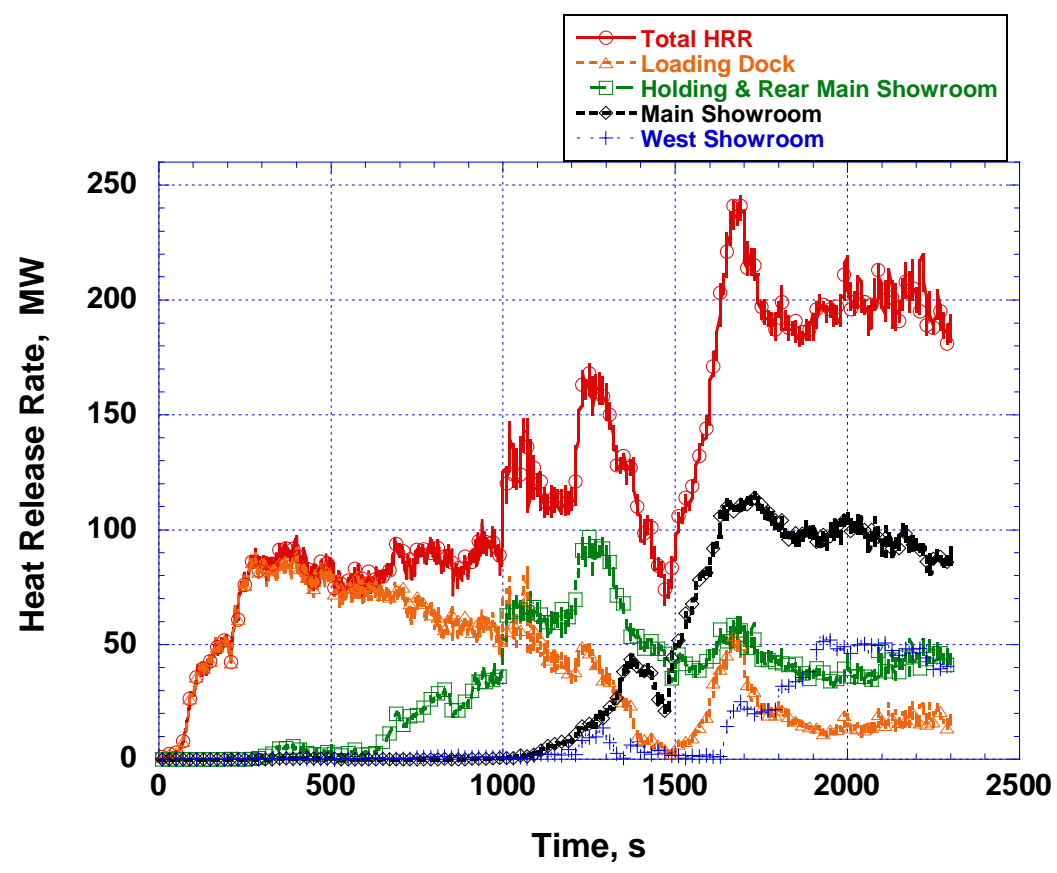

Figure 4-10. Component heat release rates for the loading dock, holding area, main showroom, and west showroom. 
By the time (110s), smoke had filled the loading dock and begun entering the void space above the main showroom ceiling through the holding area. The holding area was adjacent to the loading dock and was accessible through an open roll-down door. This room did not have a suspended ceiling and had shelves upon which futon cushions were stored. Smoke and heated combustion gases produced by the fire passed into the void space above the main showroom. This development was concealed from the fire fighters upon first entry into the building.

Figure 4-12 shows a rendered image of the loading dock and showrooms at $110 \mathrm{~s}$. In this figure, obstructions below ceiling level have been removed and all remaining obstructions are transparent (indicated only by their outlines) to allow visible access to the fire and smoke. This figure shows that very early in the fire event smoke had entered the holding area through the open roll-down door and entered the void space above the main showroom ceiling.

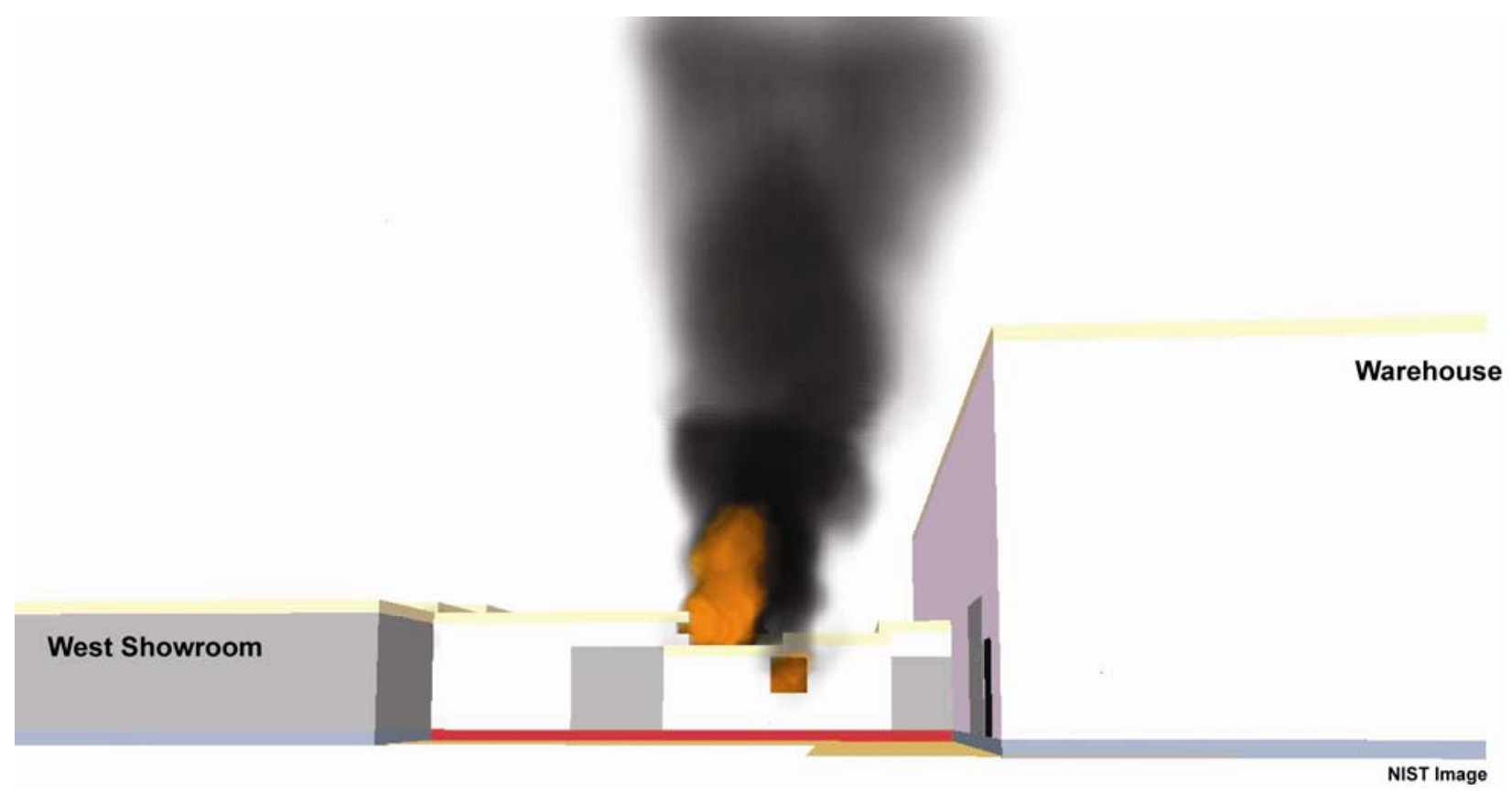

Figure 4-11. Rendered image showing the west side of the loading dock $110 \mathrm{~s}$ into the simulation.

The AC and E-10 captain entered the main showroom and initially observed clear conditions. Figure 4-13 shows an image of the main showroom, from the perspective of a person standing at the front entrance and facing south west, toward the holding area. This image was rendered $80 \mathrm{~s}$ into the simulation (7:12:13 p.m.), approximately the time the Assistant Chief entered the showroom and observed clear conditions.

At 7:13:17 p.m. (144 s) the E-11 captain called over his radio "I need an inch and a half inside this building." The AC opened the double doors connecting the west showroom to the loading dock and had the door pulled out of his hand by the force of air rushing into the loading dock. 


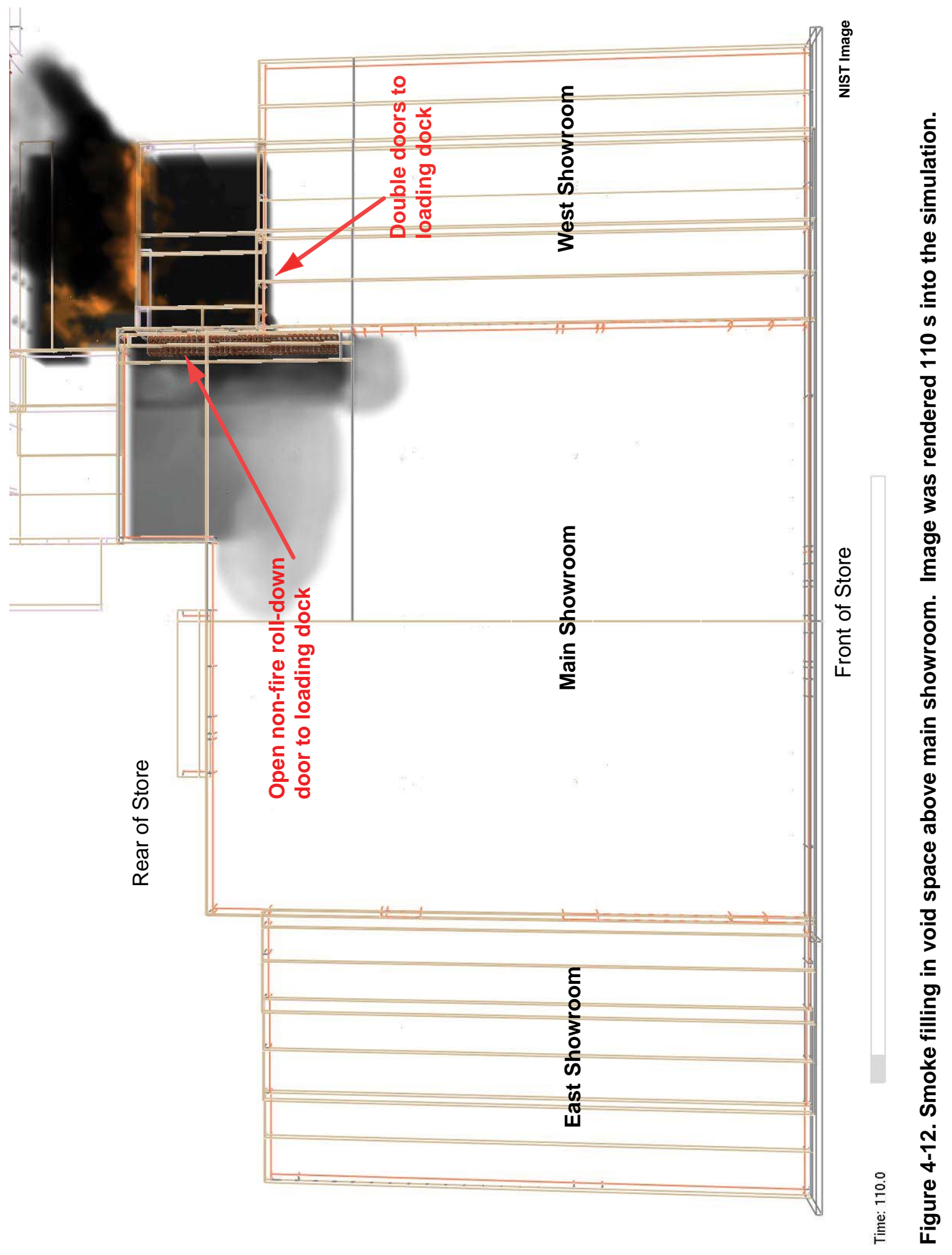




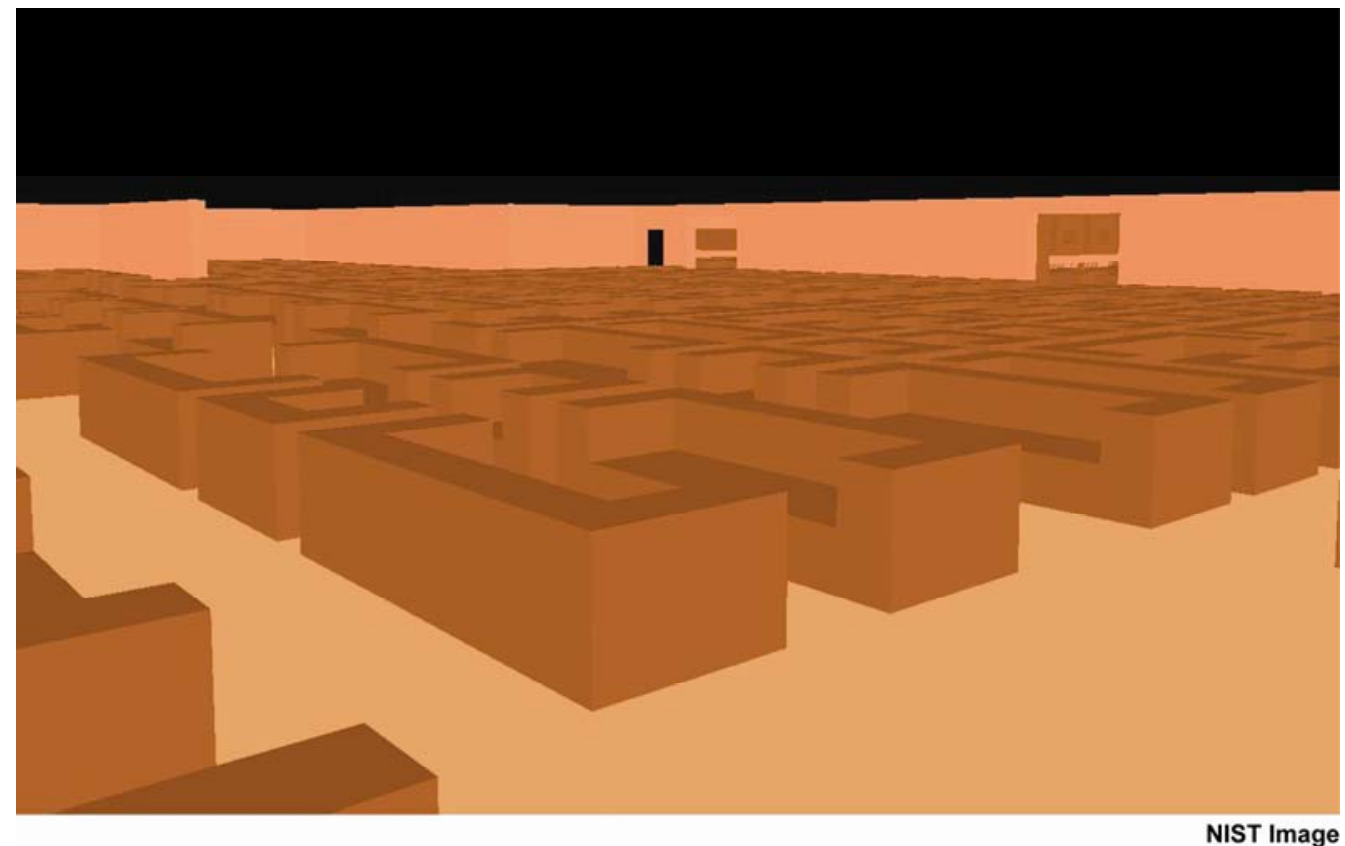

Figure 4-13. Image rendered $80 \mathrm{~s}$ (7:12:13 p.m.) into the simulation from inside the main showroom, near the entrance. View is toward the south west corner of the main showroom.

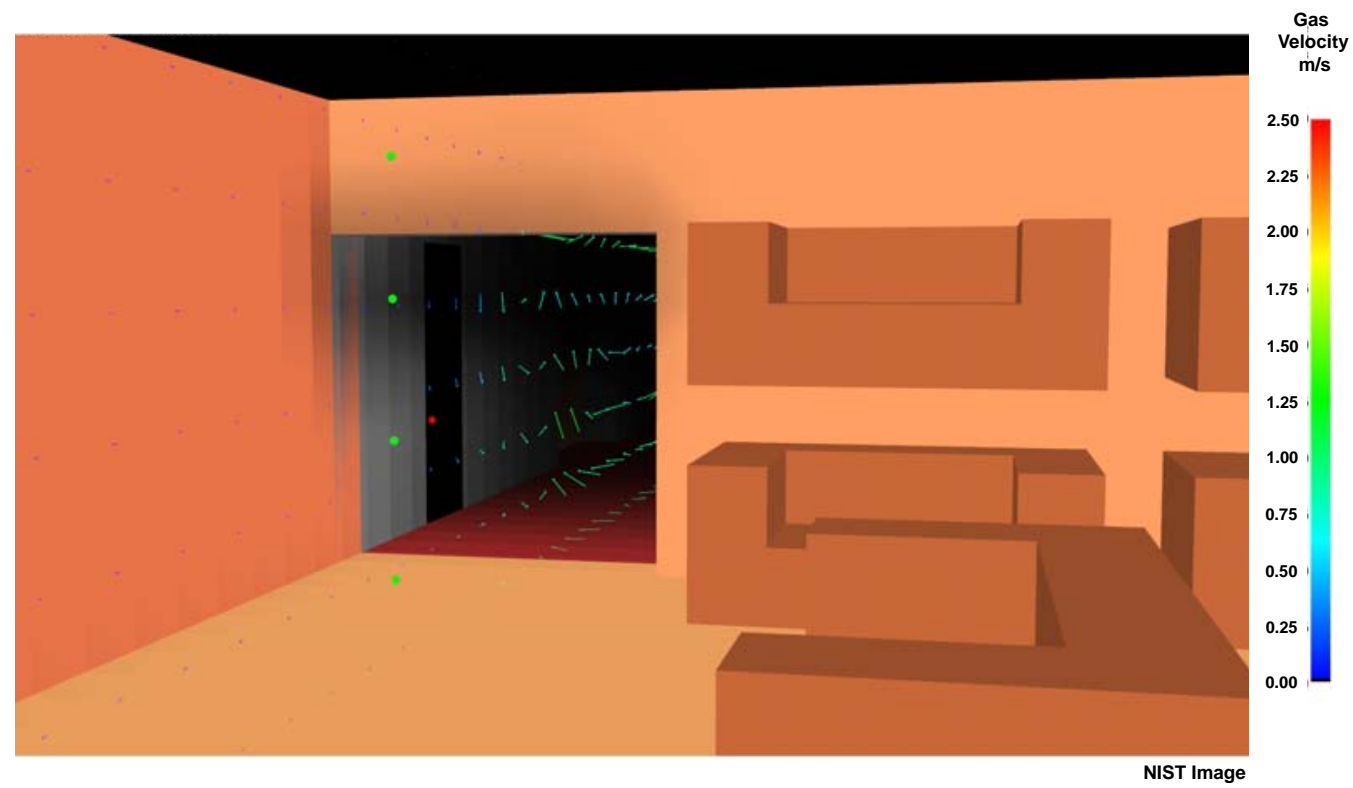

Figure 4-14. Image rendered $145 \mathrm{~s}$ (7:13:18 p.m.) into the simulation from the west showroom, near the double doors that lead to the loading dock. Arrows indicate direction and relative speed of air moving from the showroom into the loading dock (The relative speed is proportional to the length of the arrow, i.e. longer arrows indicate higher relative speeds and color scale indicates velocity magnitude). 
Figure 4-15 shows a rendered image of the double doors from inside the west showroom at $145 \mathrm{~s}$, 1 second after they were opened. The arrows or velocity vectors indicate that the air was flowing from the rear of the west showroom into the loading dock just after the doors were opened.

Smoke penetration through the ceiling was modeled by creating an opening in the rear of the main showroom when the adjacent temperature reached $50^{\circ} \mathrm{C}$. Figure $4-15$ shows the progression of fire and smoke below the ceiling level (2.6 m) throughout the loading dock, holding area and showrooms between $300 \mathrm{~s}$ (7:15:53 p.m.) and $900 \mathrm{~s}$ (7:25:53 p.m.). The images in this figure have been clipped down to the level of the ceiling in the showrooms.

At 300 s (7:13:53 p.m.) there is light smoke in the rear of the main and west showrooms. Initially, smoke in the west showroom entered through the double doors while the smoke in the main showroom entered through the ceiling. The ventilation openings in the ceiling in the main showroom (blue colored squares in Figure 4-15) opened between $261 \mathrm{~s}$ (7:15:14 p.m.) and $976 \mathrm{~s}$ (7:27:09 p.m.).

By 600 s (7:20:53 p.m.), the smoke layer had permeated the west and main showrooms, and there was evidence of a "tunneling" as fresh air was being pulled into the front door to supply oxygen. This is consistent with the account of Engineer 6, who entered the structure at approximately 7:24 p.m. (787 s) and reported a tunnel of clear space that extended several feet inside the showroom as fresh air was being pulled through the open door. Beyond this space he reported heavy smoke conditions. By $900 \mathrm{~s}$ ( $7: 25: 53$ p.m.), the fire in the rear of the main showroom had grown to approximately $23 \mathrm{MW}$.

The captain and two fire fighters from E-15 entered the main showroom at approximately 7:19:00 p.m. (487 s into the simulation). According to reports, they encountered smoke and donned their

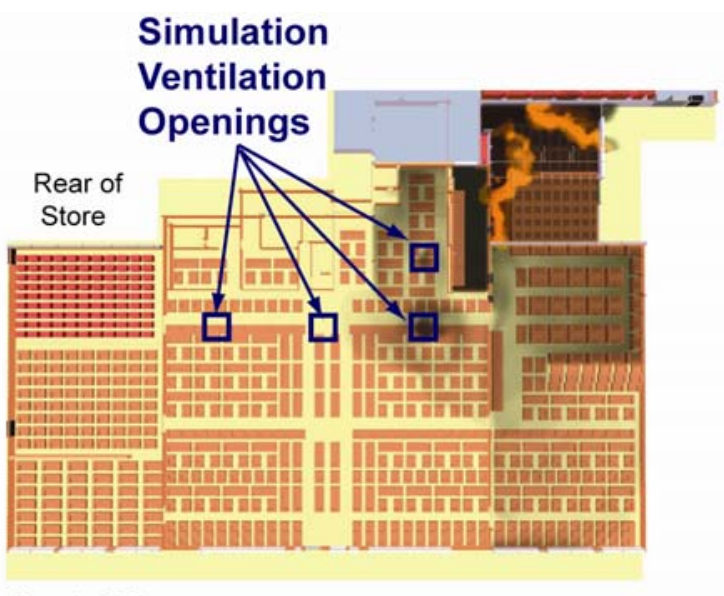

Front of Store

\section{$360 \mathrm{~s}$}

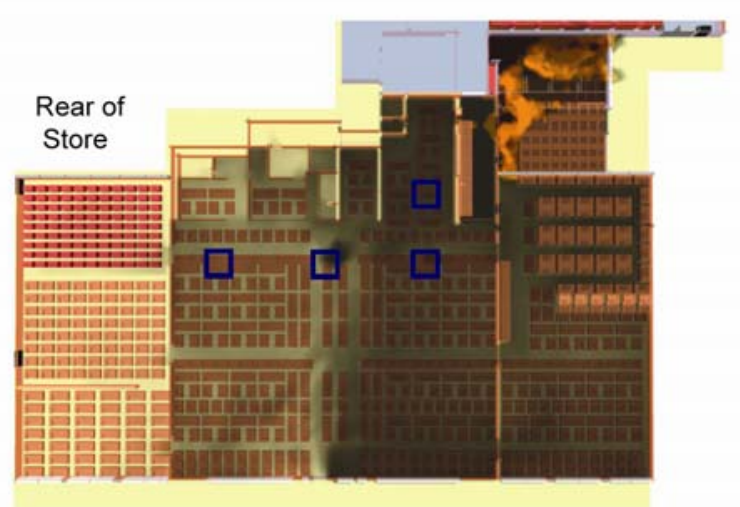

Front of Store

$480 \mathrm{~s}$

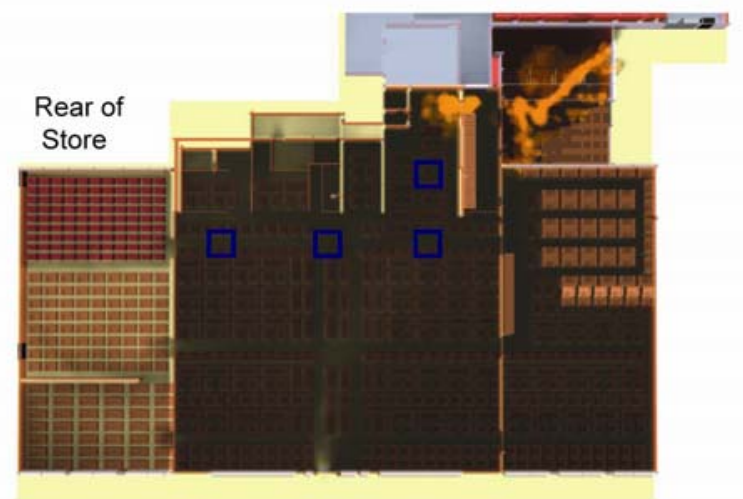

Front of Store

$$
900 \mathrm{~s}
$$

NIST Image

Figure 4-15. View of fire and smoke progression from above the showrooms from 300 to 900 s (7:15:53 p.m. to 7:25:53 p.m.). The images are clipped to view conditions below the ceiling. 


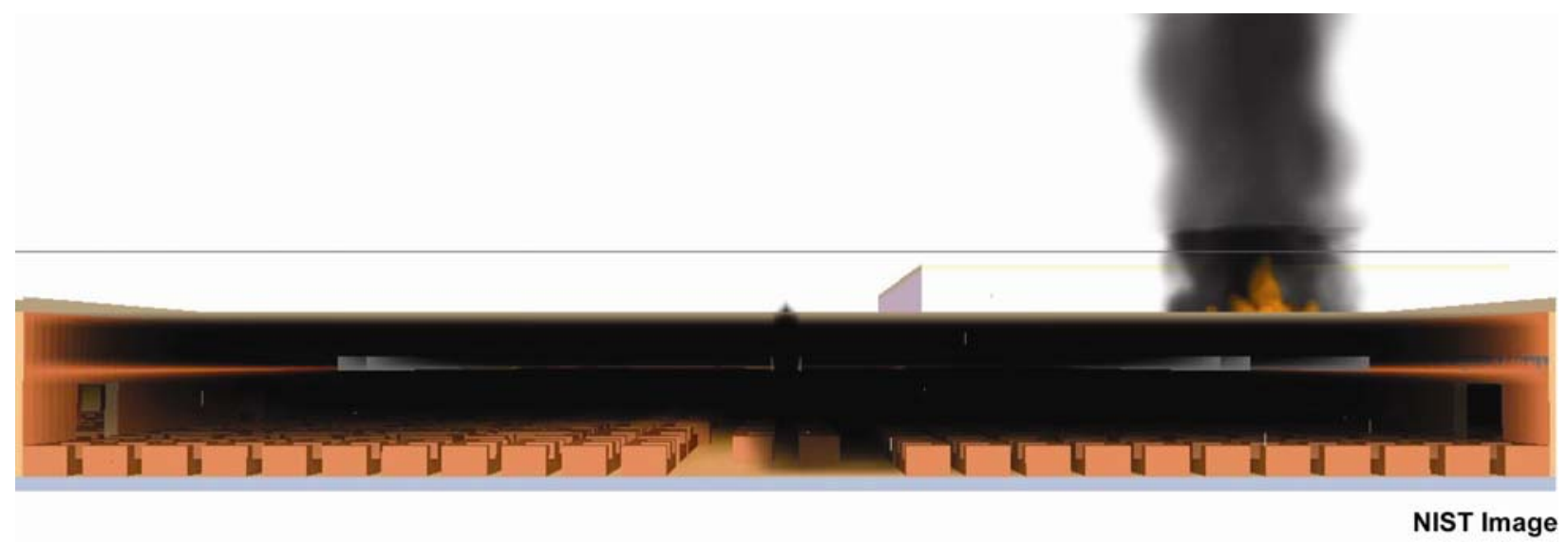

Figure 4-16. Model rendering of view inside the front of the main showroom at $487 \mathrm{~s}$ (7:19:00 p.m.).

self-contained breathing apparatus (SCBA) face pieces. Figure 4-16 shows an image of the front of the main showroom, with the front wall removed, at $487 \mathrm{~s}$. This image shows that smoke had filled the void space above the ceiling and banked down to the showroom floor. Conditions on the east side, including the area near the entrance, are not as severe. However, as one progresses toward the rear and west, conditions degrade significantly.

Engine 19 reported on scene at 7:20:08 p.m. (555 s). E-11 captain was making his way out of the structure to investigate the problem with the $6.4 \mathrm{~cm}$ (2.5 in) hand line at approximately the same time the crew from E-19 was entering the building. At this time E-11 captain noted heavy smoke conditions and increasing temperatures.

Figures 4-17 and 4-18 show smoke filling in, respectively, the main and west showrooms from the perspective of someone at the front of the room. The sequence in Figure 4-17 begins at $270 \mathrm{~s}$ (7:15:23 p.m.), after smoke began penetrating the ceiling. The sequence in Figure 4-18 begins at $270 \mathrm{~s}$ (7:15:23 p.m.). In both showrooms, conditions deteriorate considerably within a $120 \mathrm{~s}$ span.

At 1020 s (7:27:53p.m.), the fire in the main showroom reached about 70 MW and had begun moving forward toward the front of the showroom. Figure 4-19 shows the progression of fire and smoke throughout the loading dock, holding area and showrooms between 1020 and 2040 s. The front windows were vented during the period between 1457 through 1530 s (7:35:10 through 7:36:23). Fire reached the front of the main showroom at approximately $1540 \mathrm{~s}$ (7:36:33 p.m.) and spread across the west side of the main showroom by 1590 s (7:37:23 p.m.). By 1680 s (7:38:53 p.m.), the fire had moved into the front of the west showroom. This is consistent with the image in Figure 4-23, where the fire is visible in the west showroom through the window opening.

Figures 4-20 through 4-24 show comparisons of the fire and smoke progression with available photos at various times during the critical time between 7:23 p.m. and 7:45 p.m. (740 s through $2040 \mathrm{~s}$ ). Figure 4-20 shows one of the earliest photos that were obtained of the fire, taken at 7:23:16 p.m. (743 s). At this time the fire was still mainly concentrated in the loading dock and holding area. Although the showrooms were charged with smoke, there was no smoke pushing out the open door at the front of the store. The fire had impinged on the underside of the roof over the holding area and flames were visible from the exterior at the roof level. At 1530s (7:36:23 p.m.), shown in Figure 4-21, the main sections of the front windows had been broken out and smoke was pushing out the front of the main showroom. At this 


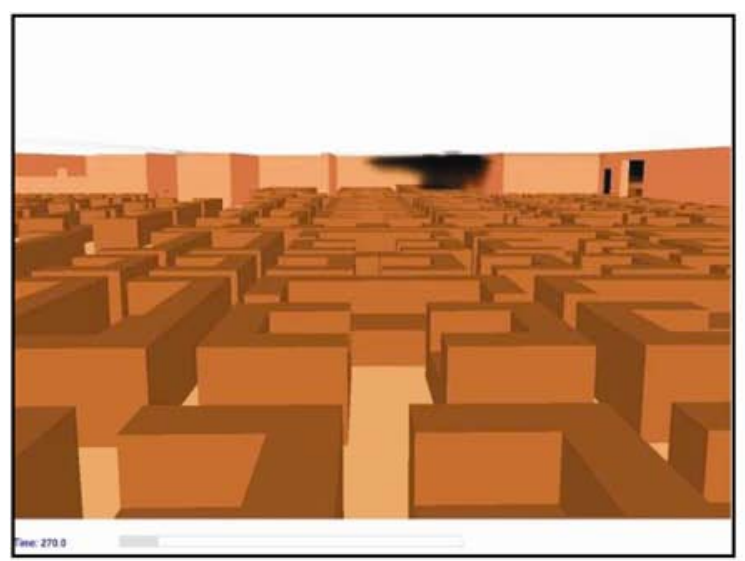

270 s West Side of Main Showroom

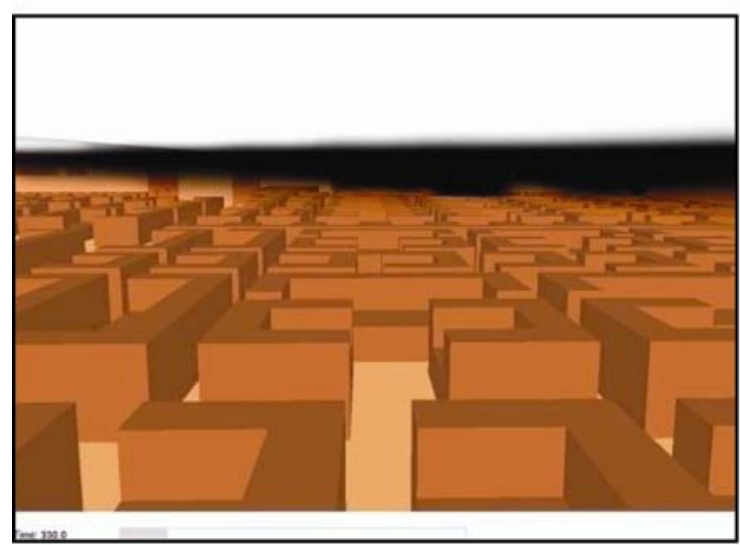

$330 \mathrm{~s}$ West Side of Main Showroom

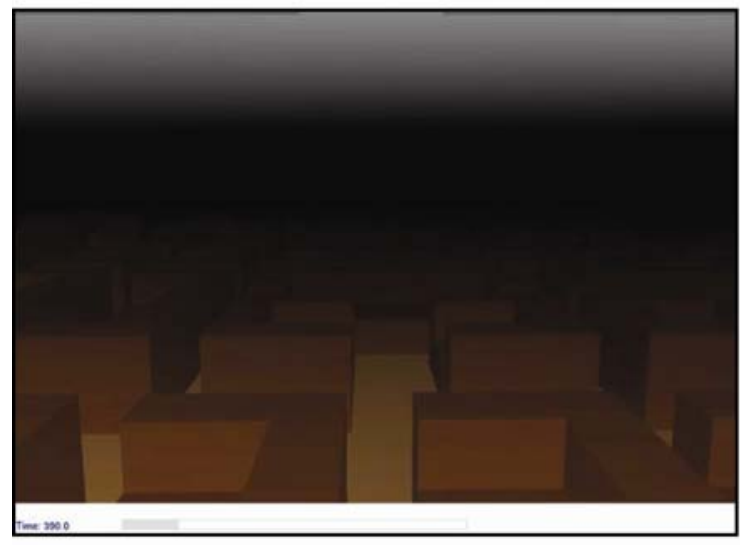

390 s West Side of Main Showroom

Figure 4-17. Smoke progression inside the west side of the main showroom between $270 \mathrm{~s}$ to $390 \mathrm{~s}$ (7:15:23 p.m. to 7:17:23 p.m.).

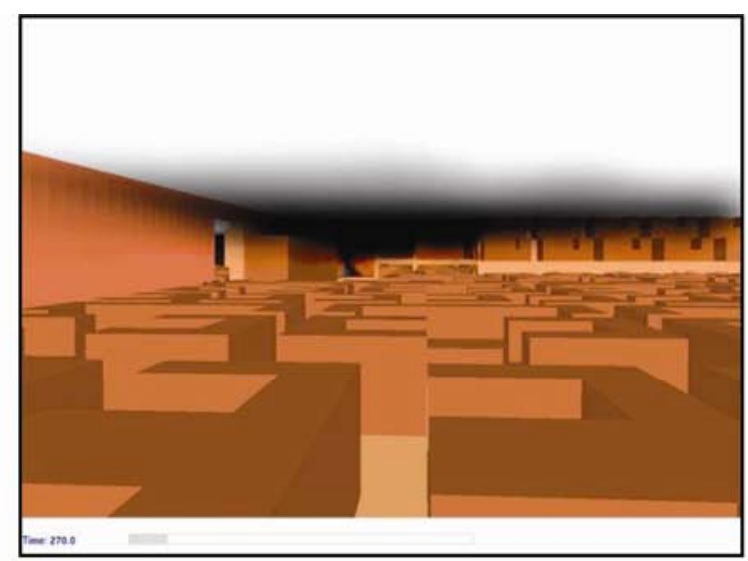

270 s West Showroom

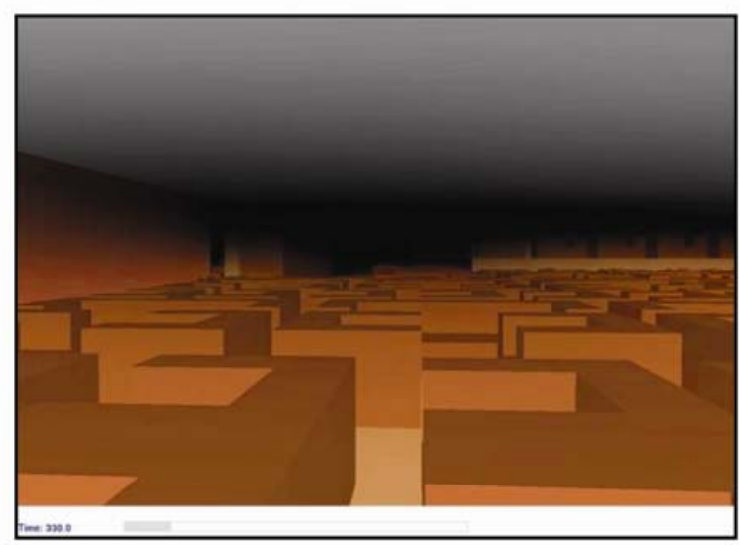

330 s West Showroom

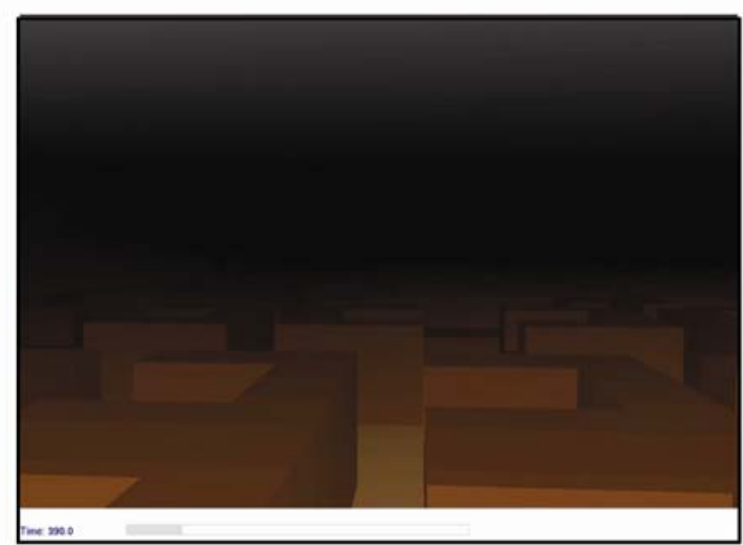

390 s West Showroom

Figure 4-18. Smoke progression inside the west showroom between $270 \mathrm{~s}$ to $390 \mathrm{~s}$ (7:15:23 p.m. to 7:17:23 p.m.). 


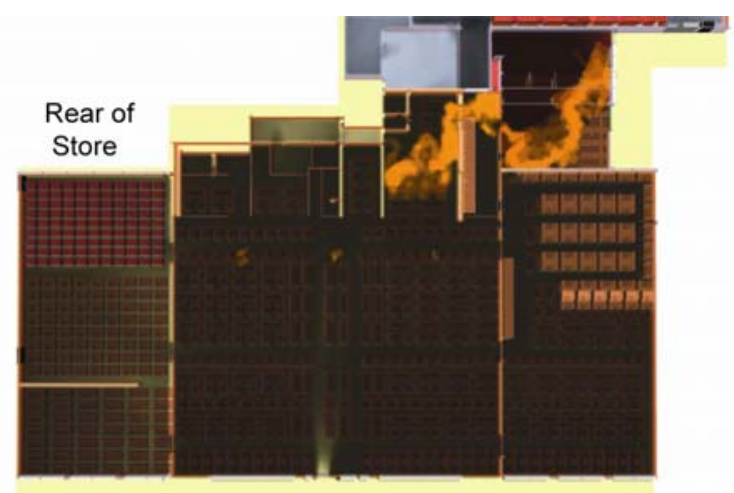

Front of Store

\section{$1020 \mathrm{~s}$}

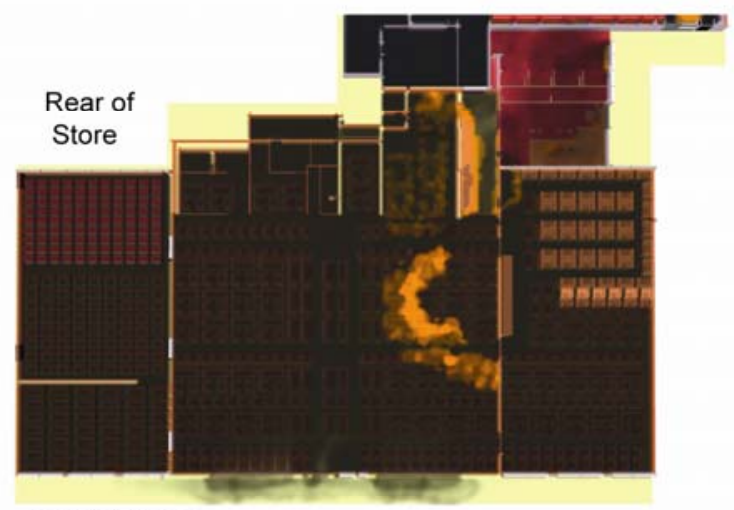

Front of Store

\section{$1500 \mathrm{~s}$}

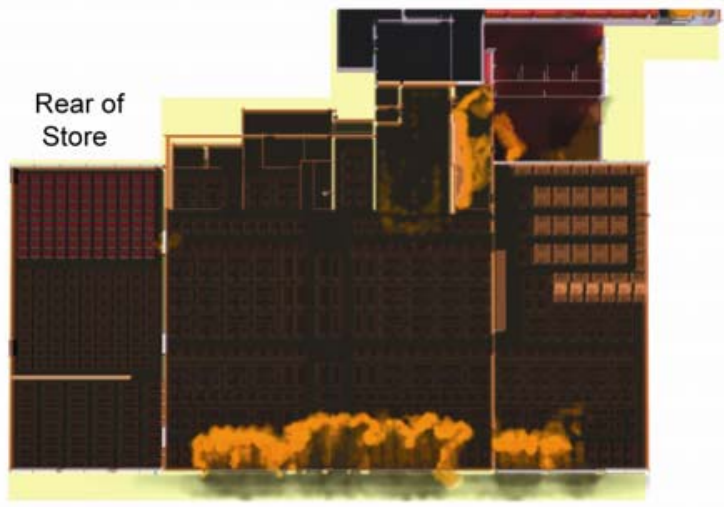

Front of Store

$1800 \mathrm{~s}$

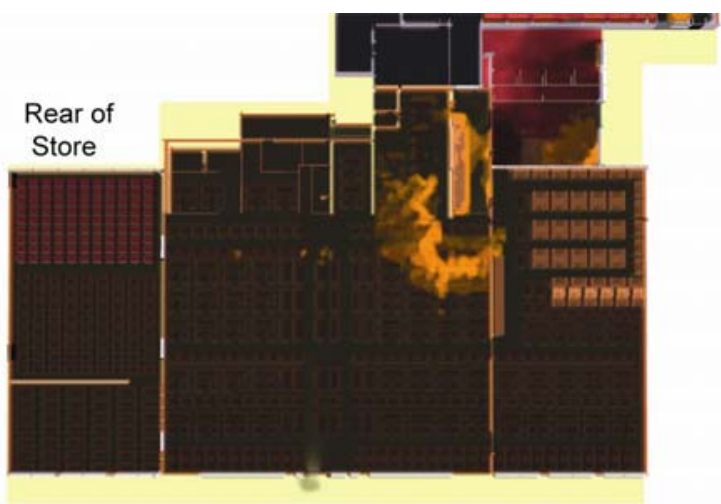

Front of Store

$1380 \mathrm{~s}$

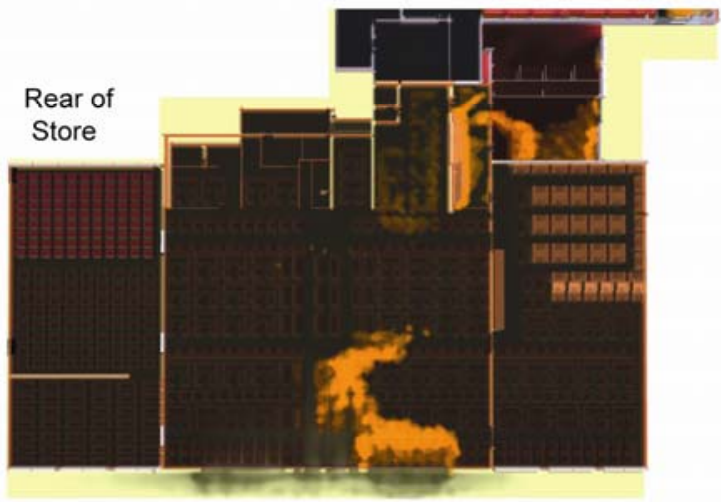

Front of Store

\section{$1620 \mathrm{~s}$}

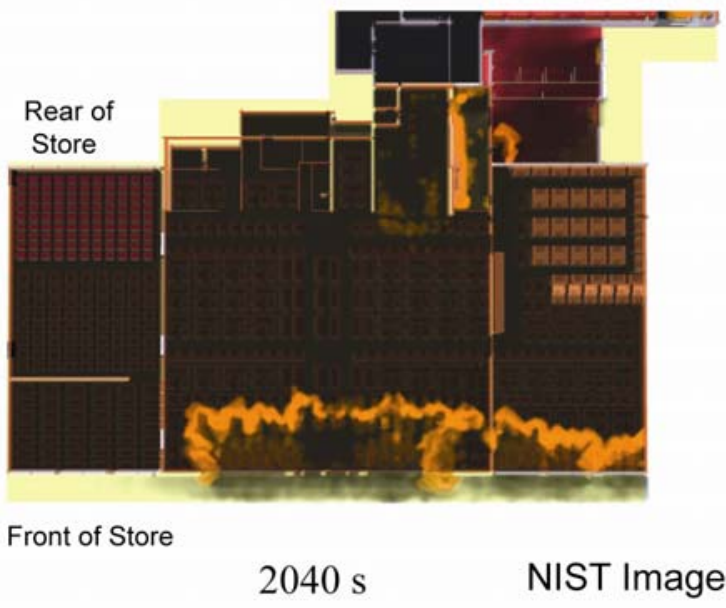

Figure 4-19. View of fire (orange color indicates stoichiometric boundary) and smoke progression from above the showrooms from 1020 s to 2040 s (7:27:53 p.m. to 7:44:53 p.m.). The images are clipped to view conditions below the ceiling. 
time, flames were not yet visible from the exterior through the front windows. By 1655 s (7:38:28 p.m.), shown in Figure 4-22, fire had reached the front of the main showroom and had stretched across the west side of the main showroom. At 1686 s (7:38:59 p.m.) flames were visible inside the west showroom, Figure 4-23, and the first window in this side had failed. By 1884 s (7:42:17), shown in Figure 4-24, fire had stretched across the front of the west showroom and two of the three windows were broken out.

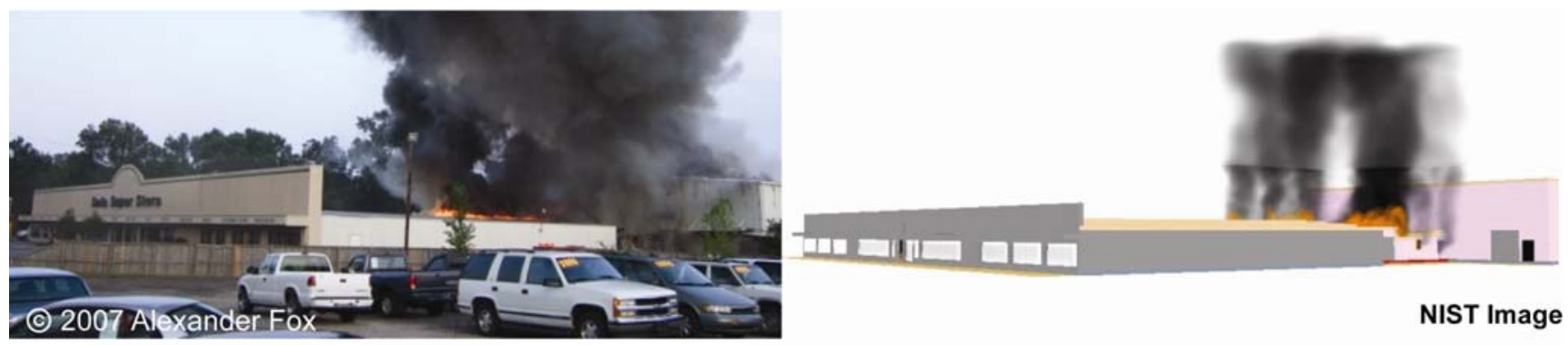

Figure 4-20. Comparison between photo and rendered image from the simulation at $743 \mathrm{~s}$ (7:23:16p.m.). The view is of the north west corner of the structure.

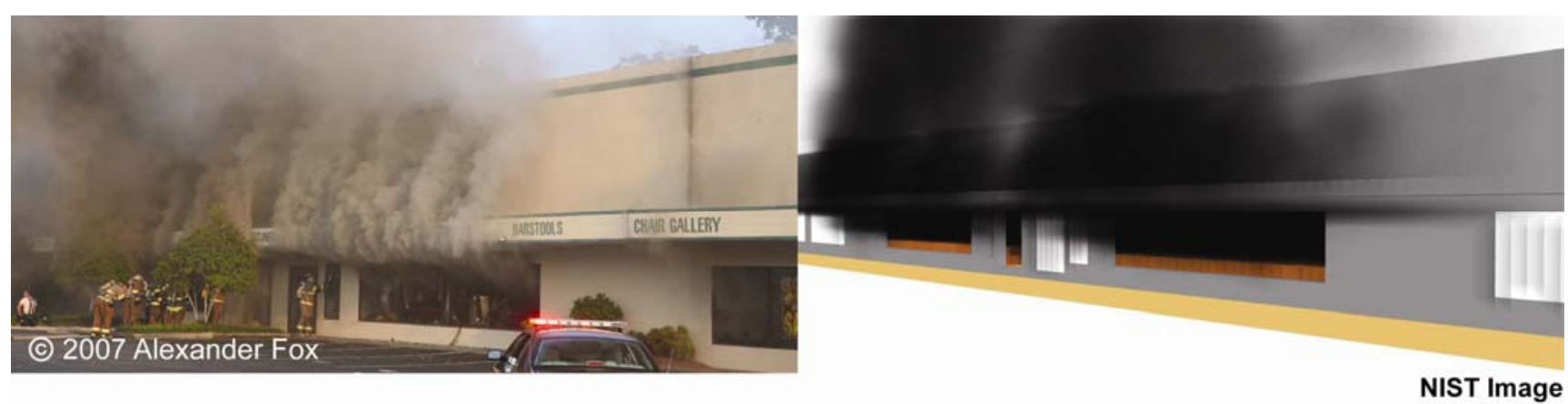

Figure 4-21. Comparison between photo and rendered image from the simulation at $1530 \mathrm{~s}$ (7:36:23 p.m.). The view is of the front of the main showroom.

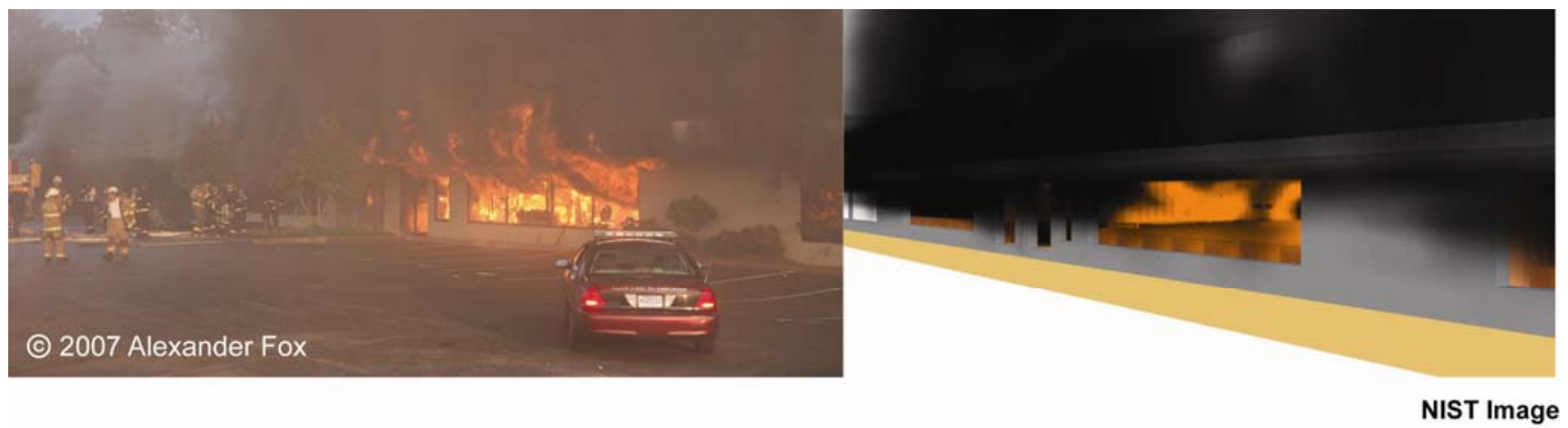

Figure 4-22. Comparison between photo and rendered image from the simulation at $1655 \mathrm{~s}$ (7:38:28 p.m.). The view is of the front of the main showroom. 

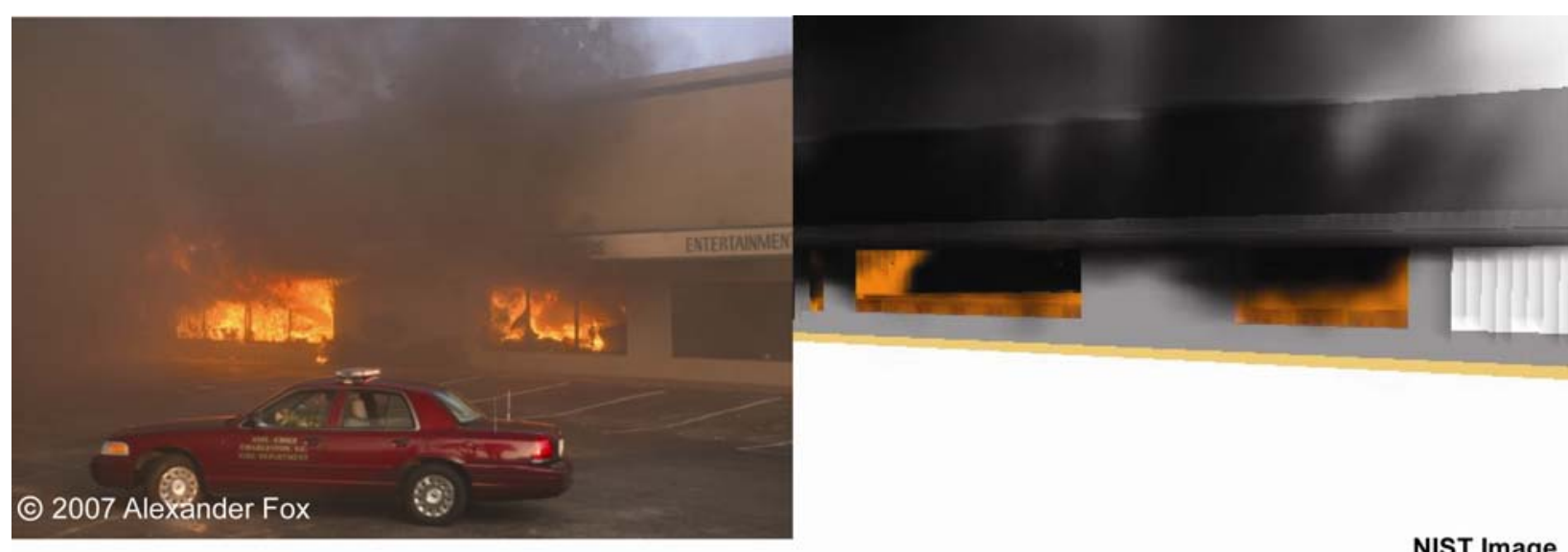

Figure 4-23. Comparison between photo and rendered image from the simulation at $1686 \mathrm{~s}$ (7:38:59 p.m.). The view is of the front of the main and west showrooms.

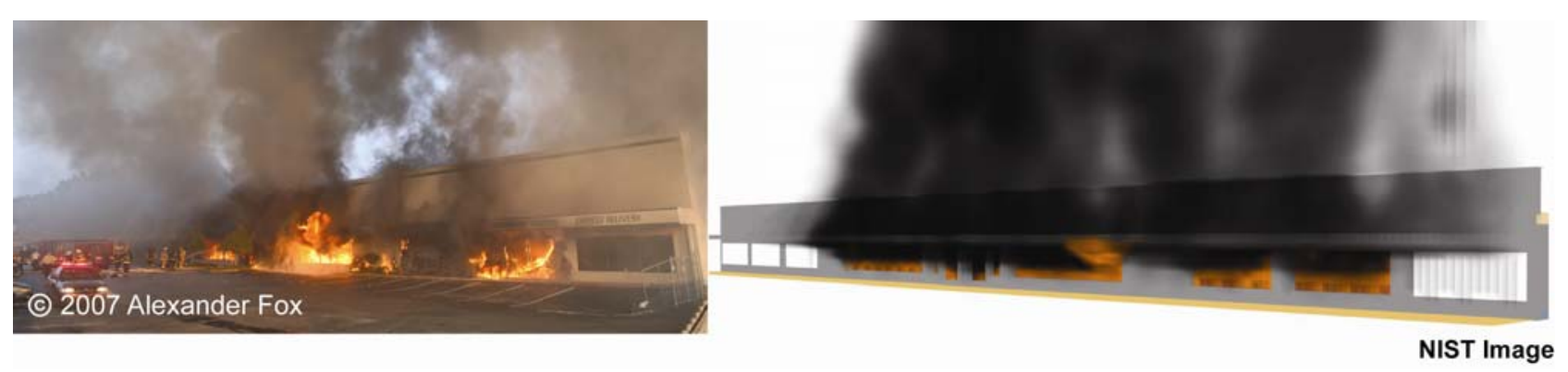

Figure 4-24. Comparison between photo and rendered image from the simulation at $1884 \mathrm{~s}$ (7:42:17 p.m.). The view is of the front of the main and west showrooms.

\subsubsection{Tenability Criteria}

Purser [2] has published data that identify when conditions become untenable for humans. Purser provides an algorithm for estimating the time to lose consciousness due to low oxygen. At 0.12 volume fraction, the time is estimated at about five minutes. In a closed fire-engulfed environment, toxic gases (such as carbon monoxide) are likely to be present at incapacitating levels before the oxygen gets this low. Since the simulation tracks the oxygen volume fraction, it will be used as one indicator for tenability. A second indicator will be when the temperature exceeds $120^{\circ} \mathrm{C}\left(250^{\circ} \mathrm{F}\right)$ for about five minutes [2]. The effects of carbon monoxide, depleted oxygen, and temperature are dose-related, involving both magnitude and time of exposure [2]. Thus the time at which $120^{\circ} \mathrm{C}\left(250^{\circ} \mathrm{F}\right)$ is exceeded is before the time at which the person is incapacitated. For each of the simulations, the time for areas to become untenable ${ }^{4}$ due to elevated temperature ${ }^{5}$ or oxygen depletion ${ }^{6}$ will be tabulated. These incapacitation criteria are simplifications of complex studies and serve as a basis for appraising the relative effects of alternate fire scenarios.

\footnotetext{
${ }^{4}$ For this study, untenability was equated to incapacitation. A person is defined as incapacitated when he or she is unable to effect his or her own escape (ISO 13943)[16].

${ }^{5}$ For this study, temperature greater than $120^{\circ} \mathrm{C}\left(250{ }^{\circ} \mathrm{F}\right)$ for at least five minutes (300 seconds).

${ }^{6}$ For this study, oxygen volume fraction less than 0.12 for at least five minutes (300 seconds).
} 
The NIST study did not include analysis of the threat to protected fire fighters. If a fire fighter in turnout gear is utilizing a self-contained breathing apparatus (SCBA) and has an adequate supply of air, the fire fighter can temporarily survive higher temperatures and depleted external oxygen levels. This safety shell ends when the fire fighter runs out of tank air or remains within the hot fire environment too long.

\subsubsection{Temperature}

Temperatures were examined to assess tenability conditions that existed during the evolution of the fire.

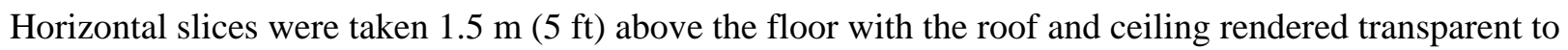
display the temperature distribution throughout the structure. Additionally, temperatures were tracked over time at different elevations at specific horizontal locations as shown in Figure 4-25 with the filled red circles. These temperature monitoring locations were defined in the simulation in order to track temperatures at a specific location during each simulation. The labels in Figure 4-25 that identify temperature locations (referred to as "sensor arrays") are consistent with those used throughout this report. The three positions indicated to the left of the figure (front, mid, rear) were located, respectively, $3.38 \mathrm{~m}(11.1 \mathrm{ft}), 14.62 \mathrm{~m}(48.0 \mathrm{ft})$, and $26.62 \mathrm{~m}(87.3 \mathrm{ft})$ from the front if the showrooms. Sensors in the west showroom were located near the center, $7.5 \mathrm{~m}(24.6 \mathrm{ft})$ from the west wall. In the west side of the main showroom, the front and mid sensors were positioned $7.9 \mathrm{~m}(25.9 \mathrm{ft})$ from the west wall. The rear and corner sensors were located $9.8 \mathrm{~m}$ (32.2 ft) from the same wall; the corner position was $39 \mathrm{~m}$ $(128.0 \mathrm{ft})$ from the front wall. The sensors positioned in the center of the main showroom were located $19.1 \mathrm{~m}(62.7 \mathrm{ft})$ from the west wall of the main showroom. Sensors in the east side of the main showroom were positioned $30 \mathrm{~m}(98.4 \mathrm{ft})$ from the west wall of the main showroom.

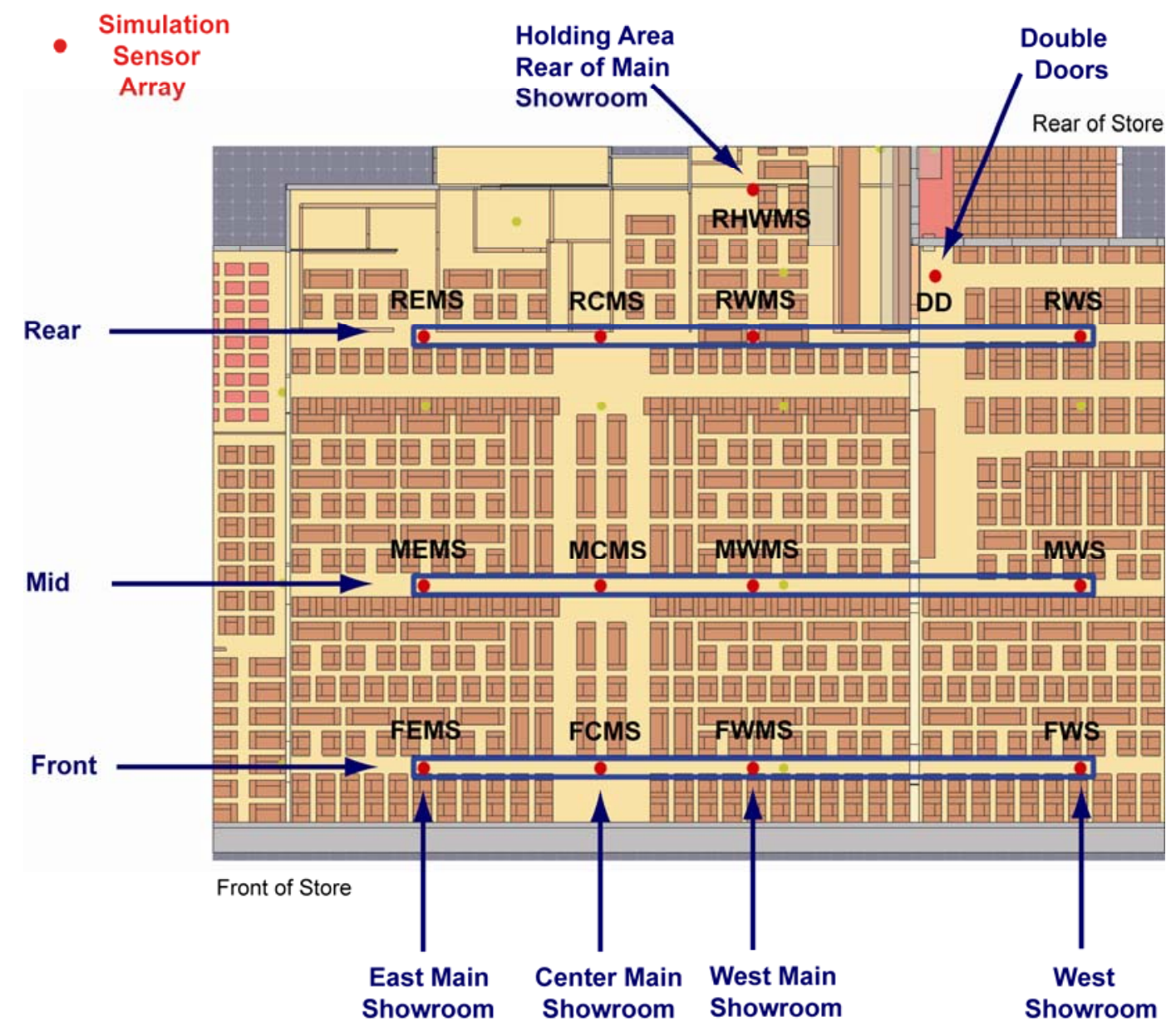

Figure 4-25. Location of simulation sensor arrays in main and west showrooms. 


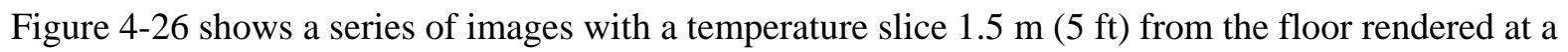
range of times between $900 \mathrm{~s}$ through $1620 \mathrm{~s}$ (7:25:53 p.m. through 7:37:53 p.m.). These images show the progression of the elevated temperatures from the loading dock, into the holding area, and eventually into the main showroom. Temperatures above $100{ }^{\circ} \mathrm{C}$ (approximately indicated by the border between dark blue and light blue) are first observed in the holding area approximately three minutes into the simulation. Note that the double doors separating the west showroom from the loading dock were opened at $144 \mathrm{~s}$, but the temperature in the west showroom remained low even as fire was spreading into the holding area.

Figure 4-27 shows a chart of temperatures recorded in the west showroom, near the double doors. The data are from sensors located $0.3 \mathrm{~m}(1 \mathrm{ft}), 0.91 \mathrm{~m}(3 \mathrm{ft}), 1.52 \mathrm{~m}(5 \mathrm{ft})$, and $2.13 \mathrm{~m}(7 \mathrm{ft})$ from the floor. Figure 4-27 shows that temperatures remained below $100{ }^{\circ} \mathrm{C}$ through approximately $750 \mathrm{~s}$ (7:23:23 p.m.). The fire was positioned near the double doors to the loading dock; however, during the early stages much of the heat was venting through the loading dock roof and later through the main showroom roof. Air was being pulled through the doorway to feed oxygen to the fire in the loading dock and holding area. There was a surge in temperature in the upper layer lasting several minutes caused by fire progression into the showroom. At 900 s (7:25:53 p.m.), a section of the roof above the holding area was removed and this resulted in the subsequent temperature drop. Temperatures dropped below $100{ }^{\circ} \mathrm{C}$, but as the fire increased in the main showroom the temperatures in both showrooms began to rise quickly. A second temperature surge, which began at approximately $1460 \mathrm{~s}$ (7:35:13 p.m.), was due to the fire entering the west showroom through the open roll-down door as it moved to the front of the main showroom. It should be noted that the focus of suppression efforts was in this area of the showroom, and that the simulation does not take this into account.

Figures 4-28 through 4-30 show charts of temperatures recorded at the locations throughout the main and

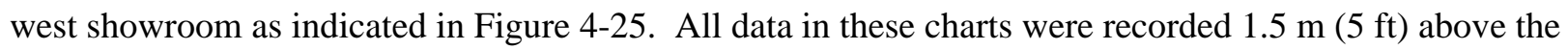
floor. Figure 4-28 shows temperatures in the west showroom. Temperatures in the west showroom remained relatively low, below $100{ }^{\circ} \mathrm{C}$, until the fire began moving toward the front of the main showroom. The temperature at the rear sensor surpassed $120^{\circ} \mathrm{C}$ at $1350 \mathrm{~s}$ (7:33:23 p.m.). As the fire in the main showroom continued to move forward, the temperature at the mid and front sensors reached $120^{\circ} \mathrm{C}$ at $1400 \mathrm{~s}(7: 34: 13$ p.m.)

Figure 4-29 shows a temperature chart that displays data from sensors located on the west side of the main showroom. This chart contains a fourth data location, labeled Rear Hold, which was identified in Figure 4-25. Temperatures in the west side of the main showroom became elevated at an earlier point than in the other areas of the showroom because the fire moved across these sensors as it moved to the front of the showroom. The rear holding area location reached $120^{\circ} \mathrm{C}$ at $864 \mathrm{~s}$ (7:25:17 p.m.); the rear location was roughly $30 \mathrm{~s}$ behind, reaching $120^{\circ} \mathrm{C}$ at $900 \mathrm{~s}$ (7:25:53 p.m.). The mid and front locations reached $120^{\circ} \mathrm{C}$ simultaneously at $1250 \mathrm{~s}$ (7:31:43 p.m.). Temperatures in the center and east areas of the main showroom showed similar trends. 

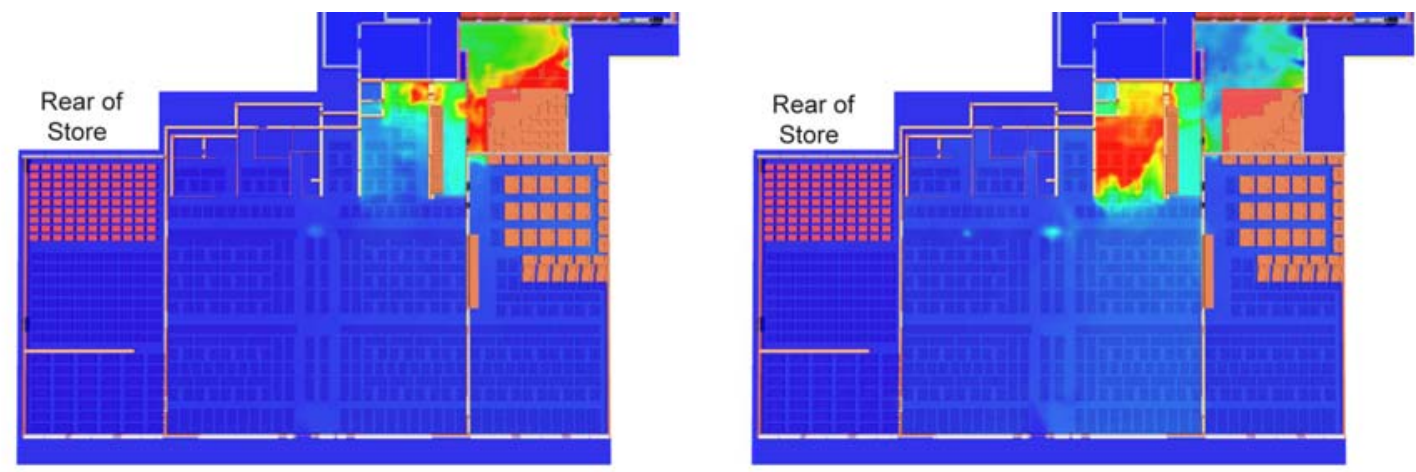

Front of Store

Front of Store

$$
1140 \mathrm{~s}
$$

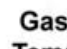

Temp

$900 \mathrm{~s}$

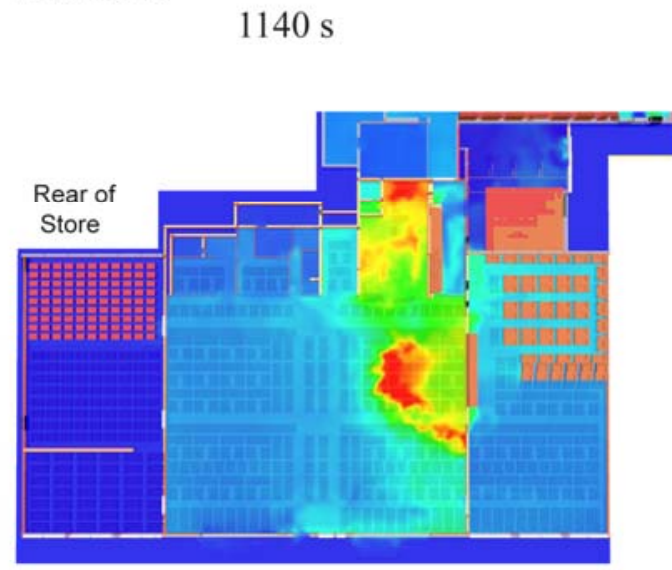

820

740

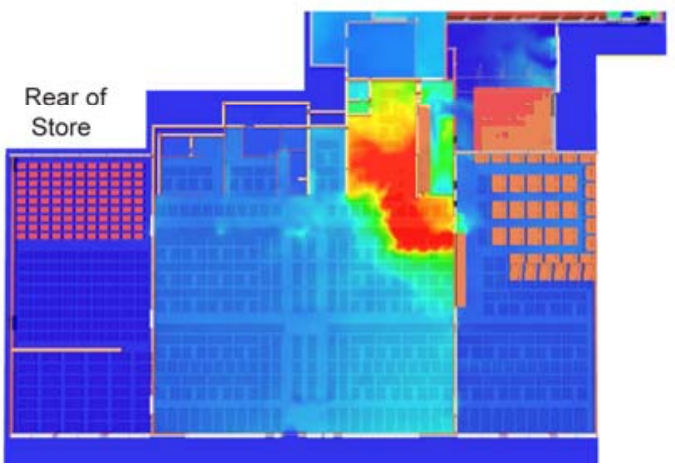

Front of Store

$1380 \mathrm{~s}$

Front of Store

$1500 \mathrm{~s}$

740

660

580

500

420

340

260

180

100

20
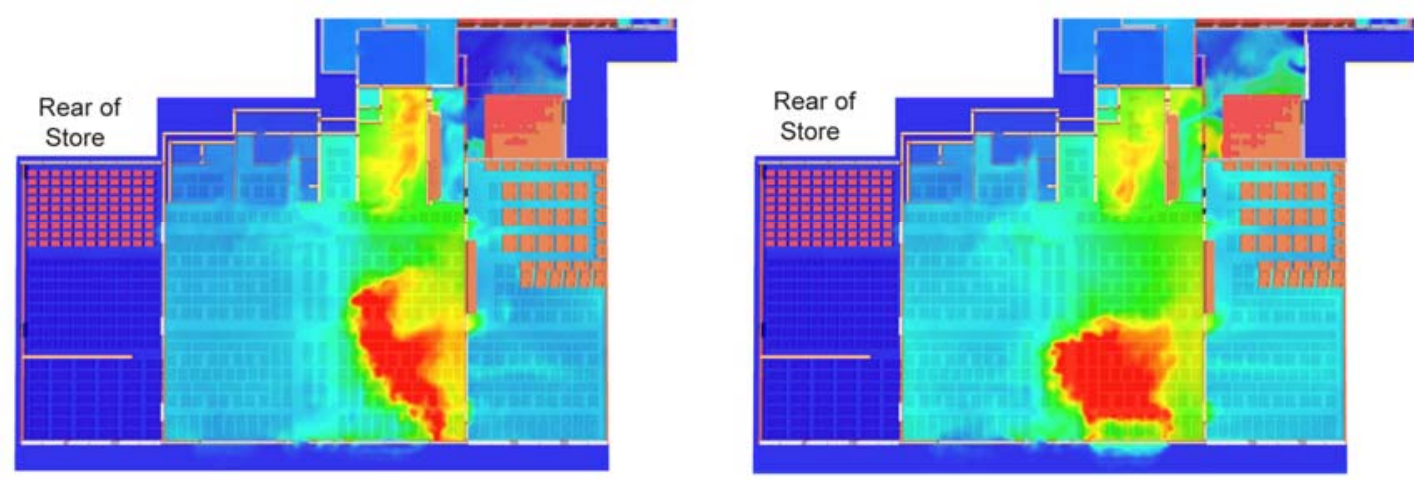

Front of Store

$$
1560 \mathrm{~s}
$$

Front of Store

NIST Image

$1620 \mathrm{~s}$

Figure 4-26. Temperature slices located $1.5 \mathrm{~m} \mathrm{(5} \mathrm{ft)} \mathrm{above} \mathrm{the} \mathrm{floor.}$ 


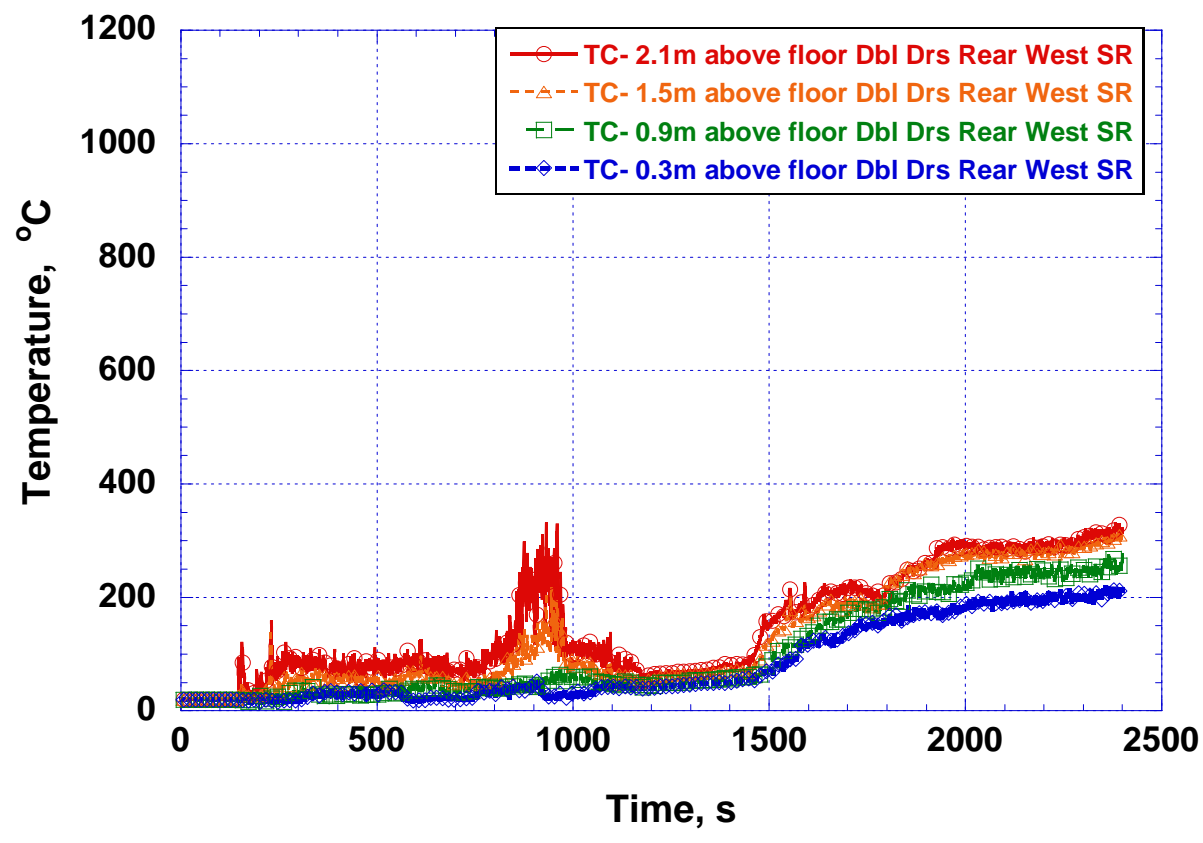

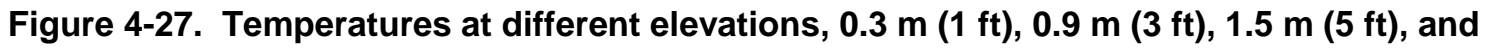
$2.1 \mathrm{~m} \mathrm{(7} \mathrm{ft)} \mathrm{in} \mathrm{rear} \mathrm{of} \mathrm{west} \mathrm{showroom} \mathrm{near} \mathrm{double} \mathrm{doors.}$

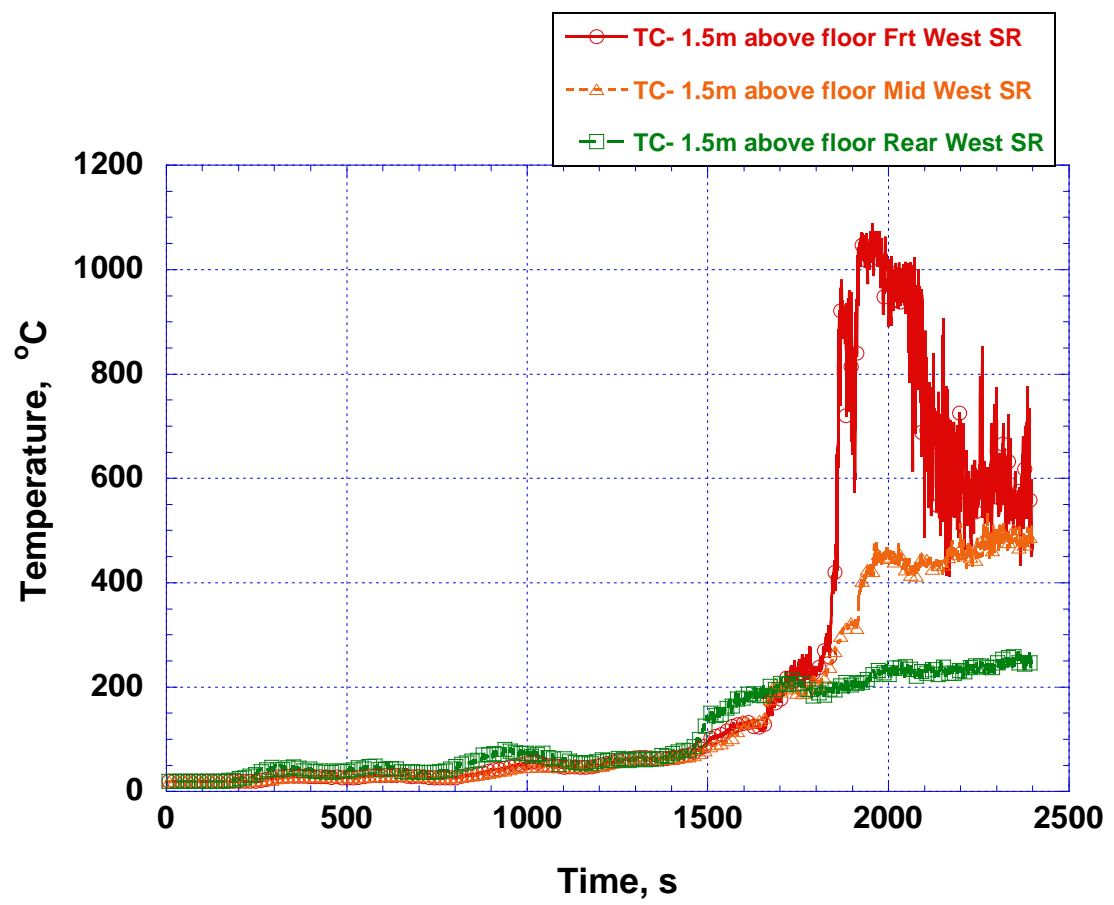

Figure 4-28. West showroom temperatures for $1.5 \mathrm{~m} \mathrm{(5} \mathrm{ft)} \mathrm{above} \mathrm{floor.}$ 


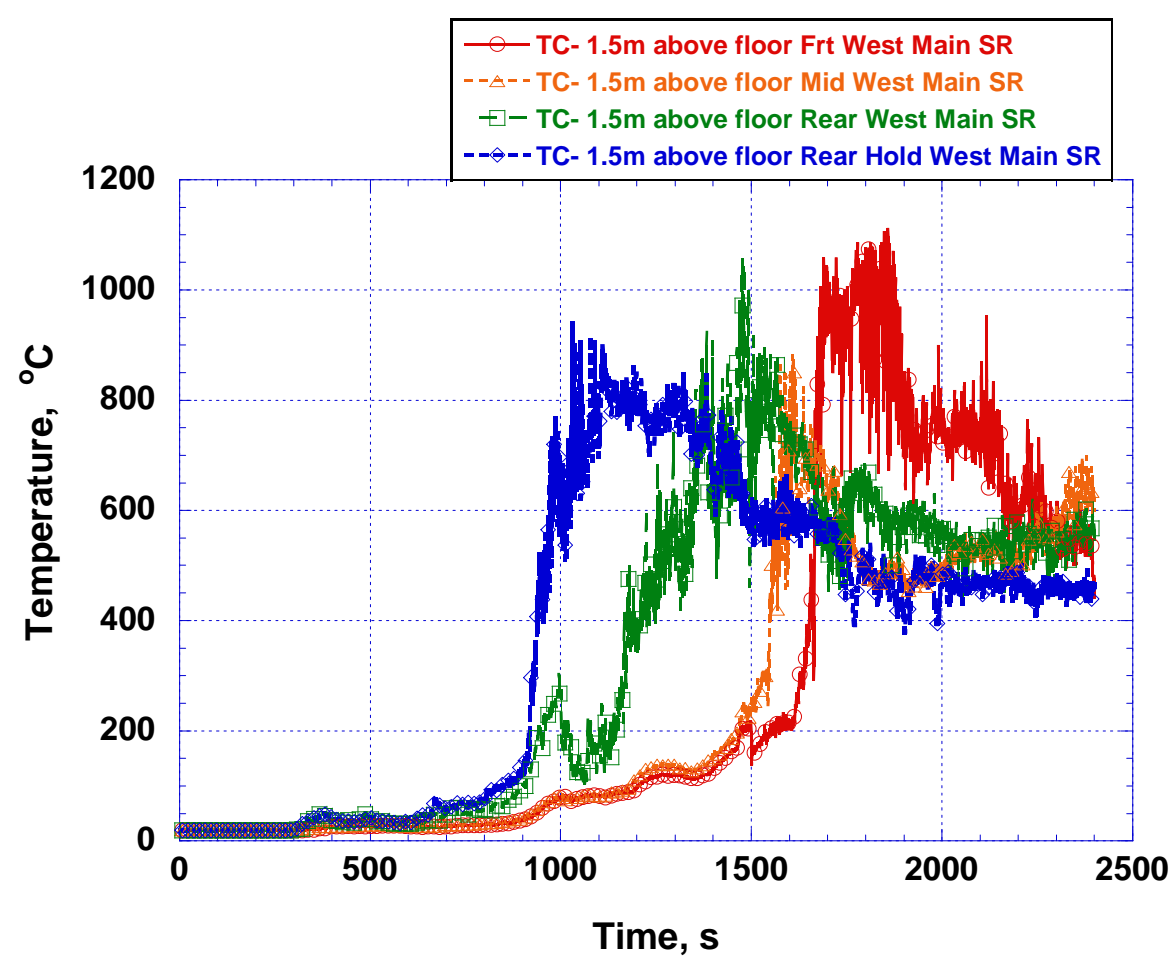

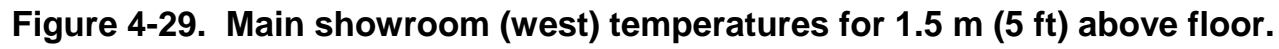

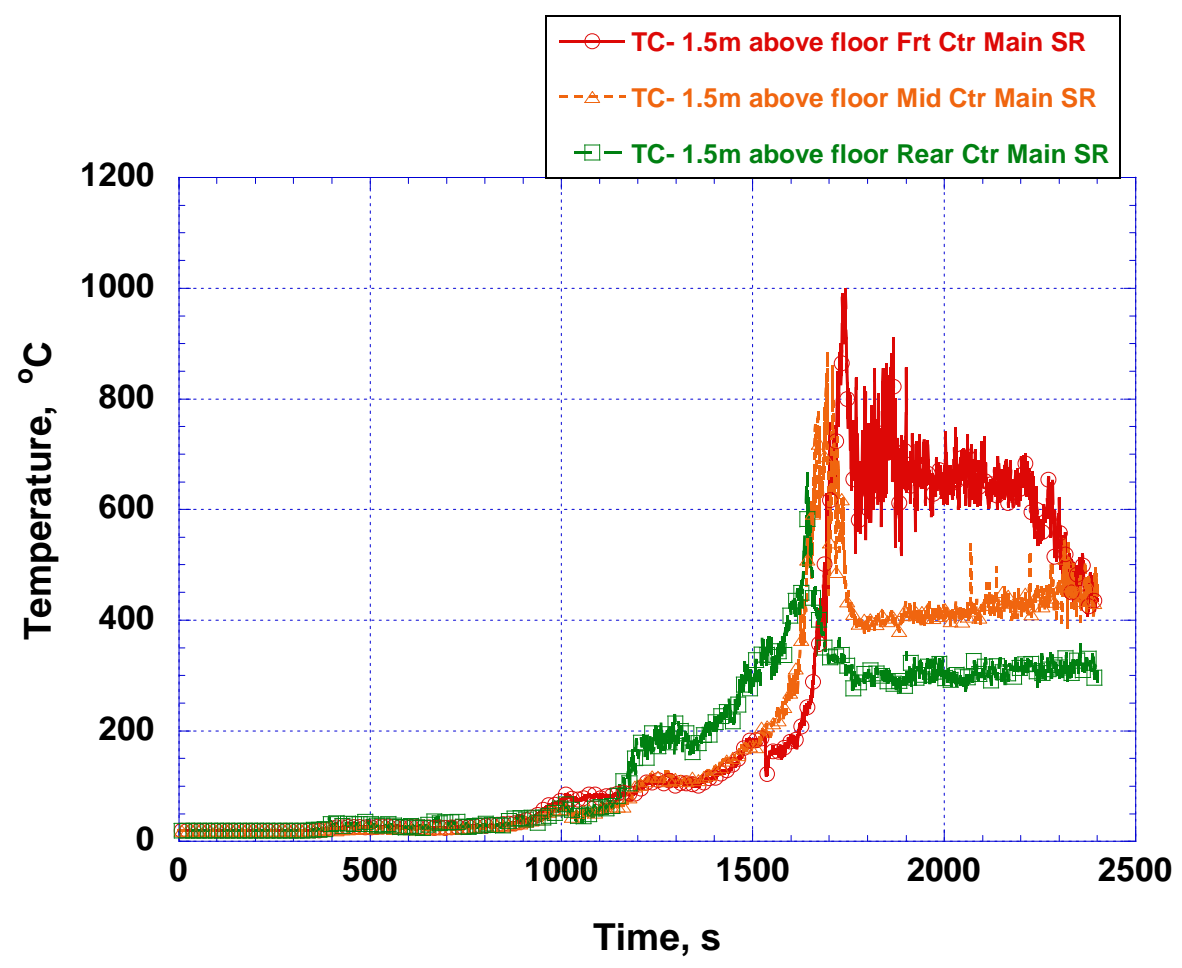

Figure 4-30. Main showroom (center) temperatures for $1.5 \mathrm{~m} \mathrm{(5} \mathrm{ft)} \mathrm{from} \mathrm{floor.}$ 


\subsubsection{Oxygen Volume Fraction}

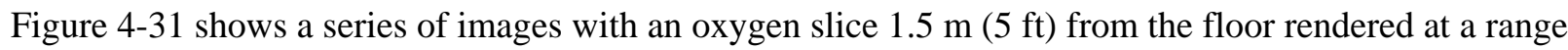
of times between $360 \mathrm{~s}$ and $1440 \mathrm{~s}$ (7:16:53 p.m. through 7:34:53 p.m.).

Figures 4-32 through 4-34 show charts of oxygen volume fraction recorded at several locations throughout the main and west showroom. All data in these charts were recorded $1.5 \mathrm{~m}(5 \mathrm{ft})$ above the floor. The locations correspond to those used for the temperature results shown in Figures 4-28 through 4-30. The oxygen volume fraction at the sensor in the rear of west showroom fell below 0.12 at $1500 \mathrm{~s}$ (7:35:53 p.m.). As the fire in the main showroom continued to move forward, the oxygen at both the mid

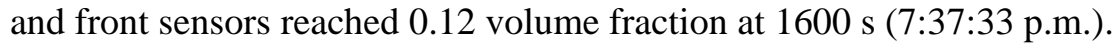

Figure 4-33 shows a chart that displays oxygen data from sensors located on the west side of the main showroom. Oxygen in the west side of the main showroom became depleted at an earlier point than in the other areas of the showroom because this was the path of the fire as it moved to the front of the showroom. The holding area location reached 0.12 volume fraction at $950 \mathrm{~s}$ (7:26:43 p.m.); the rear location was roughly six minutes behind, reaching 0.12 volume fraction at $1250 \mathrm{~s}$ (7:31:43 p.m.). The mid and front locations initially reached 0.12 volume fraction approximately the same time at $1400 \mathrm{~s}$ (7:34:13 p.m.). The mid and front locations then increased up to 0.15 volume fraction as the front windows were broken. Oxygen volume fractions in the center and east areas of the main showroom had similar trends.

\subsection{BASELINE SIMULATION WITH SPRINKLERS ADDED INSIDE THE LOADING DOCK}

\subsubsection{General}

A simulation was performed with code-compliant fire sprinklers added inside the enclosed loading dock to examine the effects that sprinklers might have had on the fire and the resulting environment inside the building. Otherwise, the simulation was identical to the baseline simulation. FDS has been shown to be able to predict the number of sprinklers activated and the approximate activation times, as well as trends, temperatures, heat fluxes and oxygen volume fractions in reasonable agreement with measured values [5; Vols. 2\&3]. However, the suppression physics in FDS is simplified and cannot capture all of the details of the suppression process.

The sprinkler system layout was designed in accordance with NFPA 13, Standard for the Installation of Sprinkler Systems [17]. The system was designed as an Ordinary Hazard Group 2 wet pipe system, assuming that the enclosed loading dock area was heated. An Ordinary Hazard Group 2 sprinkler system was utilized in order to provide a more conservative estimate for the design area/water density as compared to an Extra Hazard design, for simulating the effects of sprinklers on fire conditions. The locations of the sprinklers within the enclosed loading dock are shown in Figure 4-35. Note that given the dimensions of the cells in the simulation, the locations of the sprinklers in the simulation vary up to $2 \mathrm{~cm}$ (0.8 in) from the layout shown. The specific locations of the sprinklers are given in the FDS input file. The sprinkler characteristics and operating parameters are given in Table K-8. 


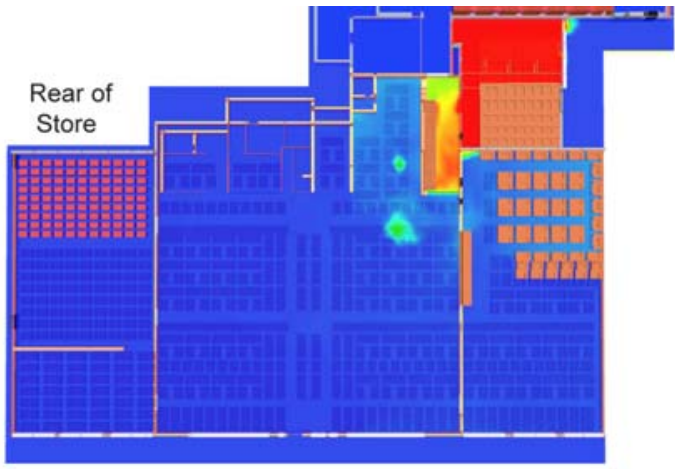

Front of Store

$360 \mathrm{~s}$

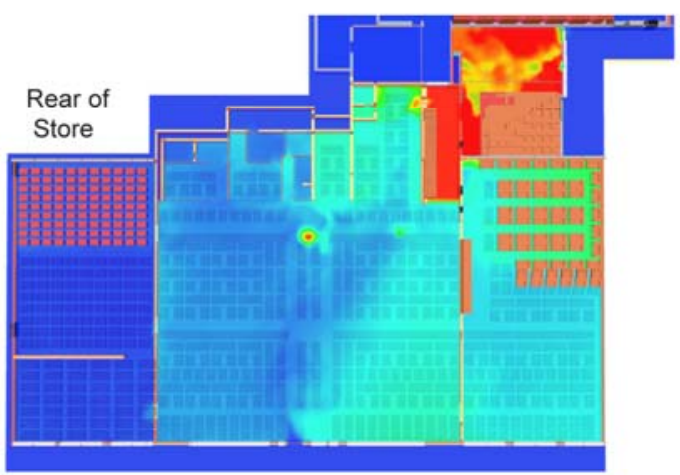

Front of Store

$840 \mathrm{~s}$

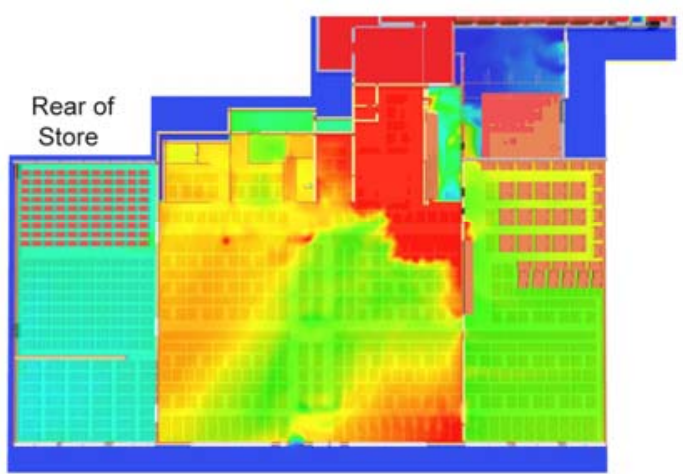

Front of Store

$1380 \mathrm{~s}$

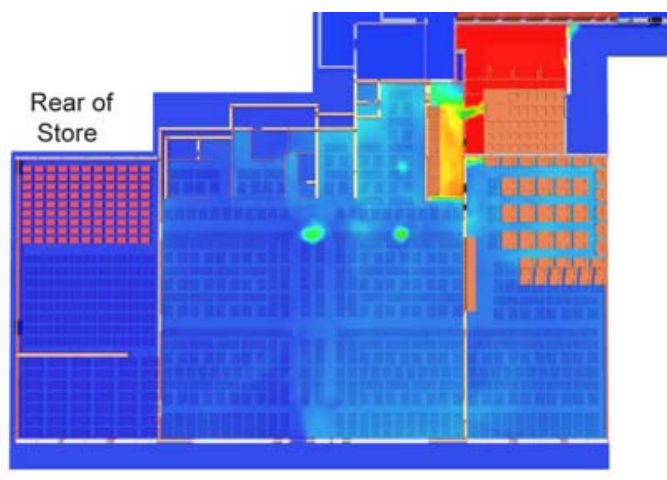

Front of Store

$480 \mathrm{~s}$

Fraction
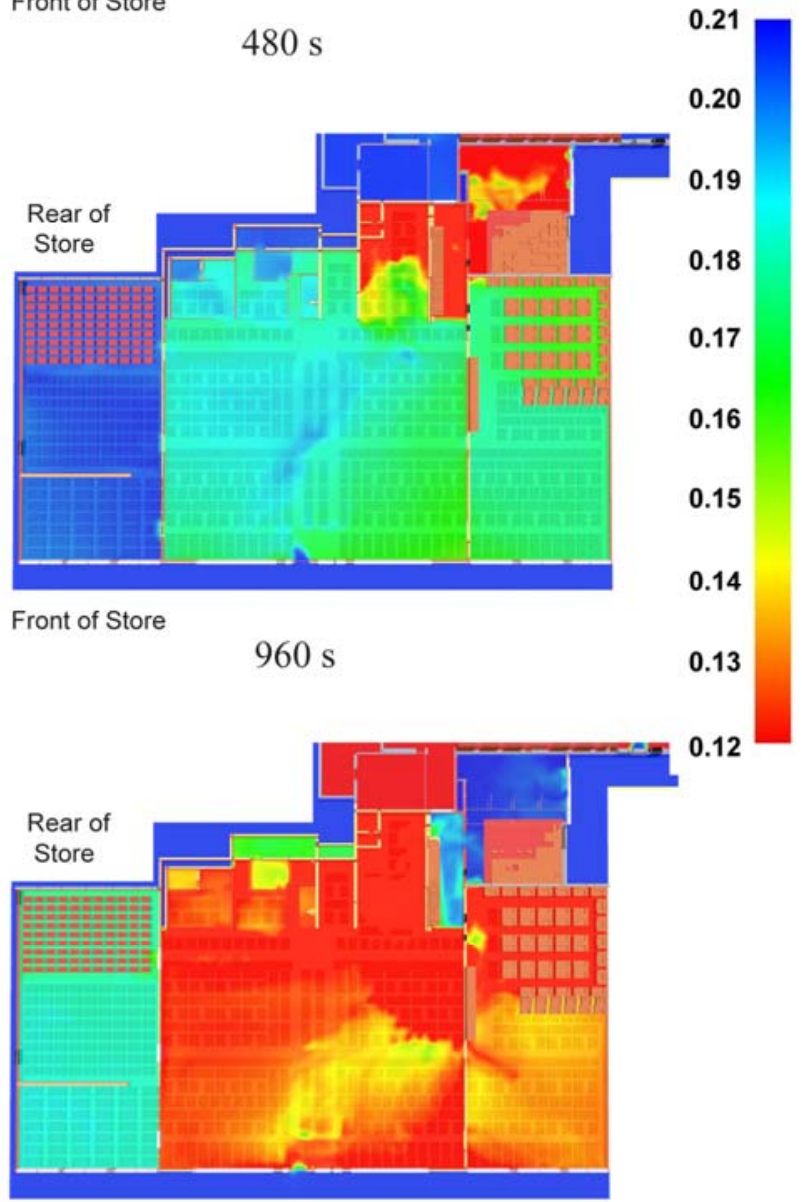

Front of Store

$1440 \mathrm{~s}$

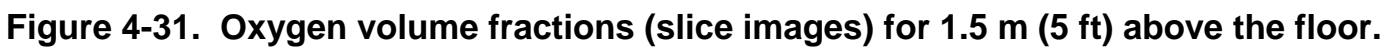




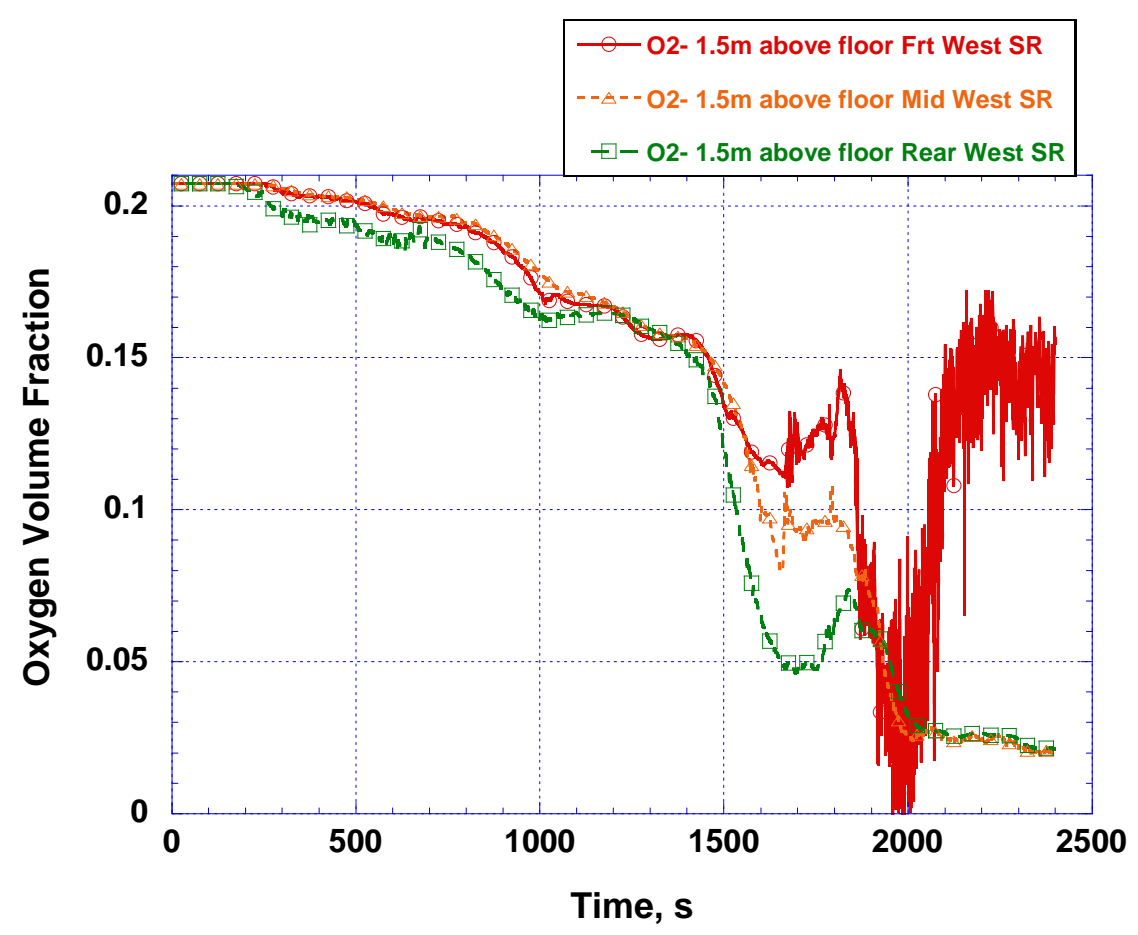

Figure 4-32. West showroom oxygen volume fractions for $1.5 \mathrm{~m}(5 \mathrm{ft})$ above the floor.

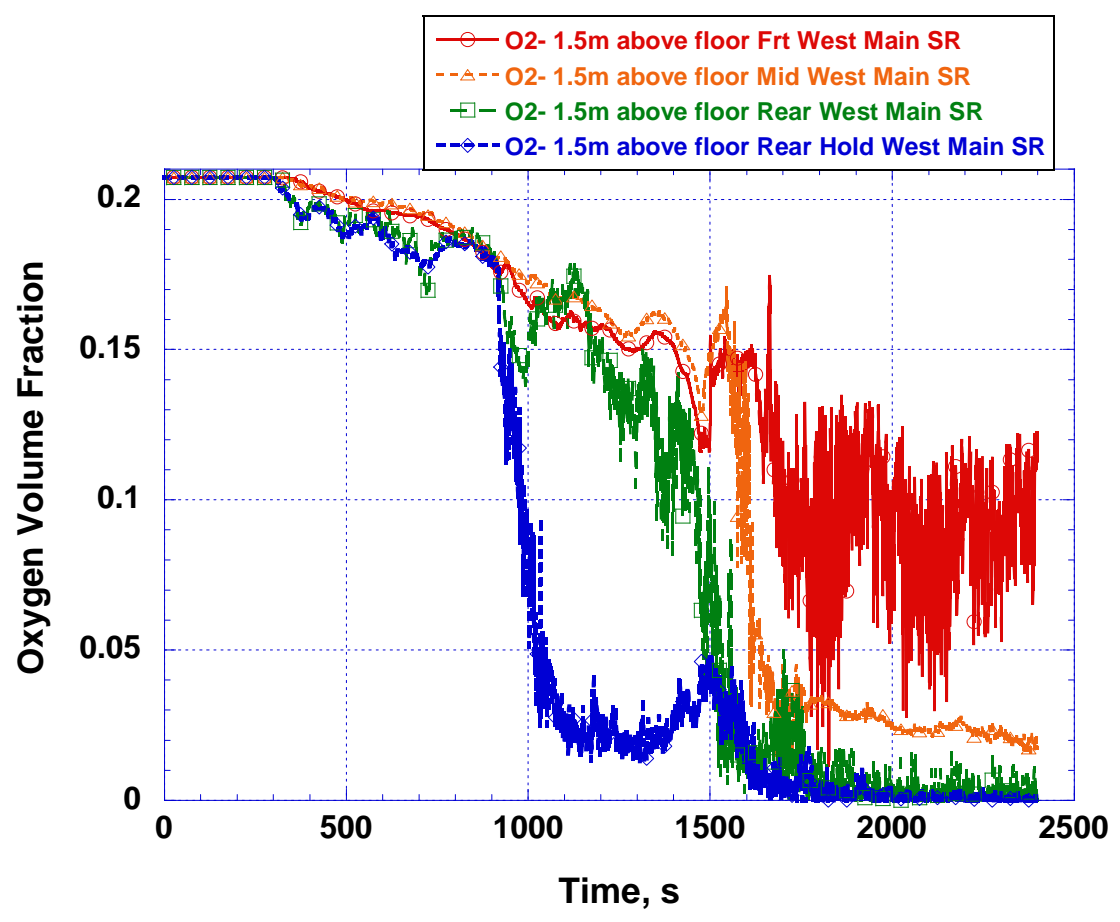

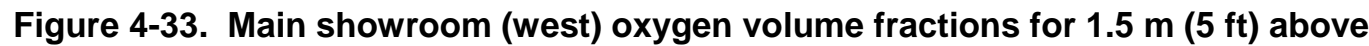
the floor. 


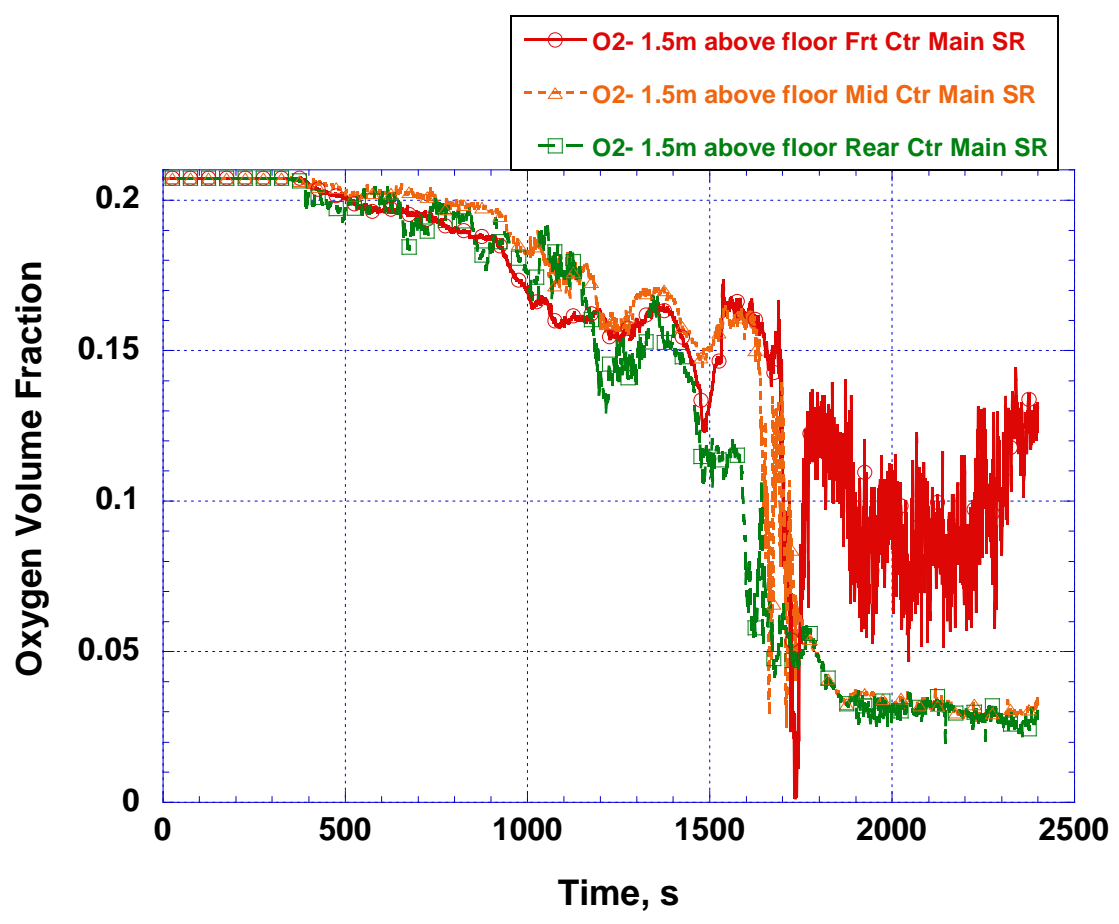

Figure 4-34. Main showroom (center) oxygen volume fractions for $1.5 \mathrm{~m} \mathrm{(5 \textrm {ft } )}$ above the floor.

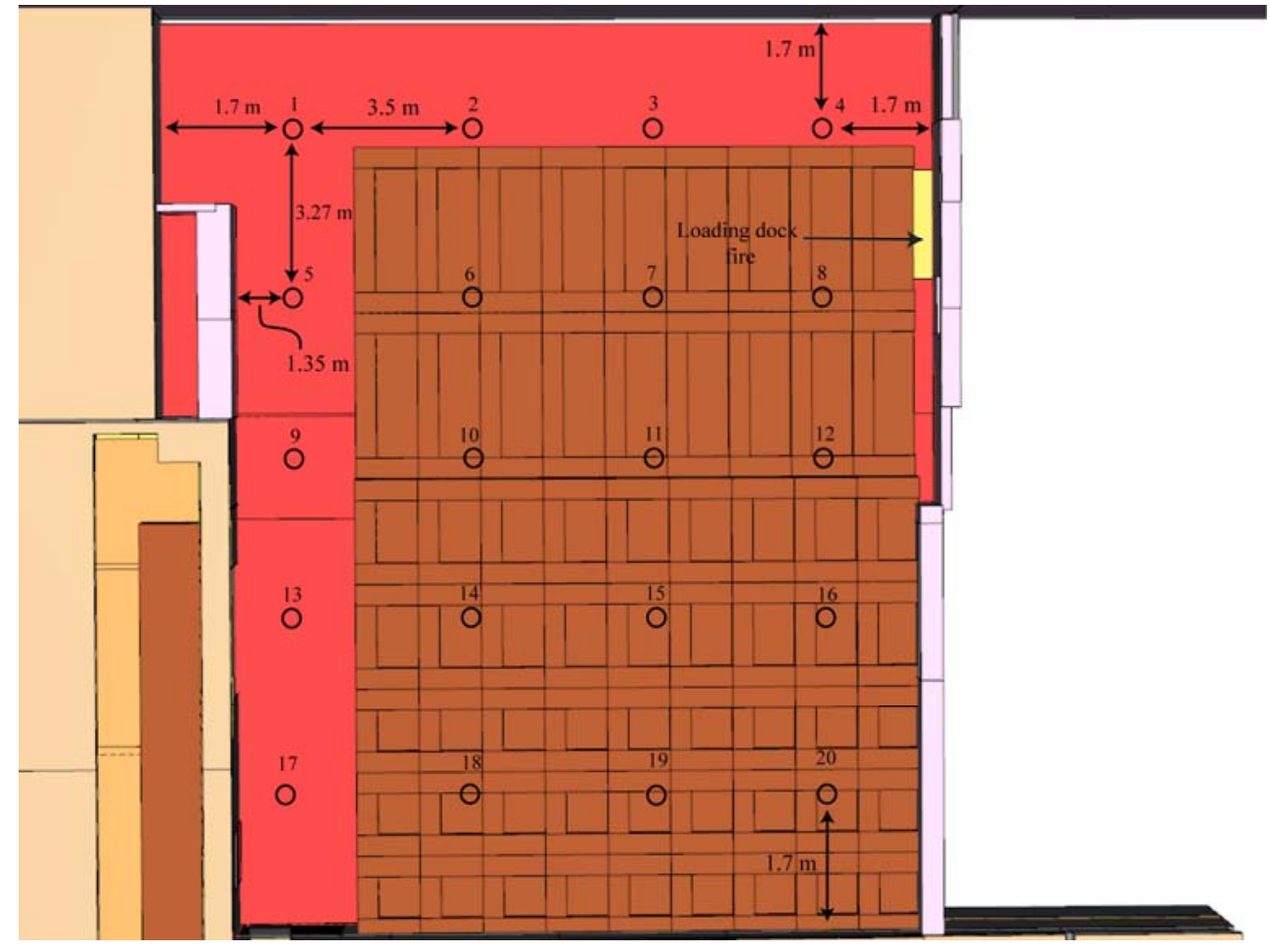

Figure 4-35. Sprinkler layout inside the enclosed loading dock. 
Twenty sprinklers were placed inside the loading dock as shown by the black circles in Figure 4-35. The sprinkler specifications that were used in the simulation are detailed in Appendix K, Table K-6. In this configuration, the maximum protection area of coverage per sprinkler was approximately $11.9 \mathrm{~m}^{2}$ $\left(128 \mathrm{ft}^{2}\right)$ with a water density of approximately $8.8 \mathrm{~L} \mathrm{~min}^{-1} \mathrm{~m}^{-2}\left(0.22 \mathrm{gpm} / \mathrm{ft}^{2}\right)$. Two sprinklers, labeled 4 and 8 in Figure 4-35, activated in the simulation. Sprinkler 8 was the first to activate, at $50 \mathrm{~s}$, while sprinkler 4 activated at $75 \mathrm{~s}$.

Figure 4-36 shows a series of images indicating the progression of fire and smoke in the loading dock during the sprinklered simulation. These images show an overhead view, centered on the loading dock (the area shaded in red). The north end of the warehouse is shown at the top of the images and the south end of the west showroom is at the bottom. The southwest corner of the main showroom (including the holding area) is shown in the lower left corner. In these images, the roof and walls of the loading dock were made invisible in order to facilitate viewing the loading dock interior. Additionally, the roofs over the main and west showrooms were clipped so that the interior of the holding area was visible. The areas colored black are the showroom ceilings. The west showroom ceiling is only partially revealed because this addition had a sloped roof and only the upper section was clipped away.

The quantity of fire generated smoke increases through the first five images in this sequence, from 30 through $210 \mathrm{~s}$. Smoke spread across the underside of the loading dock roof and began to fill downward. At $210 \mathrm{~s}$, the smoke layer was low enough to begin spilling into the holding area where there is access to the space above the showroom ceiling. By 240 s however, the fire is no longer burning and the smoke is beginning to dissipate.

The same initiating fire was used in this scenario as for the baseline case, an ultrafast $\mathrm{t}^{2}$ growth curve to a peak HRR of $750 \mathrm{~kW}$ and then held at this level for a period of two minutes, after which time it was ramped linearly down over a period of one minute. The intent of this fire was to ignite furniture in the loading dock. However, because the initiating fire was sufficient to activate two sprinklers (at $50 \mathrm{~s}$ and $75 \mathrm{~s}$ ), the fire did not spread to the nearby furniture.

\subsubsection{Temperature}

Figure 4-37 shows the sprinkler temperature at each of the sprinkler locations. The graph indicates that the temperature at locations 4 and 8 reached $74^{\circ} \mathrm{C}$, at which point the sprinklers were activated in these locations. Temperatures at locations 1 and 2 peaked in the $60^{\circ} \mathrm{C}$ to $70^{\circ} \mathrm{C}$ range but never reached the threshold for activation.

The predicted temperatures and oxygen volume fraction in the main and west showroom remained near ambient throughout since the fire in the loading dock was extinguished by the sprinklers. 


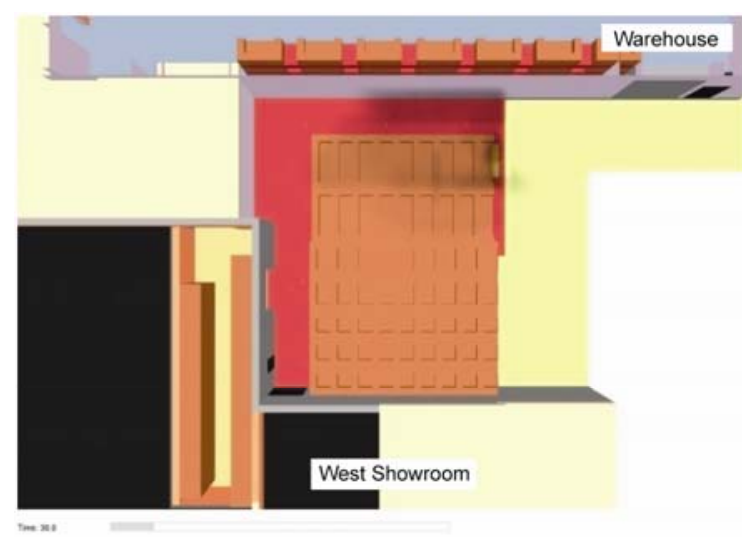

$30 \mathrm{~s}$

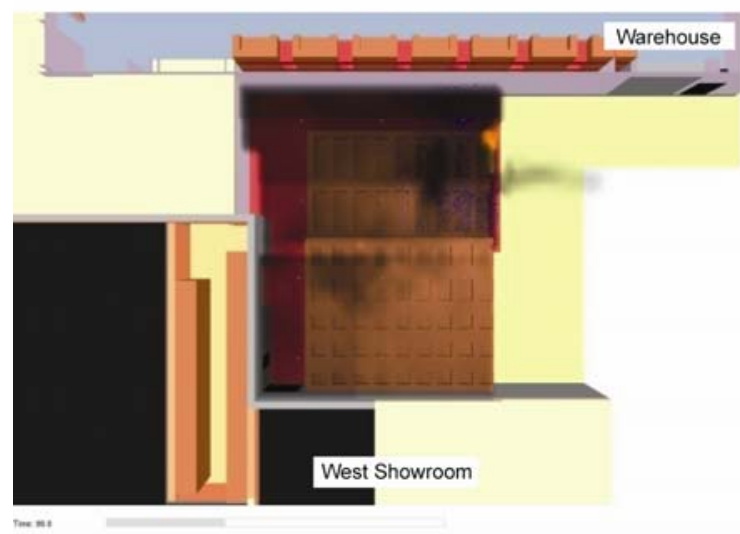

$90 \mathrm{~s}$

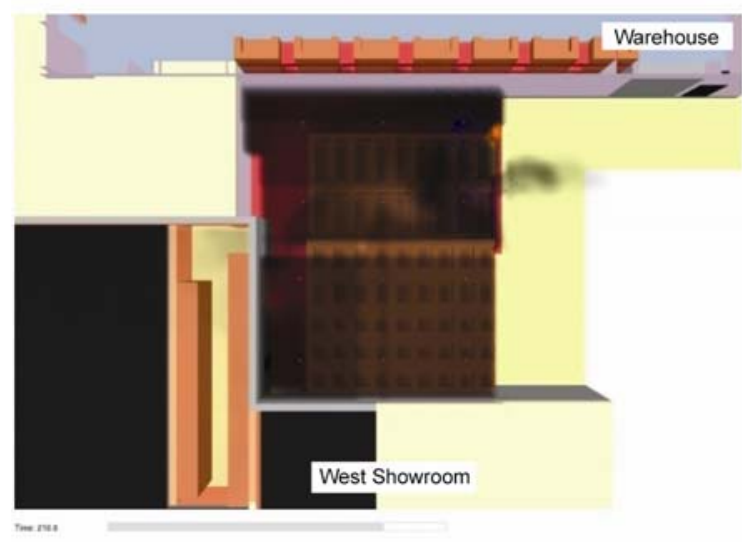

$210 \mathrm{~s}$

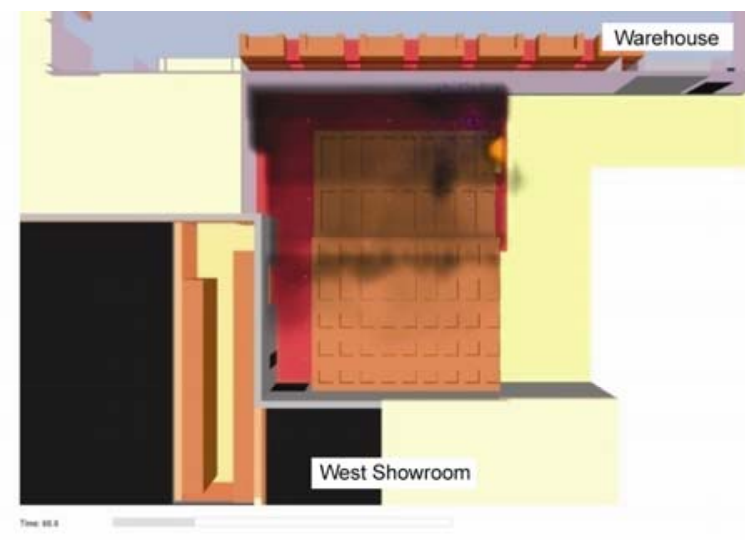

$60 \mathrm{~s}$

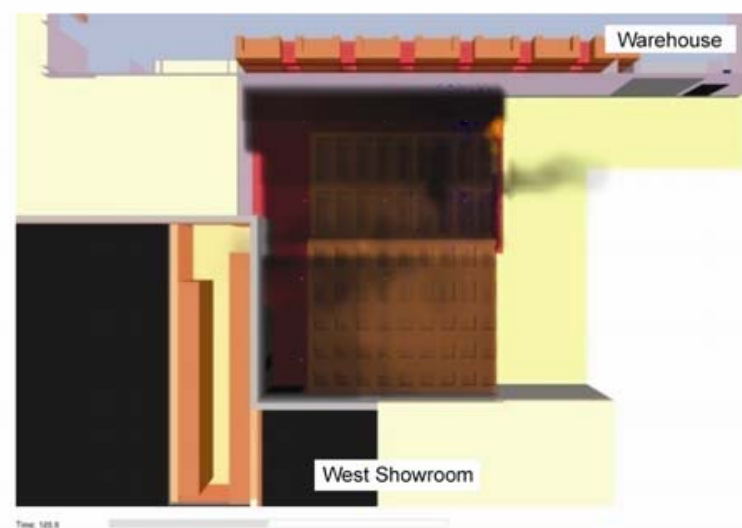

$120 \mathrm{~s}$

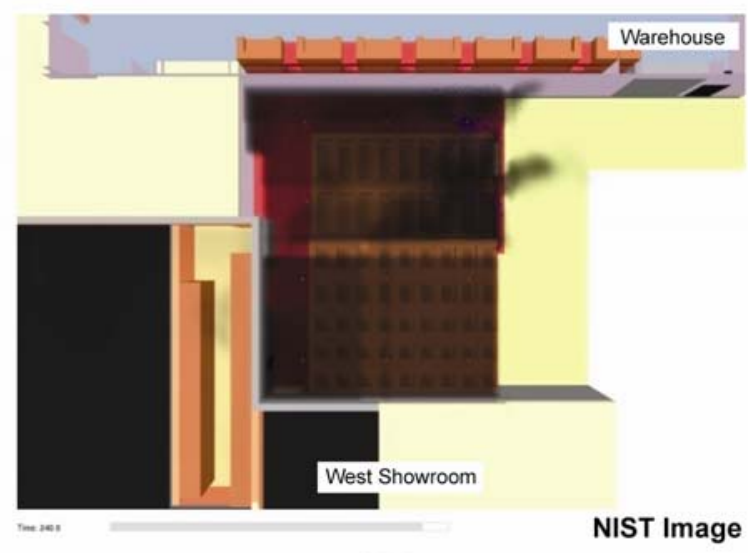

$240 \mathrm{~s}$

Figure 4-36. Fire and smoke progression in the early stages of the sprinklered scenario. Sprinkler 8 was the first to activate, at $50 \mathrm{~s}$, while sprinkler 4 activated at $75 \mathrm{~s}$. 


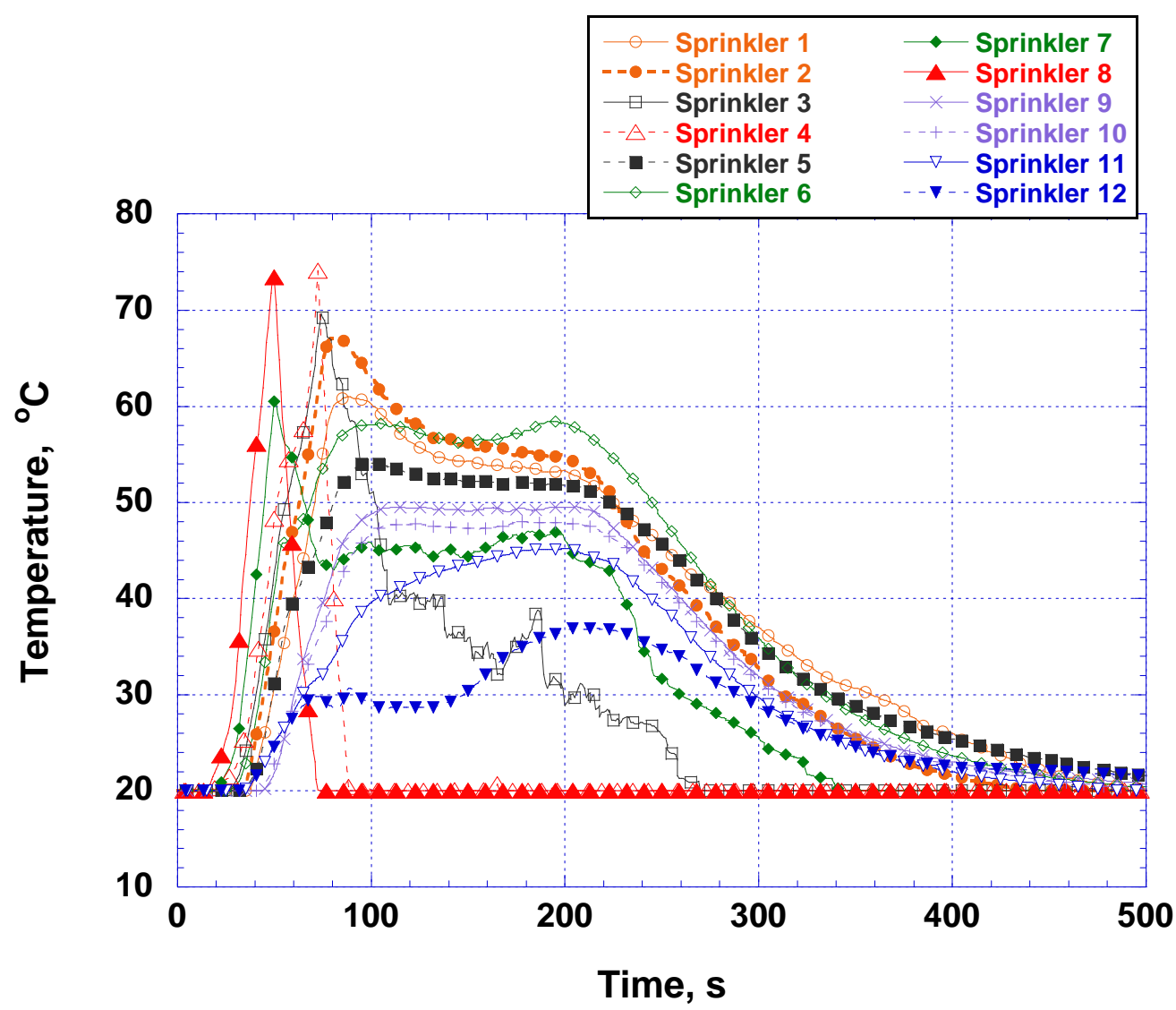

Figure 4-37. Sprinkler temperatures inside the enclosed loading dock.

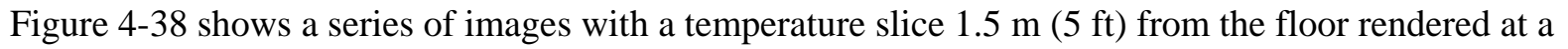
range of times between $30 \mathrm{~s}$ through $240 \mathrm{~s}$. Note that the scale on these images is consistent with those in Figure 31. These images show that the area of elevated temperatures is limited to the immediate vicinity of the fire inside the loading dock.

\subsubsection{Oxygen Volume Fraction}

A similar result is seen in the oxygen volume fraction data, shown in Figure 4-39. This figure shows a

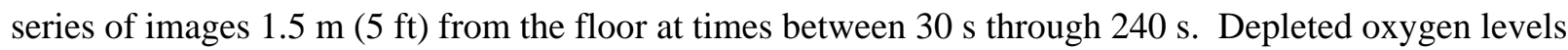
are observed in the vicinity of the holding area. The oxygen volume fraction at $1.5 \mathrm{~m}$ never drops below the tenability threshold of 0.12 (volume fraction). There is an increase in oxygen volume fraction between the final two images, as fresh air enters the holding area. 


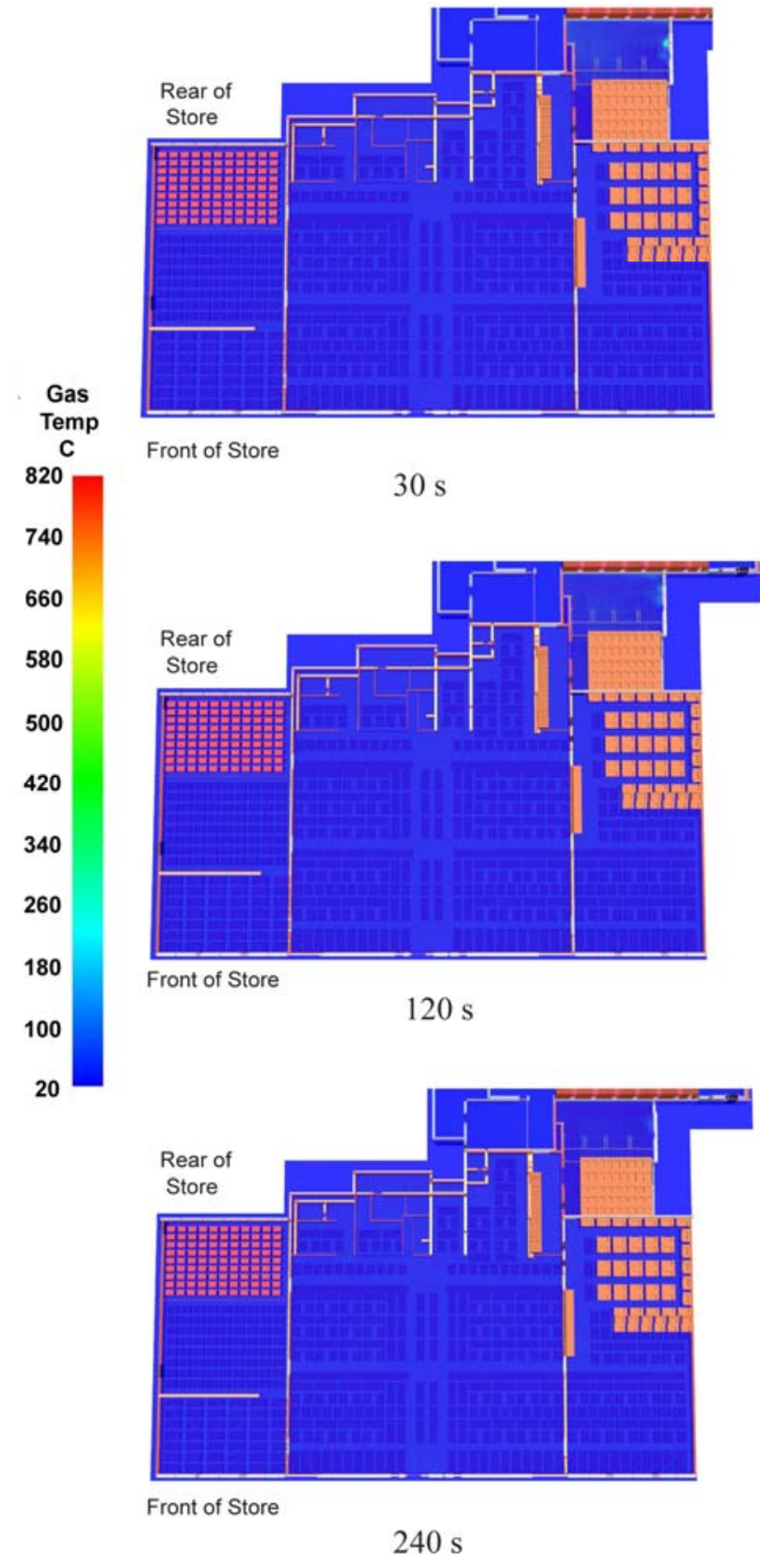

Figure 4-38. Temperatures $1.5 \mathrm{~m}$ (5 ft) above the floor in the sprinklered simulation.
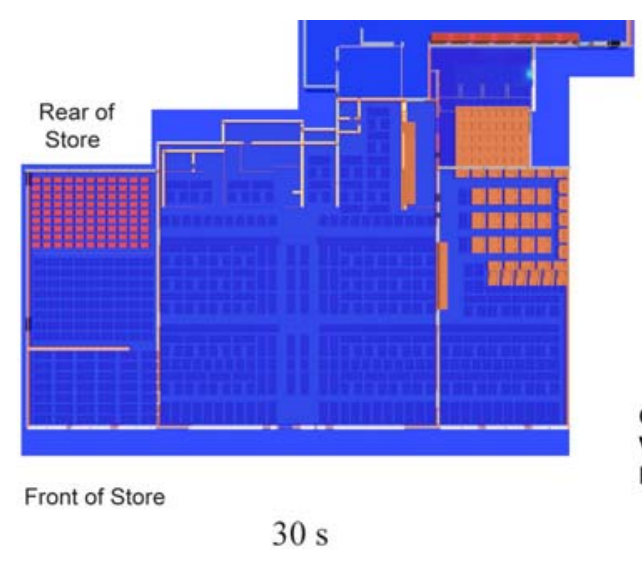

Fraction

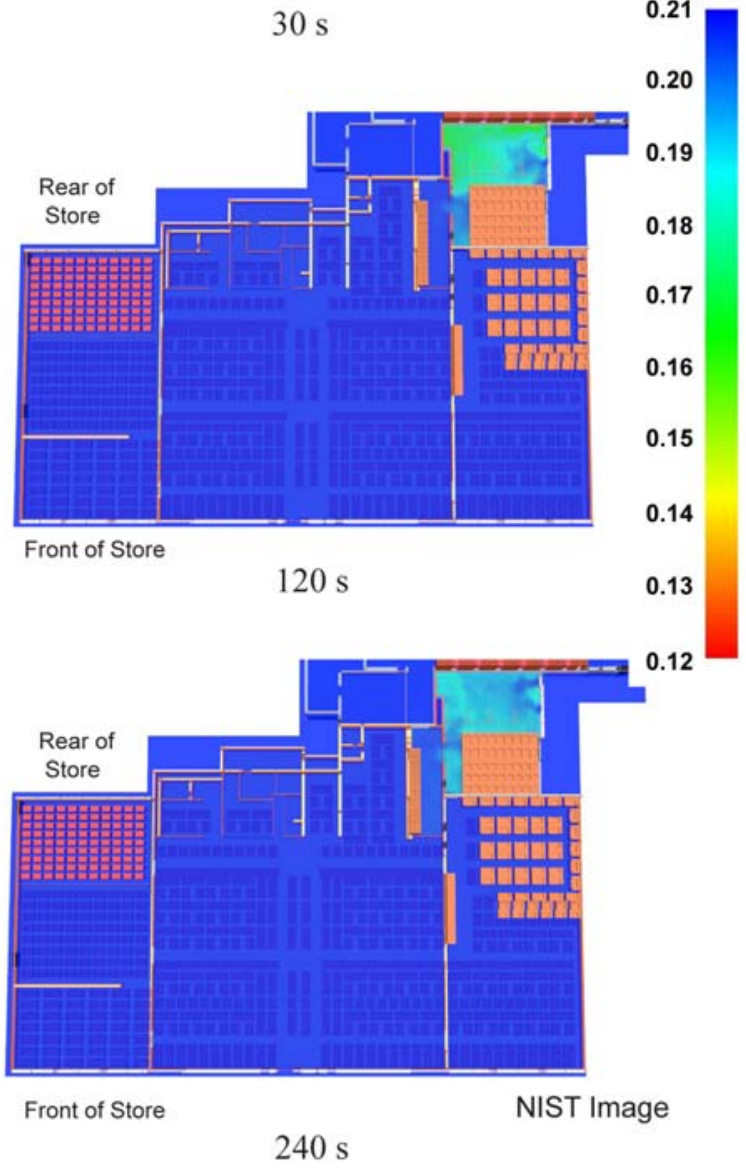

Figure 4-39. Oxygen volume fractions $1.5 \mathrm{~m} \mathrm{(5} \mathrm{ft)} \mathrm{above} \mathrm{the} \mathrm{floor} \mathrm{in} \mathrm{the}$ sprinklered simulation. 


\subsection{BASELINE WITH FRONT WINDOWS INTACT}

\subsubsection{General}

In this simulation, the windows at the north (front) end of the main and west showrooms were kept in place, while everything else remained fixed from the base scenario. The front entrance, through which fire department personnel entered and exited the main showroom, was kept open and all other ventilation parameters were unaltered. The results of this simulation are presented here.

\subsubsection{Fire Growth and Smoke Spread}

Figure 4-40 shows the progression of fire and smoke throughout the loading dock, holding area and showrooms between $1020 \mathrm{~s}$ and $2040 \mathrm{~s}$ (7:27:53 p.m. through 7:44:53 p.m.). The first three images in this figure are indistinguishable from the corresponding images in Figure 4-19 (the baseline simulation). The differences appear in the later images - $1500 \mathrm{~s}$ and beyond. Compared to Figure 4-19, Figure 4-40 shows far less burning in the northwest quadrant of the main showroom.

In the base simulation the fire HRR begins to diminish after $1380 \mathrm{~s}$, but when the front windows of the main showroom were taken out starting at $1457 \mathrm{~s}$, there was a rapid increase in the HRR. In this scenario, with the windows remaining intact, the fire HRR continues to decrease after $1380 \mathrm{~s}$. The fire moved toward the front of the showroom, where oxygen was still being supplied through the front door. With the front windows intact, the flames reached the front of the main showroom at $1800 \mathrm{~s}$ (7:40:53 p.m.), approximately 3 minutes longer than the base scenario. At 2040 s (7:44:53 p.m.) in the base case, the flames appear across the front of the main and west showrooms, while with the windows intact, the flames only appear across a small portion of the main showroom.

\subsubsection{Heat Release Rate}

Figure 4-41 shows the change in HRR over time for this scenario and the baseline simulation. In both scenarios, HRR peaked at $120 \mathrm{MW}$ at around $1300 \mathrm{~s}$ after which the HRR decreased. This would be consisent with the fire becoming underventilated. The venting of the front windows in the main showroom at $1457 \mathrm{~s}$ corresponds with the subsequent rapid increase in HRR for the base case. In the simulation with the windows intact, the HRR did not increase at approximately $1500 \mathrm{~s}$, but continued to decrease until about $1600 \mathrm{~s}$. 


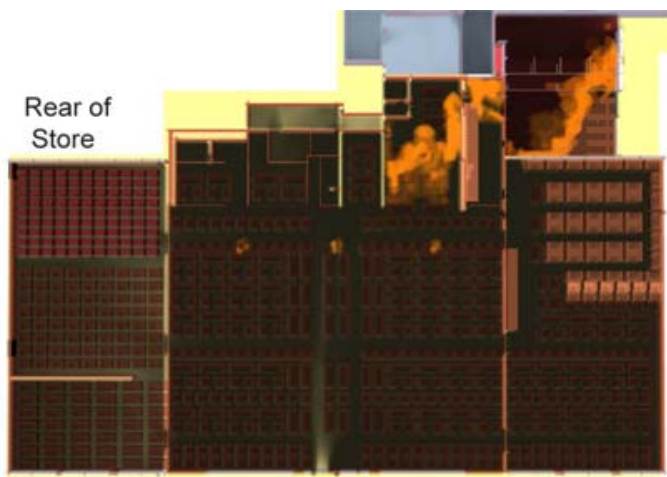

Front of Store

$1020 \mathrm{~s}$

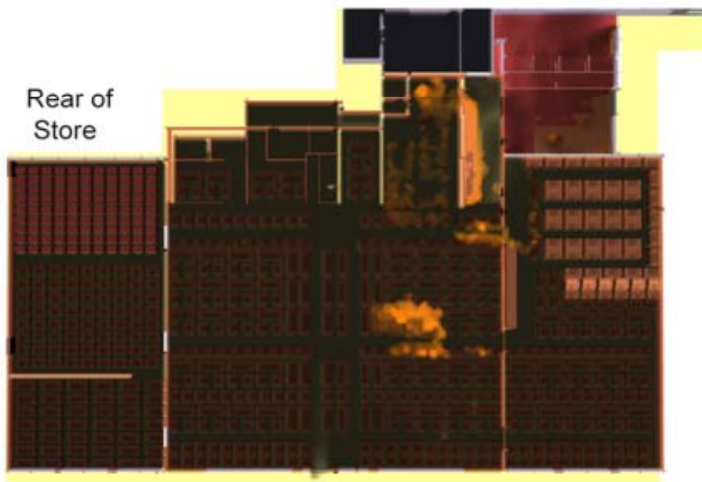

Front of Store

$1500 \mathrm{~s}$

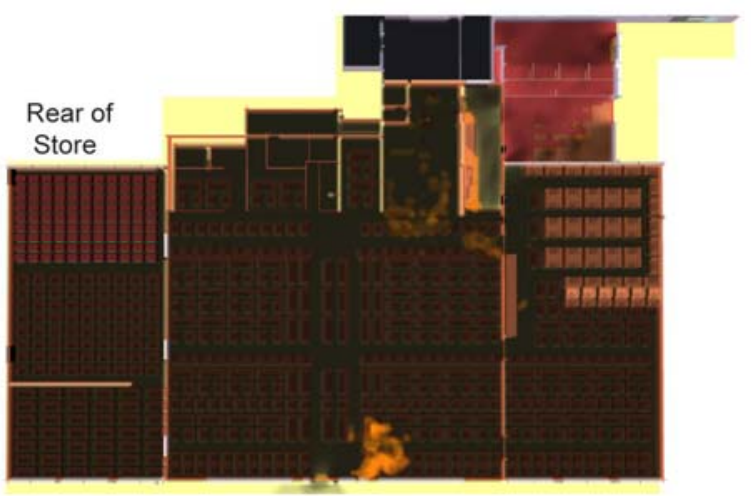

Front of Store

$1800 \mathrm{~s}$

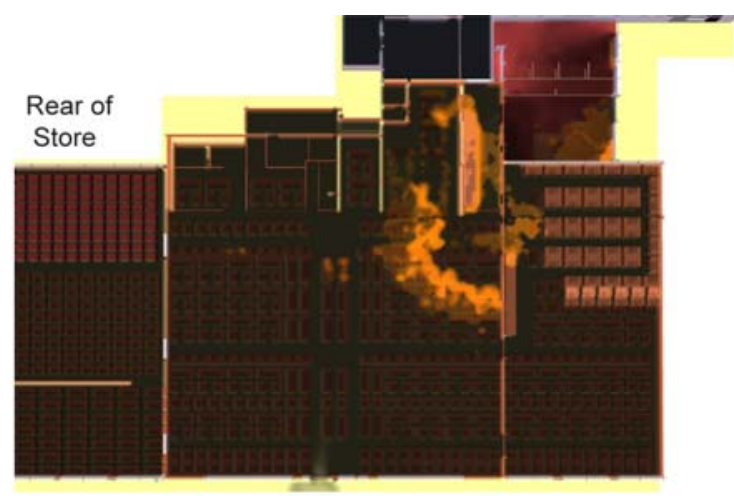

Front of Store

$1380 \mathrm{~s}$

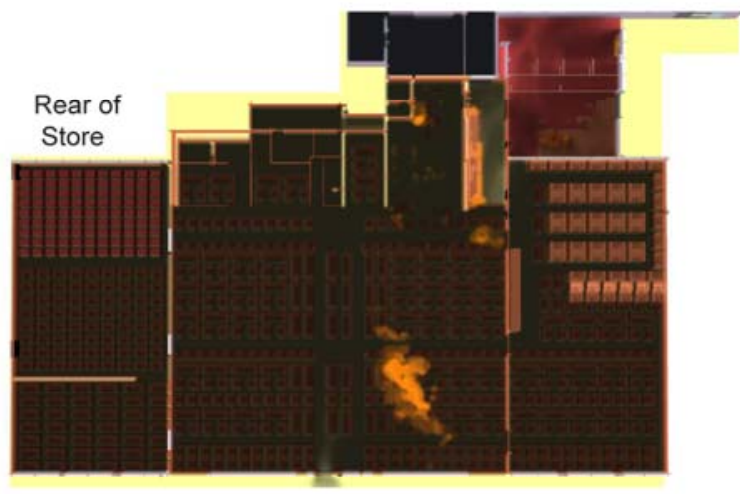

Front of Store

$1620 \mathrm{~s}$

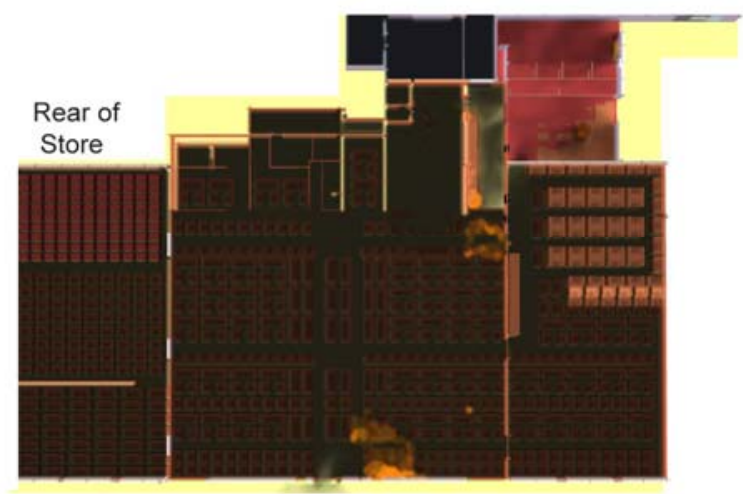

Front of Store

$2040 \mathrm{~s}$

Figure 4-40. Fire and smoke progression in simulation with front windows intact. 


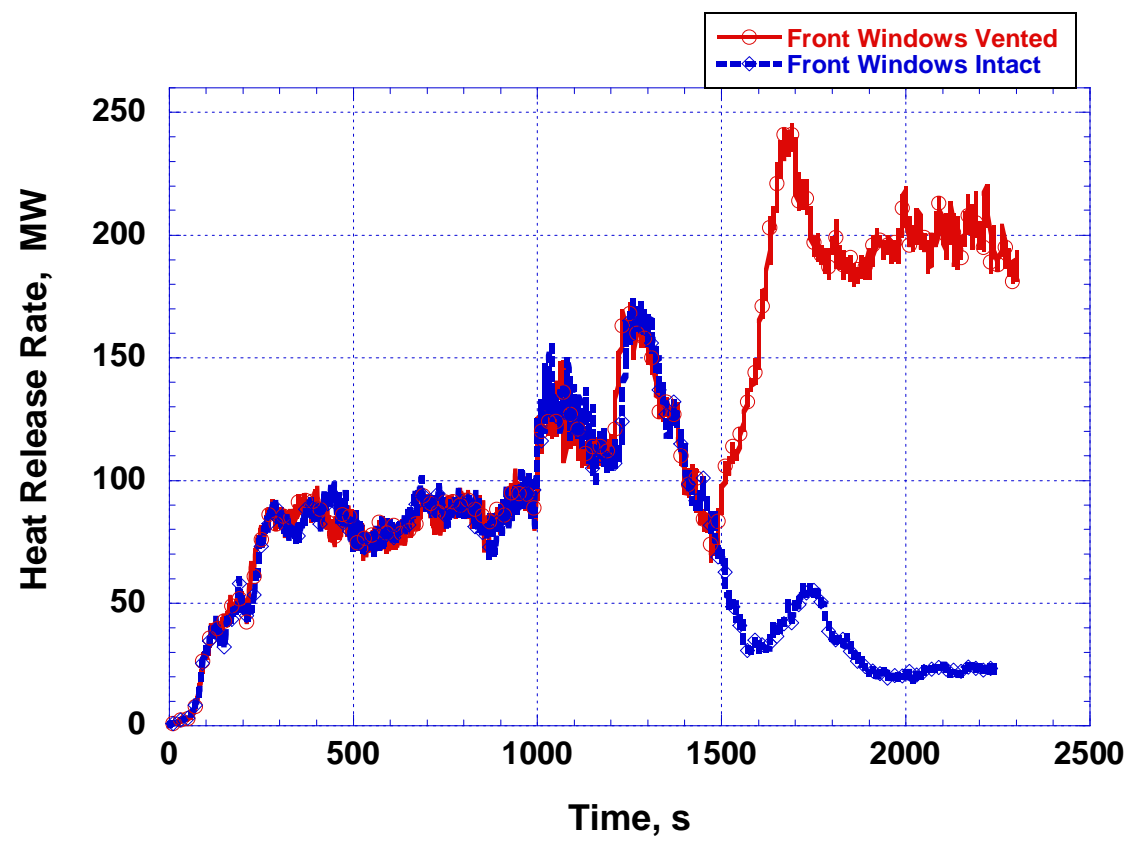

Figure 4-41. Comparison of the heat release rate in the simulations for front windows vented and front windows intact.

\subsubsection{Temperature}

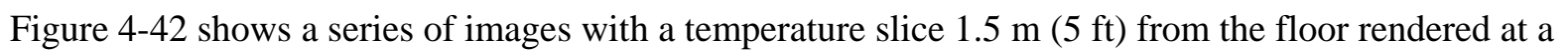
range of times between $900 \mathrm{~s}$ through $1620 \mathrm{~s}$ (7:25:53 p.m. through 7:37:53 p.m.). The trends in this figure are similar to those seen in Figure 4-28 for the baseline simulation. For the windows intact scenario the high temperature areas, shown in red, diminishes between $1380 \mathrm{~s}$ and $1500 \mathrm{~s}$. After $1500 \mathrm{~s}$ the simulation displays less red areas in the windows intact case than for the same times in the baseline case (Figure 4-28).

Figures 4-43 through Figure 4-46 show temperature data recorded at the same sensor locations used in Figure 4-25 for the baseline simulation. For comparison purposes, the scale in these figures was kept the same as the corresponding scale in Figure 4-27 through Figure 4-30. After 1500 s, the temperatures were lower in the scenario with the front windows intact as compared to the base case. The temperatures with the windows intact exceeded the $120^{\circ} \mathrm{C}$ tenability threshold at each sensor location before the time at which the windows would have been broken out.

\subsubsection{Oxygen Volume Fraction}

Figures 4-47 through 4-49 show oxygen volume fraction data for the front windows intact case that were recorded at the same sensor locations (Figure 4-25) as the baseline case. For the first 1000 s, the oxygen volume fraction in the west showroom (Figures 4-47 and 4-32) drops to about 

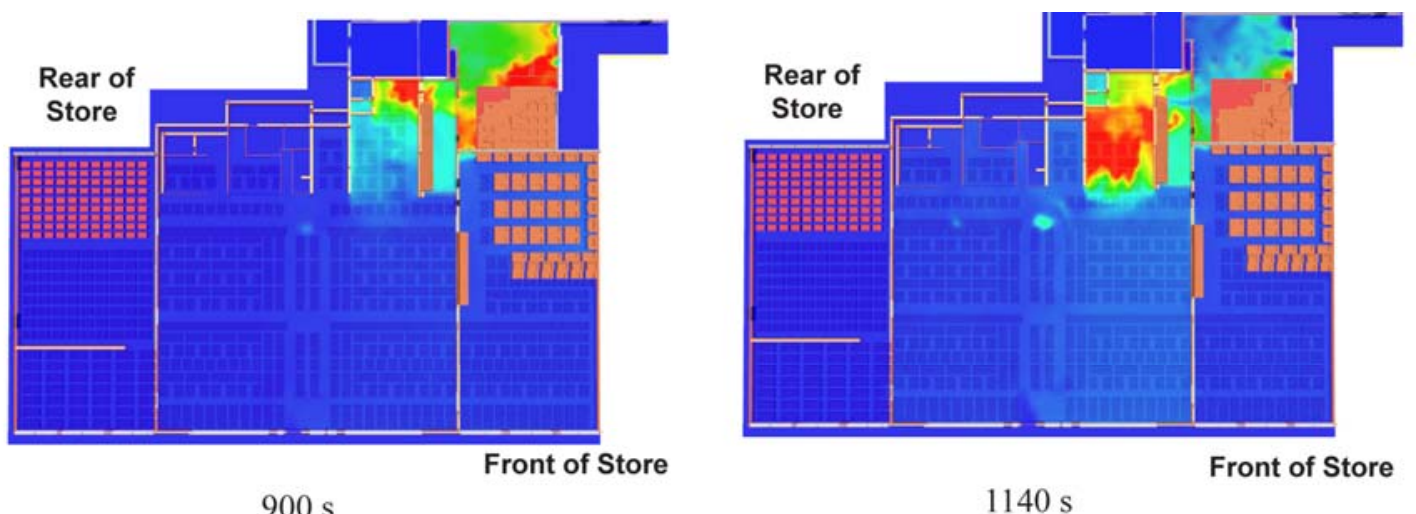

Gas

Temp

$900 \mathrm{~s}$
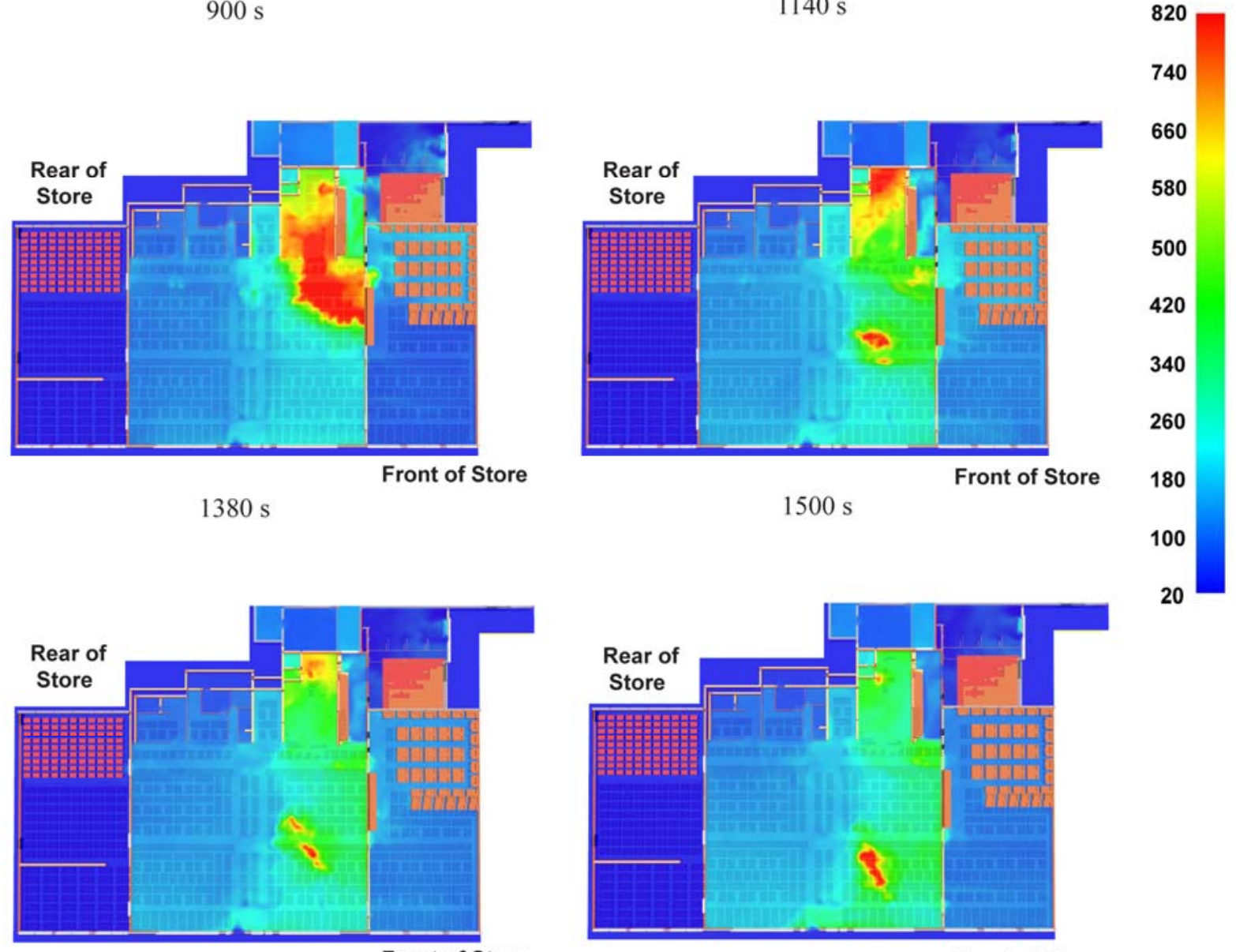

$1560 \mathrm{~s}$

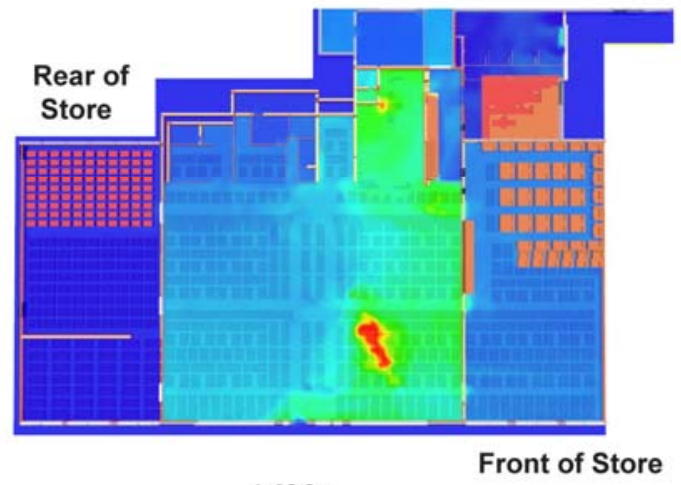

$1620 \mathrm{~s}$

Figure 4-42. Temperature slices located $1.5 \mathrm{~m} \mathrm{(5} \mathrm{ft)} \mathrm{above} \mathrm{the} \mathrm{floor} \mathrm{in} \mathrm{simulation} \mathrm{with} \mathrm{front}$ windows intact. 


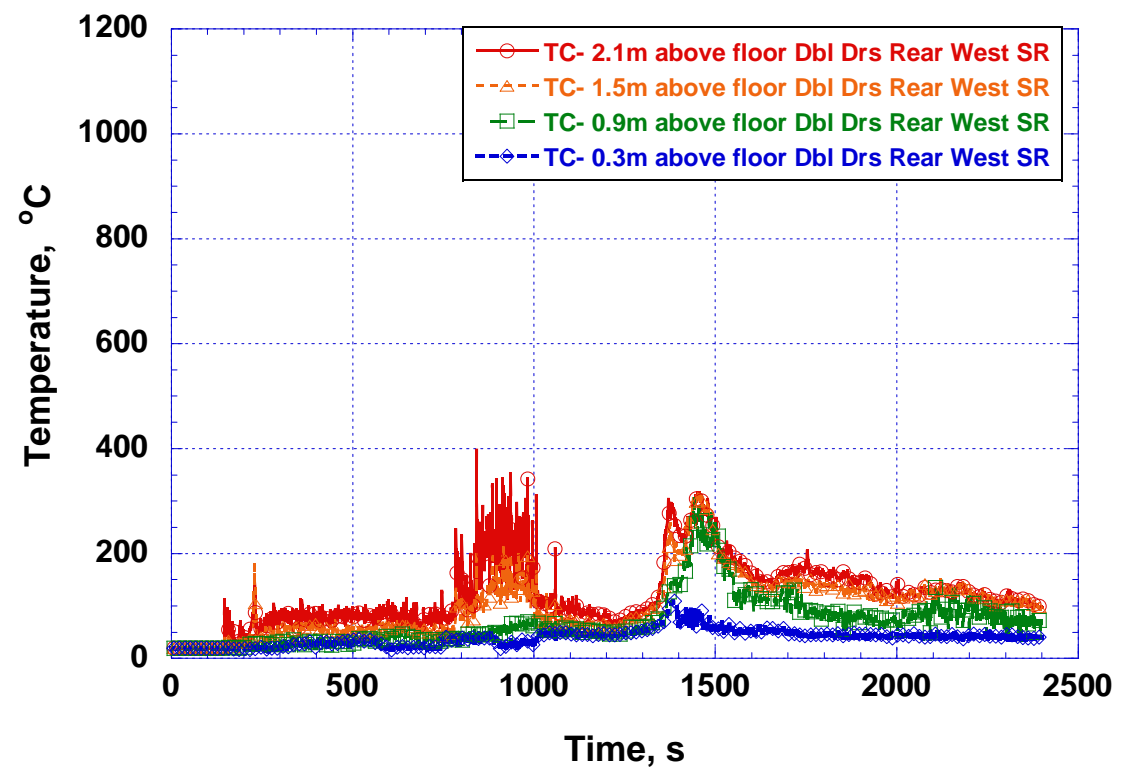

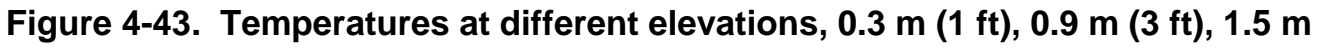
$(5 \mathrm{ft})$, and $2.1 \mathrm{~m}(7 \mathrm{ft})$ in rear of west showroom near double doors.

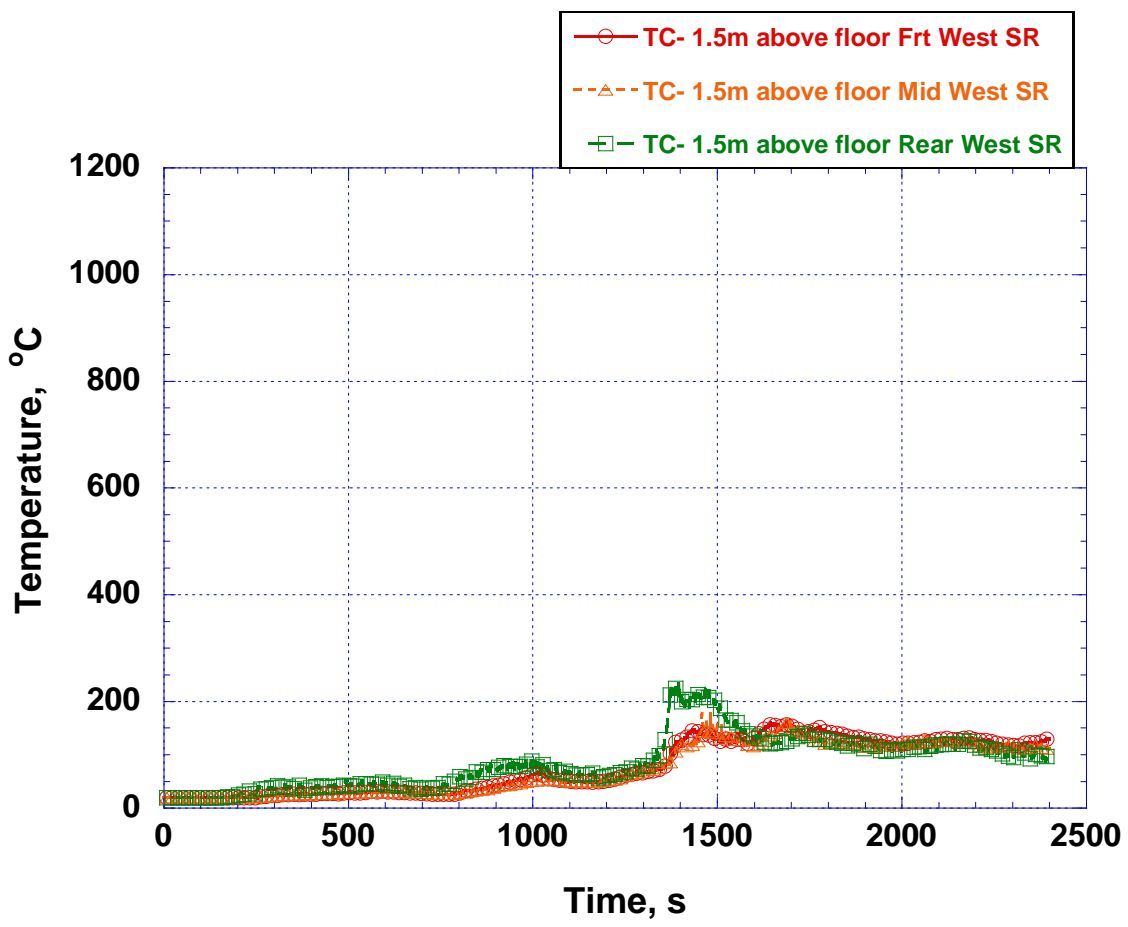

Figure 4-44. West showroom temperatures for $1.5 \mathrm{~m}(5 \mathrm{ft})$ above the floor. 


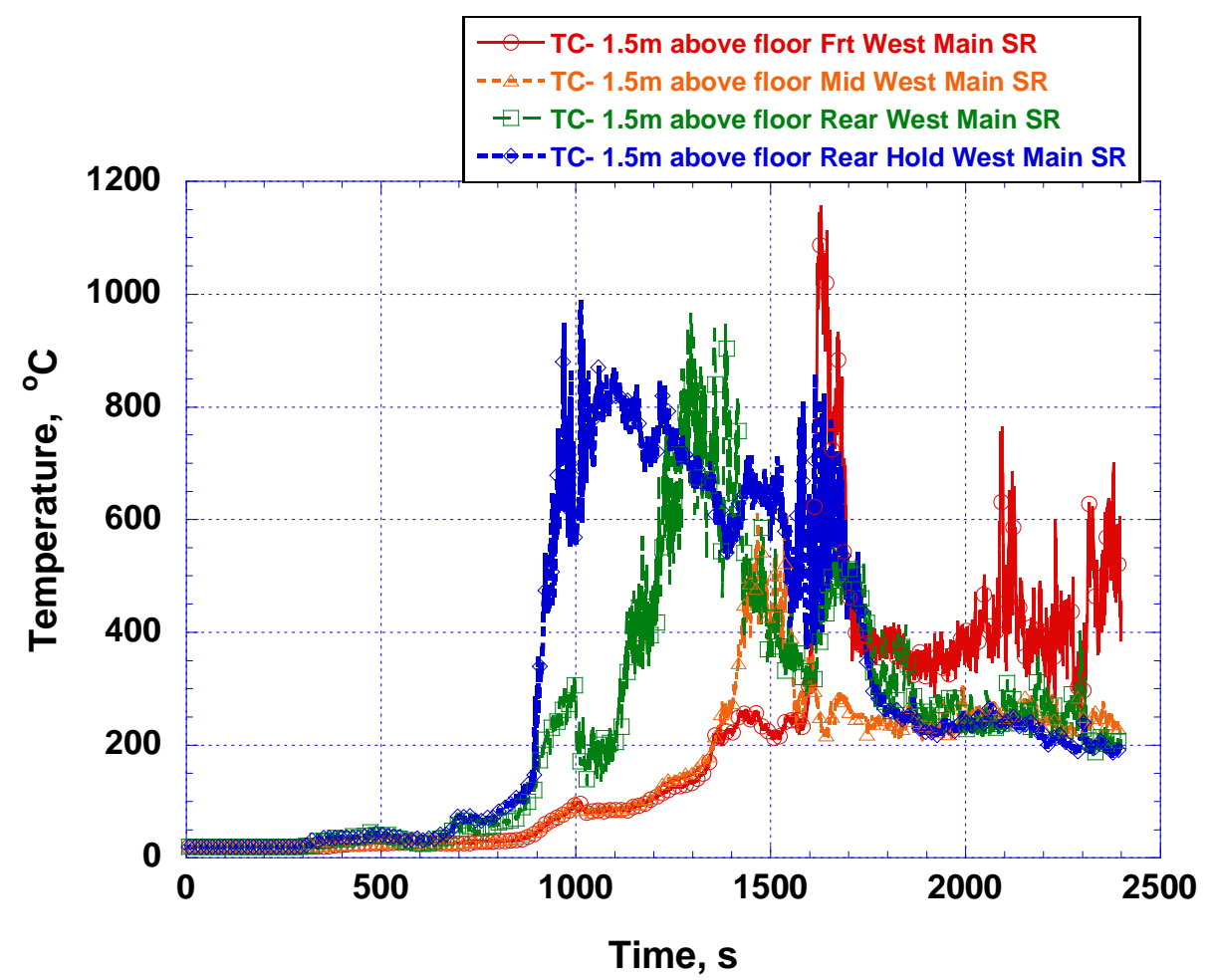

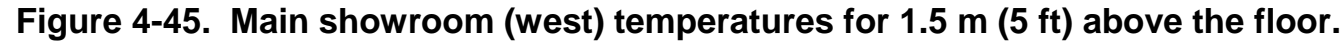

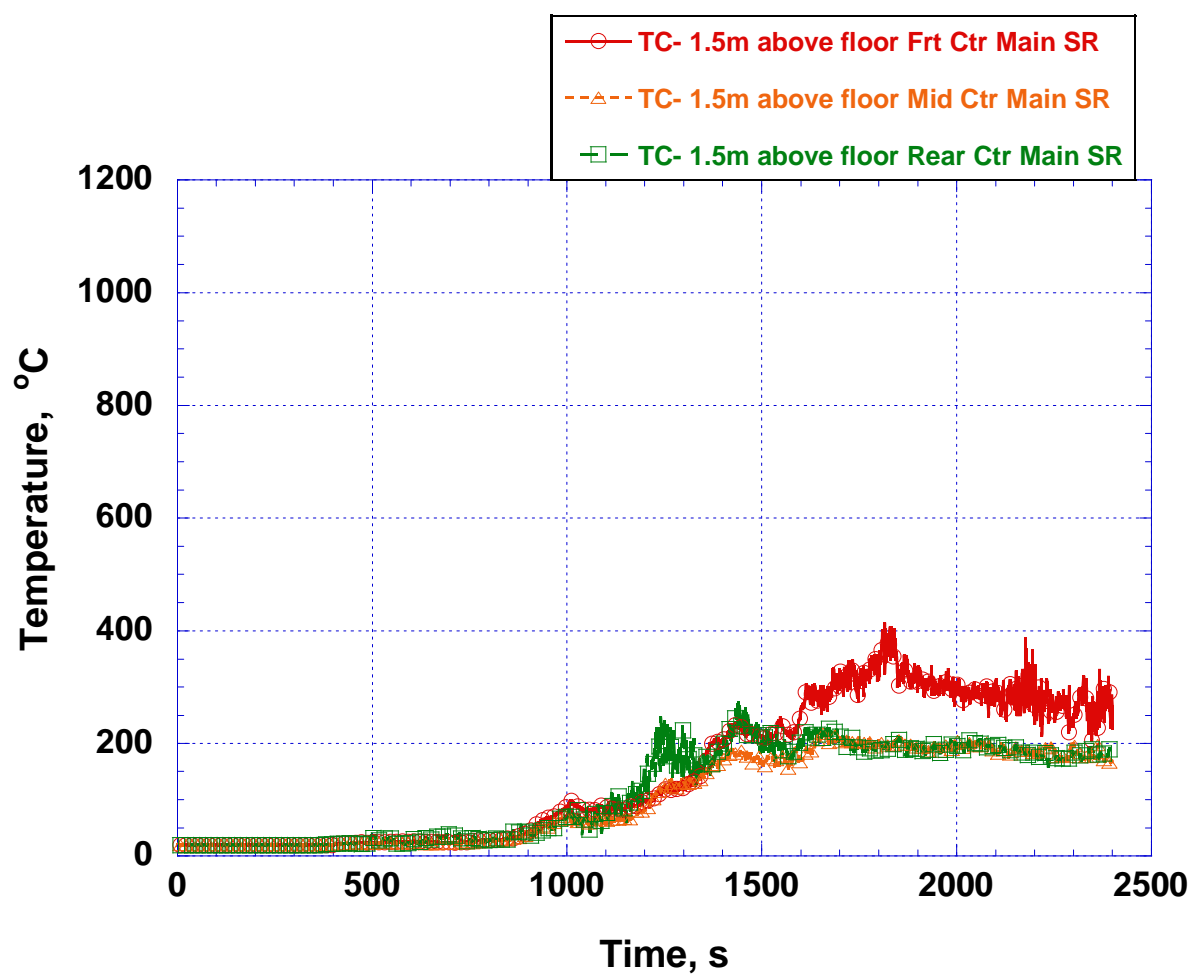

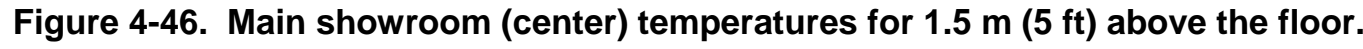


0.16 for both cases. For about the next $400 \mathrm{~s}$, the oxygen volume fraction decreases more slowly in both cases. By $1400 \mathrm{~s}$ the volume fraction drops below 0.1 for the windows intact case, but decreases to 0.15 for the base scenario. For the windows intact case, after the time when the windows would have been broken at $1457 \mathrm{~s}$, the oxygen volume fraction in the rear of the west showroom begins to increase and peak at about 0.12 at $1850 \mathrm{~s}$. The oxygen volume fractions in the mid and front of the west showroom decrease to 0.09 and 0.07 , respectively. The oxygen volume fractions in the rear of the main showroom (Figures 4-48 and 4-33) show similar trends during the first $1300 \mathrm{~s}$. For the windows intact case, the oxygen volume fraction became more steady between 0.07 and 0.09 . The oxygen volume fraction for the same location in the base scenario continues to drop to less than 0.02 . For the base case, after $1700 \mathrm{~s}$, the oxygen volume fraction is less than 0.03 for the holding area, rear, and mid showroom. For the windows intact scenario, at about the same time, $1700 \mathrm{~s}$, the oxygen volume fraction for the rear, mid, and front showroom locations are all above 0.07 . Overall, the trends for both cases are similar during the early portion of the simulations, but after the time at which the windows were broken out in the base scenario, the oxygen volume fractions appear lower than in the front windows intact case for the rear holding, rear, and mid showroom locations.

Figure 4-50 shows a series of images with an oxygen slice $1.5 \mathrm{~m}(5 \mathrm{ft})$ from the floor rendered at a range of times between $360 \mathrm{~s}$ and $1440 \mathrm{~s}$. As was the case with temperature, the conditions in the main and west showrooms become untenable because of oxygen depletion prior to $1440 \mathrm{~s}$ (7:34:53 p.m.). While minimum oxygen volume fractions were not as low in the case with the windows intact, they nonetheless dropped below 0.12 (indicated by the red shaded areas in Figure 4-50) in the main and west showrooms.

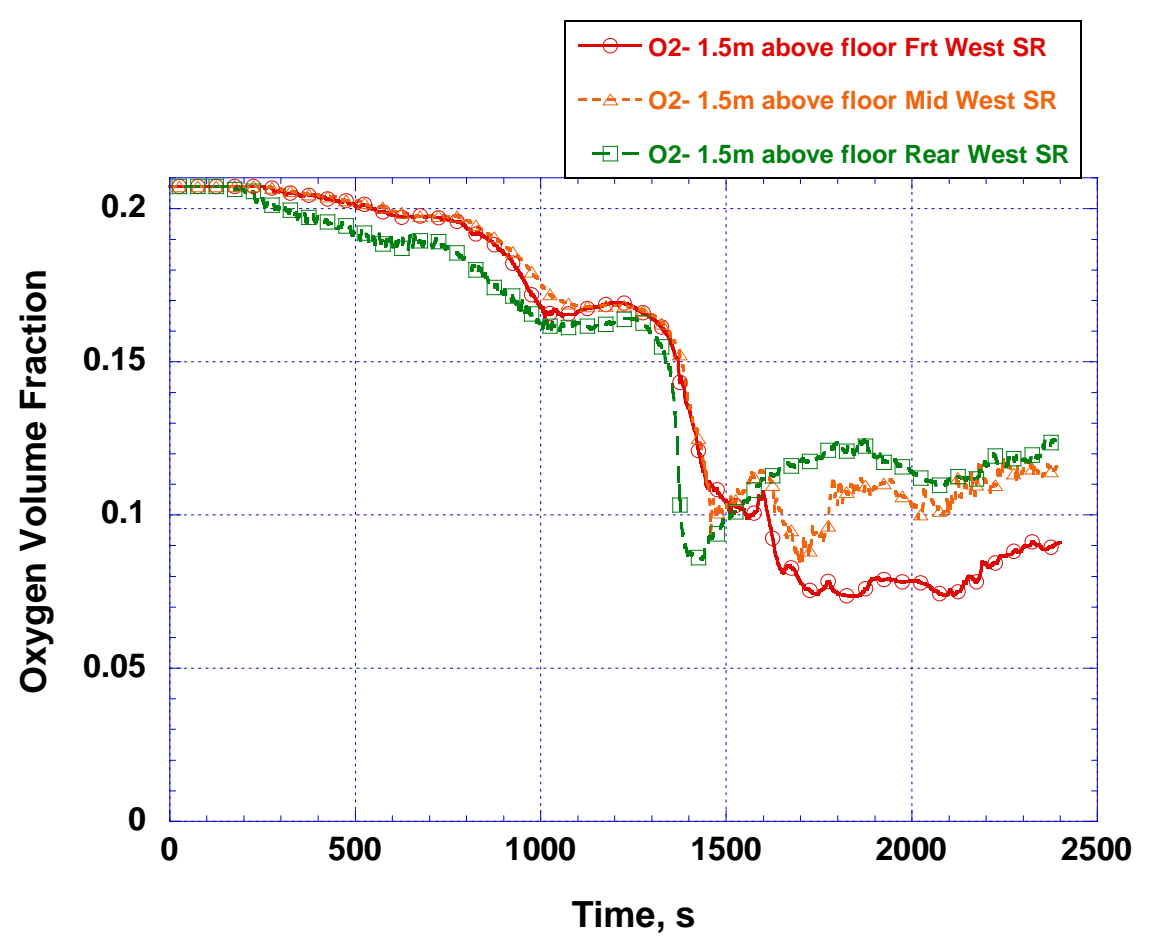

Figure 4-47. West showroom oxygen volume fractions for $1.5 \mathrm{~m}(5 \mathrm{ft})$ above the floor. 


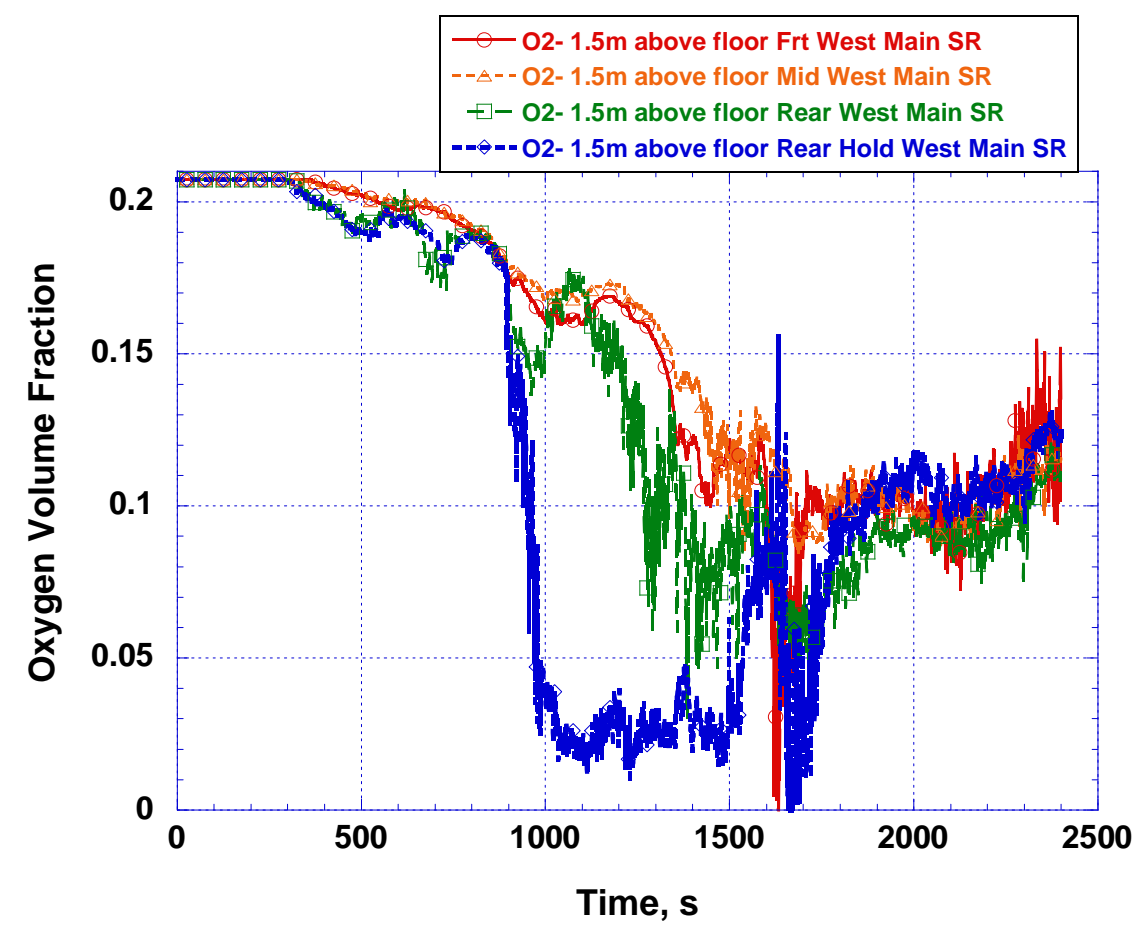

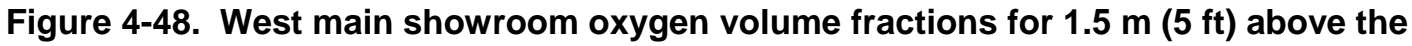
floor.

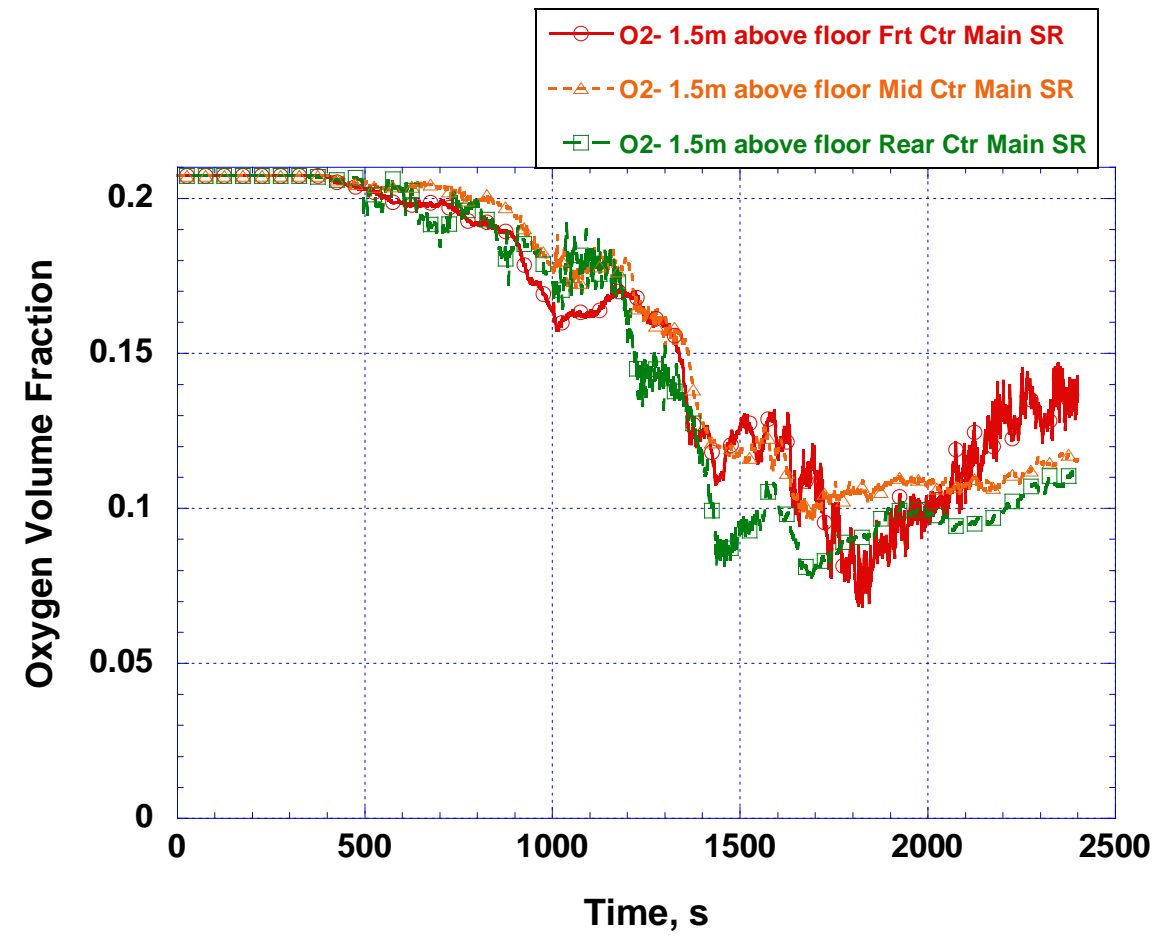

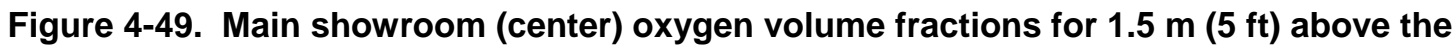
floor. 


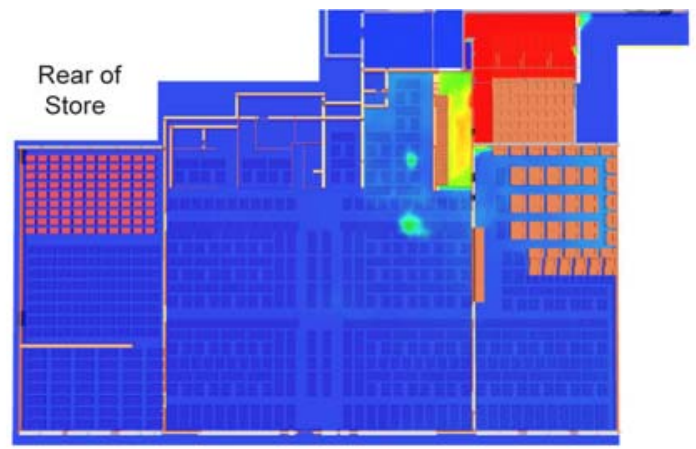

Front of Store

$360 \mathrm{~s}$

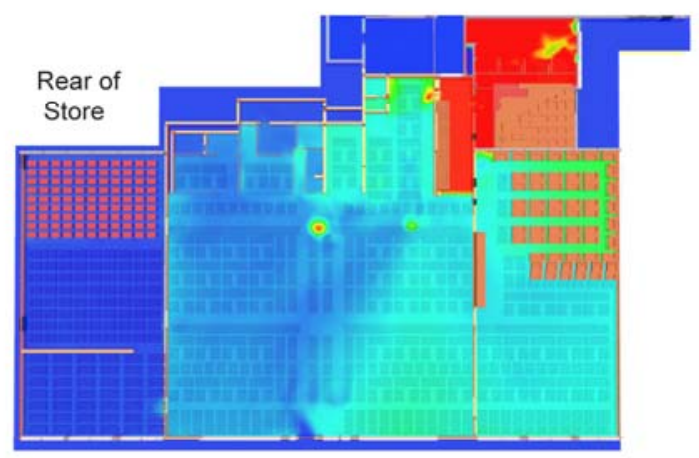

Front of Store

$840 \mathrm{~s}$

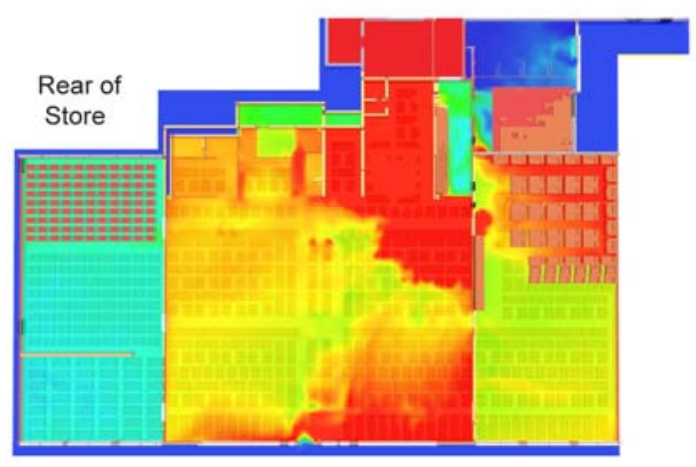

Front of Store

$1380 \mathrm{~s}$

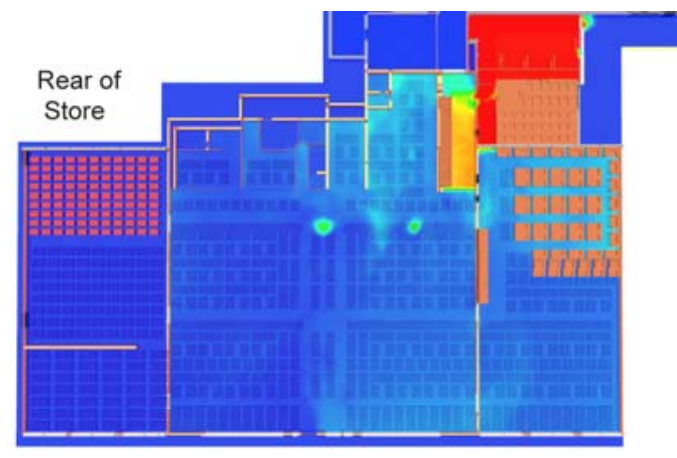

Front of Store

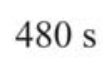

Volume

Fraction

0.21

0.20
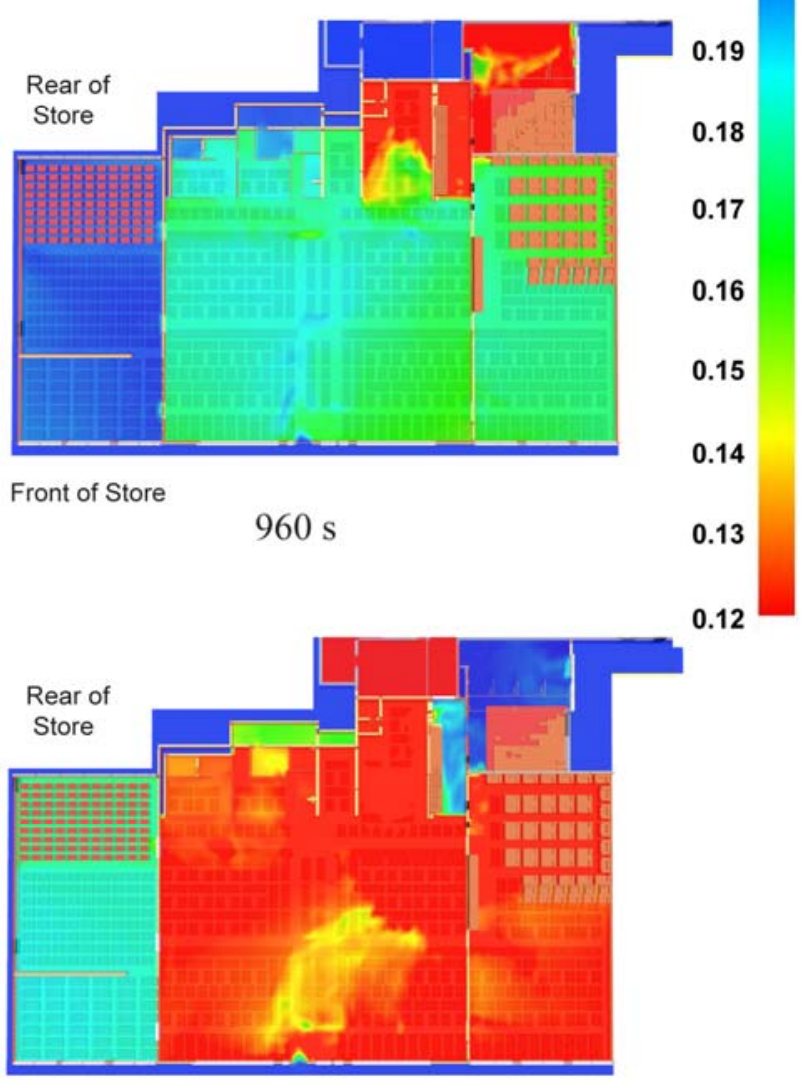

Front of Store

$1440 \mathrm{~s}$

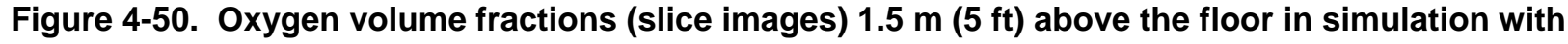
front windows intact. 


\subsection{SUMMARY OF SIMULATION RESULTS}

Using FDS, NIST modeled the development of the fire in the Sofa Super Store during the fire that occurred on June 18, 2007, in which nine fire fighters lost their lives. This baseline fire scenario was constructed using measurements from the scene, witness interviews and discussions, time stamped photographs, and radio transmission logs. The simulation was run for $2400 \mathrm{~s}$, closely corresponding to the duration of the time that passes from the time that the fire started inside the loading dock to the time when the roof of the main showroom collapsed. Simulations were designed to provide insight into:

- fire and smoke spread inside the structure,

- fire-spread into the showrooms versus the warehouse,

- impact of sprinklers on the loading dock, and

- impact of ventilation, including breaking front windows and openings in the roof.

The insights provided by these simulations served as a basis for examining the potential effects of some intervention strategies. These were the installation of a fire sprinkler system, breaking the front windows of the building, and venting the rear of the showroom with two differently sized roof openings.

For each of the five simulations, the time for areas to become untenable due to elevated temperature or oxygen depletion are tabulated in Tables 4-1 to 4-6. These untenability criteria are simplifications of complex studies and serve as a basis for appraising the relative effects of alternate fire scenarios.

The NIST study did not include analysis of the threat to protected fire fighters. If a fire fighter in turnout gear is utilizing a self-contained breathing apparatus (SCBA) and has an adequate supply of air, the fire fighter can temporarily survive higher temperatures and depleted external oxygen levels. This safety shell ends when the fire fighter runs out of tank air or remains within the hot fire environment too long. 
Table 4-1. Temperature and Oxygen Tenability Conditions for Rear of West Showroom.

\begin{tabular}{|c|c|c|c|c|c|c|}
\hline \multirow[b]{2}{*}{ Simulation } & \multicolumn{3}{|c|}{ Temperature } & \multicolumn{3}{|c|}{ Oxygen } \\
\hline & $\begin{array}{c}\text { Time to } \\
\text { Untenability } \\
\left(>120^{\circ} \mathrm{C}\right)^{1} \\
\text { S }\end{array}$ & $\begin{array}{l}\text { Peak } \\
\text { Temp } \\
{ }^{\circ} \mathrm{C}\end{array}$ & $\begin{array}{l}\text { Time to } \\
\text { Peak } \\
\text { Temp. } \\
\text { s }\end{array}$ & $\begin{array}{c}\text { Time to } \\
\text { Untenability } \\
(<0.12)^{2} \\
\mathrm{~s}\end{array}$ & $\begin{array}{l}\text { Minimum } \\
\text { Oxygen } \\
\text { Level } \\
\text { volume } \\
\text { fraction } \\
\end{array}$ & $\begin{array}{c}\text { Time to } \\
\text { Minimum } \\
\text { Oxygen } \\
\text { Level } \\
\text { s }\end{array}$ \\
\hline Base & 1650 & 260 & 2300 & 1800 & 0.02 & 2300 \\
\hline Base with Sprinklers & \multicolumn{6}{|c|}{ Fire growth limited to loading dock. Conditions remained tenable. } \\
\hline $\begin{array}{l}\text { Front Windows } \\
\text { Intact }\end{array}$ & 1650 & 200 & 1400 & 1700 & 0.09 & 1450 \\
\hline Small Vent & 1800 & 210 & 1600 & 1800 & 0.09 & 1600 \\
\hline Large Vent & 1850 & 230 & 1400 & 1650 & 0.08 & 1400 \\
\hline
\end{tabular}

Table 4-2. Temperature and Oxygen Tenability Conditions for Front of West Showroom.

\begin{tabular}{|l|c|c|c|c|c|c|}
\hline \multirow{2}{*}{ Simulation } & \multicolumn{3}{|c|}{ Temperature } & \multicolumn{3}{c|}{ Oxygen } \\
\cline { 2 - 7 } & $\begin{array}{c}\text { Time to } \\
\text { Untenability } \\
\left(>120^{\circ} \mathrm{C}\right)^{1} \\
\mathrm{~S}\end{array}$ & $\begin{array}{c}\text { Peak } \\
\text { Temp }\end{array}$ & $\begin{array}{c}\text { Time to } \\
\text { Peak } \\
\text { Temp. } \\
\mathrm{s}\end{array}$ & $\begin{array}{c}\text { Time to } \\
\text { Untenability } \\
(<0.12)^{2} \\
\mathrm{~s}\end{array}$ & $\begin{array}{c}\text { Minimum } \\
\text { Oxygen } \\
\text { Level } \\
\text { Volume } \\
\text { Fraction }\end{array}$ & $\begin{array}{c}\text { Time to } \\
\text { Minimum } \\
\text { Oxygen } \\
\text { Level } \\
\mathrm{s}\end{array}$ \\
\hline Base & 1700 & 1100 & 1950 & 1900 & 0.2 & 1950 \\
\hline Base with Sprinklers & Fire growth limited to loading dock. Conditions remained tenable. \\
\hline $\begin{array}{l}\text { Front Windows } \\
\text { Intact }\end{array}$ & 1700 & 140 & 1450 & 1750 & 0.07 & 1700 \\
\hline Small Vent & 1850 & 140 & 1600 & 1900 & 0.1 & 1700 \\
\hline Large Vent & 1700 & 170 & 1550 & 1700 & 0.06 & 1700 \\
\hline $\begin{array}{l}1 . \quad \text { Time for temperature to exceed } 120^{\circ} \mathrm{C} \text { plus } 300 \mathrm{~s} . \\
\text { 2. Time for oxygen volume fraction less than } 0.12 \text { plus } 300 \mathrm{~s} .\end{array}$ \\
\hline
\end{tabular}


Table 4-3. Temperature and Oxygen Tenability Conditions for Rear of West Side of Main Showroom.

\begin{tabular}{|l|c|c|c|c|c|c|}
\hline \multirow{2}{*}{ Simulation } & \multicolumn{3}{|c|}{ Temperature } & \multicolumn{3}{c|}{ Oxygen } \\
\cline { 2 - 7 } & $\begin{array}{c}\text { Time to } \\
\text { Untenability } \\
\left(>120^{\circ} \mathrm{C}\right)^{1} \\
\mathrm{~S}\end{array}$ & $\begin{array}{c}\text { Peak } \\
\text { Temp }\end{array}$ & $\begin{array}{c}\text { Time to } \\
\text { Peak } \\
\text { Temp. } \\
\mathrm{S}\end{array}$ & $\begin{array}{c}\text { Time to } \\
\text { Untenability } \\
(<0.12)^{2} \\
\mathrm{~s}\end{array}$ & $\begin{array}{c}\text { Minimum } \\
\text { Oxygen } \\
\text { Level } \\
\text { Volume } \\
\text { Fraction }\end{array}$ & $\begin{array}{c}\text { Time to } \\
\text { Minimum } \\
\text { Oxygen } \\
\text { Level } \\
\mathrm{s}\end{array}$ \\
\hline Base & 1200 & 850 & 1300 & 1550 & 0.01 & 1750 \\
\hline Base with Sprinklers & Fire growth limited to loading dock. Conditions remained tenable. \\
\hline $\begin{array}{l}\text { Front Windows } \\
\text { Intact }\end{array}$ & 1200 & 850 & 1300 & 1550 & 0.06 & 1400 \\
\hline Small Vent & 1200 & 600 & 1400 & 1800 & 0.07 & 1550 \\
\hline Large Vent & 1200 & 950 & 1400 & 1650 & 0.03 & 1400 \\
\hline $\begin{array}{l}\text { 1. Time for temperature to exceed } 120{ }^{\circ} \mathrm{C} \text { plus } 300 \mathrm{~s} . \\
\text { 2. Time for oxygen volume fraction less than } 0.12 \text { plus } 300 \mathrm{~s} .\end{array}$ \\
\hline
\end{tabular}

Table 4-4. Temperature and Oxygen Tenability Condition for Front of West Side of Main Showroom.

\begin{tabular}{|c|c|c|c|c|c|c|}
\hline \multirow[b]{2}{*}{ Simulation } & \multicolumn{3}{|c|}{ Temperature } & \multicolumn{3}{|c|}{ Oxygen } \\
\hline & $\begin{array}{c}\text { Time to } \\
\text { Untenability } \\
\left(>120^{\circ} \mathrm{C}\right)^{1} \\
\text { S }\end{array}$ & $\begin{array}{c}\text { Peak } \\
\text { Temp } \\
\text { C }\end{array}$ & $\begin{array}{l}\text { Time to } \\
\text { Peak } \\
\text { Temp. } \\
\text { s }\end{array}$ & $\begin{array}{c}\text { Time to } \\
\text { Untenability } \\
(<0.12)^{2} \\
\mathrm{~s}\end{array}$ & $\begin{array}{c}\text { Minimum } \\
\text { Oxygen } \\
\text { Level } \\
\text { Volume } \\
\text { Fraction }\end{array}$ & $\begin{array}{c}\text { Time to } \\
\text { Minimum } \\
\text { Oxygen } \\
\text { Level } \\
\text { s }\end{array}$ \\
\hline Base & 1200 & 850 & 1300 & 1550 & 0.01 & 1750 \\
\hline Base with Sprinklers & \multicolumn{6}{|c|}{ Fire growth limited to loading dock. Conditions remained tenable. } \\
\hline $\begin{array}{l}\text { Front Windows } \\
\text { Intact }\end{array}$ & 1200 & 850 & 1300 & 1550 & 0.06 & 1400 \\
\hline Small Vent & 1200 & 600 & 1400 & 1800 & 0.07 & 1550 \\
\hline Large Vent & 1200 & 950 & 1400 & 1650 & 0.03 & 1400 \\
\hline
\end{tabular}


Table 4-5. Temperature and Oxygen Tenability Conditions for Rear of East Side of Main Showroom.

\begin{tabular}{|l|c|c|c|c|c|c|}
\hline \multirow{2}{*}{ Simulation } & \multicolumn{3}{|c|}{ Temperature } & \multicolumn{3}{c|}{ Oxygen } \\
\cline { 2 - 7 } & $\begin{array}{c}\text { Time to } \\
\text { Untenability } \\
\left(>120^{\circ} \mathrm{C}\right)^{1} \\
\mathrm{~s}\end{array}$ & $\begin{array}{c}\text { Peak } \\
\text { Temp }\end{array}$ & $\begin{array}{c}\text { Time to } \\
\text { Peak } \\
\text { Temp. } \\
\mathrm{S}\end{array}$ & $\begin{array}{c}\text { Time to } \\
\text { Untenability } \\
(<0.12)^{2} \\
\mathrm{~s}\end{array}$ & $\begin{array}{c}\text { Minimum } \\
\text { Oxygen } \\
\text { Level } \\
\text { Volume } \\
\text { Fraction }\end{array}$ & $\begin{array}{c}\text { Time to } \\
\text { Minimum } \\
\text { Oxygen } \\
\text { Level } \\
\mathrm{s}\end{array}$ \\
\hline Base & 1550 & 1100 & 1550 & 1700 & 0.05 & 1900 \\
\hline Base with Sprinklers & Fire growth limited to loading dock. Conditions remained tenable. \\
\hline $\begin{array}{l}\text { Front Windows } \\
\text { Intact }\end{array}$ & 1550 & 800 & 1700 & 1700 & 0.06 & 1700 \\
\hline Small Vent & 1550 & 230 & 1550 & 1850 & 0.1 & 1600 \\
\hline Large Vent & 1600 & 1050 & 1500 & 1700 & 0.05 & 1500 \\
\hline $\begin{array}{l}\text { 1. Time for temperature to exceed } 120^{\circ} \mathrm{C} \text { plus } 300 \mathrm{~s} . \\
\text { 2. Time for oxygen volume fraction less than } 0.12 \text { plus } 300 \mathrm{~s} .\end{array}$ \\
\hline
\end{tabular}

Table 4-6. Temperature and Oxygen Tenability Conditions for Front of East Side of Main Showroom.

\begin{tabular}{|c|c|c|c|c|c|c|}
\hline \multirow[b]{2}{*}{ Simulation } & \multicolumn{3}{|c|}{ Temperature } & \multicolumn{3}{|c|}{ Oxygen } \\
\hline & $\begin{array}{c}\text { Time to } \\
\text { Untenability } \\
\left(>120^{\circ} \mathrm{C}\right)^{1} \\
\text { S }\end{array}$ & $\begin{array}{c}\text { Peak } \\
\text { Temp } \\
\text { C }\end{array}$ & $\begin{array}{l}\text { Time to } \\
\text { Peak } \\
\text { Temp. } \\
\text { s }\end{array}$ & $\begin{array}{c}\text { Time to } \\
\text { Untenability } \\
(<0.12)^{2} \\
\mathrm{~s}\end{array}$ & $\begin{array}{c}\text { Minimum } \\
\text { Oxygen } \\
\text { Level } \\
\text { Volume } \\
\text { Fraction }\end{array}$ & $\begin{array}{c}\text { Time to } \\
\text { Minimum } \\
\text { Oxygen } \\
\text { Level } \\
\text { s }\end{array}$ \\
\hline Base & 1650 & 1000 & 1680 & 1400 & 0.08 & 1800 \\
\hline Base with Sprinklers & \multicolumn{6}{|c|}{ Fire growth limited to loading dock. Conditions remained tenable. } \\
\hline $\begin{array}{l}\text { Front Windows } \\
\text { Intact }\end{array}$ & 1650 & 230 & 1700 & 1750 & 0.09 & 1850 \\
\hline Small Vent & 1800 & 160 & 1550 & 2450 & 0.11 & 2150 \\
\hline Large Vent & 1650 & 220 & 1500 & 1750 & 0.08 & 1700 \\
\hline
\end{tabular}




\subsubsection{Baseline Simulation}

Results from the baseline simulation were tabulated with specific events from the fire ground in Table 4-7. The simulation results are consistent with available photos, video, and witness accounts. The results indicate that fire spread from the loading dock into the holding area and void space above the main showroom. The fire also spread to the warehouse and to the rear of the west showroom. The simulation demonstrates that although the fire did spread into the rear of the west showroom, the spread through the double doors was limited. The fire moved into the main showroom through the holding area and then into the rear of the main showroom. The flow of the smoke into the holding area and up into the void space above the main showroom would have been hidden by the holding area partition wall and suspended ceiling of the main showroom.

The results indicate that as early as $270 \mathrm{~s}$ into the simulation, smoke may have begun to flow down through ventilation openings in the suspended ceiling and into the rear of the main showroom. By $300 \mathrm{~s}$, there is also a layer of smoke beginning to develop under the suspended ceiling in the rear of the west showroom. It cannot be concluded from the simulation whether an observer located in the main showroom would have noticed smoke in the rear main showroom at $300 \mathrm{~s}$, or would have been able to distinguish the source of that smoke. The smoke continued to flow down through ventilation openings and, after forming a substantial layer in the rear of the main showroom, began to spread throughout the main showroom. At about $400 \mathrm{~s}$, the simulation indicates that the smoke layer extended down to near the floor on the west side of the main showroom. As the fire spread from the holding area into the rear of the main showroom at around $500 \mathrm{~s}$, additional smoke was added to the smoke layer in the main showroom. As demonstrated by the rendering of smoke by the simulation, visibility became compromised in the showrooms within 8 minutes to 10 minutes. The simulation results are consistent with the E-11 captain reporting heavy smoke in the main showroom at 7:20 p.m., which would correspond to $555 \mathrm{~s}$ into the simulation.

At $900 \mathrm{~s}$, the baseline simulation results demonstrate dense black smoke would have been present from the floor to the ceiling in the main and west showrooms and less dense gray smoke in the east showroom. About a minute later at 7:27 p.m. there were fragmented radios transmissions suggesting fire fighters were "lost or trapped inside" and this would have been consistent with the dense black smoke in the showrooms. The model indicates that the fire continued to grow in the rear of the main showroom. By $1380 \mathrm{~s}$ in the simulation, the fire in the rear of the main showroom had exceeded $90 \mathrm{MW}$ and involved at least 15 percent of the main showroom. At about 7:35 p.m. (1450 s), the fire department vented the front windows and the fire spread extremely quickly to the front of the main showroom. Flames extended out the front windows on the west side of the main showroom at $1620 \mathrm{~s} \mathrm{(7:37:53} \mathrm{p.m.)} \mathrm{in} \mathrm{the} \mathrm{simulation.}$ This is in good agreement with fire ground photographs which show fire out the front window at 7:37 p.m.

During the base simulation, the loading dock, holding area, west showroom, and main showroom each exceeded the tenability thresholds (Tables 4-1 to Table 4-6). Although not specifically tabulated, but apparent from the temperature and oxygen plots (Figures 4-29 and 4-35), both the loading dock and the holding area became untenable early in the fire. The rear of the west side of the main showroom first became untenable due to high temperature at $1200 \mathrm{~s}$. The front of the west side of the main showroom exceeded the modeled temperature tenability threshold at $1350 \mathrm{~s}$. These times are consistent with the observed fire spreading from the rear to the front of the main showroom. The rear of the west showroom became untenable due to high temperature and oxygen depletion at $1650 \mathrm{~s}$ while the front of the west showroom exceeded both tenability thresholds at $1700 \mathrm{~s}$. The slightly longer time for the west showroom 
to exceed the tenability limits is consistent with the observed fire spreading through the main showroom first and then moving into the west showroom.

The simulation peak temperatures provide some understanding of the fire behavior within the building. The relatively low $210^{\circ} \mathrm{C}$ peak temperature in the rear of the west showroom is consistent with the understanding that the observed fire did not move directly through the rear of the west showroom to reach the main showroom. The higher simulation temperatures in the front of both showrooms, as compared to the rear of the showrooms, are consistent with additional oxygen being available in the front of the showrooms, relative to the less ventilated rear areas of the showroom.

The HRRs for the loading dock, main showroom, and west showroom are tabulated in Table 4-8. The simulation indicates that the peak HRR for the loading dock was approximately $85 \mathrm{MW}$, the peak occurred at $280 \mathrm{~s}$, and the total energy released was $95 \mathrm{GJ}$. The peak heat release rate for main showroom were about one and a half times the loading dock at 135 MW peak and $160 \mathrm{GJ}$ for total heat release. The west showroom values were a peak HRR of $50 \mathrm{MW}$ and total energy release of $30 \mathrm{GJ}$ which is consistent with the west showroom being about half the floor space of the main showroom and the rear third of the west showroom not being as involved in the fire. 
Table 4-7. Observed Fire Ground and Computer Simulation Events.

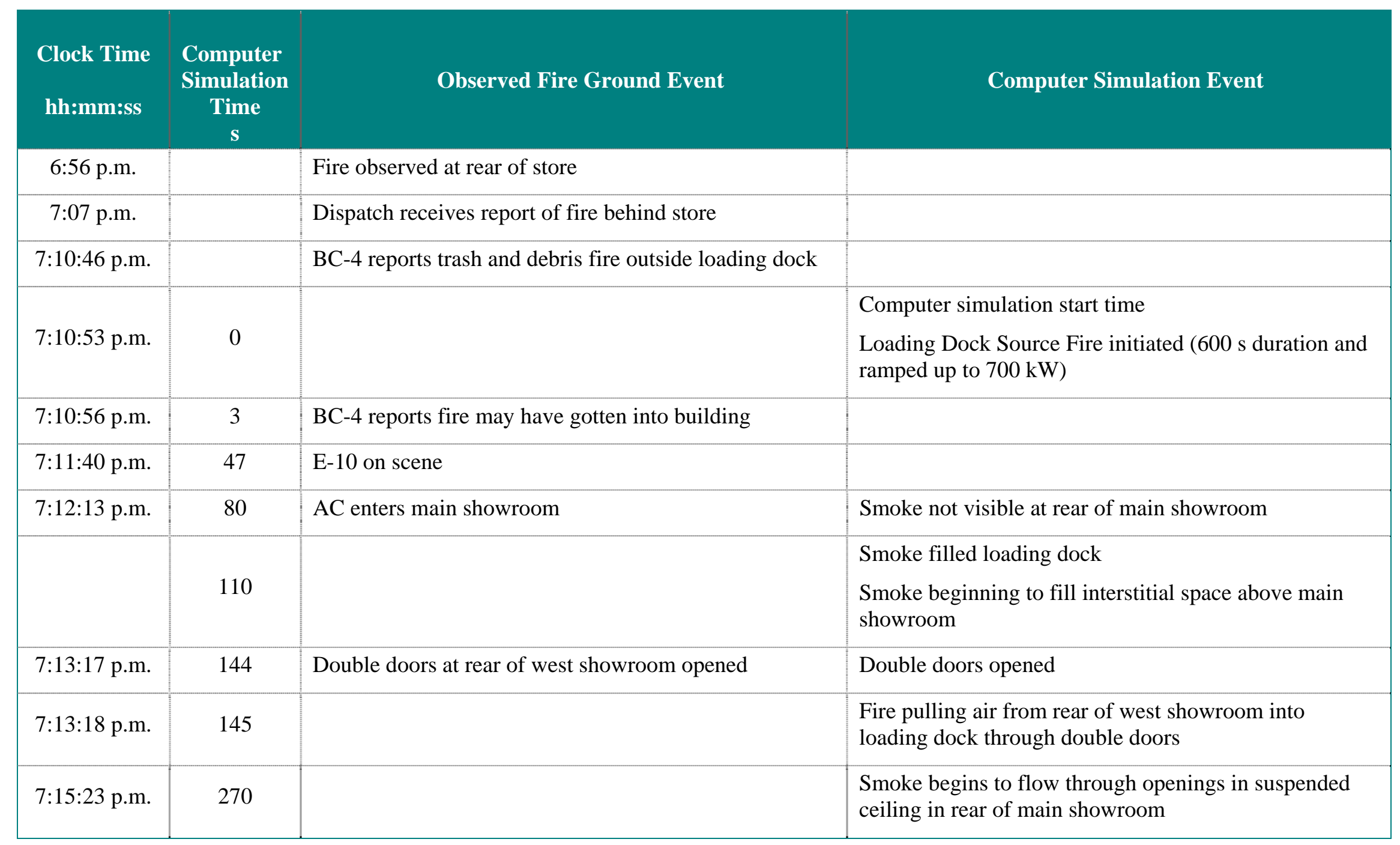




\begin{tabular}{|c|c|c|c|}
\hline $\begin{array}{l}\text { Clock Time } \\
\text { hh:mm:ss }\end{array}$ & $\begin{array}{c}\text { Computer } \\
\text { Simulation } \\
\text { Time } \\
\text { s }\end{array}$ & Observed Fire Ground Event & Computer Simulation Event \\
\hline 7:15:53 p.m. & 300 & & $\begin{array}{l}\text { Fire spread across entire loading dockSmoke continuing } \\
\text { to flow into interstitial space above main showroom } \\
\text { Light smoke flowing down through openings in } \\
\text { suspended ceiling into rear of main showroom } \\
\text { Light smoke below suspended ceiling in rear of west } \\
\text { showroom }\end{array}$ \\
\hline 7:16:32 p.m. & 339 & Fire Chief on scene & \\
\hline 7:16:53 p.m. & 360 & & $\begin{array}{l}\text { Loading dock fully involved in fire } \\
\text { Smoke continuing to flow into interstial space above } \\
\text { main showroom } \\
\text { Medium smoke flowing down through openings in } \\
\text { suspended ceiling into rear of main showroom } \\
\text { Medium smoke below suspended ceiling in rear of west } \\
\text { showroom } \\
\text { Light smoke below suspended ceiling in from of main } \\
\text { and west showrooms }\end{array}$ \\
\hline 7:17:23 p.m. & 390 & & $\begin{array}{l}\text { Hot smoke layer forms below suspended ceiling in both } \\
\text { main and west showrooms }\end{array}$ \\
\hline 7:17:33 p.m. & 400 & & Warehouse Source Fire initiated \\
\hline & 420 & & $\begin{array}{l}\text { Smoke layer filling west side of main showroom } \\
\text { suspended ceiling to floor }\end{array}$ \\
\hline 7:18:53 p.m. & 480 & & Holding area fully involved in fire \\
\hline
\end{tabular}




\begin{tabular}{|c|c|c|c|}
\hline $\begin{array}{l}\text { Clock Time } \\
\text { hh:mm:ss }\end{array}$ & $\begin{array}{l}\text { Computer } \\
\text { Simulation } \\
\text { Time } \\
\quad \text { s }\end{array}$ & Observed Fire Ground Event & Computer Simulation Event \\
\hline & & & $\begin{array}{l}\text { Smoke continuing to flow into interstitial space above } \\
\text { main showroom } \\
\text { Medium smoke flowing down through openings in } \\
\text { suspended ceiling into rear of main showroom } \\
\text { Medium smoke below suspended ceiling in rear of main } \\
\text { showroom } \\
\text { Medium smoke below suspended ceiling on west side of } \\
\text { main showroom } \\
\text { Light smoke below suspended ceiling on east side of } \\
\text { main showroom } \\
\text { Medium smoke below suspended ceiling of entire west } \\
\text { showroom }\end{array}$ \\
\hline 7:19:00 p.m. & 487 & $\begin{array}{l}\text { E-15 captain and two fire fighters enter main showroom } \\
\text { encountered smoke and donned SCBA facepieces }\end{array}$ & \\
\hline 7:19:38 p.m. & 525 & & $\begin{array}{l}\text { Main Showroom Fire Source } 1 \text { initiated (ramped up to } \\
4 \text { MW) }\end{array}$ \\
\hline 7:20:08 p.m. & 555 & $\begin{array}{l}\text { E-15 arrives on scene and as E- } 11 \text { captain exits structure } \\
\text { passes by E-15 crew entering structure. E- } 11 \text { captain } \\
\text { reports heavy smoke and increasing temperatures }\end{array}$ & \\
\hline 7:20 p.m. & & E-12 begins pumping water to E-10 at loading dock & \\
\hline 7:20:53 p.m. & 600 & & $\begin{array}{l}\text { Holding area fire has penetrated into rear of main } \\
\text { showroom } \\
\text { Fire burning in rear of main showroom and smoke from } \\
\text { fire flowing under suspended ceiling in main showroom }\end{array}$ \\
\hline
\end{tabular}




\begin{tabular}{|c|c|c|c|}
\hline $\begin{array}{l}\text { Clock Time } \\
\text { hh:mm:ss }\end{array}$ & $\begin{array}{c}\text { Computer } \\
\text { Simulation } \\
\text { Time } \\
\text { s }\end{array}$ & Observed Fire Ground Event & Computer Simulation Event \\
\hline & & & $\begin{array}{l}\text { Heavy smoke in rear of main showroom } \\
\text { Medium to heavy smoke below suspended ceiling on } \\
\text { west side of main showroom } \\
\text { Light to medium smoke below suspended ceiling on } \\
\text { east side of main showroom } \\
\text { Medium smoke below suspended ceiling of entire west } \\
\text { showroom }\end{array}$ \\
\hline 7:21:53 p.m. & 660 & & $\begin{array}{l}\text { Main Showroom Fire Source } 2 \text { initiated -(ramped up to } \\
6 \mathrm{MW} \text { ) }\end{array}$ \\
\hline 7:23:16 p.m. & 743 & $\begin{array}{l}\text { Photograph shows flames on roof above rear of main } \\
\text { showroom and/or holding area (Figure 4-23) }\end{array}$ & \\
\hline 7:25:53 p.m. & 900 & & $\begin{array}{l}\text { Fire burning in rear of main showoom grown to about } \\
23 \mathrm{MW} \text {. Smoke from fire flowing under suspended } \\
\text { ceiling in main showroom } \\
\text { Heavy smoke in rear of main showroom } \\
\text { Heavy smoke below suspended ceiling of entire main } \\
\text { showroom } \\
\text { Heavy smoke below suspended ceiling of entire west } \\
\text { showroom } \\
\text { Light smoke below suspended ceiling of east showroom }\end{array}$ \\
\hline 7:27 p.m. & & $\begin{array}{l}\text { E-16 begins pumping water to E- } 11 \text { at front of store } \\
\text { Inaudible radio transmissions -“lost or trapped inside" }\end{array}$ & \\
\hline
\end{tabular}




\begin{tabular}{|c|c|c|c|}
\hline $\begin{array}{l}\text { Clock Time } \\
\text { hh:mm:ss }\end{array}$ & $\begin{array}{l}\text { Computer } \\
\text { Simulation } \\
\text { Time } \\
\text { s }\end{array}$ & Observed Fire Ground Event & Computer Simulation Event \\
\hline 7:31:53 p.m. & 1260 & & $\begin{array}{l}\text { Fire continues to grow in southwest rear corner of main } \\
\text { showroom involving about } 10 \% \text { of main showroom }\end{array}$ \\
\hline $\begin{array}{l}\text { 7:31 p.m. to } \\
\text { 7:34 p.m. }\end{array}$ & & $\begin{array}{l}\text { Fire fighter calls "Mayday" } \\
\text { Fire Chief "we need to vacate building” }\end{array}$ & \\
\hline 7:35:10 p.m. & 1457 & Removal of front windows of main showroom & Main showroom windows opened \\
\hline 7:35:53 p.m. & 1500 & & $\begin{array}{l}\text { Fire spreading toward front of store on west side of } \\
\text { main showroom and involves about } 20 \% \text { of main } \\
\text { showroom }\end{array}$ \\
\hline 7:36 p.m. & & Thick black smoke rolls out front windows & \\
\hline 7:36:23 p.m. & 1530 & $\begin{array}{l}\text { Removal of additional front windows of main } \\
\text { showroom }\end{array}$ & Main showroom windows opened \\
\hline 7:36:53 p.m. & 1560 & & $\begin{array}{l}\text { Fire has spread to front of store on west side of main } \\
\text { showroom and involves about } 30 \% \text { of main showroom }\end{array}$ \\
\hline 7:37 p.m. & & Fire rolls out front windows of main showroom & \\
\hline
\end{tabular}




\begin{tabular}{|c|c|c|c|}
\hline Clock Time & $\begin{array}{c}\text { Computer } \\
\text { Simulation } \\
\text { Time } \\
\text { sh:mm:ss }\end{array}$ & $\begin{array}{c}\text { Observed Fire Ground Event } \\
\text { Computer Simulation Event }\end{array}$ \\
\hline $7: 37: 53$ p.m. & 1620 & Failure of front windows of west showroom & $\begin{array}{l}\text { Fire spreading to east side of main showroom and front } \\
\text { of west showroom }\end{array}$ \\
\hline $7: 38: 00$ p.m. & 1627 & Failure of additional front windows of west showroom & \\
\hline $7: 44: 00$ p.m. & 1987 & End of computer simulation - approximately 40 \\
\hline $7: 50: 53$ p.m. & 2400 & Portion of main showroom roof collapses & \\
\hline $7: 51$ p.m. & & & \\
\hline
\end{tabular}




\subsubsection{Fire Sprinklers Simulation}

In the simulation with fire sprinklers, the two sprinklers nearest the fire (in the southwest corner of the loading dock) activated early in the fire, at $50 \mathrm{~s}$ and $75 \mathrm{~s}$. The two sprinklers controlled the fire and prevented the fire from spreading into the showrooms or warehouse. As a result, the temperatures and oxygen volume fractions remained below untenability thresholds.

\subsubsection{Alternate Ventilation Scenarios}

Three simulations were performed in which the building ventilation conditions were altered from the baseline scenario.

In the first, the windows at the front of the main showroom were kept in place. While this did effectively reduce the peak heat release rate, conditions throughout the main and west showrooms became untenable due to excessive temperature and depleted oxygen. Untenability would have occurred prior to the time that the windows were removed in the base scenario.

In the second variation, a $1.7 \mathrm{~m}^{2}\left(18 \mathrm{ft}^{2}\right)$ vent was placed in the roof at the rear of the main showroom. The results of this simulation were not significantly different from the ventilation scenario with the front windows intact. With a vent or hole in the roof, the smoke and unburned fuel exited the structure and that if gases vented outside were ignited, the energy released would not have contributed to the energy inside the modeled structure.

In the final ventilation variation, the roof vent was expanded to $5.9 \mathrm{~m}^{2}\left(64 \mathrm{ft}^{2}\right)$. This enlargement did not change the peak HRR, temperature, or minimum oxygen volume fractions. However, the fire progression was delayed at the rear of the showroom by several minutes. This delay in the movement of the fire did not significantly change the time that conditions became untenable throughout the main and west showrooms. 
Table 4-8. Fire Energetics for the Loading Dock, Main Showroom, and West Showroom.

\begin{tabular}{|c|c|c|c|c|c|c|c|c|c|}
\hline \multirow[b]{2}{*}{ Simulation } & \multicolumn{3}{|c|}{ Loading Dock } & \multicolumn{3}{|c|}{ Main Showroom } & \multicolumn{3}{|c|}{ West Showroom } \\
\hline & $\begin{array}{c}\text { Time to } \\
\text { Peak } \\
\text { HRR } \\
\text { s }\end{array}$ & $\begin{array}{c}\text { Peak } \\
\text { HRR } \\
\text { MW }\end{array}$ & $\begin{array}{c}\text { Total } \\
\text { Heat } \\
\text { Release } \\
\text { GJ }\end{array}$ & $\begin{array}{c}\text { Time to } \\
\text { Peak } \\
\text { HRR } \\
\text { s }\end{array}$ & $\begin{array}{c}\text { Peak } \\
\text { HRR } \\
\text { MW }\end{array}$ & $\begin{array}{c}\text { Total } \\
\text { Heat } \\
\text { Release } \\
\text { GJ }\end{array}$ & $\begin{array}{c}\text { Time to } \\
\text { Peak } \\
\text { HRR } \\
\text { s }\end{array}$ & $\begin{array}{c}\text { Peak } \\
\text { HRR } \\
\text { MW }\end{array}$ & $\begin{array}{c}\text { Total } \\
\text { Heat } \\
\text { Release } \\
\text { GJ }\end{array}$ \\
\hline Base & 280 & 85 & 95 & 1720 & 135 & 160 & 1940 & 50 & 30 \\
\hline Base with Sprinklers & 60 & 0.9 & 1.4 & & & & & & \\
\hline $\begin{array}{l}\text { Front Windows } \\
\text { Intact }\end{array}$ & & & & 1260 & 130 & 75 & & & \\
\hline
\end{tabular}




\subsection{REFERENCES FOR CHAPTER 4}

[1] Nelson, H.E., "An Engineering Analysis of the Early Stages of Fire Development- The Fire at the Dupont Plaza Hotel and Casino- Dec. 31, 1986,” NBSIR97-3560, National Institute of Standards and Technology (formerly the National Bureau of Standards), Gaithersburg, MD, April 1987.

[2] Purser, D.A., “Toxicity Assessment of Combustion Products," SFPE Handbook of Fire Protection Engineering, $3^{\text {rd }}$ ed. DiNenno, P.J., et al. (eds). National Fire Protection Association (NFPA) Quincy, MA, 2002.

[3] McGrattan, K.B., Hostikka,S., and Floyd, J.E. Fire Dynamics Simulator (Version 5), User’s Guide. NIST Special Publication 1019-5, National Institute of Standards and Technology, Gaithersburg, MD, October 2007.

[4] Forney, G.P. Smokeview (Version 5), A Tool for Visualizing Fire Dynamics Simulation Data, Volume I: User's Guide. NIST Special Publication 1017-1, National Institute of Standards and Technology, Gaithersburg, MD, August 2007.

[5] National Institute of Standards and Technology, Gaithersburg, MD, USA, and VTT Technical Research Centre of Finland, Espoo, Finland. Fire Dynamics Simulator, Technical Reference Guide, 5th edition, October 2007. NIST Special Publication 1018-5 (Four volume set).

[6] Grosshandler , W.L., Bryner , N., Madrzykowski ,D., and Kuntz , K. Report of the Technical Investigation of The Station Nightclub Fire. NIST NCSTAR 2, National Institute of Standards and Technology, Gaithersburg, MD, July 2005.

[7] McGrattan, K., Bouldin, C., and Forney , G. Federal Building and Fire Safety Investigation of the World Trade Center Disaster: Computer Simulation of the Fires in the WTC Towers. NIST NCSTAR 15F, National Institute of Standards and Technology, Gaithersburg, MD, September 2005.

[8] Madrzykowski, D., and Vettori, R.L., "Simulation of the Dynamics of the Fire at 3146 Cherry Road NE, Washington D.C., May 30, 1999,” NISTIR 6510, National Institute of Standards and Technology, Gaithersburg, MD, April 2000.

[9] Madrzykowski, D., Forney, G.P., and Walton, W.D., "Simulation of the Dynamics of a Fire in a TwoStory Duplex-Iowa, Dec. 22, 1999,” NISTIR 6854, National Institute of Standards and Technology, Gaithersburg, MD, January 2002.

[10] Sutula, J., “Applications of Fire Dynamics Simulator in Fire Protection Engineering Consulting,” Fire Protection Engineering, No. 14, Society of Fire Protection Engineers, Bethesda, MD, Spring 2002.

[11] Rehm, R.G., Pitts, W.M., Baum, H.R., Evans, D.D., Prasad, K., McGrattan, K.B., and Forney, G.P., “Initial Model for Fires in the World Trade Center Towers," NISTIR 6879, National Institute of Standards and Technology, Gaithersburg, MD, May, 2002. 
[12] Sutula, J., "Practical Applications of Fire Dynamics Simulator in Fire Protection Engineering Consulting," Fire Protection Engineering, No. 15, Society of Fire Protection Engineers, Bethesda, MD, Summer 2002.

[13] McGrattan, K.B., and Hamins, A., "Numerical Simulation of the Howard Street Tunnel Fire, Baltimore, MD, July 2001., NISTIR 6902, National Institute of Standards and Technology, Gaithersburg, MD, August 2002.

[14] Sofa Super Store Fire - Report of Investigation, ATF National Response Team Origin and Cause Report, Investigation 763010-07-0172, Report 32, June 22, 2007.

[15] Fire Dynamics, Chapter 2, The SFPE Handbook of Fire Protection Engineering, 4th edition, Society of Fire Protection Engineers, Quincy, MA page 2-29.

[16] ISO 13943, Fire Safety - Vocabulary, International Standards Organization, Geneva.

[17] NFPA 13, Standard for the Installation of Sprinkler Systems, 2007 edition, National Fire Protection Association (NFPA) Quincy, MA 2007. 


\section{Chapter 5 \\ MODEL CODES AND STANDARDS}

\section{$5.1 \quad$ INTRODUCTION}

An analysis was performed to compare the fire safety provisions contained in a number of current and past codes and standards to the fire safety related characteristics of the Sofa Super Store. The purpose of the analysis was not only to determine if the Sofa Super Store met the applicable code provisions, but also to determine if changes are necessary to the codes and standards requirements for new and/or existing buildings in order to prevent or mitigate future incidents.

A contract was entered into with Koffel Associates, Inc. of Elkridge, Maryland, to identify the current model building and fire codes that were available for application to a structure such as the Sofa Super Store. They were also contracted to identify the model building and fire codes in place at the time the building was constructed and at the times when modifications were made to the structure. Koffel Associates provided comparisons of the requirements of the identified building and fire codes. The analysis and discussion of this chapter focus on areas that are expected to be related to the growth and spread of the fire that occurred on June 18, 2007. Any conclusions and findings that are presented are solely those of NIST.

\subsection{CODE HISTORY}

Since the 1950s or 1960s original construction of the building at 1807 Savannah Highway in Charleston, SC, numerous model codes have been published and revised. Prior to 2000, most model codes were limited to regional adoption. Table 5-1 summarizes the model building codes that were relevant to the structure over its history. Table 5-2 summarizes the model fire codes that were relevant to the structure over its history.

Table 5-1. Applicable Model Building Code

\begin{tabular}{|c|l|l|}
\hline Building Permit Date & Description of Work & Applicable Building Code \\
\hline 1950s or 1960s* & Original Building Construction & 1949 or 1955 National Building Code \\
\hline 1993 & West Showroom Addition & 1991 Standard Building Code \\
\hline 1995 & East Showroom Addition & 1994 Standard Building Code \\
\hline 1996 & Warehouse Addition & 1994 Standard Building Code \\
\hline $1996-2005^{*}$ & Four Fill-In Additions** & $\begin{array}{l}\text { 1994 or 1997 Standard Building Code or } \\
\text { 2000 International Building Code }\end{array}$ \\
\hline
\end{tabular}

* No building permit was located.

** Additions that occupy the space between existing buildings or sections of an existing building. 
Table 5-2. Applicable Model Fire Code

\begin{tabular}{|c|l|l|}
\hline Building Permit Date & Description of Work & Applicable Fire Code** \\
\hline 1950s or 1960s* & Original Building Construction & Unknown \\
\hline 1993 & West Showroom Addition & 1991 Standard Fire Prevention Code \\
\hline 1995 & East Showroom Addition & 1994 Standard Fire Prevention Code \\
\hline 1996 & Warehouse Addition & 1994 Standard Fire Prevention Code \\
\hline $1996-2005^{*}$ & Four Fill-In Additions & $\begin{array}{l}\text { 1994 or 1997 Standard Fire Prevention } \\
\text { Code or 2000 International Fire Code }\end{array}$ \\
\hline
\end{tabular}

* No building permit was located.

** Assumed fire code based on building code.

The first edition of the National Building Code (NBC) was published in 1905, by the National Board of Fire Underwriters (now the American Insurance Association). The first edition of the Standard Building Code (SBC) was adopted in November 1945 at the Annual Research Conference of the Southern Building Code Congress International (SBCCI). The first edition of the Standard Fire Prevention Code (SFPC) was published in 1974. The purpose of both the National Building Code and the Standard Building Code was to serve as a comprehensive regulatory building code designed to protect the public's life, health, and welfare in buildings. The Standard Building Code incorporated, by reference, nationally-recognized consensus standards for use in judging the performance of materials and systems. The last edition of the Standard Building Code was the 1999 Edition.

In 2000, the International Code Council (ICC) published the first International Building Code (IBC) and first International Fire Code (IFC), both now published in 2003, 2006, and 2009 editions. The ICC was founded in 1994 by three regional code writing organizations: Southern Building Code Congress (SBCCI), Building Officials and Code Administrators International (BOCA), and International Conference of Building Officials (ICBO). With the publication of the International Codes in 2000, the three regional code writing organizations ceased updating and publishing revised editions of their respective regional codes (including the SBC and SFPC).

\subsection{MODEL CODE ANALYSIS}

The model code analysis was based upon the 1991 and 1994 editions of both the Standard Building Code (SBC) $[1,2]$ and the Standard Fire Prevention Code (SFPC) [3,4] as well as the 2006 editions of the International Building Code (IBC) [5] and the International Fire Code (IFC) [6]. The 1991 editions of the SBC and SFPC were the applicable codes at the time of the west showroom addition. The 1994 editions of the SBC and SFPC were the applicable codes for the east showroom and warehouse additions and possibly for the fill-in additions as well. The 2006 editions of the IBC and IFC were the codes in effect at the time of the fire. A comparison of the relevant sections of these codes is included as Table 5-4. In areas where the codes had differing requirements, the impact of both requirements was evaluated.

NIST's technical investigation did not focus on compliance or non-compliance with the specific state or local regulations in effect at the time of the fire, nor did it seek to find fault. Rather, the focus of the study was on the relevant model codes, and how the design and operation of the Sofa Super Store 
compared with the guidance provided within the model codes. The findings and recommendations from the NIST investigation are expected to be useful across the nation by being incorporated into the model codes.

It should be noted that a portion of the NIST building code evaluation utilizes current building code requirements, which are not applied to buildings that existed, or had been issued permits, prior to the adoption and effective date of the code. Building code requirements generally apply to new construction, as well as new additions to structures, building alterations, and changes in use or occupancy. For example, changes to the height or area of a building could potentially require the installation of fire rated separations or sprinkler protection based on the new size of the building. Some local or state laws mandate that when a certain percentage of the building is renovated, the entire building must be brought into compliance with current codes. Section 101.5.1 of the 1991 edition of the SBC states that for existing buildings, "The Building Official shall determine the extent to which the existing system shall be made to conform to the requirements of the technical codes for new construction.”

Existing structures are, however, subject to some provisions of the current edition of the International Fire Code if adopted by the jurisdiction. The intent of the International Fire Code is to provide a reasonable level of fire safety, in new and existing buildings, for protection of property and to provide for the safety of the occupants, the fire service, and other emergency responders during emergency operations (IFC §101.3, 2006 edition).

\subsubsection{Administration}

IBC §105.1 requires that permits be obtained prior to enlarging, altering, repairing, or changing of the occupancy of any building. SBC and SFPC $\S 103$ contain similar requirements. Building permits for the addition of the west and east showrooms and warehouse of the Sofa Super Store were located during this study. A partial set of design drawings for the warehouse addition was provided by City of Charleston Zoning Division. Building permits for the addition of the loading dock and repair shop areas were not located.

\subsubsection{Occupancy}

Chapter 3 of the IBC and Chapter 4 of the 1991 SBC (Chapter 3 of the 1994 SBC) both classify the furniture showrooms as mercantile occupancies and the warehouse and loading dock as moderate-hazard (S-1) storage occupancies.

The moderate-hazard (S-1) storage occupancy classification includes the use of a building, or a portion of a building, for the storage of items that pose a moderate hazard. Specific examples of moderate hazard (S-1) storage occupancies are given in the building codes, and include buildings used for the storage of furniture. The use of the warehouse and loading docks for furniture storage was consistent with the moderate-hazard storage occupancy classification, but the storage of liquid hydrocarbons and solvents was potentially inconsistent with an S-1 storage occupancy. Areas where flammable paint, hydrocarbon solvents, and aerosols are used and stored, are classified by the building codes as Group H occupancies if the quantities exceed the maximum allowable quantities in the building and fire codes (1991 SBC Table 408.1.2, 1994 SBC Table 308.2B, 2006 IBC Table 307.1[1], 2006 IFC Table 2703.1.1[1]). In addition, the 1991/1994 SBC states that portions of Group S occupancies involving highly-combustible, 
flammable, or explosive products are required to be properly ventilated, protected, and separated from the remainder of the building in accordance with NFPA standards. Otherwise, the entire building is classified as a Group H occupancy. The quantities of flammable and combustible materials in the warehouse and loading dock areas of the Sofa Super Store did not appear to exceed the maximum allowable quantities for Group S-1 occupancies in the 1991/1994 SBC or 2006 IBC.

The repair shop areas, where flammable paint, hydrocarbon solvents, and aerosols were used and stored, would also have been classified by the building codes as Group $\mathrm{H}$ occupancies if the quantities exceeded the maximum allowable quantities listed in the building and fire codes. The quantities of flammable and combustible materials in the repair shop areas did not appear to exceed the maximum allowable quantities for Group M and S-1 occupancies in the 1991/1994 SBC or 2006 IBC. These quantities were estimated, however, since the containers were not cataloged individually at the site.

Additional fire protection requirements in the fire codes would apply depending on the application methods and quantities of hazardous materials in open use within the repair shops and loading dock areas. Application of flammable / combustible finishes to furniture would require consideration of ignition sources, development of flammable atmospheres, fire barriers, and automatic suppression systems, etc. It is not known to what extent the hazardous materials were in open use within these areas.

The mercantile occupancy classification describes the use of a building, or portions of a building, for the display and sale of merchandise. Examples of mercantile occupancies include department stores, retail stores, and sales rooms. The use of the showrooms to display and sell furniture was consistent with the mercantile occupancy classification.

\subsubsection{Fire Walls, Fire Areas, and Occupancy Separations}

The 1991 SBC Table 403.1 (1994 SBC Table 704.1) requires a three-hour fire resistance rated separation between moderate hazard (S-1) storage occupancies and adjacent occupancies if the building is considered a mixed occupancy. A one-hour or greater fire resistance rated separation is required between mercantile occupancies and other occupancy types, depending on the other occupancy classification. The more stringent requirement is dictated by the moderate hazard (S-1) storage occupancy, and the separation between an S-1 occupancy and an M occupancy is required to be three-hour fire resistance rated.

The gypsum board covered concrete block walls and roll-down fire doors between the showrooms appear to meet the requirements of a two-hour fire resistance rated separation, and therefore provide three showroom fire areas according to the 2006 IBC §706.3.9. It is not known, however, if the gypsum board / concrete block walls met the requirements for a fire wall (SBC §202, 2006 IBC §702 and Tables 705.4 and 715.4) with required fire resistance ratings of four hours under the SBC or three hours under the IBC. The presence of fire walls would allow the three showrooms to be considered separate buildings for height area limitations and sprinkler requirements (1994 SBC §202 definition of "building”, 2006 IBC §705.1).

When the warehouse was constructed, the moderate hazard (S-1) storage occupancy would have required a three-hour separation between it and the other occupancies. According to design drawings, the rolldown fire door at the rear of the main showroom that led to the warehouse was a three-hour fire door. The exterior walls of the warehouse, however, were two-hour fire resistance rated according to design 
drawings. The City of Charleston granted the store owner a variance ${ }^{\dagger}$ because the separation distance between the rear of the west showroom and north wall of the warehouse was in excess of $15 \mathrm{~m}(50 \mathrm{ft})$. The two-hour fire resistance rated walls are sufficient to meet code requirements for exterior walls of

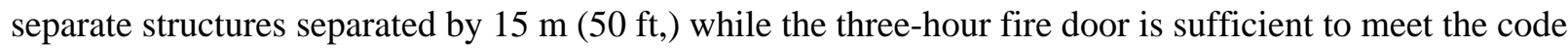
requirements for an occupancy separation and fire wall.

The SBC requires a three-hour fire resistance rated separation between the loading dock (S-1 occupancy) and the showrooms (M occupancy). There was not a fire resistance rated separation between the loading dock and the main showroom due to the unrated roll-down door. In addition, the required three-hour fire resistance rated separation was not present between the loading dock and the west showroom. The separation would not be required if the authority having jurisdiction allowed the loading dock to be considered an accessory occupancy (1994 SBC §704.1.2.2).

\subsubsection{Construction Type}

Chapter 6 of both the IBC and SBC classify the main building structures as Type II B construction and Type $\mathrm{V}$ unprotected construction respectively, in which the building elements are of unprotected noncombustible material. The wooden fill-in buildings would have been considered as Type V B construction under IBC, which is of any material approved by the code. Under the SBC, the fill-in buildings would have been classified as Type VI unprotected construction which is of wood or other approved material. Under either code, the building elements of the fill-in buildings would not have been required to have fire-resistance ratings.

Due to the varying construction types, requirements for the least fire resistant construction type would have to be met or the construction types would have to be properly separated with a fire wall. Given the existing ratings of the exterior walls of the showrooms and warehouse, when the loading dock was added, it should have been of a different construction type or the existing building walls would have had to be upgraded.

\subsubsection{Height and Area Requirements}

For a one-story building of Type II B construction, IBC Table 503 allows mercantile occupancies to be up to $1161 \mathrm{~m}^{2}\left(12,500 \mathrm{ft}^{2}\right)$ and allows storage occupancies to be up to $1626 \mathrm{~m}^{2}\left(17,500 \mathrm{ft}^{2}\right)$. SBC Table 500 allows mercantile occupancies to be up to $836 \mathrm{~m}^{2}\left(9000 \mathrm{ft}^{2}\right)$ and storage occupancies to be up to $1486 \mathrm{~m}^{2}$ $\left(16,000 \mathrm{ft}^{2}\right)$. Both codes allow for area increases due to frontage on open areas and public ways, and complete building fire sprinkler protection.

The original showroom was $1510 \mathrm{~m}^{2}\left(16,250 \mathrm{ft}^{2}\right)$. Under the SBC, with allowances for open frontage on all sides (assumed to be $9.1 \mathrm{~m}$ (30 ft) clear), the showroom building would only have been permitted to be up to $1394 \mathrm{~m}^{2}\left(15,000 \mathrm{ft}^{2}\right)$. When the additional showrooms were constructed, the frontage area was decreased. The east and west showrooms were both $669 \mathrm{~m}^{2}\left(7200 \mathrm{ft}^{2}\right)$, which is well under the $836 \mathrm{~m}^{2}$ $\left(9000 \mathrm{ft}^{2}\right)$ permitted before frontage allowances. The warehouse was $1449 \mathrm{~m}^{2}\left(15,600 \mathrm{ft}^{2}\right)$, just under the allowable $1486 \mathrm{~m}^{2}\left(16,000 \mathrm{ft}^{2}\right)$. Under the IBC, the showrooms would have been permitted to be $1161 \mathrm{~m}^{2}$ $\left(12,500 \mathrm{ft}^{2}\right)$ and the warehouse would have been permitted to be $1626 \mathrm{~m}^{2}\left(17,500 \mathrm{ft}^{2}\right)$. If the fire

\footnotetext{
${ }^{\dagger}$ The Sofa Super Store building configuration, with the enclosed breezeway connecting the rear of the main showroom and the warehouse, is not explicitly addressed by the SBC and IBC.
} 
separations between the showrooms are insufficient to meet the requirements of a fire wall, however, all three showrooms would have been considered a single building. The total showroom area would be $2882 \mathrm{~m}^{2}\left(31,060 \mathrm{ft}^{2}\right)$, which exceeds the maximum allowable area for a non-sprinkler protected mercantile occupancy in both the SBC and IBC. The separation of the main showroom from the east and west showrooms may have been designed to establish fire area separations, and therefore keep the square footage of each area under the requirements for height and area that would mandate sprinkler protection.

Table 5-3 Allowable Heights and Building Areas from Table 500 of the 1994 SBC.

\begin{tabular}{|c|c|c|c|c|}
\hline Type Construction & \multicolumn{2}{|c|}{ V Unprotected } & \multicolumn{2}{c|}{ VI Unprotected } \\
\hline Maximum Height & \multicolumn{2}{|c|}{$\mathbf{1 6 . 8} \mathbf{~ m ~ ( 5 5 ~ f t )}$} & \multicolumn{2}{c|}{12.2 m (40 ft) } \\
\hline Occupancy & $\begin{array}{c}\text { Unsprinklered } \\
{[\mathrm{h}]}\end{array}$ & $\begin{array}{c}\text { Sprinklered } \\
{[\mathrm{j}]}\end{array}$ & $\begin{array}{c}\text { Unsprinklere } \\
\text { d } \\
{[\mathrm{h}]}\end{array}$ & $\begin{array}{c}\text { Sprinklered } \\
{[\mathrm{j}]}\end{array}$ \\
\hline M - Mercantile & {$[\mathrm{f}]$} & & {$[\mathrm{f}]$} & \\
Max No. of Stories & 2 & 5 & 2 & 2 \\
Area: Multistory, $\mathrm{m}^{2}\left(\mathrm{ft}^{2}\right)$ & $836(9000)$ & $1672(18,000)$ & $557(6000)$ & $1115(12,000)$ \\
Area: One Story Only, $\mathrm{m}^{2}\left(\mathrm{ft}^{2}\right)$ & $836(9000)$ & $2508(27,000)$ & $557(6000)$ & $1672(18,000)$ \\
\hline S - Storage ${ }^{[\mathrm{g}]}$ & & & & 1 \\
Max No. of Stories & 2 & $2973(32,000)$ & & 1 \\
Area: Multistory, $\mathrm{m}^{2}\left(\mathrm{ft}^{2}\right)$ & $1486(16,000)$ & $4459(48,000)$ & $557(6000)$ & $1672(18,000)$ \\
Area: One Story Only, $\mathrm{m}^{2}\left(\mathrm{ft}^{2}\right)$ & $1486(16,000)$ & & & \\
\hline
\end{tabular}

Notes:

Lower case letters in the table refer to notes. These letters are the same as those used in the building code for easier reference. See 1994 SBC Table 500 for additional notes not included here.

Heights for construction types are limited to the number of stories and height (ft) shown in table.

Allowable building area is shown in $\mathrm{m}^{2}\left(\mathrm{ft}^{2}\right)$ per floor.

[f] The total area for unsprinklered Group M occupancies after the increases permitted by 1994 SBC §503.3 shall not exceed $1394 \mathrm{~m}^{2}\left(15,000 \mathrm{ft}^{2}\right)$.

[g] The maximum height in feet is not applicable to Group S and Group F occupancies.

[h] When all portions of buildings are sprinklered in accordance with 1994 SBC §903.2, the height of the buildings listed under this column may be increased buy one story. The general area increase in 1994 SBC $\$ 503.3 .2$ may be applied before using footnote h.

[j] When the building is fully sprinklered in accordance with 1994 SBC §903.2, the allowable building heights and areas shall be as listed under this column. 
Table 5-4 Allowable Heights and Building Areas from Table 503 of the 2006 IBC

\begin{tabular}{|c|c|c|c|}
\hline & & \multicolumn{2}{|c|}{ Construction Type } \\
\hline & & Type II B & Type V B \\
\hline Group & $\begin{array}{l}\text { Height, m (ft) } \\
\text { Stories / Area }\end{array}$ & $16.8(55)$ & $12.2(40)$ \\
\hline M & $\begin{array}{c}\text { Max. Stories } \\
\text { Max Area, } \mathrm{m}^{2}\left(\mathrm{ft}^{2}\right)\end{array}$ & $\begin{array}{c}4 \\
1161(12,500)\end{array}$ & $\begin{array}{c}1 \\
836(9000)\end{array}$ \\
\hline S-1 & $\begin{array}{c}\text { Max. Stories } \\
\text { Max Area, } \mathrm{m}^{2}\left(\mathrm{ft}^{2}\right)\end{array}$ & $\begin{array}{c}3 \\
1626(17,500)\end{array}$ & $\begin{array}{c}1 \\
836(9000)\end{array}$ \\
\hline
\end{tabular}

Notes:

See 2006 IBC for notes concerning increases to allowable heights and areas due to fire sprinkler systems and street frontage. See 2006 IBC Table 503 for additional notes not included here.

\subsubsection{Storage Height}

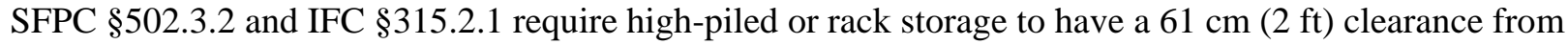
the top of the storage to the ceiling. It is unknown if $61 \mathrm{~cm}(2 \mathrm{ft})$ of clearance was maintained due to the conditions of the warehouse and stored products observed after the fire.

\subsubsection{Fire Sprinkler System}

The model codes may require fire sprinkler protection for buildings based on a combination of factors including occupancy, building area, construction type, building height, and occupant location relative to exit discharge. The SBC (SBC Table 500 Note F and SBC §903.7.1) requires sprinkler protection for mercantile occupancies with areas in excess of $1394 \mathrm{~m}^{2}\left(15,000 \mathrm{ft}^{2}\right)$ that stock combustible commodities. According to the code, the Sofa Super Store showrooms would be required to be sprinklered unless they were separated by fire walls that were positioned to produce buildings of $1394 \mathrm{~m}^{2}\left(15,000 \mathrm{ft}^{2}\right)$ or less in area. The fire barriers between the showrooms may have been installed to avoid sprinkler system installation requirements, although the fire barriers may not have met the code definition of a fire wall. Those barriers failed during the fire due to a roll-down fire door not operating properly.

The IBC (2006 IBC §903.2.6) requires sprinkler protection throughout new buildings containing a mercantile occupancy if any of the following conditions exist: a fire area exceeds $1115 \mathrm{~m}^{2}\left(12,000 \mathrm{ft}^{2}\right)$, or the fire area is more than three stories above grade plane, or the total area of all mercantile areas in the building exceeds $2230 \mathrm{~m}^{2}\left(24,000 \mathrm{ft}^{2}\right)$. According to the code, fire sprinklers would be required in the 
showrooms unless they were separated by fire walls (to form separate buildings) and fire barriers (to form smaller fire areas) to conform to the area limitations above.

Although outside of the scope of this report, the 2009 editions of the IBC [7] and IFC [8] (IBC §903.2.7 and IFC §903.2.7) require fire sprinkler systems in new buildings housing Group M occupancies if they are used, "for the display and sale of upholstered furniture." This is a new requirement in the 2009 editions of the codes.

The SBC and SFPC (Table 3605) require fire sprinkler systems for buildings that contain over $1115 \mathrm{~m}^{2}$ $\left(12,000 \mathrm{ft}^{2}\right)$ of high piled combustible furniture (Commodity III or IV) storage. Fire sprinklers are also required by the IBC and IFC (Table 2306) for high piled storage of combustible furniture (Class III or IV Commodity) with areas greater than $1115 \mathrm{~m}^{2}\left(12,000 \mathrm{ft}^{2}\right)$. Based on the square footage of the warehouse building, fire sprinklers are required by the SBC/SFPC and IBC/IFC model codes.

As stated in the occupancy section of this report, the loading dock would be classified as an S-1 occupancy by the building codes. If the loading dock was considered an accessory occupancy to the adjacent mercantile areas (1994 SBC §704.1.2.2), then it would need to be sprinkler protected according to the code sections governing the showrooms discussed above. If the loading dock was considered a different occupancy, due to increased hazard over the showrooms (mercantile), then fire rated occupancy barriers would be required, but sprinklers would not be required by the SBC due to the small area.

\subsubsection{Inspection, Testing, and Maintenance}

Both IFC §703.2 and SFPC §504.7.3 require rolling fire doors to be maintained and tested in accordance with NFPA 80 Standard for Fire Doors and Other Opening Protectives [9]. As part of their inspection, it must be verified that there are no obstructions in the path of the roll-down door and that the door assembly will properly close under fire conditions. If fire doors fail to activate and close when tested, corrective action must be taken. The fusible link(s) used to activate the door must also be inspected and replaced when fused or damaged. NFPA 80 (§5.2.1) requires that inspection and testing occur not less than annually, and that a written record of the inspection be signed and kept for possible future inspection by the authority having jurisdiction.

Any inspection, testing, and maintenance documentation for the Sofa Super Store was lost during the fire. After the fire, it was determined that multiple roll-down doors had failed to operate properly. One of the roll-down doors had the fusible link function, but the door caught on a piece of furniture, keeping it from closing completely.

\subsubsection{Egress}

Egress requirements are located in Chapter 10 of both the SBC and IBC. A travel distance limit of $61 \mathrm{~m}$ (200 ft) is dictated by both codes for both mercantile and storage occupancies. Both codes also require three exits for the showroom and two exits for the warehouse based on the code specified minimum occupant load of the buildings and the required exit remoteness of one-half the diagonal of the space (one-half of the diagonal dimension of the space, measured along the floor, typically from the most distant room corners).

Prior to the addition of the loading dock area, the east and west showrooms each had two exits of sufficient width, which led directly to the building exterior. If the showrooms are examined individually, 
the two required exits in the west showroom were adequately spaced from each other, but the two required exits in the east showroom appear to be separated slightly less than required by the SBC. The main showroom, however, does not contain the three required exits without using paths leading through the roll-down fire doors and through the east and west showrooms. The roll-down fire doors separating the east and west showrooms from the main showroom do not meet the requirements for an egress door (1994 SBC §1012.1.2 and §1012.1.8). However, if the paths through the fire door openings are assumed to be acceptable for egress due to their "normally open” status, and the space is treated as one large showroom, then the showroom areas are equipped with an adequate number of exits with adequate separation distance, adequate exit width, and exits that are within the required travel distance.

When the loading dock was added, it blocked the south exit from the west showroom and the south exit from the rear of the main showroom due to the sliding horizontal doors in the loading dock. (The horizontal doors in the loading dock are not of a type permitted by the codes to be a component of a means of egress.) The loading dock area is also an intervening space with a higher hazard than the showroom due to the storage of combustible materials and the probability of obstructed paths of travel. Without the egress paths on the south ends of the main and west showrooms, the egress paths through the roll-down doors between the showrooms are needed to provide the adequate number of exits.

The warehouse building contains the required two exits, along with adequate egress width, exit separation, and travel distance to comply with the provisions of the SBC.

Table 5-6 Maximum Travel Distance from Table 1004 of the 1994 SBC.

\begin{tabular}{|c|c|c|}
\hline \multirow{2}{*}{$\begin{array}{c}\text { Occupancy } \\
\text { Classification }\end{array}$} & \multicolumn{2}{|c|}{ Max. Travel Distance to Exit, m (ft) } \\
\cline { 2 - 3 } & Unsprinklered & Sprinklered \\
\hline Group M & $61.0(200)$ & $76.2(250)$ \\
\hline Group S & $61.0(200)$ & $76.2(250)^{[7]}$ \\
\hline
\end{tabular}

Notes:

Bracketed numbers in the table refer to notes. These numbers are the same as those used in the building code for easier reference. See 1994 SBC Table 1004 for additional notes not included here.

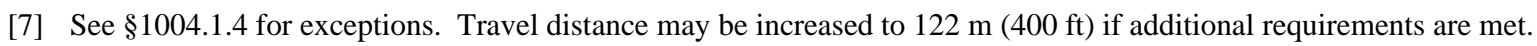

Table 5-7 Maximum Travel Distance from Table 1016.1 of the 2006 IBC.

\begin{tabular}{|c|c|c|}
\hline Occupancy & $\begin{array}{c}\text { Unsprinklered } \\
\mathbf{m}(\mathbf{f t})\end{array}$ & $\begin{array}{c}\text { Sprinklered } \\
\mathbf{m}(\mathbf{f t})\end{array}$ \\
\hline A, E, F-1, I-1, M, R, S-1 & $61.0(200)$ & $76.2(250)^{[\mathrm{b}]}$ \\
\hline
\end{tabular}

Notes:

Bracketed letters in the table refer to notes. These letters are the same as those used in the building code for easier reference. See 2006 IBC Table 1016.1 for additional notes not included here.

[b] Buildings equipped with fire sprinkler systems throughout in accordance with 2006 IBC §903.3.1.1 or §903.3.1.2. See 2006 IBC §903 for occupancies where fire sprinkler systems in accordance with 2006 IBC §903.3.1.2 are permitted. 


\section{$5.4 \quad$ LIMITING FIRE SPREAD IN LARGE FURNITURE DISPLAY AREAS}

The type and amount of fuel, in conjunction with the large open display area, enabled the Sofa Super Store fire to spread rapidly within the building. Both fire sprinklers and compartmentalization can effectively limit how fast a fire spreads within a structure. As discussed in Chapter 4, the sprinklered loading dock simulation demonstrated that fire sprinklers can be effective in controlling fire spread. In addition, during the fire incident, compartmentalization of the east showroom was effective in slowing the fire spread from the main showroom to the east showroom. As demonstrated in the computer simulations, once the fire spread into the rear of the main showroom, it moved rapidly across open spaces within the main showroom. The fire then spread quickly from the main showroom, through the open rolldown fire doors, and into and across the west showroom. The fire did not spread as quickly into the east showroom due to activation of the three roll-down fire doors, two of which closed completely. The separation of the main showroom from the east showroom by the fire resistive masonry wall and rolldown fire doors effectively slowed the spread of the fire in the Sofa Super Store.

For display areas of furniture stores, the maximum floor areas allowed by the model codes do not appear to be effective in sufficiently limiting the magnitude and severity of furniture showroom fires. As described above in Section 5.3.5, for one-story buildings of Type IIB construction, the 2006 IBC allows unsprinklered mercantile occupancies to be up to $1115 \mathrm{~m}^{2}\left(12,000 \mathrm{ft}^{2}\right)$, and the 1991/1994 SBC allows similarly constructed, unsprinklered, mercantile occupancies to be up to $836 \mathrm{~m}^{2}\left(9000 \mathrm{ft}^{2}\right)$. The computer simulations, however, demonstrate that fire was able to spread rapidly throughout the west showroom, which had a significantly smaller area, $650 \mathrm{~m}^{2}\left(7000 \mathrm{ft}^{2}\right)$, than required by the model code. Furthermore, as seen in the post-fire images in Appendix E, the building structure housing the west showroom was severely damaged in the fire incident.

Based on allowable area, merchandise sold, and configuration of furniture stores, the maximum amount of fuel that is permitted by the model code does not appear to be effective in limiting the rapid spread and magnitude of the resulting fire to a level consistent with other sections of the code. For example, in typical unsprinklered occupancies, the 2009 IBC model code limits the amount of stored flammable liquids (Class 1A, 1B, and 1C) and combustible liquids (Class II) to no more than $460 \mathrm{~L}$ (120 gal). Using diesel fuel \#2 as an example of a typical Class II combustible liquid, the energy content of $460 \mathrm{~L}$ is estimated to be $16 \mathrm{GJ}$. Using the estimated average potential energy content of a sofa (Table 1-1 and Appendix J) as 560 MJ, 28 sofas would also have an energy content of approximately 16 GJ.

Approximately $180 \mathrm{~m}^{2}\left(1900 \mathrm{ft}^{2}\right)$ of floor space would be required to display 28 sofas, based on the same average dimensions for a sofa (Appendix $\mathrm{J}$ ) and assuming 50 percent of the available floor space was used for the display of merchandise. Reducing the maximum allowable size of fire areas in furniture stores from $1115 \mathrm{~m}^{2}\left(12,000 \mathrm{ft}^{2}\right)$ to approximately $190 \mathrm{~m}^{2}\left(2000 \mathrm{ft}^{2}\right)$ would align the furniture fuel loading with the IBC allowable combustible liquid fuel loading.

In summary, the hazard of a fire spreading rapidly across a large furniture display area can be reduced by compartmentalizing the display area(s), or by installing fire sprinklers which have been demonstrated as an effective method of controlling building fires. The unsprinklered fire areas allowed by the model codes are too large to prevent rapid fire growth and sufficiently limit the magnitude and severity of fires in furniture display areas. Reducing the maximum allowable size of unsprinklered furniture showroom fire areas to $190 \mathrm{~m}^{2}\left(2000 \mathrm{ft}^{2}\right)$ would slow the rate of fire spread within buildings and reduce fire magnitude by compartmentalizing the otherwise open spaces. 


\subsection{CODE COMPARISON TABLES}

\begin{tabular}{|c|c|c|c|c|c|c|}
\hline & Section Title & 1991/1994 SBC & 1991/1994 SFPC & 2006 IBC & 2006 IFC & Analysis \\
\hline 1. & Permits & $\begin{array}{l}103 \text { Permits. A person, firm } \\
\text { or corporation shall not } \\
\text { maintain, store or handle } \\
\text { materials, or conduct } \\
\text { processes which produce } \\
\text { conditions hazardous to life } \\
\text { or property, or install } \\
\text { equipment used in } \\
\text { connection with such } \\
\text { activities without first } \\
\text { obtaining a permit from the } \\
\text { fire official. }\end{array}$ & $\begin{array}{l}103 \text { Permits. A person, } \\
\text { firm or corporation shall } \\
\text { not maintain, store or } \\
\text { handle materials, or } \\
\text { conduct processes which } \\
\text { produce conditions } \\
\text { hazardous to life or } \\
\text { property, or install } \\
\text { equipment used in } \\
\text { connection with such } \\
\text { activities without first } \\
\text { obtaining a permit from } \\
\text { the fire official. }\end{array}$ & $\begin{array}{l}\text { 105.1 Required. Any owner } \\
\text { or authorized agent who } \\
\text { intends to construct, } \\
\text { enlarge, alter, repair, move, } \\
\text { demolish, or change the } \\
\text { occupancy of a building or } \\
\text { structure, or to erect, install, } \\
\text { enlarge, alter, repair, } \\
\text { remove, convert or replace } \\
\text { any electrical, gas, } \\
\text { mechanical or plumbing } \\
\text { system, the installation of } \\
\text { which is regulated by this } \\
\text { code, or to cause any such } \\
\text { work to be done, shall first } \\
\text { make application to the } \\
\text { building official and obtain } \\
\text { the required permit. }\end{array}$ & $\begin{array}{l}315.1 \text { General. } \\
\text { Storage, use and } \\
\text { handling of } \\
\text { miscellaneous } \\
\text { combustible materials } \\
\text { shall be in accordance } \\
\text { with this section. A } \\
\text { permit shall be obtained } \\
\text { in accordance with } \\
\text { Section } 105.6 \text {. }\end{array}$ & $\begin{array}{l}\text { Permits were required } \\
\text { by both the older and } \\
\text { newer codes. }\end{array}$ \\
\hline 2. & Mercantile Occupancy & $\begin{array}{l}410 \text { Mercantile Occupancy - } \\
\text { Group M } \\
410.1 \text { Scope Group M } \\
\text { occupancy is the use of a } \\
\text { building or structure or any } \\
\text { portion thereof, for the } \\
\text { display and sale of } \\
\text { merchandise including stocks } \\
\text { of goods, wares or } \\
\text { merchandise incidental to } \\
\text { such purposes and } \\
\text { accessible to the public and } \\
\text { shall include, among others, } \\
\text { the following: department } \\
\text { stores, drug stores, markets, } \\
\text { retail stores, shopping } \\
\text { centers, sales rooms, } \\
\text { wholesale stores (other than } \\
\text { warehouses). }\end{array}$ & & $\begin{array}{l}309.1 \text { Mercantile Group M. } \\
\text { Mercantile Group M } \\
\text { occupancy includes, among } \\
\text { others, buildings and } \\
\text { structures or a portion } \\
\text { thereof, for the display and } \\
\text { sale of merchandise, and } \\
\text { involves stocks of goods, } \\
\text { wares or merchandise } \\
\text { incidental to such purposes } \\
\text { and accessible to the } \\
\text { public. Mercantile } \\
\text { occupancies shall include, } \\
\text { but not be limited to, the } \\
\text { following: department } \\
\text { stores, drug stores, } \\
\text { markets, motor fuel- } \\
\text { dispensing facilities, retail } \\
\text { or wholesale stores, sales } \\
\text { rooms. }\end{array}$ & & $\begin{array}{l}\text { Mercantile occupancy } \\
\text { definitions are nearly } \\
\text { identical. }\end{array}$ \\
\hline
\end{tabular}




\begin{tabular}{|c|c|c|c|c|c|c|}
\hline & Section Title & 1991/1994 SBC & 1991/1994 SFPC & 2006 IBC & 2006 IFC & Analysis \\
\hline 3. & Storage Occupancy & $\begin{array}{l}\text { 412 Storage Occupancy - } \\
\text { Group S } \\
412.1 \text { Scope } \\
412.1 .1 \text { Group S occupancy } \\
\text { is the principal use of a } \\
\text { building or structure, or any } \\
\text { portion thereof, for storage } \\
\text { that is not classed as a } \\
\text { Group H occupancy or used } \\
\text { for the purpose of sheltering } \\
\text { animals. } \\
\text { 412.1.2 S1 Moderate Hazard } \\
\text { Storage shall include } \\
\text { buildings used for the storage } \\
\text { of combustible materials } \\
\text { when not classified as S2 } \\
\text { Low Hazard or Group H. } \\
\text { 412.1.4 Portions of Group S } \\
\text { occupancy involving highly } \\
\text { combustible, flammable or } \\
\text { explosive products or } \\
\text { materials shall be properly } \\
\text { ventilated, protected and } \\
\text { properly separated from the } \\
\text { remainder of the building in } \\
\text { accordance with the } \\
\text { appropriate NFiPA } \\
\text { or the entandard } \\
\text { classified as Grouing will be } \\
\text { occupancy. } \\
412.1 .5 \text { Refer to Chapter } 36 \\
\text { of the Standard Fire } \\
\text { Prevention Code for } \\
\text { provisions on storage of high- } \\
\text { piled combustible material } \\
\text { and high-rack storage } \\
\text { systemss. }\end{array}$ & & $\begin{array}{l}\text { SECTION } 311 \text { STORAGE } \\
\text { GROUP S } \\
\text { 311.1 Storage Group S. } \\
\text { Storage Group S } \\
\text { occupancy includes, among } \\
\text { others, the use of a building } \\
\text { or structure, or a portion } \\
\text { thereof, for storage that is } \\
\text { not classified as a } \\
\text { hazardous occupancy. } \\
311.2 \text { Moderate-hazard } \\
\text { storage, Group S-1. } \\
\text { Buildings occupied for } \\
\text { storage uses that are not } \\
\text { classified as Group S-2, } \\
\text { including, but not limited to, } \\
\text { storage of the following: } \\
\text {... furniture... }\end{array}$ & & $\begin{array}{l}\text { Furniture falls into the } \\
\text { same moderate hazard } \\
\text { occupancy } \\
\text { classification in both } \\
\text { codes. }\end{array}$ \\
\hline
\end{tabular}

‡ The SBC and SFPC use the abbreviation "NFiPA", while the IBC and IFC use the abbreviation "NFPA" for the National Fire Protection Association, Batterymarch Park, MA. NFiPA and NFPA are synonymous in this report. 


\begin{tabular}{|c|c|c|c|c|c|c|}
\hline & Section Title & 1991/1994 SBC & 1991/1994 SFPC & 2006 IBC & 2006 IFC & Analysis \\
\hline 4. & Occupancy Separation & $\begin{array}{l}\text { 403.1.3 The minimum fire } \\
\text { resistance of construction } \\
\text { separating any two } \\
\text { occupancies in a building of } \\
\text { mixed occupancy shall be the } \\
\text { higher rating required for the } \\
\text { occupancies being } \\
\text { separated, as specified in } \\
\text { Table } 403.1 . \\
\text { Table } 403.1 \text { Occupancy } \\
\text { Separation Requirements } \\
\text { Storage, Moderate Hazard } \\
\text { S1...3 hour. } \\
\text { Table } 403.1 \text { Occupancy } \\
\text { Separation Requirements } \\
\text { Mercantile...1 hour. }\end{array}$ & & $\begin{array}{l}\text { 508.3 Mixed occupancies. } \\
\text { Each portion of a building } \\
\text { shall be individually } \\
\text { classified in accordance } \\
\text { with Section } 302.1 \text {. Where } \\
\text { a building contains more } \\
\text { than one occupancy group, } \\
\text { the building or portion } \\
\text { thereof shall comply with } \\
\text { Sections } 508.3 .1,508.3 .2 \text {, } \\
508.3 .3 \text { or a combination of } \\
\text { these sections. Exceptions: } \\
\text { 1. Occupancies separated } \\
\text { in accordance with Section } \\
509.2 \text {. Where required by } \\
\text { Table } 415.3 .2 \text {, areas of } \\
\text { Group H-1, H-2 or H-3 } \\
\text { occupancies shall be } \\
\text { located in a separate and } \\
\text { detached building or } \\
\text { structure. }\end{array}$ & & $\begin{array}{l}\text { If quantities of high- } \\
\text { hazard materials } \\
\text { beyond the maximum } \\
\text { allowable amount were } \\
\text { stored in the repair } \\
\text { areas using flammable } \\
\text { solvents and paints } \\
\text { would have to be } \\
\text { classified as a Group } \\
\text { H-3 occupancy. Below } \\
\text { the maximum allowable } \\
\text { quantity, the areas } \\
\text { could have been } \\
\text { separated as incidental } \\
\text { occupancies. }\end{array}$ \\
\hline 5. & Height and Area & $\begin{array}{l}\text { Table } 500 \text { Type } V \\
\text { Unsprinklered } \\
\text { Mercantile One-Story = } \\
9000 \mathrm{ft}^{2}, 59 \mathrm{ft} \text { height } \\
\text { Storage One-Story = } \\
16,000 \mathrm{ft}^{2}, 59 \mathrm{ft} \text { height } \\
506.1 \text { General. The areas } \\
\text { limited by Table } 503 \text { shall be } \\
\text { permitted to be increased } \\
\text { due to frontage }(I f) \text { and } \\
\text { automatic sprinkler system } \\
\text { protection }(I s) \text { in accordance } \\
\text { with the following: } \\
A_{a}=\left\{A_{t}+\left[A_{t} \times I_{f}\right]+\left[A_{t} \times I_{s}\right]\right\} \\
(E q u a t i o n ~ 5-1) \\
\text { where: } \\
A_{a}=\text { Allowable area per } \\
\left.\text { story (ft' } \mathrm{ft}^{2}\right) . \\
A_{t}=\text { Tabular area per story in }\end{array}$ & & $\begin{array}{l}\text { Table } 400 \text { Type 2B } \\
\text { Unsprinklered } \\
\text { Mercantile }=12,500 \mathrm{ft}^{2} \text {, } \\
55 \mathrm{ft} \text { height } \\
\text { Storage }=26,000 \mathrm{ft}^{2}, 55 \mathrm{ft} \\
\text { height } \\
402.3 .2 \text { Where streets or } \\
\text { public spaces, or horizontal } \\
\text { separation from property } \\
\text { lines of total width of not } \\
\text { less than } 30 \mathrm{ft}(9144 \mathrm{~mm} \text { ), } \\
\text { or } 30 \mathrm{ft}(9144 \text { mm) between } \\
\text { buildings on commonly } \\
\text { owned property, extend } \\
\text { along the building } \\
\text { perimeter, except for } \\
\text { hazardous occupancies, } \\
\text { the areas permitted by } \\
\text { Table } 400 \text { may be } \\
\text { increased as follow: } \\
\text { I = } 4 / 3[100(\mathrm{~F} / \mathrm{P}-0.25 \text { )] } \\
\text { Where }\end{array}$ & & $\begin{array}{l}\text { Current code has } \\
\text { tighter restrictions on } \\
\text { height and area. Code } \\
\text { compliance is } \\
\text { dependent on whether } \\
\text { the additions were } \\
\text { treated as one building } \\
\text { or separated buildings. } \\
\text { See analysis above. }\end{array}$ \\
\hline
\end{tabular}




\begin{tabular}{|c|c|c|c|c|c|}
\hline Section Title & 1991/1994 SBC & 1991/1994 SFPC & 2006 IBC & 2006 IFC & Analysis \\
\hline & $\begin{array}{l}\text { accordance with } \\
\text { Table } 503 \text { (ft }{ }^{2} \text { ). } \\
I_{f}=\text { Area increase factor due } \\
\text { to frontage as calculated in } \\
\text { accordance with Section } \\
506.2 \text {. } \\
I_{s}=\text { Area increase factor due } \\
\text { to sprinkler protection as } \\
\text { calculated in accordance with } \\
\text { Section } 506.3 \text {. } \\
506.2 \text { Frontage increase. } \\
\text { Every building shall adjoin or } \\
\text { have access to a public way } \\
\text { to receive an area increase } \\
\text { for frontage. Where a } \\
\text { building has more than } 25 \\
\text { percent of its perimeter on a } \\
\text { public way or open space } \\
\text { having a minimum width of } \\
20 \mathrm{ft}(6096 \text { mm), the frontage } \\
\text { increase shall be determined } \\
\text { in accordance with the } \\
\text { following: } \\
I_{f}=[F / P \text { - } 0.25] \text { W/30 } \\
\text { (Equation } 5-2 \text { ) } \\
\text { where: } \\
I_{f}=\text { Area increase due to } \\
\text { frontage. } \\
F=\text { Building perimeter that } \\
\text { fronts on a public way or } \\
\text { open space having } 20 \mathrm{ft} \\
\text { (6096 mm) open minimum } \\
\text { width (ft). } \\
P=\text { Perimeter of entire } \\
\text { building (feet). } \\
W=\text { Width of public way or } \\
\text { open space (ft) in accordance } \\
\text { with Section } 506.2 .1 .\end{array}$ & & $\begin{array}{l}\text { I = Percent increase of } \\
\text { unsprinklered areas in } \\
\text { Table } 400 \text {. } \\
\mathrm{F}=\text { Building perimeter } \\
\text { which fronts on streets, } \\
\text { public spaces or horizontal } \\
\text { separation not less than } \\
30 \mathrm{ft} \text { ( } 9144 \mathrm{~mm} \text { ) wide. } \\
\mathrm{P}=\text { Total perimeter of } \\
\text { building. } \\
\text { 402.3.3 For both an } \\
\text { unsprinklered building and } \\
\text { a sprinklered building the } \\
\text { percent increase is } \\
\text { multiplied by the } \\
\text { unsprinklered area } \\
\text { permitted in Table } 400 \text { for } \\
\text { the type of construction of } \\
\text { the building, and the } \\
\text { resulting are increase is } \\
\text { added to either the } \\
\text { sprinklered or } \\
\text { unsprinklered areas in } \\
\text { Table } 400 \text {. When there are } \\
\text { no unsprinklered areas } \\
\text { permitted for the building in } \\
\text { Table } 400 \text { an unsprinklered } \\
\text { area can be computed for } \\
\text { use in this section. The } \\
\text { corresponding } \\
\text { unsprinklered areas are } \\
\text { computed as one-third of } \\
\text { the sprinklered area for one } \\
\text { story only and as one-half } \\
\text { of the sprinklered area for } \\
\text { multi-stories. }\end{array}$ & & \\
\hline
\end{tabular}




\begin{tabular}{|c|c|c|c|c|c|c|}
\hline & Section Title & 1991/1994 SBC & 1991/1994 SFPC & 2006 IBC & 2006 IFC & Analysis \\
\hline 6. & Construction Type & $\begin{array}{l}603 \text { Type } V \text { Construction } \\
\text { Type } V \text { is construction in } \\
\text { which the exterior bearing or } \\
\text { nonbearing walls are of } \\
\text { noncombustible material and } \\
\text { have fire resistance not less } \\
\text { than that specified in } \\
\text { Table } 600 \text {; bearing portions } \\
\text { of interior walls are of } \\
\text { material permitted in } \\
\text { Table } 600 \text {, and have fire } \\
\text { resistance not less than that } \\
\text { specified in Table } 600 ; \text { and } \\
\text { beams, girders, trusses, } \\
\text { arches, floors, roofs, and } \\
\text { interior framing are wholly or } \\
\text { partly of wood or other } \\
\text { approved materials and have } \\
\text { fire resistance not less than } \\
\text { that specified in Table } 600 . \\
\text { Type } V \text { construction may be } \\
\text { either protected or } \\
\text { unprotected. Fire resistance } \\
\text { requirements for structural } \\
\text { elements of Type } V \\
\text { construction shall be as } \\
\text { specified in Table } 600 . \\
605 \text { Type VI Construction } \\
\text { Type VI is construction in } \\
\text { which the exterior bearing } \\
\text { and nonbearing walls and } \\
\text { partitions, floors and roofs } \\
\text { and their supports are wholly } \\
\text { or partly of wood or other } \\
\text { approved materials. Type VI } \\
\text { construction may be either } \\
\text { protected or unprotected. } \\
\text { Fire resistance requirements } \\
\text { for structural elements of } \\
\text { Type VI construction shall be } \\
\text { specified in Table } 600 . \\
609.1 \text { When two or more } \\
\text { types of construction not } \\
\text { separated by fire walls occur } \\
\text { in the same building, the area }\end{array}$ & & $\begin{array}{l}602.2 \text { Types I and II. Type I } \\
\text { and II construction are } \\
\text { those types of construction } \\
\text { in which the building } \\
\text { elements listed in } \\
\text { Table } 601 \text { are of } \\
\text { noncombustible materials, } \\
\text { except as permitted in } \\
\text { Section } 603 \text { and elsewhere } \\
\text { in this code. } \\
602.5 \text { Type } V \text {. Type } V \\
\text { construction is that type of } \\
\text { construction in which the } \\
\text { structural elements, exterior } \\
\text { walls and interior walls are } \\
\text { of any materials permitted } \\
\text { by this code. }\end{array}$ & & Similar. \\
\hline
\end{tabular}




\begin{tabular}{|c|c|c|c|c|c|c|}
\hline & Section Title & 1991/1994 SBC & 1991/1994 SFPC & 2006 IBC & 2006 IFC & Analysis \\
\hline & & $\begin{array}{l}\text { of the entire building shall not } \\
\text { exceed the least area } \\
\text { permitted based on } \\
\text { occupancy for the types of } \\
\text { construction used in the } \\
\text { building. }\end{array}$ & & & & \\
\hline 7. & $\begin{array}{l}\text { Building Separation } \\
\text { Distances }\end{array}$ & & & & $\begin{array}{l}503.1 .2 \text { Buildings on } \\
\text { same lot. } \\
\text { Two or more buildings } \\
\text { on the same lot shall be } \\
\text { regulated as separate } \\
\text { buildings or shall be } \\
\text { considered as portions } \\
\text { of one building if the } \\
\text { height of each building } \\
\text { and the aggregate area } \\
\text { of buildings are within } \\
\text { the limitations of } \\
\text { Table } 503 \text { as modified } \\
\text { by Sections } 504 \text { and } \\
506 \text {. The provisions of } \\
\text { this code applicable to } \\
\text { the aggregate building } \\
\text { shall be applicable to } \\
\text { each building. }\end{array}$ & New requirement. \\
\hline 8. & $\begin{array}{l}\text { Suppression Systems - } \\
\text { Based on Occupancy } \\
\text { Type }\end{array}$ & $\begin{array}{l}\text { 901.7.1 Group M. An } \\
\text { approved automatic sprinkler } \\
\text { system shall be provided in } \\
\text { stores and similar } \\
\text { occupancies where stocks of } \\
\text { combustible materials are on } \\
\text { display for public sale and } \\
\text { where the story floor area } \\
\text { exceeds } 15,000 \mathrm{ft}^{2}\left(1395 \mathrm{~m}^{2}\right) \text {. }\end{array}$ & & & $\begin{array}{l}\text { 903.2.6 Group M. An } \\
\text { automatic sprinkler } \\
\text { system shall be } \\
\text { provided throughout } \\
\text { buildings containing a } \\
\text { Group M occupancy } \\
\text { where one of the } \\
\text { following conditions } \\
\text { exists: } 1 \text {. Where a } \\
\text { Group M fire area } \\
\text { exceeds } 12,000 \mathrm{ft}^{2} \\
\left(1115 \mathrm{~m}^{2}\right) ; 2 \text {. Where a } \\
\text { Group M fire area is } \\
\text { located more than three } \\
\text { stories above grade } \\
\text { plane; or } 3 \text {. Where the } \\
\text { combined area of all } \\
\text { Group M fire areas on } \\
\text { all floors, including any } \\
\text { mezzanines, exceeds } \\
24,000 \mathrm{ft}^{2}\left(2230 \mathrm{~m}^{2}\right) .\end{array}$ & $\begin{array}{l}\text { Newer code is more } \\
\text { restrictive in area. }\end{array}$ \\
\hline
\end{tabular}




\begin{tabular}{|c|c|c|c|c|c|c|}
\hline & Section Title & 1991/1994 SBC & 1991/1994 SFPC & 2006 IBC & 2006 IFC & Analysis \\
\hline 9. & $\begin{array}{l}\text { Suppression Systems - } \\
\text { Based on Storage } \\
\text { Configuration }\end{array}$ & $\begin{array}{l}\text { 901.7.3 High Piled } \\
\text { Combustible Stock. An } \\
\text { approved automatic sprinkler } \\
\text { system shall be provided } \\
\text { throughout buildings required } \\
\text { to have sprinkler protection } \\
\text { by Chapter } 36 \text { of the } \\
\text { Standard Fire Prevention } \\
\text { Code. } \\
\text { Exception: Automatic } \\
\text { sprinkler systems may be } \\
\text { provided only in the storage } \\
\text { area of the building when the } \\
\text { storage is separated from the } \\
\text { remainder of the building by a } \\
\text { minimum 2-hour fire resistant } \\
\text { separation. }\end{array}$ & & & $\begin{array}{l}\text { 903.2.6.1 High-piled } \\
\text { storage. An automatic } \\
\text { sprinkler system shall } \\
\text { be provided in } \\
\text { accordance with the } \\
\text { International Fire Code } \\
\text { in all buildings of } \\
\text { Group M where storage } \\
\text { of merchandise is in } \\
\text { high-piled or rack } \\
\text { storage arrays. }\end{array}$ & $\begin{array}{l}\text { Newer code does not } \\
\text { include exception for } \\
\text { separation. }\end{array}$ \\
\hline 10. & Commodity Definitions & & $\begin{array}{l}3604.1 \text { Commodity } \\
\text { classifications shall be } \\
\text { defined and in } \\
\text { accordance with the } \\
\text { following: ... 3. Class III } \\
\text { commodity - a commodity } \\
\text { of wood, paper, natural } \\
\text { fiber cloth, or Group C } \\
\text { plastics or products } \\
\text { thereof, with or without } \\
\text { pallets. Products may } \\
\text { contain a limited amount } \\
\text { of Group A or B plastics, } \\
\text { such as wood dressers } \\
\text { with plastic drawer glides, } \\
\text { handles and trim. } \\
\text { Examples of Class III } \\
\text { commodities include but } \\
\text { are not limited to the } \\
\text { following: combustible } \\
\text { fiberboard; baled cork, } \\
\text { bagged feed, bagged } \\
\text { fertilizers, furniture } \\
\text { (wood, natural fiber, } \\
\text { upholstered, non-plastic } \\
\text { or wood or metal with } \\
\text { plastic-padded and } \\
\text { covered arm rests), } \\
\text { lubricating or hydraulic }\end{array}$ & & & $\begin{array}{l}\text { No parallel section in } \\
\text { newer code. }\end{array}$ \\
\hline
\end{tabular}




\begin{tabular}{|c|c|c|c|c|c|c|}
\hline & Section Title & 1991/1994 SBC & 1991/1994 SFPC & 2006 IBC & 2006 IFC & Analysis \\
\hline & & & $\begin{array}{l}\text { fluid in metal cans, } \\
\text { lumber stored flat), } \\
\text { mattresses (excluding } \\
\text { foamed rubber and } \\
\text { foamed plastics), } \\
\text { nonflammable liquids in } \\
\text { plastic containers, oil } \\
\text { base paints in cans, } \\
\text { paper and pulp } \\
\text { (horizontal storage), } \\
\text { baled waste paper, food } \\
\text { containers, plywood, } \\
\text { baled rags, rugs (no } \\
\text { foamed backing), bagged } \\
\text { sugar, baled wood, wood } \\
\text { doors, frames and } \\
\text { cabinets, yarns (natural } \\
\text { fiber and viscose). }\end{array}$ & & & \\
\hline 11. & Commodity Suppression & & $\begin{array}{l}3605 \text { Fire protection for } \\
\text { buildings used for high- } \\
\text { piled combustible storage } \\
\text { shall be in accordance } \\
\text { with Table } 3605 \text { and the } \\
\text { building code. Nationally } \\
\text { recognized standards or } \\
\text { guidelines as applicable } \\
\text { may be used when } \\
\text { approved by the fire } \\
\text { official. }\end{array}$ & & & See below. \\
\hline 12. & $\begin{array}{l}\text { Automatic Sprinkler } \\
\text { Systems (Where } \\
\text { Required) }\end{array}$ & $\begin{array}{l}\text { 903.7.1 Group M. Automatic } \\
\text { sprinkler system required in } \\
\text { stores and similar } \\
\text { occupancies where stocks of } \\
\text { combustible materials are on } \\
\text { display for public sale and the } \\
\text { storey floor area exceeds } \\
15,000 \mathrm{ft}^{2} \text {. }\end{array}$ & & $\begin{array}{l}\text { [F] 903.2.6 IBC contains } \\
\text { language identical to IFC. } \\
\text { [F] 903.2.6.1 IBC contains } \\
\text { language identical to IFC. }\end{array}$ & $\begin{array}{l}\text { [F] 903.2.6 Automatic } \\
\text { sprinklers are required } \\
\text { in } \mathrm{M} \text { occupancies where } \\
\text { one of the following } \\
\text { exists: } 1 . \text { An } \\
\mathrm{M} \text { occupancy fire area } \\
\text { exceeds } 12,000 \mathrm{ft}^{2} \\
\left(1115 \mathrm{~m}^{2}\right) ; 2 \text {. An } \\
\mathrm{M} \text { occupancy fire area is } \\
\text { located more than } \\
3 \text { stories above grade; } \\
3 \text {. The combined area of } \\
\text { all } \mathrm{M} \text { occupancy fire } \\
\text { areas exceeds } \\
24,000 \mathrm{ft}^{2}\left(2230 \mathrm{~m}^{2}\right) \text {. } \\
\\
{[\mathrm{F}] 903.2 .6 .1 \text { Automatic }} \\
\text { sprinklers are required }\end{array}$ & $\begin{array}{l}\text { The } 2006 \text { IFC } \\
\text { incorporates an area } \\
\text { allowance for the } \\
\text { combination of fire } \\
\text { barriers and automatic } \\
\text { sprinklers. Sprinklers } \\
\text { are required for all M } \\
\text { occupancies with high } \\
\text { piled or rack storage of } \\
\text { merchandise, however. }\end{array}$ \\
\hline
\end{tabular}




\begin{tabular}{|c|c|c|c|c|c|c|}
\hline & Section Title & $1991 / 1994$ SBC & 1991/1994 SFPC & 2006 IBC & 2006 IFC & Analysis \\
\hline & & & & & $\begin{array}{l}\text { in all buildings of Group } \\
\text { M occupancy where } \\
\text { storage of merchandise } \\
\text { is in high piled or rack } \\
\text { storage arrays. }\end{array}$ & \\
\hline 13. & $\begin{array}{l}\text { Automatic Sprinkler } \\
\text { Systems (Where } \\
\text { Required) }\end{array}$ & $\begin{array}{l}\text { 903.7.3 High Piled } \\
\text { Combustible Stock. } \\
\text { Automatic sprinkler system } \\
\text { required throughout buildings } \\
\text { where required by } \\
\text { Chapter } 36 \text { of the Fire Code. }\end{array}$ & $\begin{array}{l}\text { Table } 3605 \text {. Automatic } \\
\text { fire extinguishing system } \\
\text { required for high piled } \\
\text { combustible storage } \\
(\text { Commodity III) for areas } \\
\text { greater than } 12,000 \mathrm{ft}^{2} \\
\left(1115 \mathrm{~m}^{2}\right) .\end{array}$ & $\begin{array}{l}\text { [F] 903.2.8 IBC contains } \\
\text { language identical to IFC. }\end{array}$ & $\begin{array}{l}\text { [F] 903.2.8 Group S-1. } \\
\text { An automatic sprinkler } \\
\text { system shall be } \\
\text { provided throughout all } \\
\text { buildings containing a } \\
\text { Group S-1 occupancy } \\
\text { where one of the } \\
\text { following conditions } \\
\text { exists: } 1 . \text { A Group S-1 } \\
\text { fire area exceeds } \\
12,000 \mathrm{ft}^{2}\left(1115 \mathrm{~m}^{2} \text { ); }\right. \\
2 . \text { A Group S-1 fire area } \\
\text { is located more than } \\
\text { three stories above } \\
\text { grade plane; or } 3 \text {. The } \\
\text { combined area of all } \\
\text { Group S-1 fire areas on } \\
\text { all floors, including any } \\
\text { mezzanines, exceeds } \\
24,000 \mathrm{ft}^{2} \text { ( } 2230 \mathrm{~m}^{2} \text { ). } \\
\text { Table } 2306.2 \text { Automatic } \\
\text { sprinklers are required } \\
\text { for high piled storage } \\
\text { areas of Class III } \\
\text { Commodities (furniture) } \\
\text { with areas greater than } \\
2500 \mathrm{ft}^{2} \text { if public } \\
\text { accessible. } \\
\text { Table } 2306.2 \text { Automatic } \\
\text { sprinklers are required } \\
\text { for high piled storage } \\
\text { areas of Class III } \\
\text { Commodities (furniture) } \\
\text { with areas greater than } \\
12,000 \mathrm{ft}^{2}\left(1115 \mathrm{~m}^{2} \text { ). }\right.\end{array}$ & $\begin{array}{l}\text { Table } 3605 \text { of the } \\
\text { SFPC required } \\
\text { automatic fire } \\
\text { extinguishing systems } \\
\text { for high-piled } \\
\text { combustible storage } \\
\text { (Commodity III) in } \\
\text { areas greater than } \\
12,000 \mathrm{ft}^{2} \text { (the } \\
\text { warehouse was } \\
15,600 \mathrm{ft}^{2} \text { ). The } 2006 \\
\text { IFC also requires } \\
\text { sprinkler protection for } \\
\text { this area of storage. } \\
\text { The } 2006 \text { IFC, } \\
\text { however, contains } \\
\text { stricter limits on } \\
\text { unsprinklered areas if } \\
\text { they are publicly } \\
\text { accessible }\left(2500 \mathrm{ft}^{2} \text { ). }\right.\end{array}$ \\
\hline 14. & $\begin{array}{l}\text { Storage of Readily } \\
\text { Combustible Materials/ } \\
\text { Miscellaneous } \\
\text { Combustible Materials }\end{array}$ & & $\begin{array}{l}502.3 .2 \text { Storage in } \\
\text { buildings shall be orderly, } \\
\text { shall not be within } 2 \mathrm{ft} \text { of } \\
\text { the ceiling, shall be } \\
\text { separated from heaters }\end{array}$ & & & \\
\hline
\end{tabular}




\begin{tabular}{|c|c|c|c|c|c|c|}
\hline & Section Title & 1991/1994 SBC & 1991/1994 SFPC & 2006 IBC & 2006 IFC & Analysis \\
\hline & Storage & & $\begin{array}{l}\text { or heating devices by } \\
\text { distance or shielding so } \\
\text { that ignition cannot occur, } \\
\text { and not so located as to } \\
\text { endanger exit from the } \\
\text { building. Storage in the } \\
\text { open shall not be more } \\
\text { than } 20 \mathrm{ft} \text { in height, shall } \\
\text { be so located with } \\
\text { respect to adjacent } \\
\text { buildings, as not to } \\
\text { constitute a hazard, and } \\
\text { shall be compact and } \\
\text { orderly. }\end{array}$ & & & \\
\hline 15. & Storage & & & & $\begin{array}{l}315.2 \text { Storage in } \\
\text { buildings. Storage of } \\
\text { combustible materials in } \\
\text { buildings shall be } \\
\text { orderly. Storage shall } \\
\text { be separated from } \\
\text { heaters or heating } \\
\text { devices by distance or } \\
\text { shielding so that ignition } \\
\text { cannot occur. } \\
315.2 .1 \text { Ceiling } \\
\text { Clearance. Storage } \\
\text { shall be maintained } 2 \mathrm{ft} \\
(610 \text { mm) or more } \\
\text { below the ceiling in } \\
\text { nonsprinklered areas of } \\
\text { buildings or a minimum } \\
\text { of } 18 \text { in ( } 457 \text { mm) below } \\
\text { sprinkler head } \\
\text { deflectors in sprinklered } \\
\text { areas of buildings. }\end{array}$ & \\
\hline 16. & Building & $\begin{array}{l}\text { 202. Building is defined as } \\
\text { the structure that encloses } \\
\text { any occupancy. Each portion } \\
\text { of a building that is separated } \\
\text { by other portions of the } \\
\text { building by a fire wall are } \\
\text { considered separate } \\
\text { buildings. }\end{array}$ & & $\begin{array}{l}\text { 202. Building is defined as } \\
\text { a structure that intended to } \\
\text { support or shelter an } \\
\text { occupancy or use. } \\
705.1 \text {. Each portion of a } \\
\text { building separated from all } \\
\text { others by fire walls } \\
\text { providing a complete } \\
\text { separation are considered } \\
\text { separate buildings. If the }\end{array}$ & & $\begin{array}{l}\text { Fire walls can be used } \\
\text { to separate a structure } \\
\text { into one or more } \\
\text { separate buildings for } \\
\text { purposes of height/area } \\
\text { limits, sprinkler } \\
\text { requirements, etc. }\end{array}$ \\
\hline
\end{tabular}




\begin{tabular}{|c|c|c|c|c|c|c|}
\hline & Section Title & 1991/1994 SBC & 1991/1994 SFPC & 2006 IBC & 2006 IFC & Analysis \\
\hline & & & & $\begin{array}{l}\text { fire wall(s) also separate } \\
\text { occupancies that are } \\
\text { required to be separated by } \\
\text { a fire barrier wall, the most } \\
\text { restrictive requirements of } \\
\text { each separation wall apply. }\end{array}$ & & \\
\hline 17. & Fire Barrier, Fire Area & & & $\begin{array}{l}\text { 702. Fire Area. Building } \\
\text { area surrounded by exterior } \\
\text { walls, fire barriers, fire } \\
\text { walls, or horizontal barriers. } \\
\text { 702. Fire Barrier. Fire rated } \\
\text { wall assembly that restricts } \\
\text { the spread of fire. } \\
\text { Table } 706.3 .9 \text { The fire } \\
\text { barrier separating an M } \\
\text { occupancy into different fire } \\
\text { areas is required be of } \\
2 \text { hour fire rated } \\
\text { construction, with } 1.5 \text { hour } \\
\text { fire rated doors } \\
\text { (Table } 715.4 \text { ). } \\
\text { Table } 706.3 .9 \text { The fire } \\
\text { barrier separating an S-1 } \\
\text { occupancy into different fire } \\
\text { areas is required be of } \\
3 \text { hour fire rated } \\
\text { construction, with } 3 \text { hour } \\
\text { fire rated doors } \\
\text { (Table } 715.4 \text { ). }\end{array}$ & & $\begin{array}{l}\text { In some buildings, fire } \\
\text { barriers can be used to } \\
\text { compartmentalize a } \\
\text { building to slow fire } \\
\text { development and as an } \\
\text { alternative to sprinkler } \\
\text { requirements. }\end{array}$ \\
\hline 18. & Fire Walls, Fire Doors. & $\begin{array}{l}\text { 202. Fire wall. A } 4 \text { hour fire } \\
\text { resistant wall, with protected } \\
\text { penetrations or openings, } \\
\text { extending from the } \\
\text { foundation to / through the } \\
\text { roof with sufficient stability to } \\
\text { withstand the collapse of the } \\
\text { construction on either side. }\end{array}$ & & $\begin{array}{l}\text { 702. Fire wall. Fire rated } \\
\text { wall, with protected } \\
\text { penetrations or openings, } \\
\text { extending from the } \\
\text { foundation to / through the } \\
\text { roof with sufficient stability } \\
\text { to withstand the collapse of } \\
\text { the construction on either } \\
\text { side. } \\
\text { Table } 705.4 \text { Fire wall fire } \\
\text { resistance rating for M } \\
\text { occupancies shall not be } \\
\text { less than } 3 \text { hours. Fire wall } \\
\text { fire resistance rating for S-1 }\end{array}$ & & $\begin{array}{l}\text { Older code more } \\
\text { stringent. }\end{array}$ \\
\hline
\end{tabular}




\begin{tabular}{|c|c|c|c|c|c|c|}
\hline & Section Title & 1991/1994 SBC & 1991/1994 SFPC & 2006 IBC & 2006 IFC & Analysis \\
\hline & & & & $\begin{array}{l}\text { occupancies shall not be } \\
\text { less than } 3 \text { hours. } \\
\text { Table } 715.4 \text { Fire doors } \\
\text { installed in } 3 \text { hour rated fire } \\
\text { walls are required to be } 3 \\
\text { hour fire rated or consist of } \\
\text { two } 1.5 \text { hour fire rated } \\
\text { doors installed on opposite } \\
\text { sides of the wall. }\end{array}$ & & \\
\hline 19. & Fire Walls, Fire Doors & & $\begin{array}{l}504.7 .1 \text { Fire walls, fire } \\
\text { stops, and fire rated } \\
\text { partitions and floors } \\
\text { required by the Building } \\
\text { Code shall be } \\
\text { maintained. All openings } \\
\text { made therein for the } \\
\text { passage of pipes, } \\
\text { electrical and the like, } \\
\text { and holes made for any } \\
\text { reason shall be sealed } \\
\text { with approved } \\
\text { noncombustible material } \\
\text { to protect against } \\
\text { passage of smoke and } \\
\text { fire. All openings through } \\
\text { these partitions (i.e., } \\
\text { access doors) shall be } \\
\text { protected by self-closing } \\
\text { or automatic doors of } \\
\text { approved construction } \\
\text { meeting the partition } \\
\text { requirements. }\end{array}$ & & $\begin{array}{l}703.1 \text { Maintenance. } \\
\text { The required fire- } \\
\text { resistance rating of fire- } \\
\text { resistance-rated } \\
\text { construction (including } \\
\text { walls, firestops, shaft } \\
\text { enclosures, partitions, } \\
\text { smoke barriers, floors, } \\
\text { fire-resistive coatings } \\
\text { and sprayed fire- } \\
\text { resistant materials } \\
\text { applied to structural } \\
\text { members and fire- } \\
\text { resistant joint systems) } \\
\text { shall be maintained. } \\
\text { Such elements shall be } \\
\text { properly repaired, } \\
\text { restored or replaced } \\
\text { when damaged, altered, } \\
\text { breached or penetrated. } \\
\text { Openings made therein } \\
\text { for the passage of } \\
\text { pipes, electrical conduit, } \\
\text { wires, ducts, air transfer } \\
\text { openings and holes } \\
\text { made for any reason } \\
\text { shall be protected with } \\
\text { approved methods } \\
\text { capable of resisting the } \\
\text { passage of smoke and } \\
\text { fire. Openings through } \\
\text { fire-resistance-rated } \\
\text { assemblies shall be } \\
\text { protected by self- or } \\
\text { automatic-closing doors } \\
\text { of approved } \\
\text { construction meeting }\end{array}$ & Similar. \\
\hline
\end{tabular}




\begin{tabular}{|c|c|c|c|c|c|c|}
\hline & Section Title & 1991/1994 SBC & 1991/1994 SFPC & 2006 IBC & 2006 IFC & Analysis \\
\hline & & & & & $\begin{array}{l}\text { the fire protection } \\
\text { requirements for the } \\
\text { assembly. }\end{array}$ & \\
\hline 20. & Fire Walls, Fire Doors & & $\begin{array}{l}504.7 .3 \text { All fire and } \\
\text { smokestop doors shall be } \\
\text { kept in operable } \\
\text { condition. No fire door } \\
\text { may be blocked or } \\
\text { obstructed or otherwise } \\
\text { made inoperable. } \\
\text { Fusible links shall be } \\
\text { replaced promptly } \\
\text { whenever fused or } \\
\text { damaged. }\end{array}$ & & $\begin{array}{l}703.2 \text { Opening } \\
\text { protectives. Opening } \\
\text { protectives shall be } \\
\text { maintained in an } \\
\text { operative condition in } \\
\text { accordance with } \\
\text { NFPA } 80 \text { [9]. Fire doors } \\
\text { and smoke barrier doors } \\
\text { shall not be blocked or } \\
\text { obstructed or otherwise } \\
\text { made inoperable. } \\
\text { Fusible links shall be } \\
\text { replaced promptly } \\
\text { whenever fused or } \\
\text { damaged. Fire door } \\
\text { assemblies shall not be } \\
\text { modified. }\end{array}$ & $\begin{array}{l}\text { More detailed } \\
\text { requirements in newer } \\
\text { code. }\end{array}$ \\
\hline 21. & Fire Walls, Fire Doors & & $\begin{array}{l}\text { 504.7.4 Fire doors } \\
\text { designed to be kept } \\
\text { normally open shall be } \\
\text { marked: FIRE DOOR - } \\
\text { DO NOT BLOCK. Fire } \\
\text { doors designed to be } \\
\text { kept normally closed } \\
\text { (such as stairwell doors) } \\
\text { shall be marked: FIRE } \\
\text { DOOR - KEEP CLOSED. }\end{array}$ & & $\begin{array}{l}\text { 703.2.1 Signs. Where } \\
\text { required by the fire code } \\
\text { official, a sign shall be } \\
\text { permanently displayed } \\
\text { on or near each fire } \\
\text { door in letters not less } \\
\text { than } 1 \text { in }(25 \mathrm{~mm}) \text { height } \\
\text { to read as follows: } 1 . \\
\text { For doors designed to } \\
\text { be kept normally open: } \\
\text { FIRE DOOR - DO NOT } \\
\text { BLOCK. 2. For doors } \\
\text { designed to be kept } \\
\text { normally closed: FIRE } \\
\text { DOOR - KEEP } \\
\text { CLOSED. }\end{array}$ & Similar. \\
\hline 22. & Fire Walls, Fire Doors & & $\begin{array}{l}504.7 .5 \text { Hold open } \\
\text { devices and automatic } \\
\text { door closers, where } \\
\text { provided shall be } \\
\text { maintained. During the } \\
\text { period that any such } \\
\text { device is out of service } \\
\text { for repairs, the door it } \\
\text { operates shall remain in } \\
\text { the closed position. }\end{array}$ & & $\begin{array}{l}703.2 .2 \text { Hold-open } \\
\text { devices and closer. } \\
\text { Hold-open devices and } \\
\text { automatic door closers, } \\
\text { where provided, shall be } \\
\text { maintained. During the } \\
\text { period that such device } \\
\text { is out of service for } \\
\text { repairs, the door it } \\
\text { operates shall remain in } \\
\text { the closed position. }\end{array}$ & Identical. \\
\hline
\end{tabular}




\begin{tabular}{|c|c|c|c|c|c|c|}
\hline & Section Title & $1991 / 1994$ SBC & 1991/1994 SFPC & 2006 IBC & 2006 IFC & Analysis \\
\hline 23. & $\begin{array}{l}\text { Fire Resistance-Rated } \\
\text { Construction }\end{array}$ & & & & $\begin{array}{l}703.4 \text { Testing. } \\
\text { Horizontal and vertical } \\
\text { sliding and rolling fire } \\
\text { doors shall be inspected } \\
\text { and tested annually to } \\
\text { confirm proper } \\
\text { operation and full } \\
\text { closure. A written } \\
\text { record shall be } \\
\text { maintained and be } \\
\text { available to the fire code } \\
\text { official. }\end{array}$ & $\begin{array}{l}\text { Only in newer code. } \\
\text { NFPA 80, Section } 5.2 .1 \\
\text { also requires that } \\
\text { inspections and testing } \\
\text { is completed at least } \\
\text { annually with a written } \\
\text { record kept. }\end{array}$ \\
\hline 24. & $\begin{array}{l}\text { Portable Fire } \\
\text { Extinguishers }\end{array}$ & & & & $\begin{array}{l}901.6 \text { Inspection, } \\
\text { testing and } \\
\text { maintenance. Fire } \\
\text { detection, alarm and } \\
\text { extinguishing systems } \\
\text { shall be maintained in } \\
\text { an operative condition } \\
\text { at all times, and shall be } \\
\text { replaced or repaired } \\
\text { where defective. } \\
\text { Nonrequired fire } \\
\text { protection systems and } \\
\text { equipment shall be } \\
\text { inspected, tested and } \\
\text { maintained or removed. }\end{array}$ & \\
\hline 25. & $\begin{array}{l}\text { Inspection, Testing and } \\
\text { Maintenance }\end{array}$ & & & & $\begin{array}{l}\text { 901.6.1 Standards. Fire } \\
\text { protection systems shall } \\
\text { be inspected, tested } \\
\text { and maintained in } \\
\text { accordance with the } \\
\text { referenced standards } \\
\text { listed in Table } 901.6 .1 \\
\text { [Table indicates } \\
\text { Portable fire } \\
\text { extinguishers use } \\
\text { NFPA 10]. }\end{array}$ & \\
\hline 26. & $\begin{array}{l}\text { Portable Fire } \\
\text { Extinguishers }\end{array}$ & & $\begin{array}{l}\text { 603.3.1 Portable fire } \\
\text { extinguishers shall be } \\
\text { installed in occupancies } \\
\text { and locations as set for } \\
\text { the in this Code, or as } \\
\text { may be determined by } \\
\text { the Fire Official. Portable } \\
\text { fire extinguishers shall be } \\
\text { in accordance with }\end{array}$ & & $\begin{array}{l}\text { 906.1 Where required. } \\
\text { Portable fire } \\
\text { extinguishers shall be } \\
\text { installed in the following } \\
\text { locations. } 1 \text {. In new } \\
\text { and existing Group A, B, } \\
\text { E, F, H, I, M, R-1, R-2, } \\
\text { R-4, and S. }\end{array}$ & $\begin{array}{l}\text { Older code more } \\
\text { restrictive. }\end{array}$ \\
\hline
\end{tabular}




\begin{tabular}{|c|c|c|c|c|c|c|}
\hline & Section Title & 1991/1994 SBC & 1991/1994 SFPC & 2006 IBC & 2006 IFC & Analysis \\
\hline & & & NFiPA 10. & & occupancies.... & \\
\hline 27. & $\begin{array}{l}\text { Portable Fire } \\
\text { Extinguishers }\end{array}$ & & & & $\begin{array}{l}906.2 \text { General } \\
\text { requirements. Portable } \\
\text { fire extinguishers shall e } \\
\text { selected, installed and } \\
\text { maintained in } \\
\text { accordance with this } \\
\text { section and NFPA 10.... }\end{array}$ & Similar. \\
\hline 28. & Movable Furniture & & $\begin{array}{l}808 \text { Where the floor } \\
\text { space of an occupancy is } \\
\text { occupied by tables, } \\
\text { chairs or other movable } \\
\text { furniture, aisles at least } \\
36 \text { in clear width shall be } \\
\text { maintained to provide } \\
\text { ready access to exit } \\
\text { doorways. }\end{array}$ & & & \\
\hline 29. & Number of Exits & $\begin{array}{l}\text { 1004.2 Minimum Number of } \\
\text { Exits } \\
\text { 1004.2.1 There shall be not } \\
\text { less than two approved } \\
\text { independent exits, accessible } \\
\text { to each tenant area, serving } \\
\text { every story, except in Group } \\
\text { R3 occupancies and as } \\
\text { modified in } 1018 \text {. } \\
\text { 1004.2.2 The minimum } \\
\text { number of exits for all } \\
\text { occupancies, except as } \\
\text { modified by } 1018, \text { based on } \\
\text { occupant load, shall be as } \\
\text { follows: } \\
\text { Minimum Number of Exits: } \\
\text { Occupancy Load per Story } \\
2: 1-500 \\
3: 501-1000 \\
4: \text { more than } 1000\end{array}$ & & $\begin{array}{l}1019.1 \text { Minimum number of } \\
\text { exits. All rooms and } \\
\text { spaces within each story } \\
\text { shall be provided with and } \\
\text { have access to the } \\
\text { minimum number of } \\
\text { approved independent exits } \\
\text { required by Table } 1019.1 \\
\text { based on the occupant load } \\
\text { of the story, except as } \\
\text { modified in Table } 1019.1 \\
\text { based on the occupant load } \\
\text { of the story, except as } \\
\text { modified in Section } 1015.1 \\
\text { or } 1019.2 \text {. For the purposes } \\
\text { of this chapter, occupied } \\
\text { roofs shall be provided with } \\
\text { exits as required for stories. } \\
\text { The required number of } \\
\text { exits from any story, } \\
\text { basement or individual } \\
\text { space shall be maintained } \\
\text { until arrival at grade or the } \\
\text { public way. }\end{array}$ & & \\
\hline
\end{tabular}




\begin{tabular}{|c|c|c|c|c|c|c|}
\hline & Section Title & 1991/1994 SBC & 1991/1994 SFPC & 2006 IBC & 2006 IFC & Analysis \\
\hline 30. & Exit Remoteness & $\begin{array}{l}\text { 1104.1.2 Where more than } \\
\text { one exit or exit access door is } \\
\text { required, at least two of the } \\
\text { exit doors or exit access } \\
\text { doors shall be placed a } \\
\text { distance apart equal to not } \\
\text { less than one half of the } \\
\text { length of the maximum } \\
\text { overall diagonal dimension of } \\
\text { the building or area to be } \\
\text { served measured in a straight } \\
\text { line between such doors. } \\
\text { The two doors shall be so } \\
\text { located and constructed to } \\
\text { minimize the possibility that } \\
\text { both may be blocked by any } \\
\text { one fire or other emergency } \\
\text { condition. }\end{array}$ & & $\begin{array}{l}\text { 1015.2.1 Two exits or exit } \\
\text { access doorways. Where } \\
\text { two exits or exit access } \\
\text { doorways are required from } \\
\text { any portion of the exit } \\
\text { access, the exit doors or } \\
\text { exit access doorways shall } \\
\text { be placed a distance apart } \\
\text { equal to not less than one- } \\
\text { half of the length of the } \\
\text { maximum overall diagonal } \\
\text { dimension of the building or } \\
\text { area to be served } \\
\text { measured in a straight line } \\
\text { between exit doors or exit } \\
\text { access doorways. } \\
\text { Interlocking or scissor stairs } \\
\text { shall be counted as one exit } \\
\text { stairway. } \\
\text { 1015.2.2 Three or more } \\
\text { exits or exit access } \\
\text { doorways. Where access to } \\
\text { three or more exits is } \\
\text { required, at least two exit } \\
\text { doors or exit access } \\
\text { doorways shall be arranged } \\
\text { in accordance with the } \\
\text { provisions of Section } \\
1015.2 .1 \text {. }\end{array}$ & & \\
\hline 31. & Exit Width & $\begin{array}{l}\text { 1003.2.1 The width of the } \\
\text { means of egress shall be } \\
\text { determined from occupants } \\
\text { served in accordance with } \\
\text { Table } 1004 \text {. }\end{array}$ & & $\begin{array}{l}1005.1 \text { Minimum required } \\
\text { egress width. The means of } \\
\text { egress width shall not be } \\
\text { less than required by this } \\
\text { section. The total width of } \\
\text { means of egress in inches } \\
\text { (mm) shall not be less than } \\
\text { the total occupant load } \\
\text { served by the means of } \\
\text { egress multiplied by the } \\
\text { factors in Table } 1005.1 \text { and } \\
\text { not less than specified } \\
\text { elsewhere in this code. } \\
\text { Multiple means of egress } \\
\text { shall be sized such that the }\end{array}$ & & \\
\hline
\end{tabular}




\begin{tabular}{|c|c|c|c|c|c|c|}
\hline & Section Title & 1991/1994 SBC & 1991/1994 SFPC & 2006 IBC & 2006 IFC & Analysis \\
\hline & & & & $\begin{array}{l}\text { loss of any one means of } \\
\text { egress shall not reduce the } \\
\text { available capacity to less } \\
\text { than } 50 \text { percent of the } \\
\text { required capacity. The } \\
\text { maximum capacity required } \\
\text { from any story of a building } \\
\text { shall be maintained to the } \\
\text { termination of the means of } \\
\text { egress. } \\
\text { Exception: Means of egress } \\
\text { complying with Section } \\
1025 \text {. }\end{array}$ & & \\
\hline 32. & Travel Distance & $\begin{array}{l}\text { 1004.1 Arrangement of Exits } \\
\text { 1004.1.1 Exist shall be so } \\
\text { located that the distance from } \\
\text { the most remote point in the } \\
\text { floor area, room or space } \\
\text { served by them to the } \\
\text { nearest exit, measured along } \\
\text { the line of travel, shall not be } \\
\text { more than specified in } \\
\text { Table } 1104 \text {. }\end{array}$ & & $\begin{array}{l}\text { 1016.1 Travel distance } \\
\text { limitations. } \\
\text { Exits shall be so located on } \\
\text { each story such that the } \\
\text { maximum length of exit } \\
\text { access travel, measured } \\
\text { from the most remote point } \\
\text { within a story to the } \\
\text { entrance to an exit along } \\
\text { the natural and } \\
\text { unobstructed path of egress } \\
\text { travel, shall not exceed the } \\
\text { distances given in Table } \\
\text { 1016.1. Where the path of } \\
\text { exit access includes } \\
\text { unenclosed stairways } \\
\text { or ramps within the exit } \\
\text { access or includes } \\
\text { unenclosed exit ramps or } \\
\text { stairways as permitted in } \\
\text { Section } 1020.1 \text {, the } \\
\text { distance of travel on such } \\
\text { means of egress } \\
\text { components shall also be } \\
\text { included in the travel } \\
\text { distance measurement. The } \\
\text { measurement } \\
\text { along stairways shall be } \\
\text { made on a plane parallel } \\
\text { and tangent to the stair } \\
\text { tread nosings in the center }\end{array}$ & & $\begin{array}{l}\text { Mercantile and storage } \\
\text { Occupancies have the } \\
\text { same travel distance } \\
\text { requirement }(200 \mathrm{ft}) \\
\text { under both codes. }\end{array}$ \\
\hline
\end{tabular}




\begin{tabular}{|c|c|c|c|c|c|}
\hline Section Title & 1991/1994 SBC & 1991/1994 SFPC & 2006 IBC & 2006 IFC & Analysis \\
\hline & & & $\begin{array}{l}\text { of the stairway. } \\
\text { Exceptions: } \\
\text { 1. Travel distance in open } \\
\text { parking garages is } \\
\text { permitted to be measured } \\
\text { to the closest riser of open } \\
\text { stairs. } \\
2 \text {. In outdoor facilities with } \\
\text { open exit access } \\
\text { components and open } \\
\text { exterior stairs or ramps, } \\
\text { travel distance is permitted } \\
\text { to be measured to the } \\
\text { closest riser of a stair or the } \\
\text { closest slope of the ramp. } \\
3 \text {. Where an exit stair is } \\
\text { permitted to be unenclosed } \\
\text { in accordance with } \\
\text { Exception } 8 \text { or } 9 \text { of Section } \\
1020.1, \text { the travel distance } \\
\text { shall be measured from the } \\
\text { most remote point within a } \\
\text { building to an exit } \\
\text { discharge. }\end{array}$ & & \\
\hline
\end{tabular}




\subsection{REFERENCES FOR CHAPTER 5}

[1] 1991 Standard Building Code, Southern Building Code Congress International, Inc., Birmingham, AL.

[2] 1994 Standard Building Code, Southern Building Code Congress International, Inc., Birmingham, AL.

[3] 1991 Standard Fire Prevention Code, Southern Building Code Congress International, Inc., Birmingham, AL.

[4] 1994 Standard Fire Prevention Code, Southern Building Code Congress International, Inc., Birmingham, AL.

[5] 2006 International Building Code, International Code Council, Inc., Falls Church, VA.

[6] 2006 International Fire Code, International Code Council, Inc., Falls Church, VA.

[7] 2009 International Building Code, International Code Council, Inc., Falls Church, VA.

[8] 2009 International Fire Code, International Code Council, Inc., Falls Church, VA.

[9] NFPA 80 Standard for Fire Doors and Other Opening Protectives, 2007 Ed., National Fire Protection Association, Batterymarch Park, MA. 


\section{Chapter 6 \\ SUMMARY, FINDINGS AND RECOMMENDATIONS}

\subsection{SUMMARY OF TECHNICAL STUDY}

The National Institute of Standards and Technology established a team of engineers and researchers to reconstruct the 2007 fire in the Charleston Sofa Super Store that resulted in a high number of fire fighter casualties. The technical study included the following objectives:

- to establish the likely technical cause or causes of the rapid fire growth inside the Sofa Super Store; and

- to recommend appropriate actions, including further research, to improve the structural safety of similar buildings, and to improve evacuation and emergency response procedures.

The following activities were undertaken by the team to reach the first objective and to establish the basis for the second objective:

- identifying technical issues and developing hypotheses for examination;

- collecting data from local authorities, including building design documents, video and photographic data, radio transmissions, field data, and other relevant records and plans, and from interviews with emergency responders and discussions with store employees;

- analyzing and comparing national model building and fire codes and practices; and

- simulating and analyzing phenomena, such as fire spread, smoke movement, tenability, and operation of active and passive fire protection systems.

The preceding chapters of this report describe the methodology used to conduct the technical study; detail what occurred on the night of June 18, 2007; review the history of the building and the model codes and standards that applied to the building; and present the results of the simulations. The key findings from the technical study are summarized in Section 6.2, Recommendations for Improving Model Building and Fire Standards. Codes and practices are listed in Section 6.3, and recommendations and other appropriate actions are identified in Section 6.4.

The analysis of the fire department response and the associated recommendations were reported in the National Institute for Occupational Safety and Health's (NIOSH) Line of Duty Death Report 2007-18 [1] and the City of Charleston's Post Incident Assessment and Review Team, Phase II Report [2]. The NIST study addressed the emergency response only when necessary to reconstruct the behavior and time line of the fire. 


\subsection{FINDINGS}

\subsubsection{General}

During the course of this technical study, NIST was able to identify the reasons for the rapid spread of fire and smoke, and the reasons for the difficulties encountered by the fire fighters as they attempted to exit the main showroom. Many of the findings summarized in this section had a direct bearing on the tragic outcome of the fire. Those particular findings are highlighted below (boldface). Other findings had a more peripheral role but are important to capture because of the potential to help mitigate the consequences of a similar situation in the future.

\subsubsection{Fire Growth}

\section{(i) Overview}

Fire was observed at rear of store at 6:56 p.m. The fire began in trash outside the loading dock and spread into the enclosed loading dock. Fire department arrived at 7:11 p.m., less than four minutes after being dispatched. From the loading dock, the fire spread through the merchandise holding area to the rear of the main showroom, then to the front of the main showroom, and then into the west and east showrooms. At the same time the fire was spreading into the holding area, the fire also spread through a metal wall into the warehouse.

The fire in the main showroom resulted in six fire fighter fatalities in the main showroom. Fire spread through three open roll-down fire doors into the west showroom and resulted in three additional fire fighter fatalities. Although the intense heat from the fire weakened lightweight steel trusses that led to the partial collapse of the roof, the coroner's report indicated that the fire fighters died from thermal burns and/or smoke inhalation, not from compression type injuries that would have been associated with the collapse.

The following sections present a more detailed description of the progression of the fire.

\section{(ii) Loading Dock}

- $\quad$ The fire ignited outside the structure and spread into the enclosed loading dock.

- A large amount of fuel (130 GJ) was present, including a) furniture that was staged for delivery, b) wood framing, c) liquid hydrocarbon solvents, and d) flooring.

- An open floor plan and the large amount of fuel allowed rapid fire growth across the loading dock.

- An open non-fire-activated roll-down door allowed smoke and flames to flow into the holding area.

- Metal walls that the loading dock shared with the warehouse and west showroom allowed the fire to spread into those spaces.

- $\quad$ The loading dock area was fully engulfed in fire before the fire department arrived.

- The heat release rate of the fire was slowed by the lack of air; that is, the fire was under-ventilated. 
(iii) Holding Area

- The roll-down fire door to the breezeway activated and closed before arrival of the fire department.

- A small amount of fuel (20 MJ) was available including a) chairs/sofas/futons, and b) futon cushions.

- Smoke and flames entered the holding area through the open roll-down door (non-fire activated). Furniture and other items within the holding area were ignited by the flames and thermal radiation from the loading dock fire.

- During the early stages of the fire (5 minutes to 10 minutes after fire department arrived), the fire spread into the holding area. The fire in the holding area was not visible from the main or west showrooms.

- Smoke and flames flowed from the holding area into the space above the main showroom suspended ceiling. At a later stage, fire spread either over or through the holding area partition wall and into the rear of the main showroom.

- The heat release rate of the fire was slowed by the lack of air; that is, the fire was under-ventilated.

(iv) Showrooms

- Fire spread through the holding area into the rear of the main showroom, then through the entire main showroom, and then into the west and east showrooms.

- Three roll-down fire doors between the main and west showrooms activated, but did not close during the fire. Three roll-down fire doors between the main and east showrooms activated; two doors closed completely and the third partially closed.

- A large amount of fuel was available, including up to 1100 combustible items (480 GJ) displayed in the main, west, and east showrooms.

- Smoke and flames from the fire on the loading dock and holding area flowed into the space above the main showroom suspended ceiling.

- Smoke flowed down into the main showroom through ventilation openings in the ceiling. A smoke layer formed under the suspended ceiling of the main showroom impairing visibility.

- An open floor plan and the large amount of fuel allowed the fire to grow and spread in the rear of the main showroom.

- During the early stages of the fire (10 minutes to 15 minutes after fire department arrival) the heat release rate of the fire in the rear of the main showroom was slowed by the lack of air; that is, the fire was under-ventilated.

- Front windows were broken or vented by the fire department to improve visibility. 
- Fire spread extremely rapidly from the rear to the front of the showroom as additional air flowed through the broken windows, feeding the fire in the rear of the showroom.

- Within the main and west showrooms, both the temperatures and oxygen depletion reached concentrations that were life-threatening to unprotected individuals.

- The fire in the main showroom resulted in six fire fighter fatalities in the main showroom. Fire spread through three open roll-down fire doors into the west showroom and resulted in three additional fire fighter fatalities.

- Intense heat from sustained burning of furniture weakened the roof supports and resulted in the collapse of the roof over the main showroom and sagging of the roof over the west showroom.

\section{(v) Warehouse}

- Intense heat from the loading dock fire passed through a shared metal wall and ignited combustibles in the warehouse.

- A large amount of fuel was available, including up to 1,900 combustible items (840 GJ) stored on high-rack shelves in the warehouse.

- An open floor plan and the large amount of fuel allowed the fire to grow and spread from the front to the rear of the warehouse.

- Intense heat from sustained burning of the furniture weakened roof supports and resulted in collapse of the roof and walls into the warehouse.

- No fire fighters entered the warehouse to attempt to extinguish the flames and no one was injured in this portion of the structure.

\subsubsection{Fire Protection Systems}

\section{(i) Overview}

The lack of fire sprinklers to control the fire during an early stage of its growth and the lack of effective compartmentation were direct contributors to the loss of nine fire fighters' lives and the loss of the retail showrooms and distribution warehouse. Fire sprinklers are designed to activate in response to a fire and to deliver a spray of water droplets to suppress or control fire growth [3]. Compartmentation is designed to create a series of smaller spaces which slows the spread of a fire. Fire walls and fire doors can be used to divide a single large space into multiple smaller compartments. The following was found regarding the installation and operation of fire suppression systems and other safety systems relevant to the building:

\section{(ii) Fire Sprinklers}

- Fire sprinklers were not installed in the showrooms or distribution warehouse.

- Computer model simulations demonstrated that fire sprinklers in the loading dock would have controlled the fire and prevented the fire from extending beyond the loading dock. 
- Computer model simulations demonstrated that tenable (survivable) conditions were maintained within the loading dock, showrooms, and warehouse had a sprinkler system been installed on the loading dock.

\section{(iii) Compartmentation}

- Large open spaces allowed the fire to spread throughout the structure, including the loading dock, showrooms, and warehouse. Interior walls and fire doors did not provide adequate compartmentation.

- The open roll-down door between the loading dock and holding area was not a fire-activated door and remained open, allowing the fire to spread to the rear of the main showroom.

- Only three of the seven roll-down fire doors activated and closed fully during the fire.

- Uninsulated metal walls (the north wall of the warehouse and the south wall of the west showroom) allowed heat from the fire to ignite fuels that were against the walls in the warehouse and west showroom.

- Concrete block walls of the main showroom prevented the fire from spreading through the walls to the west or east showrooms.

- Partition walls that separated the holding area from main showroom did not extend to the underside of the roof. Smoke and flames filled the space above the suspended ceiling in the main showroom and provided a path for the fire to spread from the holding area to the rear of the main showroom.

- The exterior west wall/elevated floor of the enclosed loading dock did not prevent the exterior fire from spreading to the inside of the structure.

(iv) Other Fire Protection Systems

- The store did not have a fire alarm system, smoke detectors, or wet or dry standpipes.

- There were more than five portable fire extinguishers located in the structure. A store employee discharged two portable extinguishers at the loading dock fire.

\subsubsection{Occupant Egress}

\section{(i) Overview}

The two front doors allowed all of the occupants in the retail showrooms and office areas at the rear of the main showroom to exit safely. An employee was trapped for a period of time in the repair shop/warehouse area due to blocked exits. The fire department was able to rescue the trapped employee. Specific findings regarding the occupant load and egress process are presented here. 


\section{(ii) Emergency Exit Doors}

Neither of the workshop areas had the proper number of or adequately designed exits to meet 2006 model code requirements $[4,5]$. Doors in the warehouse, two single-wide doors and a roll-down, the two slider doors on the loading dock, and the single exit door near the front of the west showroom were locked while the store was occupied. The doors on the east side of the east showroom were equipped with exit alarms, but were also equipped with vertical door latches. It was unclear if the exit doors in the east showroom were latched or unlatched during the fire. If any of the doors in the warehouse had been properly equipped for emergency exits, the trapped employee would likely have been able to exit without assistance.

\subsubsection{Combustible Material}

\section{(i) Overview}

The large fuel load made up of the retail merchandise staged in the loading dock, displayed in the show rooms, and stored in the warehouse were key contributors to the spread of the fire and the eventual failure of the building. In addition, the storage of flammable solvents in the loading dock area allowed the fire to spread more quickly to the holding area and to the warehouse. Specific findings regarding the merchandise, construction materials, and flammable solvents are listed below.

\section{(ii) Fuel Load}

- Furniture inventory records were not recovered after the fire. The amount and type of retail merchandise had to be estimated.

- The high total energy content of the structure and contents, estimated at up to $1450 \mathrm{GJ}$, was a contributing factor to the severity of the fire.

o Loading dock fuel load was up to $130 \mathrm{GJ}$.

o Retail merchandise in the showrooms was up to $480 \mathrm{GJ}$.

o Retail merchandise on high racks in the warehouse was up to $840 \mathrm{GJ}$.

o Flammable solvents on the loading dock were at least $3 \mathrm{GJ}$ in fuel.

- The furniture fuel mass loading was estimated to range up to $16 \mathrm{~kg} / \mathrm{m}^{2}$ (3.4 $\left.\mathrm{lbs} / \mathrm{ft}^{2}\right)$ for the showrooms and $52 \mathrm{~kg} / \mathrm{m}^{2}\left(10.6 \mathrm{lbs} / \mathrm{ft}^{2}\right)$ for the warehouse. The high-rack storage in the warehouse contributed to the higher fuel mass loading than in the showrooms.

(iii) Fuel Package

- The type and configuration of the fuel also contributed to the fire growth in the loading dock, showrooms, and warehouse.

- A significant fraction of the fuel was upholstered furniture which has a large surface area, synthetic coverings, and foam padding. The coverings and foam padding contributed to the rapid spread of the fire.

- Wood was also an important component of the upholstered furniture and a large amount of wood furniture was displayed throughout the showrooms or stored in 
the warehouse. The wood contributed to the sustained burning that occurred after the initial rapid spread of the fire.

\subsubsection{Model Codes and Standards}

Specific findings regarding model codes and standards, both current and in effect at the time of construction:

- Strict adherence to the 2006 model building and fire codes $[4,5]$ available at the time of the fire would have required the main showroom and warehouse to be sprinklered. With the addition of the loading dock and repair shops, compliance with the model codes would have required either sprinklers on the loading dock and/or higher rated fire barriers between the loading dock and the holding area, between the loading dock and the west showroom, and between the loading dock and the warehouse. Sprinklers and/or higher rated fire barriers would have reduced the rate of fire spread and have improved occupant and fire fighter safety.

- The team was unable to locate any building permits for the enclosed loading dock and two repair workshops. Aerial images demonstrate that these areas were constructed between 1996 and 2006. The model building codes at the time of construction (1991/1994 SBC/SFPC [6 -9]) required construction permits.

- Wood framing and decking were used in construction of the loading dock and workshop areas, which were located in the space between the showrooms and warehouse and resulted in common walls. The model building codes at the time of construction (1991/1994 SBC/SFPC [6-9]) would have required either the installation of fire sprinklers in these areas or upgrading the fire rating of the common walls.

- The roll-down door between the loading dock and holding area was not a fire door. If the loading dock was to be considered as a separate fire area, current model fire codes at the time of construction required a fire rated door assembly.

- The fire rating of fire barriers including the concrete block walls and fire doors between the three showrooms, main, west, and east, was sufficient under 1991/1994 SBC/SFPC to allow each showroom to be considered a separate fire area of less than $1390 \mathrm{~m}^{2}\left(15,000 \mathrm{ft}^{2}\right)$. Therefore, each showroom was not required to have fire sprinklers.

- The walls that the warehouse and west showroom shared in common with the loading dock were designed as exterior walls. The separation distance between the north wall of the warehouse and the rear walls of the main $6.8 \mathrm{~m}(22.31 \mathrm{ft})$ and west $15.2 \mathrm{~m}$ (49.87 ft) showrooms was sufficient under the model codes (1991/1994 SBC /SFPC). The offset or separation distance between the warehouse and west showroom allowed these two areas to be considered non-adjacent spaces.

- The addition of an enclosed loading dock area between the north wall of the warehouse and the south wall of the west showroom without the upgrading of 
the fire resistance of these partition walls would have caused the warehouse, loading dock area, and west showroom to be considered a single $2330 \mathrm{~m}^{2}$ $\left(25,040 \mathrm{ft}^{2}\right)$ building lacking the required occupancy separations. This building area exceeds the allowable unsprinklered building areas in the 1991/1994 SBC and 2006 IBC $[4,5]$ for both mercantile and storage occupancies. In addition, the 1991/1994 SBC and 2006 IBC codes would both have required a fire sprinkler system for the entire area $2330 \mathrm{~m}^{2}\left(25,040 \mathrm{ft}^{2}\right)$ of the building.

- The 1991 SFPC[7] and 2006 IFC[5], both require sprinkler protection for the warehouse based on the high-piled storage of upholstered furniture.

- Large amounts of hydrocarbon solvents were stored on the loading dock, but quantities do not appear to exceed the maximum allowable quantities for storage occupancies in the 1991/1994 SBC or 2006 IBC. These flammable and combustible liquids were not stored in compliance with NFPA 30 Flammable and Combustible Liquids Code [10] that requires metal cabinets, enclosures, and/or safety cans.

- Neither current nor contemporaneous fire codes sufficiently address the uniquely high fire hazard from the type and configuration of the combustibles in a building loaded with upholstered furniture. Furniture is often displayed in large open areas. As demonstrated in the main and west showrooms and warehouse, displaying large amounts of furniture in large open spaces can contribute to extremely rapid fire spread.

- High fuel-load mercantile occupancies, including furniture stores, represent a significantly greater fire hazard than low fuel-load occupancies.

\subsubsection{Emergency Response}

\section{(i) Overview}

Detailed analysis of the fire department response and recommendations were reported previously by others $[1,2]$. Therefore, the NIST study examined the emergency response only as needed to reconstruct the behavior and time line of the fire. The NIST study found the following:

- The fire department arrived on scene in fewer than 4 minutes after the 911 dispatch received report of an exterior trash fire behind the Sofa Super Store.

- Upon initial survey of the exterior of the structure, the fire department located a fire inside the enclosed loading dock.

- Initial survey of the interior did not find any smoke or fire in the showrooms. Three minutes after arrival, inspection of the rear of the west showroom confirmed the loading area was fully involved in fire.

- Up to five minutes after arrival, there were still no reports of significant smoke or fire being observed inside any of the showrooms.

- Within five minutes of arrival the fire department began suppressing the loading dock fire using tank water from the first arriving engine. 
- The Fire Chief arrived on the scene approximately 6 minutes after arrival of the first unit.

- The Fire Chief directed operations at the loading dock and the Assistant Chief directed operations at the front of the store.

- The fire department required about 10 minutes to establish a water supply from a fire hydrant to the exterior loading dock area.

- A mutual aid company arrived on scene about 14 minutes after first unit of the Charleston Fire Department.

- The fire department took about 16 minutes to establish a water supply from a fire hydrant to the front of the store.

- Between 16 minutes and 19 minutes after arrival, radio communications indicated that fire fighters may be disoriented or lost in the structure and a "Mayday" call was transmitted.

- The Assistant Chief led a team between 16 minutes and 21 minutes after the first unit arrived to rescue an employee trapped inside the rear of the store.

- The fire department vented the front windows about 24 minutes after arrival.

- Heavy smoke flowed out of front windows within 2 minutes of the windows being vented.

- Flames emerged from the front windows within 3 minutes of the windows being vented.

- The last fire fighters to exit successfully from the front of the store did so within 4 minutes of windows being vented.

- The roof collapsed over the west side of the main showroom about 40 minutes after fire department arrived on scene.

- Material, including furniture and merchandise, in the showrooms and warehouse continued to burn for an additional 140 minutes before the fire was extinguished.

\section{(ii) Risk Management Plan and Initial Response}

The initial response of the fire department included two engine companies, a ladder truck company, and a battalion chief. With an engineer, a fire fighter, and an officer on each apparatus, the fire department's initial response was 10 people. A comprehensive risk management plan developed according to NFPA 1500 [11] for the Sofa Super Store would likely have identified it as a high hazard occupancy due to the lack of sprinklers and the presence of large open areas and a large fuel load. For high hazard occupancies, NFPA 1710 [12] advocates a minimum crew size of five to six members for each apparatus, which for this incident would amount to 16 to 19 people for the initial response.

\section{(iii) Situational Awareness}

The responders did not know when fire and smoke entered the showrooms. The fire department visually checked below the suspended ceiling for fire spread. The NIST study was not able to 
document any fire fighter removing a ceiling tile to check for fire spread above the suspended ceiling. Because the fire was pulling air from the west showroom, when the door to the loading dock area was opened, the door was pulled into the loading dock. If the fire had been pushing at the time that the door was opened, fire and hot gases could have enveloped the fire fighters when the door was opened. There were no heat or smoke alarms installed in the building and there was no central fire alarm panel to provide such information to the fire fighters.

\section{(iv) Water Supply}

The supply of water to the fire fighters was limited to the water on the fire engines for 9 minutes at the loading dock and 15 minutes at the front of the store. When the connection was made to the municipal water supply, the two engines were pumping water to the store through long lines of small diameter $6.4 \mathrm{~cm}$ ( $2.5 \mathrm{in}$ ) hose. The water being supplied was inadequate to suppress the fire in a timely fashion due to the following factors:

- The time required to establish connections to water hydrants.

- The limited number of water supply hose lines established before the structure was evacuated.

- The significant water pressure drop caused by long runs of hose.

\section{(v) Incident Command}

Fire department operations were directed by the Fire Chief on the loading dock and the Assistant Chief at the front of the store. Specific findings regarding incident command include:

- The Assistant Chief led a team of fire fighters around to the rear of the main showroom to rescue the trapped employee.

- During this same time period, conditions within the showroom deteriorated and radio transmissions indicate that fire fighters were becoming disoriented or lost within the store.

- Shortly after the Assistant Chief returned to the front of the store after the rescue effort, the decision was made to break the front windows to vent the smoke.

- Conditions within the store were deteriorating rapidly. At the loading dock, the Fire Chief held back fire teams from re-entering.

- While the trapped employee was being rescued, the Fire Chief radioed, “... we need to evacuate the building," but it is not clear what was done at the front of the store to implement this order.

\section{(vi) Ventilation}

A burning structure can be ventilated by breaking windows and cutting holes in the roof, which can allow the smoke and hot gases to escape the structure in order to provide better visibility for fire fighters. As the smoke and hot gases exhaust from the structure, fresh air is pulled into the building, which may result in an increased heat release rate.

- The front windows of the main showroom were broken to allow the smoke and hot gases to vent. 
- Venting the front windows of the main showroom did allow the smoke to escape, but it also provided more air to feed the fire and provided a new path for the fire to spread.

- After the windows were broken, the fire spread extremely rapidly into the main showroom and into the west showroom.

\subsubsection{Building Record-keeping Practices for Public Safety}

Inspections and record-keeping practices are an integral part of a community fire safety program. Findings related to this area that are relevant to the Sofa Super Store fire include the following:

- Records were not found for the initial building design. Records of modifications - when located-lacked sufficient detail to adequately track the changes made to the structure.

- Neither the historical nor current building use and occupancy permit for the building was located; however, the use of the Sofa Super Store was consistent with the SBC 1994[8], IBC 2006[4], and IFC 2006[5] occupancy classifications of Group M with Class III commodity.

- Records documenting fire department inspections of the structure noted deficiencies in exit signs and cluttered aisles. The inspection records also documented the lack of fire alarms and sprinklers.

- Fire department inspections did not identify the large fuel load, the non-code compliant wood construction additions, the solvent storage on the loading dock, or the lack of a fire door between loading dock and holding area as significant fire hazards.

\subsection{RECOMMENDATIONS FOR IMPROVING MODEL STANDARDS, CODES, AND PRACTICES}

Neither of the 2006 model codes $[4,5]$ was required to be followed at the time of the Sofa Super Store fire. NIST did not examine the code actually in force in Charleston on June 18, 2007, since the goal of the study was to understand how the incident happened, how it progressed, and how changes could be made in current standards, codes and practices to avoid similar situations.

Adoption of a model code, in and of itself, is not sufficient to guarantee the safety of a building. The source of a building failure that leads to significant loss of life usually can be traced to a breakdown in one or more of the following key assumptions upon which model codes are based: (1) that the building designer, constructor, owner, operator, staff and patrons will adhere to all applicable code provisions; (2) that the authorities having jurisdiction (AHJs) properly interpret and enforce the code provisions; (3) that the historical record is a reliable predictor of worst case events; and (4) that implementation is non-retroactive. Recognizing this, model codes need to be robust and contain sufficient redundancies to minimize the chances of loss of life caused by the failure of a building that is built or operating out of compliance with code provisions. 
The findings presented above and the first four recommendations that follow raise a number of issues concerning model codes and standards, and the practices surrounding their adoption, application, and enforcement.

\section{Recommendation 1}

NIST recommends that, at a minimum, all state and local jurisdictions adopt a building and fire code based upon one of the model codes, covering new and existing high fuel-load mercantile occupancies, and update local codes as the model codes are revised.

If current model codes had been adopted and applied retroactively to high fuel-load mercantile occupancies, the model codes would have required the Sofa Super Store's main showroom and warehouse be sprinklered.

\section{Recommendation 2}

NIST recommends that all state and local jurisdictions implement aggressive and effective fire inspection and enforcement programs that address:

a) all aspects of the building and fire codes;

b) adequate documentation of building permits and alterations;

c) means of fire protection systems inspection and detailed record keeping;

d) frequency and rigor of fire inspections, including follow-up and auditing procedures; and

e) guidelines for remedial requirements when inspections identify deviations from code provisions.

Effective inspections and enforcement of the 2006 model building and fire codes available at the time of the Sofa Store fire would have required the door and walls of the showrooms and warehouse to be upgraded or would have required fire sprinklers to be installed throughout the structure. Either of those measures would go a long way to toward preventing similar tragedies in the future.

\section{Recommendation 3}

NIST recommends that all state and local jurisdictions ensure that fire inspectors and building plan examiners are professionally qualified to a national standard such as NFPA 1031 [13]. Professional qualification may be demonstrated through a nationally accepted certification examination, such as the Fire Plan Examiner [14]; Fire Inspector I and II [15,16], and Certified Fire Marshal [17].

If fire inspectors had identified the wood framing, solvent storage, and lack of fire-rated barriers and if corrective actions had been implemented, the fire would not have moved into the loading dock and 
the fire spread from the loading dock to the rest of the structure would have been slowed significantly.

\section{Recommendation 4}

NIST recommends that model codes require sprinkler systems and that state and local authorities adopt and aggressively enforce this provision:

a) for all new commercial retail furniture stores regardless of size; and

b) for existing retail furniture stores with any single display area of greater than 190 $m^{2}\left(2000 \mathrm{ft}^{2}\right)$.

An installed fire sprinkler system that complied with a national standard such as NFPA 13 [3] would have activated and would have controlled the fire growth. If the showrooms had been divided into smaller areas with fire barriers, the compartmentation would have slowed the spread of the fire as well.

\section{Recommendation 5}

NIST recommends that state and local jurisdictions develop comprehensive fire risk management plans to:

a) identify low, medium, and high-hazard occupancies;

b) allocate resources according to identified risks; and

c) develop operating procedures that respond to specific risks.

A fire risk management plan, properly implemented, would have identified the hazards associated with the size, type, and configuration of the fuel load and the large open spaces that existed at the Sofa Super Store.

\section{Recommendation 6}

NIST recommends that state and local authorities:

a) develop guidelines as to how and when ventilation should be implemented during a fire;

b) provide education to fire fighters on the science of fire behavior in vented and nonvented structures and how the addition of air can impact the burning characteristics of the fuel; and

c)provide training to fire fighters on different types of ventilation (vertical, horizontal, or positive-pressure) and integrate into daily operations on the fire ground.

Standard operating guidelines on when, how, and why ventilation should be used — would have prevented the rapid fire movement that occurred after the front windows were broken. 


\subsection{RESEARCH RECOMMENDATIONS AND OTHER APPROPRIATE ACTIONS}

This study focused on the Sofa Super Store fire. Several recommendations in this report relate directly to commercial retail structures, and other recommendations apply more broadly. Model building and fire code organizations as well as state and local regulatory authorities may benefit from reviewing this study and considering the findings regarding fire sprinklers, combustible loads, compartmentation, and fire protective system performance as they make revisions to their codes.

The acceptance of the recommendations made in this report by the model code and standards organizations and the adoption of any modified provisions of the national model codes into local codes and enforcement practices, will depend upon the perceived benefits weighed against the costs of implementing any changes. There are a number of areas where the benefits may be obvious and the costs of implementation may be easily determined. In those areas, policy decisions to adopt particular provisions of the code are made according to technical information and recommendations available to the decision maker.

There are other areas in which the basis for making changes to local codes is not currently supported by reliable technical information. Continuing research is needed to gain new understanding and to collect the data necessary to ensure that changes are adopted, or rejected, based upon sound scientific findings. Research results may also serve as the basis for setting thresholds or pass/fail criteria for fire protection systems and recommendations for fire operations and training.

\subsubsection{Recommendations for Research}

Based upon the findings of this study and the resulting recommendations presented in section 6.3, additional research is recommended in three general areas:

- Fire performance of upholstered furniture.

- Fire spread.

- Decision guidance.

\section{Recommendation 7}

In terms of furniture flammability, fire science needs to focus additional research on the development of two types of knowledge: 1) how to make furniture that is less flammable, and 2) how to accurately simulate the burning of existing furniture for forensic use. This research will help develop an understanding of the ignition and spread of fire over common furniture items and the resulting release of heat and harmful combustion products. At present, it is necessary to rely on scientific experiments and real-scale fire testing of products in room geometries that are similar to what existed in the actual event to develop empirical data as input to computer fire models.

NIST recommends that research be conducted to better understand ignition and fire spread on upholstered furniture in order to provide the tools needed by design professionals to improve the fire performance of furniture. The following areas require research: 
a) prediction of ignition of natural and synthetic coverings, and foam padding, for furniture, wall, ceiling and floor lining materials, and room furnishings;

b) prediction of fire spread over actual furniture with and without fire barriers, fire retardants, and fire resistive materials; and

c) quantification of smoke and toxic gas production in realistic room fires.

\section{Recommendation 8}

Improving fire barriers requires that additional research be focused on: 1) how to design products that will contain a fire while at the same time meeting other functional requirements, and 2) replicating the performance of existing partitions in forensic models. Fire-resistance testing of walls, floors, ceilings, and door assemblies typically ends when the temperature on the non-fire side exceeds a standard value. There is insufficient understanding of the mechanisms by which partitions and door assemblies pass flames into adjacent spaces, especially for the composite assemblies typical of real construction. Having an accurate modeling capability for how flames pass into adjacent spaces will improve the ability to accurately establish fire time lines and to evaluate the relative importance of multiple fire paths.

NIST recommends that research be conducted to provide the tools needed by design professionals to improve the performance of compartmentation. The following specific areas require research:

a) prediction of fire spread through walls constructed of wood, metal, and gypsum wallboard;

b) prediction of fire spread through doors constructed of glass, wood, and metal;

c) prediction of fire spread through penetrations; and

d) prediction of performance of roll-down fire doors in actual fires and after extended service.

\section{Recommendation 9}

New knowledge, data, and predictive methods generated in the above research will lead to new technologies and improved building and fire codes and standards. The selection among alternative fire safety technologies or building design options, and the threshold values established in the model codes, can have significant economic ramifications. New tools are needed that can be tailored to specific situations and rigorously account for costs and other impacts in a manner transparent to competing interests.

\section{NIST recommends that research be conducted to:}

a) refine computer-aided decision tools for determining the costs and benefits of alternative code changes and fire safety technologies; and

b) develop computer models to assist communities in allocating resources (money and staff) to ensure that their response to an emergency with a large number of potential casualties will be effective. 


\section{Recommendation 10}

First responders commonly use ventilation is to improve the firefighting environment, increase the survivability of trapped occupants, and reduce property damage. In some cases though, ventilation may improve conditions within a structure, but may also lead to increased fire growth and spread, flashover, or back draft (deflagration). The effects of natural ventilation on the fire environment during fire fighter operations are not well understood.

NIST recommends that additional research be conducted to:

a) improve understanding and characterization of how ventilation affects the growth and spread of fire within structures; and

b) provide the fire service with better guidance on when and how to use ventilation to improve the fire environment during fire service operations.

\section{Recommendation 11}

Providing fire protection for a community involves a range of factors including building stock, population demographics, climate, resource allocation, water supply, response time, and adoption of model codes. Assessment of the value of each of these factors is key to informed decision-making regarding technologies and procedures to provide an acceptable level of protection.

NIST recommends that research be conducted to:

a) develop performance and effectiveness metrics for community fire protection;

b) survey effectiveness of existing fire services; and

c) use metrics to optimize development of new fire protection technologies.

\subsubsection{Impact of Research}

Completing the research recommended will provide a reliable technical foundation for making changes to codes, standards and practices. Specifically, a comprehensive research program would facilitate:

- Improved understanding of the relationship between material properties and prediction of ignition and fire spread for upholstered furniture and room furnishing.

- Improved accuracy in predicting smoke and toxic gas levels, and how they affect fire spread.

- Improved characterization of the mechanisms that allow fires to spread through composite walls and doors.

- Creation of computer-aided decision tools for determining the costs and benefits of alternative code changes and fire safety technologies.

- Development of performance and effectiveness metrics for community fire protection. 


\subsection{REFERENCES FOR CHAPTER 6}

[1] Fatality Assessment and Control Evaluation Investigation Report \#F2007-18, National Institute for Occupational Safety and Health, Fire Fighter Fatality Investigation and Prevention Program, Morgantown, WV, February 2009. http://www.cdc.gov/niosh/fire/pdfs/face200718.pdf

[2] "Fire Fighter Fatality Investigative Report, Sofa Super Store, 1807 Savannah Highway, Charleston, South Carolina, June 18, 2007,”. City of Charleston Post-Incident Assessment and Review Team, Phase II Report, June 2008.

[3] NFPA 13, Standard for the Installation of Sprinkler Systems, National Fire Protection Association, Quincy, MA, 2002.

[4] 2006 International Building Code, International Code Council, Inc., Falls Church, VA.

[5] 2006 International Fire Code, International Code Council, Inc., Falls Church, VA.

[6] 1991 Standard Building Code, Southern Building Code Congress International, Inc., Birmingham, AL.

[7] 1991 Standard Fire Code, Southern Building Code Congress International, Inc., Birmingham, AL.

[8] 1994 Standard Building Code, Southern Building Code Congress International, Inc., Birmingham, AL.

[9] 1994 Standard Fire Code, Southern Building Code Congress International, Inc., Birmingham, AL.

[10] NFPA 30, Flammable and Combustible Liquids Code, National Fire Protection Association, Quincy, MA, 2008.

[11] NFPA 1500, Standard on Fire Department Occupational Safety and Health Program, 2010 National Fire Codes, National Fire Protection Association, Quincy, MA, pp. 1500-11, 2007.

[12] NFPA 1710, Standard for the Organization and Deployment of Fire Suppression Operations, Emergency Medical Operations, and Special Operations to the Public by Career Fire Departments, 2010 National Fire Codes, National Fire Protection Association, Quincy, MA, pp. 1710-9, 2010.

[13] NFPA 1031, Professional Qualifications for Fire Inspector and Plan Examiner, National Fire Protection Association, Quincy, MA, 2003.

[14] Fire Plan Examiner (CFE) Program - NFPA 1, Fire Code, NFPA 13, Installation of Sprinkler Systems, NFPA 72, National Fire Alarm Code, and NFPA 101, Life Safety Code.

http://www.nfpa.org/certifications

[15] Certified Fire Inspector I (CFI/I) Program- NFPA 1, Fire Code, NFPA 13 Installation of Sprinkler Systems, NFPA 25, Inspection, Testing, and Maintenance of Water-Based Fire Protection Systems, NFPA 72, National Fire Alarm Code, and NFPA 101, Life Safety Code. http://www.nfpa.org/certifications 
[16] Certified Fire Inspector II (CFI/II) Program- CFI/I codes listed above and NFPA 24, Installation of Private Fire Service Mains and Their Appurtenances, and NFPA 220, Types of Building Construction. http://www.nfpa.org/certifications

[17] Certified Fire Marshal - International Building Code, International Fire Code, NFPA 921 Guide for Fire and Explosion Investigations, International Fire Service Training Association (IFSTA) Introduction to Fire Origin and Cause, and IFSTA Fire and Life Safety Educator. http://www.iccsafe.org/accreditation 